University of Rhode Island

DigitalCommons@URI

Open Access Master's Theses

2013

\title{
AIR-WATER EXCHANGE AND TRENDS OF PERSISTENT BIOACCUMULATIVE TOXICS (PBTS) ACROSS LAKE SUPERIOR
}

Zoe Ruge

University of Rhode Island, zruge@my.uri.edu

Follow this and additional works at: https://digitalcommons.uri.edu/theses

\section{Recommended Citation}

Ruge, Zoe, "AIR-WATER EXCHANGE AND TRENDS OF PERSISTENT BIOACCUMULATIVE TOXICS (PBTs) ACROSS LAKE SUPERIOR" (2013). Open Access Master's Theses. Paper 158.

https://digitalcommons.uri.edu/theses/158

This Thesis is brought to you for free and open access by DigitalCommons@URI. It has been accepted for inclusion in Open Access Master's Theses by an authorized administrator of DigitalCommons@URI. For more information, please contact digitalcommons-group@uri.edu. 


\author{
AIR-WATER EXCHANGE AND TRENDS OF \\ PERSISTENT BIOACCUMULATIVE TOXICS (PBTs) \\ ACROSS LAKE SUPERIOR \\ BY \\ ZOE RUGE
}

A THESIS SUBMITTED IN PARTIAL FULFILLMENT OF THE

REQUIREMENTS FOR THE DEGREE OF

MASTER OF SCIENCE

IN

OCEANOGRAPHY

UNIVERSITY OF RHODE ISLAND 
MASTER OF SCIENCE THESIS

OF

ZOE RUGE

\section{APPROVED:}

Thesis Committee:

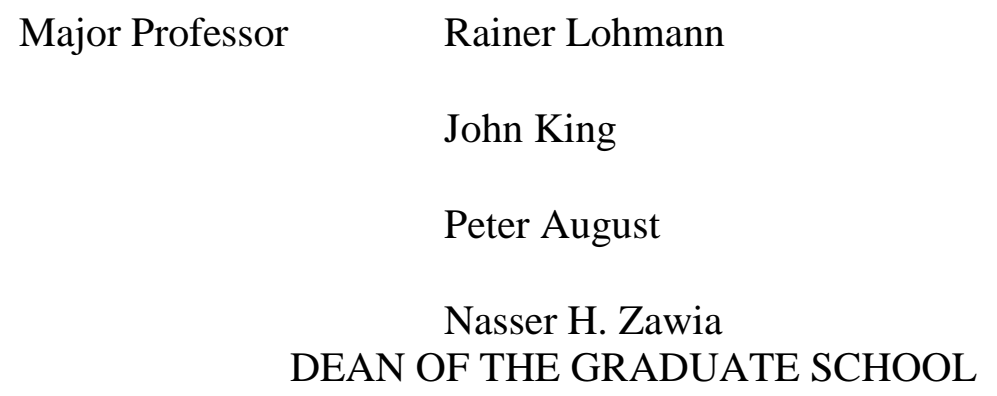

UNIVERSITY OF RHODE ISLAND

2013 


\begin{abstract}
Persistent bioaccumulative toxics (PBTs) have long been studied in Lake Superior air, water, sediment, and biota, however, sampling has often been constrained to a few study sites. Polyethylene passive samplers (PEs) provide the ability to collect time-averaged, tandem air and water measurements from any accessible point along the shore or in open water. PEs were deployed in the air and water at 19 sites across Lake Superior from June-October 2011. Samples were solvent extracted and analyzed using gas chromatography/tandem-mass spectroscopy to quantify 22 polycyclic aromatic hydrocarbons (PAHs), 11 polybrominated diphenyl ethers (PBDEs), 24 organochlorine pesticides (OCPs), and 18 polychlorinated biphenyls (PCBs).

PAHs are still emitted to the atmosphere from both anthropogenic activity and natural sources, and flux rates suggest net deposition into Lake Superior from the atmosphere. They were found at most sites, however, distributions appear to be associated with populated and industrialized areas (air and water ranges below detection, bd, to $190 \mathrm{ng} / \mathrm{m}^{3}$ and bd-130 ng/L, respectively). Retene, a signal of conifer trees and used as an indicator of forest fires, was present across the lake, representing a large portion of total PAH concentrations at rural areas, particularly in the water. PBDEs were similarly connected to developed areas, but were present at much lower concentrations (air and water range bd-19 pg/m³ and 0.051-7.6 pg/L, respectively). PBDE flux rates were dominated by BDE-47, however, flux direction was not consistent across the lake and deployment periods. PCB concentrations were also greatest near developed areas (up to $57 \mathrm{pg} / \mathrm{m}^{3}$ in Ontonagon air and $45 \mathrm{pg} / \mathrm{L}$ in Sault
\end{abstract}


Saint Marie water), but a ban on direct emissions since the 1970s has resulted in upward flux rates. This net volatilization suggests Lake Superior is acting as a secondary source of these compounds to the atmosphere. OCPs varied greatly between individual compounds, but were overall detected at every site across Lake Superior. Long-banned hexachlorobenzene (range bd-180 $\mathrm{pg} / \mathrm{m}^{3}$ ) and $\alpha$-hexachlorocyclohexane (bd-640 pg/L) dominated the air and water concentrations, respectively. Both exhibited fluxes indicative of near-equilibrium or net volatilization. Conversely, recently-used endosulfan I had negative flux rates across the lake due to ongoing terrestrial emissions.

Continuing deposition trends of currently used PBTs, changes in recently-banned PBTs, and possible secondary emissions of long-banned PBTs must continue to be monitored across Lake Superior and the other Great Lakes in order to evaluate the efficacy of regulatory measures and threats to human and environmental health. PEs provide an easy and affordable alternative to active sampling ideal for high resolution sampling of large regions, such as Lake Superior. 


\section{ACKNOWLEDGMENTS}

I would like to thank Dr. Rainer Lohmann for his guidance and expertise throughout this research. Many thanks to all in the Lohmann Lab, especially Dave Adelman and Mohammed Khairy for critical analytical assistance. This work was a collaboration with many great people at the Ontario Ministry of the Environment and Environment Canada, particularly Paul Helm, Derek Muir, and Camilla Teixeira. We also could not have completed a project on this scale without the generous help from volunteers all around Lake Superior. Thank you to Peter August and Brice Loose for assisting with concepts beyond chemistry. And my deepest gratitude to my family and friends for their endless support. 


\section{TABLE OF CONTENTS}

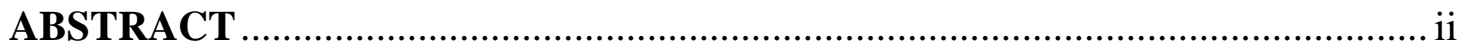

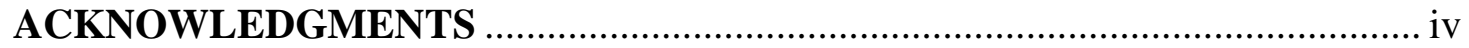

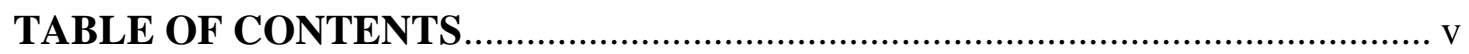

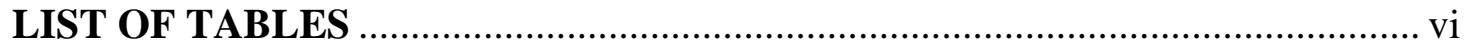

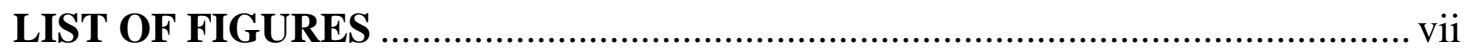

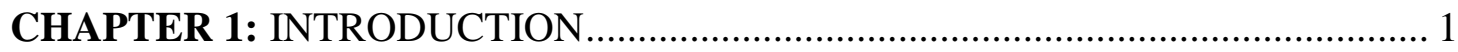

CHAPTER 2: POLYCLYCLIC AROMATIC HYDROCARBONS AND

POLYBROMINATED DIPHENYL ETHERS …........................................ 9

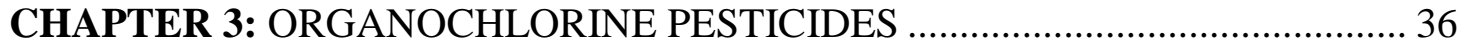

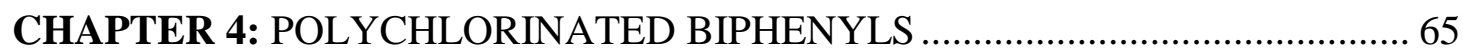

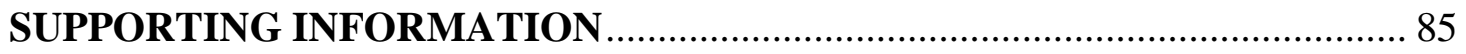

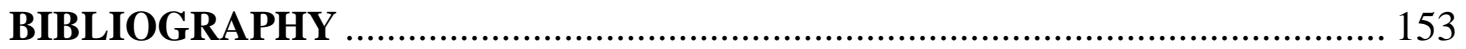




\section{LIST OF TABLES}

TABLE

PAGE

Table 2.1. $\Sigma_{22} \mathrm{PAH}$ concentrations in air and water by deployment period. .............. 29

Table 2.2. $\Sigma_{11}$ PBDE concentrations in air and water by deployment period .............. 34

Table 3.1. Average individual OCP concentrations in gas- and dissolved-phases ..... 59

Table 4.1. $\Sigma_{18} \mathrm{PCB}$ concentrations in air and water by deployment period................ 81 


\section{LIST OF FIGURES}

FIGURE

PAGE

Figure 2.1. Map of Lake Superior sampling sites. ............................................. 28

Figure 2.2. Average $\Sigma_{22} \mathrm{PAH}$ concentrations at each Lake Superior sampling site. ... 30

Figure 2.3. Change in retene concentration from June-August and August-October. 31

Figure 2.4. $\Sigma_{21} \mathrm{PAH}$ fluxes across the air-water interface of Lake Superior ............... 32

Figure 2.5. Average $\Sigma_{11}$ PBDE concentrations at each Lake Superior sampling site .. 33

Figure 2.6. $\Sigma_{11} \mathrm{PBDE}$ fluxes across the air-water interface of Lake Superior...........35

Figure 3.1. Average $\Sigma_{24} \mathrm{OCP}$ concentrations in the Lake Superior atmosphere........60

Figure 3.2. Recorded and predicted $\alpha-\mathrm{HCH}$ trends from 1996 to $2011 \ldots \ldots \ldots \ldots \ldots . \ldots 6$

Figure 3.3. Average $\Sigma_{24} \mathrm{OCP}$ concentrations in the Lake Superior surface water.......62

Figure 3.4. Fluxes for four OCPs across the air-water interface of Lake Superior...66

Figure 3.5. Technical DDT and metabolite fluxes across June-October 2011 ..........64

Figure 4.1. Gaseous and dissolved PCB concentrations across Lake Superior.........82

Figure 4.2. Relative PCB congener contributions in Lake Superior air and water......83

Figure 4.3. PCB flux rates for urban, rural, and open-lake sites...................84 


\section{CHAPTER 1}

\section{INTRODUCTION}

The Great Lakes region has long been affected by anthropogenic pollution. Heavy industry, areas of dense population, and extensive cargo shipping spanning back to the mid- $20^{\text {th }}$ century led to pollution and invasive species prompting the joint action of the United States and Canada to establish the Great Lakes Water Quality Agreement in 1972 (EPA 2012). The agreement, revised in 2012, seeks to "protect, restore, and enhance water quality of the waters of the Great Lakes and their intention to prevent further pollution and degradation of the Great Lakes Basin Ecosystem" (EPA 2012). It followed the establishment of the Great Lakes Commission (GLC) under the Great Lakes Basin Compact of 1955. The purpose of the commission is to "promote the orderly, integrated, and comprehensive development, use, and conservation of the water resources of the Great Lakes Basin" (GLC 2012).

The GLC created the Great Lakes Air Deposition (GLAD) program to address the deposition of toxic pollutants to the waters of the Great Lakes region and to reduce the resulting adverse impacts on human and wildlife health (GLC 2011). The targeted pollutants are referred to as persistent bioaccumulative toxics (PBTs), chemicals that have been identified by the United Nations Economic Commission for Europe (UNCE) as (1) being resistant to natural degradation, (2) having adverse effects on human health and the environment, (3) being able to biomagnify in upper trophic levels, and (4) being capable of atmospheric transportation to regions far from their 
original sources. Several classes of compounds meet these criteria, including polycyclic aromatic hydrocarbons (PAHs), organochlorine pesticides (OCPs), polychlorinated biphenyls (PCBs), and polybrominated diphenyl ethers (PBDEs).

The Integrated Atmospheric Deposition Network (IADN) monitors trends of nonpoint source pollution in the Great Lakes basin (Buehler and Hites 2002). IADN is a joint effort between Canada and the United States established in 1990 to determine whether the concentrations of PBTs in air and precipitation near the Great Lakes are changing as a function of time (Hillery et al. 1998; Buehler and Hites 2002). Five master stations, one on each lake, were selected to represent regional air near the lakes with minimal impact from local sources (Hillery et al. 1998). Lake Superior's master station, Eagle Harbor, MI, has concentrations among the lowest measured (Buehler et al. 2001). As the least industrialized and least populated of the Great Lakes (Hillery et al. 1998), Lake Superior air quality is considered to be representative of regional background atmospheric concentrations.

Lake Superior is the largest freshwater lake in the world by surface area $\left(82,100 \mathrm{~km}^{2}\right)$ and third largest by volume (MN Sea Grant 2012). It holds more water than the other Laurentian Great Lakes combined (MN Sea Grant 2012), accounting for $28 \%$ of the world's freshwater supply (Buehler and Hites 2002). Lake Superior has a relatively small watershed $\left(127,700 \mathrm{~km}^{2}\right)$ containing 848 tributaries (MN Sea Grant 2012). The only water outputs are through the St. Mary's River flowing into Lake Huron to the east $\left(27,120 \mathrm{~m}^{3} / \mathrm{sec}\right)$ and evaporation to the atmosphere $\left(18,430 \mathrm{~m}^{3} / \mathrm{sec}\right)$ (MN Sea Grant 2012). 
The Lake Superior region is home to over 600,000 people (MN Sea Grant 2012). The largest cities, Thunder Bay, ON and Duluth, MN, account for 110,000 and 100,000 people, respectively. Although not densely populated, Lake Superior experiences major shipping traffic from March to January through the Soo Locks (MN Sea Grant 2012). Duluth/Superior is one of the busiest inland ports in the United States, accommodating ca. 1,000 ships carrying 42 million tons of cargo every year (MN Sea Grant 2012). Iron ore and coal account for $80 \%$ of the cargo shipped.

Despite its rural location, water and air quality in the Lake Superior region are affected by anthropogenically produced PBTs. PBTs are semivolatile compounds making them available for atmospheric transportation in both the gas and particle phases (Gevao et al. 1998). Thus, through a repeating process of evaporation and precipitation, these persistent pollutants can be distributed to remote areas far from known sources (Gustafson and Dickhut 1997; Baker and Eisenreich 1990). The small, rural watershed and large surface area (catchment:surface area 0.6:1) mean that atmospheric deposition is the major input pathway for PBTs to Lake Superior. Net atmospheric loadings to Lake Superior are controlled by five main factors: atmospheric-tributary inputs, wet deposition, dry deposition, gas transfer, and bubblespray production (Gustafson and Dickhut 1997; Hillery et al. 1998). In addition to the influence of PBT point sources, atmospheric concentrations of semivolatile organic compounds have a seasonal component whereby ambient temperature determines the direction of PBT transfer across the air-water interface (Hillery et al. 1998). Particularly in regions with lower PBT concentrations, cold temperatures in the winter and spring can lead to net PBT deposition, whereas peak temperatures in 
the fall may lead to net volatilization (Hornbuckle et al. 1994; Morgan and Lohmann 2008; Sabin et al. 2010).

Temperature control on atmospheric PBT concentrations and air-water exchange may become even more significant with climate change in the Great Lakes region. In general, Lake Superior exhibits water stratification characteristics typical of mid-latitude lakes: strong positive stratification during the summer, one or more isothermal mixing events during spring warming and fall cooling, and seasonal ice formation causing weakly negative stratification in the winter (Austin and Colman 2007; Jay Austin, University of Minnesota, personal communication). However, Lake Superior is one of the most rapidly warming lakes in the world (LSBF 2013), altering its seasonality. Since 1980, surface water temperature in the summer has increased ca. $1{ }^{\circ} \mathrm{C}$ per decade and regional air temperature has increased by $0.5^{\circ} \mathrm{C}$ (Moen 2008; $\mathrm{MN}$ Sea Grant 2012). Ice coverage is decreasing by ca. $0.5 \%$ per year (Moen 2008), resulting in a cumulative $79 \%$ loss since 1973 (LSBF 2013). Concurrently, wind speeds have increased, resulting in the early arrival of the spring turnover by ca. 0.5 days per year, earlier summer stratification, and a deeper warmed layer (Moen 2008). Higher temperatures could mean an increase in evaporation of surface water of $7-17 \%$ by 2030 and more intense rain, worsening wastewater overflows (Moen 2008). Combined with drought and too little snow to feed the lakes, these factors have resulted in water levels in the Great Lakes below their long term averages for the past 14 years and historically low water marks (NYT 2013). In the Great Lakes Water Quality Agreement, the U.S. and Canada recognize that climate change may affect the use, release, transport and fate of chemicals in the Great Lakes Basin Ecosystem, 
thereby contributing to impacts on human health and the environment (GLWQA 2012). As a result of changing concentrations and increasing evaporation, Lake Superior may experience greater net volatilization of PBTs and become a significant secondary contributor of pollutants back to the atmosphere.

While IADN's active atmospheric monitoring is useful for tracking emissions trends and can indicate deposition rates, there are several limitations which render high-volume air sampling unsuitable for regional monitoring of PBT distributions. Active samplers are noisy and require electricity and maintenance (Khairy and Lohmann 2012). Sampling is not continuous; it consists of 24 hours of high volume (hi-vol) air collection every 12 days to assess year-round spatial and temporal trends of organic pollutants in gas, particle, and precipitation phases (EPA 2012; Hillery et al. 1998; Buehler and Hites 2002). High volume air samplers use filters, which can experience breakthrough and degassing of pollutants from particles and can affect the measurement quality (Khairy and Lohmann 2012). Additionally, the IADN active air sampling program excludes water concentrations and contributions to the atmosphere as a result of volatilization, affecting the assessment of net fluxes across the air-water interface. As an alternative, polyethylene (PE) passive samplers can be independently deployed for days or weeks at a time to establish time-averaged concentrations of trace compounds and do not require a power source. This independence means there are no limitations on spatial distribution, permitting higher resolution monitoring of large geographic areas. Comparisons between PEs and active sampling find an agreement generally within a factor of 2 (Khairy and Lohmann 2012; Khairy and Lohmann 2013). 
Passive sampling is a widely accepted method for measuring active (truly dissolved or vapor-phase) compounds in water and atmosphere (Lohmann 2012; Morgan and Lohmann 2008; Lohmann et al. 2012). Compared to other passive sampler matrices, $\mathrm{PE}$ is the simplest in chemical makeup and the cheapest polymer available (Lohmann 2012). Low-density polyethylene (LDPE) is produced by free radical polymerization and is made up of ca. 20-40 long and short chain branches per 1000 carbon atoms off the main PE chain (Lohmann 2012). LDPE density is generally between $0.91-0.923 \mathrm{~g} / \mathrm{cm}^{3}$. Simple commercial 2 mil dropcloth can be easily obtained and prepared.

PE passively accumulates hydrophobic organic compounds in proportion to their active concentrations, which is directly related to their availability for mass transfers and bio-uptake in the environment (Adams et al. 2007; Lohmann et al. 2012). PBTs are nonpolar or weakly polar, hydrophobic substances which are largely sorbed to particulate material, meaning their freely dissolved concentrations are extremely low (Lohmann et al. 2012). PE absorbs hydrophobic compounds from the aqueous and gaseous phases and concentrates them from their trace levels (Lohmann et al. 2012). Cavities in the polymer matrix are only on the order of $1 \mathrm{~nm}$, reducing the uptake of particle bound compounds and limiting sampling to gas and dissolved phase compounds (Lohmann et al. 2012).

Hydrophobic organic contaminant uptake is described by the partitioning constant between $\mathrm{PE}$ and water or air, $\mathrm{K}_{\mathrm{PEx}}$, at equilibrium:

$$
\mathrm{K}_{\mathrm{PEx}}=\mathrm{C}_{\mathrm{PE}} / \mathrm{C}_{\mathrm{x}}
$$


where $\mathrm{C}_{\mathrm{PE}}$ is the concentration of the compound in the $\mathrm{PE}(\mathrm{mol} / \mathrm{kg} \mathrm{PE})$ and $\mathrm{C}_{\mathrm{x}}$ is the concentration of the compound freely dissolved in water $\left(\mathrm{mol} / \mathrm{L} \mathrm{H}_{2} \mathrm{O}\right)(\mathrm{Lohmann} 2012)$ or gaseous in the atmosphere (mol/L air). The magnitude of $\mathrm{K}_{\mathrm{PEw}}$ is almost entirely dominated by a compound's solubility in water and we can assume constant solubility in LDPE (Lohmann 2012). Uptake of hydrophobic compounds is an absorptive process whereas surface adsorption is not significant (Lohmann 2012).

The objective of this project is to enhance our understanding of the distribution of PBTs across Lake Superior in order to evaluate the effects of local and long-range inputs. The GLC funded this project to achieve two main goals: (1) uniquely enhance measurements of the spatial variability of atmospheric concentration of PBTs around Lake Superior, and (2) assess whether the lake is volatilizing or absorbing gas-phase PBTs to derive fluxes and loading to Lake Superior.

Passive samplers, such as PEs, are ideal for sampling PBTs across Lake Superior and the Great Lakes region in general. In the following study, we employ PE passive samplers to collect air and water samples across the entire surface of Lake Superior. Passive samplers are inexpensive, light-weight, and do not require a power source, so they can be deployed by volunteers at any dock around the perimeter and on any buoy in the open lake. Currently, IADN samplers are only operating at two locations (Brule River and Eagle Harbor), limiting the scope of influence from point sources around the lake perimeter. Expanded sampling coverage of Lake Superior can significantly improve the spatial resolution of PBT concentrations in both the air and water. PEs can also be deployed in quick succession, providing a continuous, timeaveraged dataset to monitor changes in PBT concentrations with time. 
Coastal population distributions and changes in PBT production based upon enforced policies can affect PBT trends and should be tracked in Lake Superior, especially if we depend upon those atmospheric concentrations to determine background conditions in the Great Lakes region. Increasing emissions of emerging contaminants will lead to deposition into Lake Superior, whereas continued decreases of banned PBTs in the atmosphere could cause an equilibrium shift across the airwater interface whereby the lake may become a secondary source of toxic compounds back to the atmosphere. Additional stressors related to climate change underscore the importance of expanded and continued monitoring of PBTs in the Lake Superior region. 


\section{CHAPTER 2}

\section{POLYCLYCLIC AROMATIC HYDROCARBONS AND POLYBROMINATED DIPHENYL ETHERS}

\section{Introduction}

Polycyclic aromatic hydrocarbons (PAHs) and polybrominated diphenyl ethers (PBDEs) are two classes of PBTs that have been monitored in the Great Lakes' atmosphere over the past two decades. The United Nations Economic Commission for Europe designated both as persistent organic pollutants due to their persistence, bioaccumulation, long-range transport toxicity, and mutagenicity. Of the 100 known PAHs, seven are identified as possible human carcinogens (MA DEP 2008), as is DecaBDE (U.S. EPA 2008).

PAHs are composed of two or more fused aromatic rings pyrogenically released as the result of incomplete combustion of both anthropogenic (fossil fuels) and natural (biomass) sources (Gewurtz et al. 2008; Slater et al. 2013). They can also result from petrogenic releases (oil spills) and volatilization from polluted grounds (Sabin et al. 2010; Khairy and Lohmann 2012). PAHs are actively emitted to the environment through car exhaust, industrial activity, residential heating, and wildfires (Buehler et al. 2001), leading to a ubiquitous presence and continued atmospheric deposition across the Great Lakes (Slater et al. 2013). 
Likewise, PBDEs are emitted from industrial and urban centers where they are incorporated in a wide range of products, from textiles and polyurethane foam to circuit boards and are subsequently transported and deposited by the atmosphere (Crimmins et al. 2012). PBDEs are brominated flame retardants in widespread use since the 1970s (U.S. EPA 2008) and easily released to the atmosphere because they are not chemically incorporated into polymer matrices (SFT 2009). There are 209 BDE congeners, ranging from 2-10 bromine substituents per molecule (Raff and Hites 2007). While BDE-209 is easily lost from the atmosphere by wet and dry deposition, $90 \%$ of the removal of gas-phase congeners with $2-6$ bromines is caused by photolysis (Raff and Hites 2007). Lower brominated congeners tend to bioaccumulate more than higher brominated congeners and are more persistent in the environment (U.S. EPA 2008). BDE-47, 99, and 100 are nearly ubiquitous in North American freshwater and marine environments, at concentrations typically 10-20 times higher than elsewhere (Raff and Hites 2007; Crimmins et al. 2012). PentaBDEs were voluntarily phased out of U.S. industry in 2004, however, DecaBDE was only scheduled for North American phase out in 2012 (Crimmins et al. 2012). PBDEs are still in imported products, suggesting continued release to the environment and deposition into Lake Superior.

The objective of this study is to enhance our understanding of the distribution and behavior of PAHs and PBDEs across Lake Superior. We deployed PEs in the air and water at 19 sites across Lake Superior from April-October 2011 with the aim to (1) enhance the spatial coverage of air and water sampling stations across Lake Superior; (2) determine PBT distributions, concentrations, and air-water exchange; 
(3) discern seasonal temporal trends; and (4) evaluate the efficacy of PEs as tools to monitor regional PBT distributions.

\section{Sampling Methodology}

Low density polyethylene ( 2 mil) was cut into appx. 10x40 cm strips from commercial sheeting (Berry Plastics Corporation, Evansville, IN) yielding passive samplers $\sim 2 \mathrm{~g}$ each. PEs were cleaned successively in dichloromethane and hexane for $24 \mathrm{~h}$ each. PEs were spiked with performance reference compounds (PRCs) to account for mass-transfer limitations during deployment. Deuterated PAHs (naphthalene-d8, pyrene-d10, benzo(a)pyrene-d12) and brominated biphenyls (dibromobiphenyl, tetrabromobiphenyl, pentabromobiphenyl) were equilibrated with the PEs in 80:20 methanol:water on a shaker table for 4 weeks based on the procedure reported by Booij et al. (2002). PEs were woven onto stainless steel wire and distributed to collaborators and volunteers. Air PEs were deployed in inverted bowl stations at 11 coastal and 3 open-lake sites (Figure 2.1). Surface water PEs were deployed in tandem with the coastal air samplers, as well as at 3 open-lake sites and two additional coastal sites. Samples were collected in three deployment periods to evaluate temporal trends: April-June, June-August, and August-October 2011. Duplicate air samples and triplicate water samplers were deployed at two sites during each deployment. Field blanks were taken from 2-3 sites per deployment period. After retrieval, samplers were wrapped in foil, shipped to the lab and stored at $4^{\circ} \mathrm{C}$ until analysis. 


\section{Analytical Methodology}

PEs were wiped clean with Kimwipes and extracted for 24 hours in ethyl acetate. Extracts were spiked with 45-50 ng of labeled PAH (acenaphthalene-d10, phenanthrene-d10, chrysene-d12, perylene-d12) and $50 \mathrm{ng} \operatorname{PBDE}\left({ }^{13} \mathrm{C}_{12}-\mathrm{BDE} 28\right.$, ${ }^{13} \mathrm{C}_{12}$-BDE47, ${ }^{13} \mathrm{C}_{12}$-BDE99, ${ }^{13} \mathrm{C}_{12}$-BDE153, ${ }^{13} \mathrm{C}_{12}$-BDE183) surrogates to determine analyte recovery during sample processing (see Supporting Information). Extracted PEs were air dried and weighed. Extracts were nitrogen evaporated to $100 \mu \mathrm{l}$ in a $30^{\circ} \mathrm{C}$ water bath using a Biotage Turbovap II and minivap, then transferred to amber vials with spring-bottom glass inserts and spiked with $30 \mathrm{ng}$ of para-terphenyl (injection standard).

PAHs were analyzed on an Agilent 6890 Series GC (gas chromatograph) System coupled with an Agilent 5973 Network MS (mass spectrometer) and quantified using Agilent Technologies MSD Productivity ChemStation D.03.00552 software as presented elsewhere (Lohmann et al. 2012). Samples were held at $60{ }^{\circ} \mathrm{C}$ for 2 minutes, ramped up to $100{ }^{\circ} \mathrm{C}$ at $5{ }^{\circ} \mathrm{C} / \mathrm{min}$ and held for 2 minutes, ramped up to $200{ }^{\circ} \mathrm{C}$ at ${ }^{\circ} \mathrm{C} / \mathrm{min}$, and ramped up to $315^{\circ} \mathrm{C}$ at $5^{\circ} \mathrm{C} / \mathrm{min}$ and held for ten minutes. PBDEs were analyzed on a Waters Quattro micro GS Micromass MS-MS and quantified using Waters QuanLynx V4.1 software as detailed elsewhere (Sacks and Lohmann 2012). Samples were held at $100{ }^{\circ} \mathrm{C}$ for 1 minute, ramped up to $220^{\circ} \mathrm{C}$ at 5 ${ }^{\circ} \mathrm{C} / \mathrm{min}$ and held for 10 minutes, then ramped up to $280{ }^{\circ} \mathrm{C}$ at $4{ }^{\circ} \mathrm{C} / \mathrm{min}$ and held for 5 minutes. Both analyses were conducted in splitless injection mode and using a 30m x $0.250 \mathrm{~mm}$ i.d. (film thickness $0.25 \mu \mathrm{m}$ ) DB-5MS column. 


\section{Quality Assurance/Quality Control}

Matrix spikes were prepared in each batch of approximately 20 samples. Average surrogate recoveries for PAHs were generally $>60 \%$ and spiked matrix recoveries were typically around $100 \%$ (see Supporting Information). Average surrogate recoveries for PBDEs ranged from $80-150 \%$ and spiked matrix recoveries were typically $80-90 \%$. Method blanks were prepared with each batch of samples to monitor for laboratory contamination. Samples were blank-corrected by subtracting the average of the method and field blank concentrations. Only sample amounts greater than 3 times the standard deviation of the average blank values are reported. Standard checks were analyzed every ten samples to monitor instrument performance.

\section{$\underline{\text { Calculations/Data Analysis }}$}

Total $\Sigma_{22} \mathrm{PAH}$ concentrations were determined for each site. The $22 \mathrm{PAHs}$ are naphthalene, biphenyl, acenaphthylene, acenaphthene, fluorene, phenanthrene, anthracene, methyl phenanthrenes, fluoranthene, pyrene, retene, benz(a)anthracene, chrysene, benzo(b)fluoranthene, benzo(k)fluoranthene, benzo(a)pyrene, benzo(e)pyrene, perylene, benzo(j)fluoranthene, indeno(1,2,3-cd)pyrene, dibenzo(a,h)anthracene, benzo(g,h,i)perylene. Sums of PBDEs were also determined for each site from the congeners BDE-2, 8, 15, 28, 30, 47, 49, 99, 100, 153, 154.

Truly dissolved concentrations of PBTs in water, $\mathrm{C}_{\mathrm{W}}(\mathrm{ng} / \mathrm{L})$, were calculated according to Adams et al. (2007):

$$
\mathrm{C}_{\mathrm{W}}=\mathrm{C}_{\mathrm{eq}} / \mathrm{K}_{\mathrm{PEW}}
$$


$\mathrm{C}_{\mathrm{eq}} \mathrm{w}$ is the concentration of the $\mathrm{PBT}$ in the PE when in equilibrium with water ( $\mathrm{pg} / \mathrm{kg}_{\mathrm{PE}}$ ), and $\mathrm{K}_{\mathrm{PEW}}$ is the PBT partitioning coefficient from water into polyethylene (L/kg). K KEW values were obtained from Lohmann (2012) and temperature-corrected according to a modified form of the Van't Hoff equation

$$
\mathrm{K}_{\mathrm{PEW}(\mathrm{T})}=\mathrm{K}_{\mathrm{PEW}(298 \mathrm{~K})} \mathrm{e}^{(-(\Delta \mathrm{Hvap} / \mathrm{R}) *[(1 / 298 \mathrm{~K})-(1 / \mathrm{T})])}
$$

where $\Delta \mathrm{H}_{\text {vap }}$ is the enthalpy of vaporization $(\mathrm{kJ} / \mathrm{mol}), \mathrm{R}$ is the gas constant $(\mathrm{kJ} / \mathrm{K} * \mathrm{~mol})$ and $\mathrm{T}$ is the average water temperature during deployment (Kelvin). Gas-phase atmospheric PBT concentration, $\mathrm{C}_{\mathrm{A}}$, was determined with the same calculations, substituting the air-PE partitioning coefficient, $\mathrm{K}_{\mathrm{PEA}}$, for $\mathrm{K}_{\mathrm{PEW}}$.

The extent of equilibrium achieved for each compound was determined by fitting the equilibrium of the performance reference compounds and their temperaturecorrected $\log \mathrm{K}_{\mathrm{PE}}$ values to a model curve derived as

$$
\% \text { equilibrium }=1-\mathrm{e}^{\left(-\left(\mathrm{Rs}^{*} \mathrm{t}\right) /\left(\mathrm{V} * \mathrm{~K}_{\mathrm{PE}}\right)\right)}
$$

where $R_{s}$ is the sampling rate used to adjust the curve (L/day), $t$ is the sampling time (days), and V is the PE volume. Performance reference compound equilibrium was calculated by comparing the concentrations remaining at time $t$ to the concentrations at time 0 (assumed to be equivalent to concentrations in the field blanks).

The gradient of air-water exchange is the ratio of the equilibrium concentration of the $\mathrm{PBT}$ in air $\left(\mathrm{C}_{\mathrm{eqA}}, \mathrm{pg} / \mathrm{L}\right)$ to the equilibrium concentrations of the $\mathrm{PBT}$ in water $\left(\mathrm{C}_{\text {eqw }}, \mathrm{pg} / \mathrm{L}\right)$, where a gradient $>1$ indicates atmospheric deposition and a gradient $<1$ indicates volatilization from the water to the air. Net air-water fluxes $\left(\mathrm{ng} / \mathrm{m}^{2} / \mathrm{day}\right)$ were calculated by modifying the equation Flux $=\mathrm{k}_{\mathrm{Ol}} *\left(\mathrm{C}_{\mathrm{W}}-\mathrm{C}_{\mathrm{A}} / \mathrm{K}_{\mathrm{AW}}\right)($ Schwarzenbach et al. 2003), to 


$$
\text { Flux } \left.=\mathrm{k}_{\mathrm{ol}} *\left[\left(\mathrm{C}_{\mathrm{eqW}}-\mathrm{C}_{\mathrm{eqA}}\right) / \mathrm{K}_{\mathrm{PEW}}\right)\right]
$$

where $\mathrm{k}_{\mathrm{ol}}$ is mass transfer coefficient (m/day) (see Supporting Information) and $\mathrm{K}_{\mathrm{PEW}}$ is the temperature-corrected PBT partitioning coefficient from water to $\mathrm{PE}(\mathrm{L} / \mathrm{kg})$.

\section{$\underline{\text { Results and Discussion }}$}

Polycyclic Aromatic Hydrocarbons (PAHs)

Spatial Distributions in Air: Seasonally averaged $\Sigma_{22} \mathrm{PAH}$ gas-phase concentrations in the atmosphere ranged from $<1$ to $>100 \mathrm{ng} / \mathrm{m}^{3}$ (Figure 2.2A). Concentrations were always greatest at Sault Saint Marie, ON (June-October mean $150 \mathrm{ng} / \mathrm{m}^{3}$ ), and lowest at Eagle Harbor, MI (June-August $0.060 \mathrm{ng} / \mathrm{m}^{3}$ ) and the open lake sites (mean $0.15-1.3 \mathrm{ng} / \mathrm{m}^{3}$ ) (Table 2.1). PAHs tend to have a strong urban signature from vehicle emissions, power generation plants, and industrial activity (Hafner and Hites 2003; Sun et al. 2006). An urban-rural gradient can occur due to particle scavenging near urban sources, precipitation scrubbing, and $\mathrm{OH}$ radical degradation (Offenberg and Baker 2002; Hafner and Hites 2003). Fluorene, phenanthrene, fluoranthene, and pyrene are all byproducts of gasoline combustion and are therefore used as indicators of urban signals (Hafner and Hites 2003). Fluorene has the longest atmospheric lifetime (22-26 hours) and thereby the strongest source trend. The presence of fluorene at a Lake Superior site indicates a source within 350700 km. For Eagle Harbor this includes Milwaukee, WI, Madison, WI, Chicago, IL, and to a lesser extent Minneapolis and St. Paul, MN (Hafner and Hites 2003).

Previous sediment studies measured the greatest PAH concentrations near Lake Superior's second largest city, Duluth, MN (Gewurtz et al. 2008), however, 
those studies did not include Sault Saint Marie. Although not the largest city along the Lake Superior shoreline, Sault Saint Marie is located on the Soo Locks, which sees $>70,000,000$ net tons of cargo annually (USACE 2011). Shipping traffic may significantly contribute to local PAH concentrations. Atmospheric PAH concentrations at Sault Saint Marie were dominated by the more volatile two- and three-ring compounds: acenaphthene $\left(24 \mathrm{ng} / \mathrm{m}^{3}\right)$, fluorene $\left(21 \mathrm{ng} / \mathrm{m}^{3}\right)$, phenanthrene $\left(57 \mathrm{ng} / \mathrm{m}^{3}\right)$, anthracene $\left(1.7 \mathrm{ng} / \mathrm{m}^{3}\right)$, methyl phenanthrenes $\left(9.1 \mathrm{ng} / \mathrm{m}^{3}\right)$, fluoranthene $\left(20 \mathrm{ng} / \mathrm{m}^{3}\right)$, plus the four-ringed pyrene $\left(8.8 \mathrm{ng} / \mathrm{m}^{3}\right)$. These compounds are emitted from gasoline engines, coal combustion, and coke ovens (Hafner and Hites 2003). Relative contributions from petroleum and combustion can be assessed by establishing characteristic ratios of PAHs, such as anthracene/anthracene+phenanthrene, fluoranthene/fluoranthene+pyrene, and benz(a)anthracene/benz(a)anthracene + chrysene ratios (Yunker et al. 2002). The Ant/Ant+Phen ratio at Sault Saint Marie was $<0.10(0.03)$, which indicated a greater contribution from petroleum. The Flra/Flra+Pyr was just above equilibrium (0.5) at a ratio of 0.69 , likely indicating a combination of combustion and petroleum. The less-commonly used BaA/BaA+Chry was $<0.2(0.05)$, indicating the presence of crude oil and confirming petroleum is a major source atmospheric PAHs in the area.

The second greatest atmospheric PAH concentrations were at Ashland, WI (June-October average $31 \mathrm{ng} / \mathrm{m}^{3}$ ). Located along the southeastern shore of Lake Superior, Ashland is a major industrial port with a history of iron ore processing, manufactured gas, and lumber mills. It is now designated as a U.S. EPA Superfund site polluted with benz(a)anthracene and benzo(a)pyrene (U.S. EPA 2012). A cleanup 
plan has been designed for $>40,000 \mathrm{~m}^{2}$ of contaminated sediment offshore (WI DNR 2013). Our samplers were deployed near the Soo Line Ore dock, a now unused jetty originally serving ships and trains with iron ore. Acenaphthene $\left(26 \mathrm{ng} / \mathrm{m}^{3}\right)$, fluorene $\left(5.2 \mathrm{ng} / \mathrm{m}^{3}\right)$, phenanthrene $\left(6.0 \mathrm{ng} / \mathrm{m}^{3}\right)$, and fluoranthene $\left(1.8 \mathrm{ng} / \mathrm{m}^{3}\right)$ contributed to Ashland PAH concentrations. However, retene, produced by conifer trees, was also significantly present $\left(3 \%, 1.4 \mathrm{ng} / \mathrm{m}^{3}\right)$. It is also associated with wood varnish and lumber treatment (Sun et al. 2006), therefore, the lumber industry in Ashland could be contributing to the retene signal in that region.

Atmospheric PAH concentrations at other urban locations, while a tenth and a third of those at Sault Saint Marie and Ashland, respectfully, were still two- to tentimes greater than rural coastal sites, and several times the open-water air concentrations. Duluth had a lower atmospheric PAH signal (June-October average $13 \mathrm{ng} / \mathrm{m}^{3}$ ) than Sault Saint Marie and Ashland despite the Duluth/Superior harbor. This may be because the PE was deployed at the regional EPA office northeast (upwind) of the city center. It was followed by Marquette (June-August average 10 $\mathrm{ng} / \mathrm{m}^{3}$ ) and Thunder Bay/Welcome Isle (June-October average $5.9 \mathrm{ng} / \mathrm{m}^{3}$ ). Concentrations were characterized by many of the same petroleum- and biomassderived PAHs measured at shipping sites: phenanthrene, methyl phenanthrenes, fluoranthene, and pyrene. Thunder Bay and Duluth have relatively modest populations $(110,000$ and 100,000 people, respectively), and these samples demonstrate the effect even small cities have on local atmospheric PAH concentrations. 
Eagle Harbor, MI atmospheric PAH concentrations were below the detection limit for April-June and $<0.1 \mathrm{ng} / \mathrm{m}^{3}$ for June-August; August-October data was not available, however, temporal trends for other sites suggest atmospheric concentrations may have been even higher during the late summer. The IADN master station for Lake Superior is located at Eagle Harbor and has been collecting high volume air samples of PAHs since 1990 (Sun et al. 2006). The site is used as the background atmosphere standard for Lake Superior and the entire Great Lakes region (Cortes et al. 2000). Typical IADN PAH concentrations are ca. $1 \mathrm{ng} / \mathrm{m}^{3}$ (Cortes et al. 2000; Buehler et al. 2001). Although gas-phase PAH concentrations decreased since 1991 at all Great Lakes IADN sites and coal-fired power plant emissions are currently decreasing (Cortes et al. 2000; Slater et al. 2013), concentrations measured in this study may be lower than IADN values due to differences in sampling procedure. PEs were deployed from April to October, when PAH emissions are lowest. IADN samplers collect air samples throughout the entire year and results are reported as annual means, including the winter months when residential heating causes a spike in PAH emissions, particularly in the Canadian Great Lakes region (Sun et al. 2006). Additionally, PEs only sample the truly gas phase fraction of atmospheric PAHs. High volume air samplers can yield overestimates of gas PBTs as a result of compounds desorbing from particles onto the filter. Likewise, subsequent entrapment of analytes from the filter can lead to underestimates of gas-phase PAHs, overall making measurements difficult to interpret (Perlinger et al. 2005).

Assuming regional background concentrations are $1 \mathrm{ng} / \mathrm{m}^{3}$ as indicated by IADN data, central and western open lake samples were below the background 
atmospheric PAH threshold. Northern, rural coastal sites (Sturgeon Bay: $1.5 \mathrm{ng} / \mathrm{m}^{3}$; Foster Island: $\left.0.94 \mathrm{ng} / \mathrm{m}^{3}\right)$, and eastern open lake $\left(1.3 \mathrm{ng} / \mathrm{m}^{3}\right)$ were all at background levels.

Spatial Distributions in Water: PAH concentrations in the water followed similar spatial patterns as the atmospheric PAH distributions (Figure 2.2B). Seasonally averaged $\Sigma_{22} \mathrm{PAH}$ concentrations in Lake Superior were greatest at Sault Saint Marie (June-October 69 ng/L), followed by Ashland (33 ng/L). Concentrations at Sault Saint Marie were dominated by acenaphthene ( $8.3 \mathrm{ng} / \mathrm{L})$, fluorene $(5.4 \mathrm{ng} / \mathrm{L})$, phenanthrene (13 ng/L), methyl phenanthrenes (8.7 ng/L), fluoranthene (14 ng/L) and pyrene (12 ng/L). Phenanthrene, methyl phenanthrenes, fluoranthene, and pyrene also contributed to Ashland concentrations (5.3, 5.4, 2.7, and $4.8 \mathrm{ng} / \mathrm{L}$, respectively), however the greatest PAH present was retene (13 ng/L), possibly due to degradation of wood from lumber production and treatment. Water PAH levels at northern rural and open-water sites. Retene accounted for nearly $50 \%$ of the dissolved PAHs at Foster Island, Sturgeon Bay, and Station 139 and 70-80\% at the open-water sites. Methyl phenanthrenes were typically $>1 \mathrm{ng} / \mathrm{L}$, reaching $>7.0 \mathrm{ng} / \mathrm{L}$ at Sault Saint Marie, Sturgeon Bay, and Michopicoten Bay, as well as accounting for 50\% of the dissolved PAHs at Foster Island. Concentrations of dissolved PAHs were lower than expected at Station 221, east of Duluth, however, the sampler was deployed appx. 3 $\mathrm{km}$ offshore and may not receive a direct urban signal.

Retene: Although PAH concentrations near urban, industrial, and shipping centers are generally characterized by fossil fuel emissions, total dissolved concentration of PAHs across most sites were dominated by retene. Retene is the 
combustion byproduct of abietic acid, a natural product mainly found in coniferous trees (Sun et al. 2006). Retene can be produced in urban areas from municipal waste incinerators, tire burning, and incineration of building waste; however, it is primarily emitted by burning wood. Rural households consume about three times more wood than urban homes (Sun et al. 2006). It is therefore not surprising that retene accounts for $20-50 \%$ of the total PAHs at the northern coastal sites and is the only PAH present in open lake waters. Retene concentrations peak in the winter months when wood is burned for residential heating, but lower-magnitude spikes can occur between April and September due to naturally occurring wildfires (Sun et al. 2006).

Temporal Distributions: Atmospheric temperature nearly doubled between April-June and remained roughly the same through October, while water temperature continued to rise. $\Sigma_{21} \mathrm{PAH}$ (not including retene) atmospheric concentrations peaked from June-August at Sault Saint Marie $\left(190 \mathrm{ng} / \mathrm{m}^{3}\right)$ and water concentrations exhibited a decrease between April-June and June-August (130 to $72 \mathrm{ng} / \mathrm{L}$ ). Temperature trends were similar at Duluth where atmospheric concentrations also increased between the first two deployments $\left(7.8\right.$ to $\left.11 \mathrm{ng} / \mathrm{m}^{3}\right)$, and water concentrations decreased from June-October (7.6 to $1.1 \mathrm{ng} / \mathrm{L})$. However, Ashland and Michopicoten Bay had significantly elevated water concentrations August-October (10 to 31 and 3.3 to 12 ng/L, respectively) despite a similar temperature trend. Several PAHs increased at Ashland, whereas, the increase in water concentration at Michopicoten Bay appeared to be from increased methyl phenanthrenes.

Open water site (Station 23 and Station 113) temperature trends were different from coastal sites. Atmospheric and water temperatures doubled between June- 
August and August-October (8.3 to $14{ }^{\circ} \mathrm{C}$ and 6 to $14{ }^{\circ} \mathrm{C}$, respectively). While low, water concentrations increased (averaged 1.3 to $3.5 \mathrm{ng} / \mathrm{L}$ ), mainly in response to greater fluoranthene, pyrene, benzo(b)fluoranthene, and benzo(e)pyrene concentrations. Atmospheric concentrations of semi-volatile compounds generally have a seasonal component due to the effect of ambient temperature on the direction of pollutant transfer across the air-water interface (Hillery et al. 1998). It has been suggested, however, that atmospheric PAH concentrations are a function of emissions source rather than temperature (Cortes et al. 2000). Our results do not follow a clear temperature trend and PAH concentrations in Lake Superior from April-October likely fluctuate in response to changes in source emission and wind direction.

Several sites exhibited elevated retene concentrations in both air and water during deployment 3 (August-October) (Figure 2.3). Dissolved retene increased strongly at Sturgeon Bay (5.3 to $36 \mathrm{ng} / \mathrm{L})$, central open (0.17 to $19 \mathrm{ng} / \mathrm{L})$, and Station 139 (1.0 to $13 \mathrm{ng} / \mathrm{L})$. Because PE sampling was limited to one season, we cannot confirm whether these trends occur in annual cycles or are due to unique events. However, sites with the greatest retene concentrations are all northern and central lake locations which may have received elevated retene inputs following record-setting forest fires in Ontario in 2011 (Ontario Ministry of Natural Resources 2012). We hypothesize that water concentrations in those areas are more strongly affected than the air because of the direct input of water and sediment from the northern watershed by the Nipigon River.

PAH Air-Water Exchange Gradients: The direction of air-water exchange was determined by the ratio of the concentration of an analyte in the PE at equilibrium 
with the air to the concentrations of the analyte in the PE at equilibrium with the water:

$$
\text { Flux direction }=\mathrm{C}_{\mathrm{eqA}} / \mathrm{C}_{\mathrm{eqW}}
$$

A ratio $>1$ indicates a higher equilibrium concentration in the air, and therefore, net deposition. A ratio < 1 suggests a higher equilibrium concentration in the water, resulting in net volatilization. Significant departure from equilibrium between the two reservoirs was considered to be ca. 290\%. Generally, PAHs were deposited into Lake Superior at most sites, especially at shipping and urban centers. Exceptions were Sturgeon Bay and Michopicoten Bay, where methyl phenanthrenes were being volatilized, and open lake sites, which exhibited net equilibrium or slight volatilization.

PAH Flux Rates: Net air-water exchange of gas-phase PAHs were generally into the lake near populated or industrialized sources, however fluxes were low at most sites ( $<5 \mu \mathrm{g} / \mathrm{m}^{2} /$ day). Sault Saint Marie displayed the greatest flux and variety of PAHs (Figure 2.4). At this site average deposition was dominated by 6 PAHs: fluorene, phenanthrene, methyl phenanthrenes, fluoranthene, and pyrene; however, only phenanthrene $\left(6.9 \mu \mathrm{g} / \mathrm{m}^{2} /\right.$ day $)$, fluoranthene $\left(3.3 \mu \mathrm{g} / \mathrm{m}^{2} /\right.$ day $)$ and pyrene $(1.6$ $\mu \mathrm{g} / \mathrm{m}^{2} /$ day) underwent net deposition significant from equilibrium. Retene was deposited at most sites, with notable exceptions at the central open lake site and Sturgeon Bay, where retene concentrations in the water were exceptionally high and significant air-water exchange was near equilibrium. Elevated retene was likely due to the proximity of those sites to the Nipigon River, which supplies terrestrial water from the rural Ontario region north of Lake Superior. As previously discussed, retene 
inputs may have been elevated due to high wildfire activity in the region that season, resulting in net volatilization of retene into the atmosphere at the central open lake and Sturgeon Bay. This volatilization was in contrast to the eastern and western open lake site where retene was being deposited.

Atmospheric deposition is a major source of pollutants to the Great Lakes (Buckley et al. 2004; Li et al. 2006; Gewurtz et al. 2008). Chemical exchange across the air-water interface is one of the processes controlling concentrations and residence times of pollutants in these water bodies (Baker and Eisenreich 1990; Gevao et al. 1998; Hillery et al. 1998). PE sampling improves upon previous estimates of air-water PAH exchange. Simultaneous time-averaged concentrations for both the air and water dampen diurnal effects, minimize anomalous signals, and only equilibrate with gas- or dissolved-phase compounds directly available for exchange across the air-water interface. However, there are uncertainties in gas-transfer loadings estimated by this method. We used the two-film model for air-water gas exchange, which assumes diffusive flux of compounds between the air and water is limited by transport across two thin films at the interface and not by turbulent transport in the bulk mixed layers (Gevao et al. 1998; Perlinger et al. 2005). The rate of gas exchange is given by equation 3 and depends upon the Henry's Law constant, wind speed, and temperature. All of these parameters have a degree of uncertainty and thereby limit our ability to calculate accurate net fluxes of gas-phase PAHs (see Supporting Information).

\section{Polybrominated Diphenyl Ethers (PBDEs)}

Spatial Distributions: $\Sigma_{11} \mathrm{BDE}$ concentrations were more than three orders of magnitude lower than PAHs across Lake Superior (Figure 2.5A). Atmospheric PBDE 
concentrations were greatest at Marquette (June-October average $13 \mathrm{pg} / \mathrm{m}^{3}$ ) (Table 2.2). This station is located at a dock for a coal-fired power plant and in proximity to a number of sites registered with the EPA Toxic Release Inventory, including facilities that manufacture polyurethane and explosives (U.S. EPA 2013), where PBDEs might have been used in the past. Sault Saint Marie and Duluth also had elevated atmospheric PBDE concentrations from June-October, 6.2 and $3.6 \mathrm{pg} / \mathrm{m}^{3}$, respectively. Atmospheric concentrations at all other sites were $<1 \mathrm{pg} / \mathrm{m}^{3}$. The eastern open lake site (ODAS45004) exhibited concentrations >10 times higher than the other open lake sites, perhaps receiving input downwind from Marquette.

Water concentrations had the same spatial distributions (Figure 2.5B). Concentrations were greatest at Marquette (June-August average 7.6) followed by Sault Saint Marie, Thunder Bay/Welcome Island, Duluth, and Eagle Harbor (JuneOctober average 2.0, 1.2, 1.1, and 1.3, respectively). Dissolved PBDE concentrations were lowest at rural Canadian sites: Sturgeon Bay (0.056 pg/L), Foster Island (0.15 pg/L), and Michopicoten Bay (0.30 pg/L). Open lake sites generally exhibited higher PBDE concentrations than coastal rural sites, with the exception of Eagle Harbor.

Temporal Distributions: BDE-47 was generally the most abundant congener present (appx. 20 to 70\% in both air and water) throughout the sampling period, followed by BDE-28, 49, 99, and 100. BDE-153 concentrations were low or below detection at all most sites and BDE-154 was not detected in any samples.

Atmospheric concentrations near urban sources were typically higher from June-August than during the other two sampling periods, whereas water concentrations were fairly constant. Open lake sites all had different trends. While all 
at very low concentrations, eastern lake air and water concentrations both increased over the sampling period, western lake concentrations both decreased, and central lake air went below detection, whereas water concentrations doubled.

PBDE Air-Water Exchange Gradients: Equilibrium concentration ratios varied greatly between sites and PBDE congener, however the greatest fluxes were depositing at Sault Saint Marie and Duluth. Eagle Harbor and open lake site ratios suggest mostly net volatilization. Except at the open lake sites where it volatilized, BDE-47 appeared to undergo net deposition during the first two deployments. However, BDE-47 did volatilize at some coastal sites during August-October.

PBDE Flux Rates: PBDEs were depositing into Lake Superior at half of the coastal sites. The greatest fluxes were at Marquette, Duluth, and Sault Saint Marie (Figure 2.6). Deposits were primarily composed of BDE-47 with lighter congeners contributing to Sault Saint Marie fluxes. Conversely, the central open lake and Eagle Harbor sites generally volatilized PBDEs into the atmosphere, mainly BDE-47. Interestingly, the eastern open lake site (Station 23) exhibited strong deposition of diand tribromodiphenyl ethers (160 and $17 \mathrm{pg} / \mathrm{m}^{2} /$ day, respectively) from AugustOctober, perhaps indicating an upwind source during that time period.

PBDE Sources: PBDE concentrations in both the air and water were correlated with industrial and urban sites, reflecting their origin as flame retardants used widely in commercial and industrial products. Atmospheric deposition is the dominant source of PBDEs to Lake Superior and is the main method of input to midlake sites ( $\mathrm{Li}$ et al. 2006). The global fractionation theory predicts that lighter congeners will travel farther from PBDE sources (Li et al. 2006). Tri-, tetra-, and 
pentaBDEs were most commonly detected at Lake Superior sites, whereas lighter and heavier congers were typically below detection. We cannot determine whether this is a reflection of global fractionation of BDEs, their use, or our sampling approach.

Commercial pentaBDE was the most commonly used technical mixture of PBDEs, composed primarily of BDE-47, -99, and -100 (Crimmins et al. 2012). These congeners are found ubiquitously in North American freshwater, at concentrations typically more than 10 times higher than European values (Crimmins et al. 2012). Prior to a voluntary U.S. industry phase out in $2004,95 \%$ of worldwide pentaBDE was produced in North America (Crimmins et al. 2012). The Great Lakes Chemical Corporation located in West Lafayette, IN was the sole producer of commercial pentaBDE (SFT 2009). Since the end of its production, BDE47/BDE153 ratios decreased in Great Lakes fish (Crimmins et al. 2012), which may indicate decreasing atmospheric trends (Li et al. 2006).

Waning PBDE sources may explain the reduced atmospheric PBDE concentrations found in this study compared to IADN-derived measurements. $\Sigma_{7} \mathrm{BDE}$ atmospheric concentrations from 2005-2006 were $2.8+-0.28 \mathrm{pg} / \mathrm{m}^{3}$ (Venier and Hites 2008). Our atmospheric concentrations were two orders of magnitude lower at Eagle Harbor, possibly indicating the positive effect of reduced emissions in the region. Likewise, our Eagle Harbor fluxes indicate reduced gas deposition (1.9 kg/year) since 2005-2006 (18+-9.5 kg/year) (Venier and Hites 2008), however, urban locations may contribute to greater depositions. 


\section{Conclusions and Implications}

Current emissions of PAHs and PBDEs to the environment near urban and industrial centers continue to supply PBTs to Lake Superior. Although long-range atmospheric transport is a major pathway for PAH and PBDE distribution across Lake Superior, point sources along the lake perimeter significantly impact local and regional concentrations. Fluxes for both currently-emitted PBTs were generally into the lake near industrial and urban sources, whereas the open lake sites appeared to volatilize PBTs back into the atmosphere at much lower rates. Enhancing spatial and temporal coverage of the Great Lakes region will provide meaningful trends in PAH and PBDE concentrations and fluxes as use and regulations change. We anticipate PAH concentrations to remain constant or even increase with time, but PBDE concentrations may decrease as use is phased out. Changes in atmospheric concentrations could lead to an equilibrium reversal and the volatilization of PBDEs out of Lake Superior into the atmosphere. Such trends can be monitored effectively and affordably with polyethylene passive samplers. 


\section{Tables and Figures}

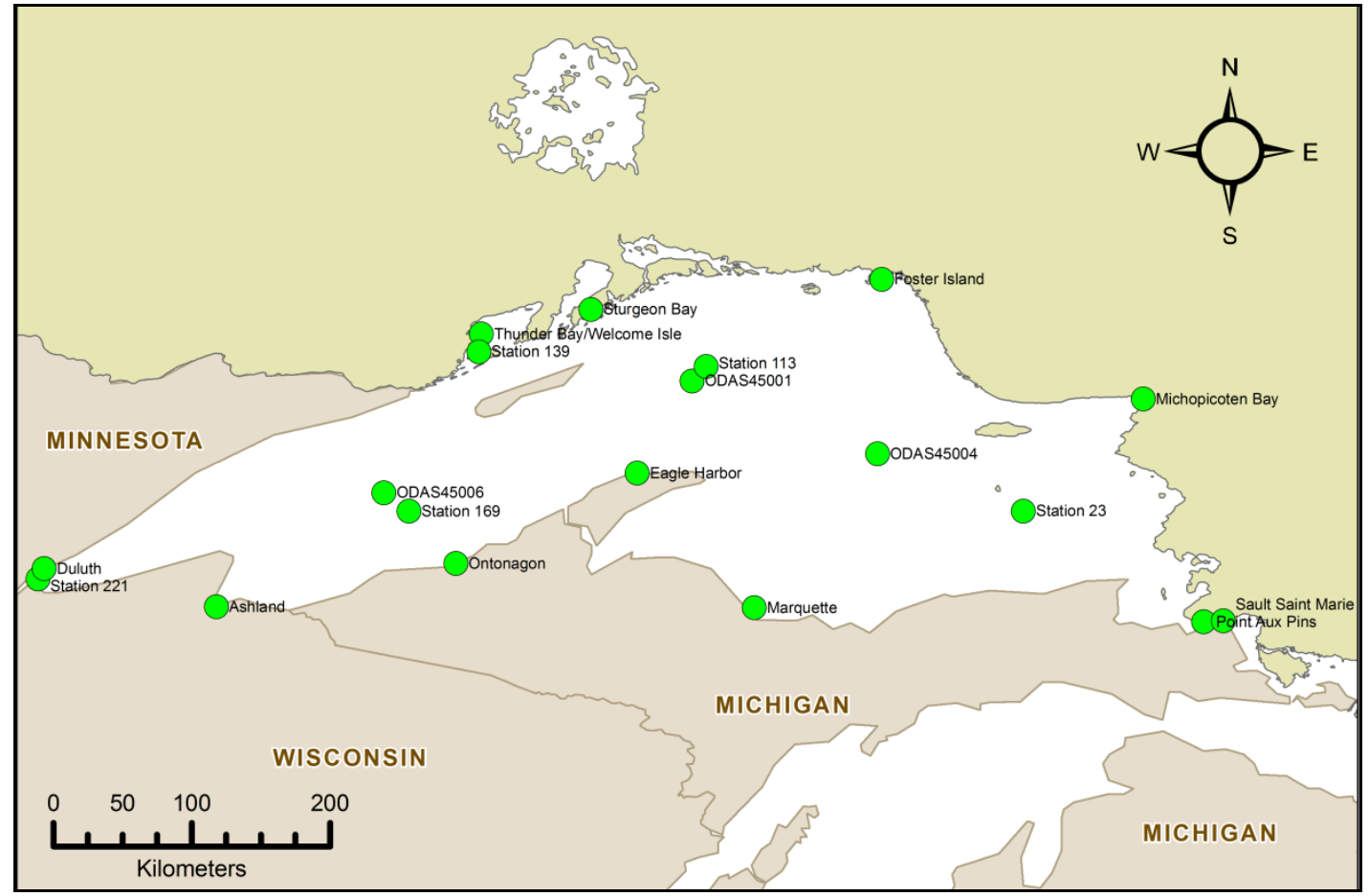

Figure 2.1: Map of study area. Green dots are deployment sites. Stations are Environment Canada buoys; ODAS sites are NOAA buoys. 
Table 2.1: $\Sigma_{22} \mathrm{PAH}$ concentrations in air $\left(\mathrm{ng} / \mathrm{m}^{3}\right)$ and water $(\mathrm{ng} / \mathrm{L})$ by deployment period

\begin{tabular}{|c|c|c|c|c|c|c|c|c|}
\hline \multirow[b]{2}{*}{ Site } & \multicolumn{4}{|c|}{ Air (ng/m³) } & \multicolumn{4}{|c|}{ Water (ng/L) } \\
\hline & $\begin{array}{l}\text { April- } \\
\text { June }\end{array}$ & $\begin{array}{c}\text { June- } \\
\text { August }\end{array}$ & $\begin{array}{l}\text { August- } \\
\text { October }\end{array}$ & $\begin{array}{c}\text { June-October } \\
\text { Average }\end{array}$ & $\begin{array}{l}\text { April- } \\
\text { June }\end{array}$ & $\begin{array}{l}\text { June- } \\
\text { August }\end{array}$ & $\begin{array}{l}\text { August- } \\
\text { October }\end{array}$ & $\begin{array}{c}\text { June-October } \\
\text { Average }\end{array}$ \\
\hline Sault Saint Marie & 71 & 190 & 100 & 150 & 127 & 73 & 65 & 69 \\
\hline Point Aux Pins & & 7.1 & 3.7 & 5.4 & & $\mathrm{~N} / \mathrm{A}$ & 9.8 & N/A \\
\hline Ashland & 72 & 12 & 49 & 31 & 56 & 25 & 41 & 33 \\
\hline $\begin{array}{l}\text { Thunder Bay } \\
\text { Welcome Isle }\end{array}$ & & 4.9 & 6.9 & 5.9 & & 7.3 & 8.2 & 7.7 \\
\hline Station 139 & & & & & & 4.1 & 18 & 11 \\
\hline Duluth/Station 221 & 7.8 & 11 & 16 & 13 & & 9.2 & 1.8 & 5.6 \\
\hline Marquette & 4.0 & 10 & N/A & N/A & 12 & 9.8 & N/A & $\mathrm{N} / \mathrm{A}$ \\
\hline Ontonagon & & $\mathrm{bd}$ & 5.1 & 2.5 & & 4.9 & 6.1 & 5.5 \\
\hline Michopicoten Bay & & 0.14 & 1.3 & 0.74 & & 4.1 & 13 & 8.7 \\
\hline Sturgeon Bay & & 0.63 & 2.4 & 1.5 & & 18 & 51 & 34 \\
\hline Foster Island & & 0.99 & 0.89 & 0.94 & & 3.7 & 8.8 & 6.3 \\
\hline Eagle Harbor & $\mathrm{bd}$ & 0.060 & N/A & $\mathrm{N} / \mathrm{A}$ & & 0.010 & 0.53 & 0.27 \\
\hline Eastern Open Lake & & bd & 2.7 & 1.3 & & 1.1 & 8.5 & 4.8 \\
\hline Central Open Lake & & $b d$ & 0.31 & 0.15 & & 1.7 & 23 & 12 \\
\hline Western Open Lake & & $\mathrm{bd}$ & 0.45 & 0.22 & & 0.53 & 2.2 & 1.4 \\
\hline
\end{tabular}



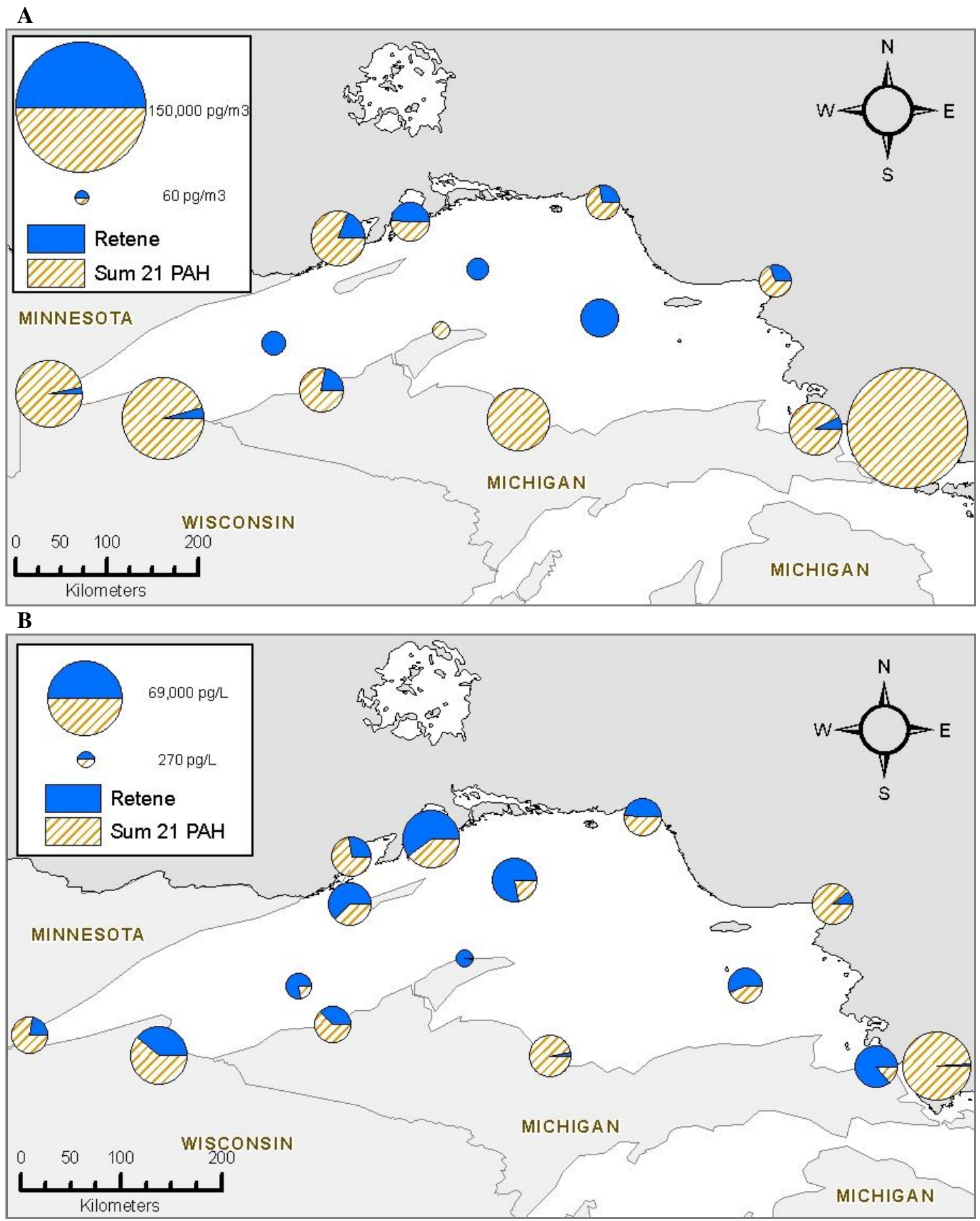

Figure 2.2: Average PAH concentrations at each station. (A) Air concentrations; average from June to October 2011 for all stations except Marquette and Eagle Harbor, which only represent June-August. (B) Water concentrations; average from June to October 2011 for all stations except Marquette, which only represents JuneAugust, and Point Aux Pins, which represents August-October 2011. 

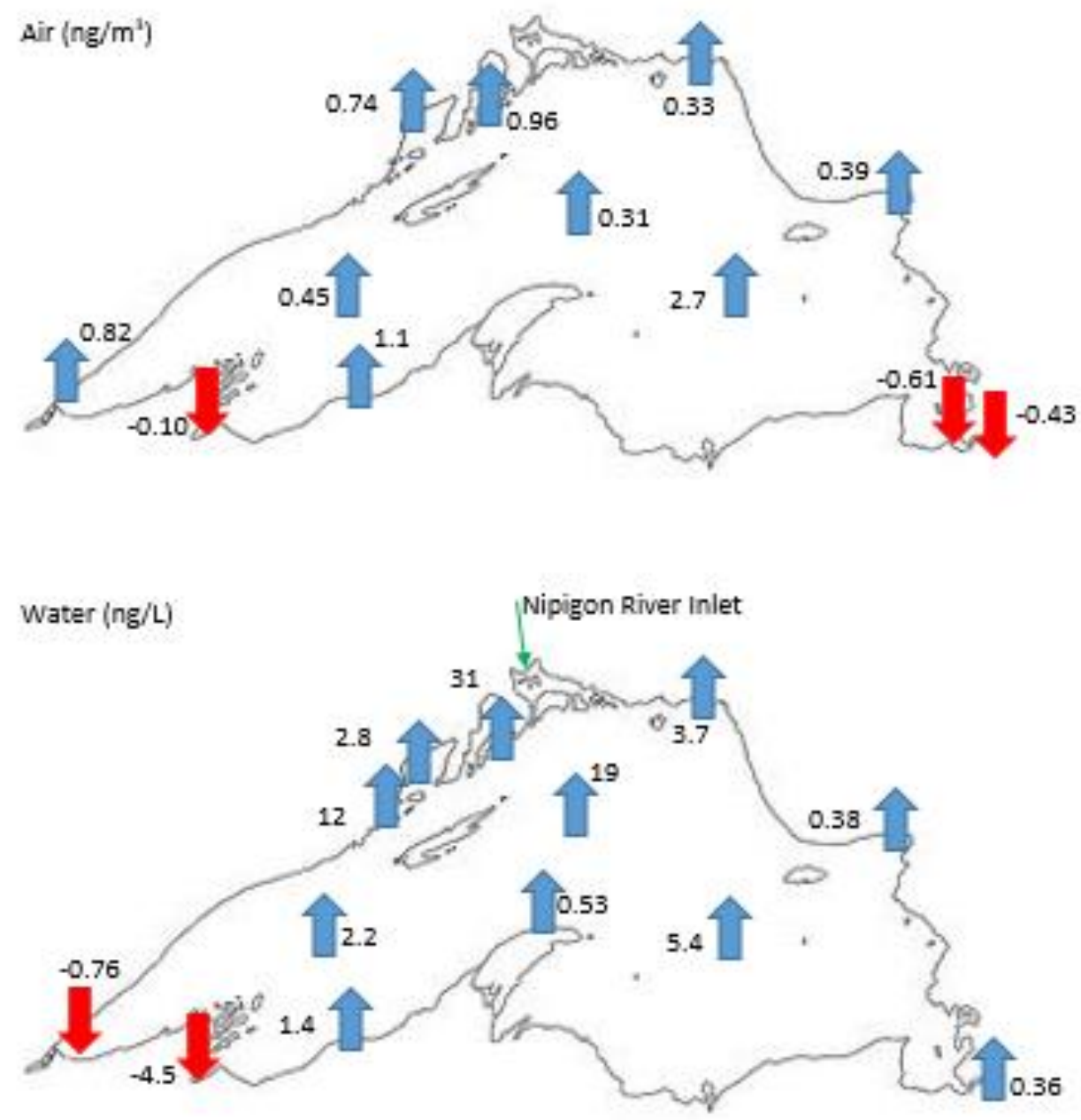

Figure 2.3: Increases in retene concentration $(\Delta)$ between June-August and AugustOctober 2011. 


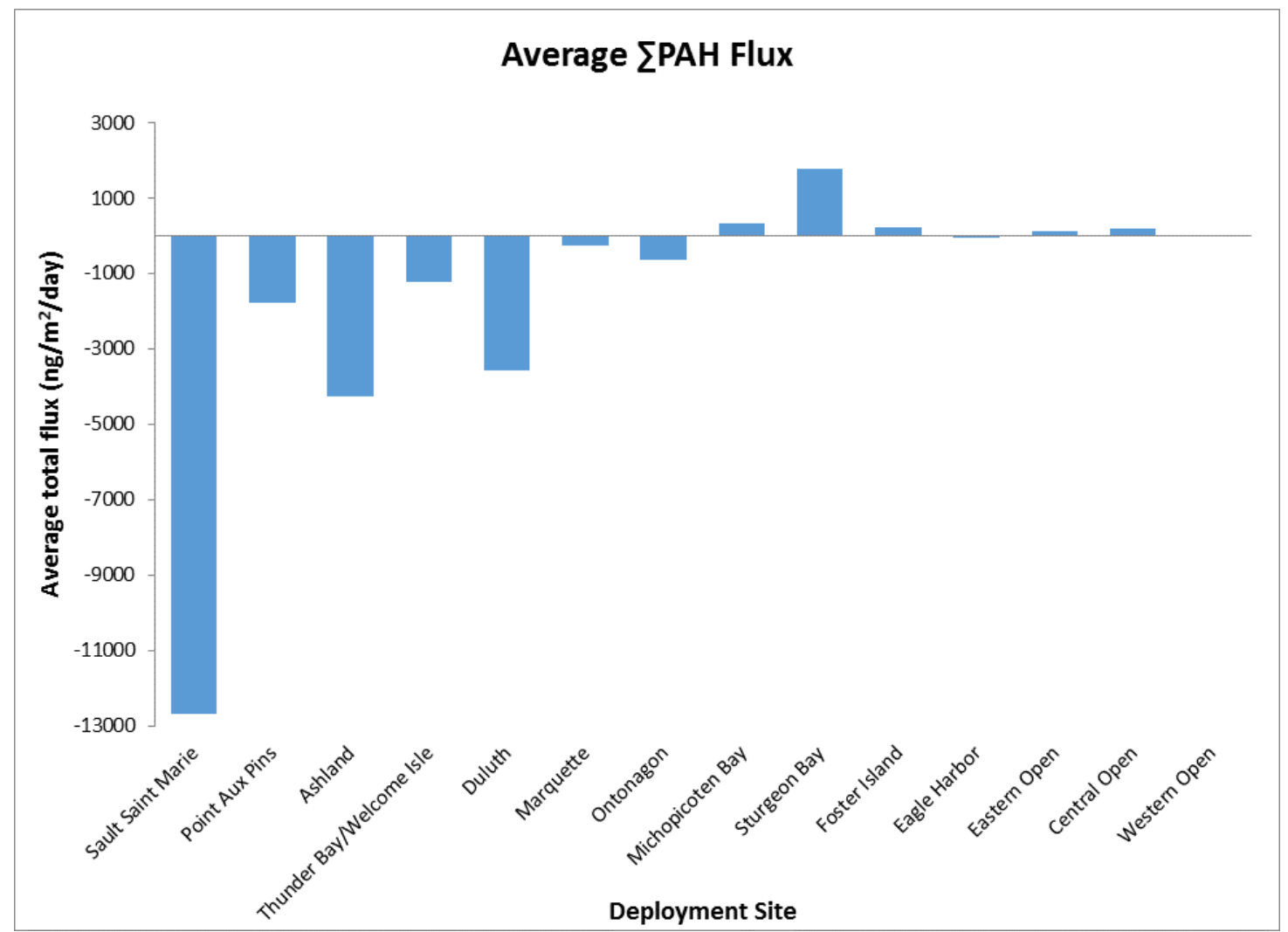

Figure 2.4: PAH fluxes across the air-water interface of Lake Superior. Positive values indicate volatilization from the surface water, while negative values indicate atmospheric deposition. Only values from significant Ceq-a/Ceq-w ratios were averaged. Averages from June to October 2011 for all stations except Marquette and Eagle Harbor which only account for the second deployment (June-August 2011), and Point Aux Pins which only accounts for the third deployment (August-October 2011). Eastern refers to buoys Station 23 and ODAS45004, Central is Station 113 and ODAS45001, and Western is Station 169 and ODAS45006. 

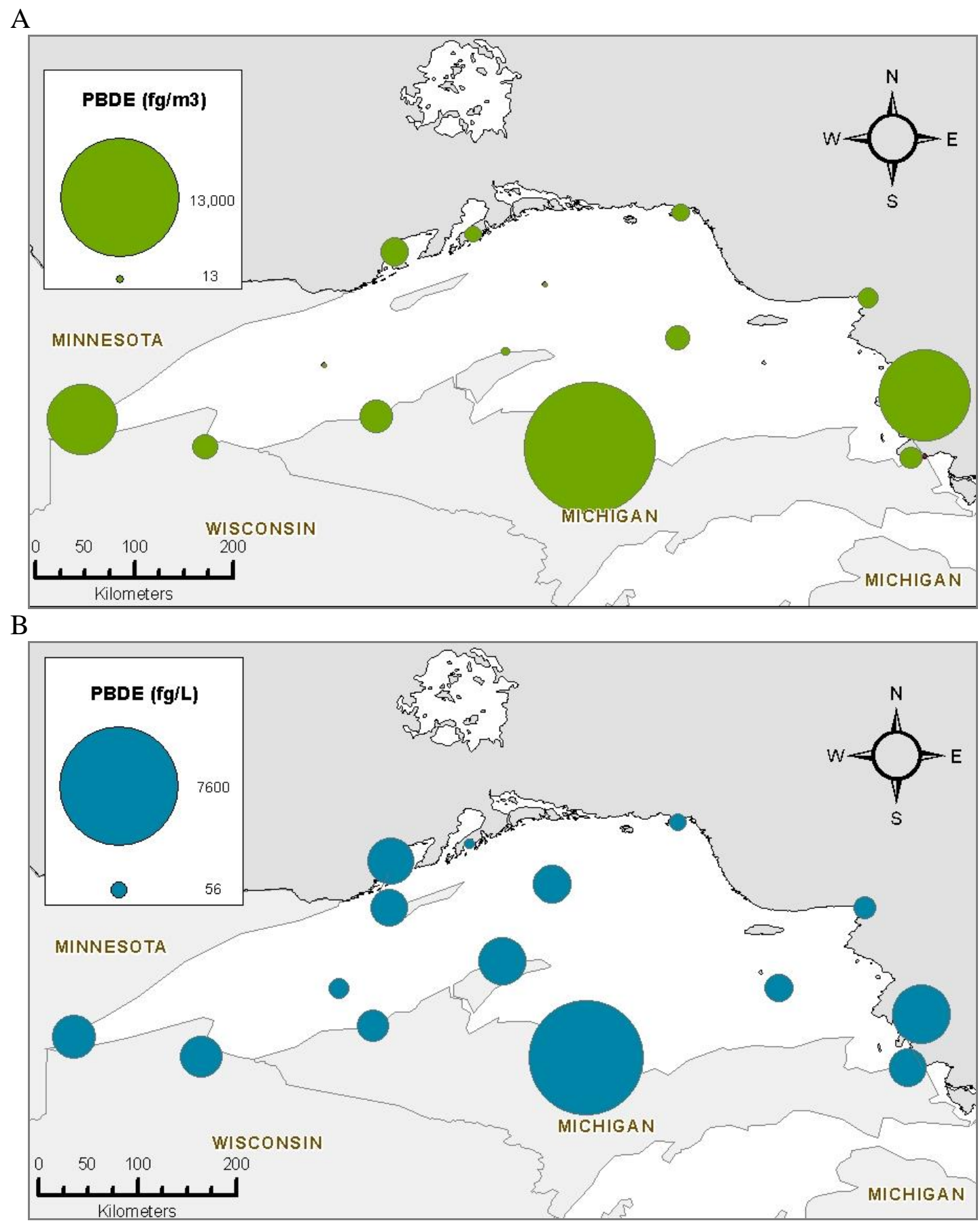

Figure 2.5: Average $\Sigma_{11} \mathrm{PBDE}$ concentrations at each station. (A) Air concentrations $\left(\mathrm{fg} / \mathrm{m}^{3}\right)$ are averaged from June to October 2011. (B) Water concentrations (fg/L) are averaged from June to October 2011 for all stations except Marquette, which represents June-August. 
Table 2.2: $\Sigma_{11} \mathrm{PBDE}$ concentrations in air $\left(\mathrm{pg} / \mathrm{m}^{3}\right)$ and water $(\mathrm{pg} / \mathrm{L})$ by deployment period

\begin{tabular}{|c|c|c|c|c|c|c|c|c|}
\hline \multirow[b]{2}{*}{ Site } & \multicolumn{4}{|c|}{$\operatorname{Air}\left(\mathrm{pg} / \mathrm{m}^{3}\right)$} & \multicolumn{4}{|c|}{ Water (pg/L) } \\
\hline & $\begin{array}{l}\text { April- } \\
\text { June }\end{array}$ & $\begin{array}{l}\text { June- } \\
\text { August }\end{array}$ & $\begin{array}{l}\text { August- } \\
\text { October }\end{array}$ & $\begin{array}{c}\text { June-October } \\
\text { Average }\end{array}$ & $\begin{array}{l}\text { April- } \\
\text { June }\end{array}$ & $\begin{array}{l}\text { June- } \\
\text { August }\end{array}$ & $\begin{array}{l}\text { August- } \\
\text { October }\end{array}$ & $\begin{array}{c}\text { June-October } \\
\text { Average }\end{array}$ \\
\hline Sault Saint Marie & 0.95 & 11 & 1.1 & 6.2 & 2.2 & 1.8 & 2.1 & 2.0 \\
\hline Point Aux Pins & & 0.32 & 0.37 & 0.34 & & 1.0 & 0.60 & 0.81 \\
\hline Ashland & 0.21 & 0.59 & 0.28 & 0.43 & 0.53 & 1.0 & 0.97 & 0.99 \\
\hline Thunder Bay/Welcome Isle & & 0.57 & 0.59 & 0.58 & & 1.3 & 1.2 & 1.2 \\
\hline Station 139 & & & & & & 0.75 & 0.81 & 0.78 \\
\hline Duluth & 0.75 & 6.3 & 0.80 & 3.6 & & 1.2 & 0.92 & 1.1 \\
\hline Marquette & 0.45 & 19 & 6.3 & 13 & 2.1 & 7.6 & N/A & N/A \\
\hline Ontonagon & & 1.4 & 0.14 & 0.76 & & 0.40 & 0.71 & 0.55 \\
\hline Michopicoten Bay & & 0.22 & 0.34 & 0.28 & & 0.36 & 0.24 & 0.30 \\
\hline Sturgeon Bay & & 0.15 & 0.25 & 0.20 & & 0.061 & 0.051 & 0.056 \\
\hline Foster Island & & 0.17 & 0.28 & 0.22 & & 0.089 & 0.23 & 0.16 \\
\hline Eagle Harbor & 0.030 & 0.10 & $b d$ & 0.049 & & 1.3 & 1.6 & 1.3 \\
\hline Eastern Open Lake & & 0.16 & 0.65 & 0.41 & & 0.34 & 0.58 & 0.46 \\
\hline Central Open Lake & & 0.027 & $b d$ & 0.013 & & 0.52 & 1.2 & 0.83 \\
\hline Western Open Lake & & 0.026 & $\mathrm{bd}$ & 0.013 & & 0.41 & 0.058 & 0.23 \\
\hline
\end{tabular}




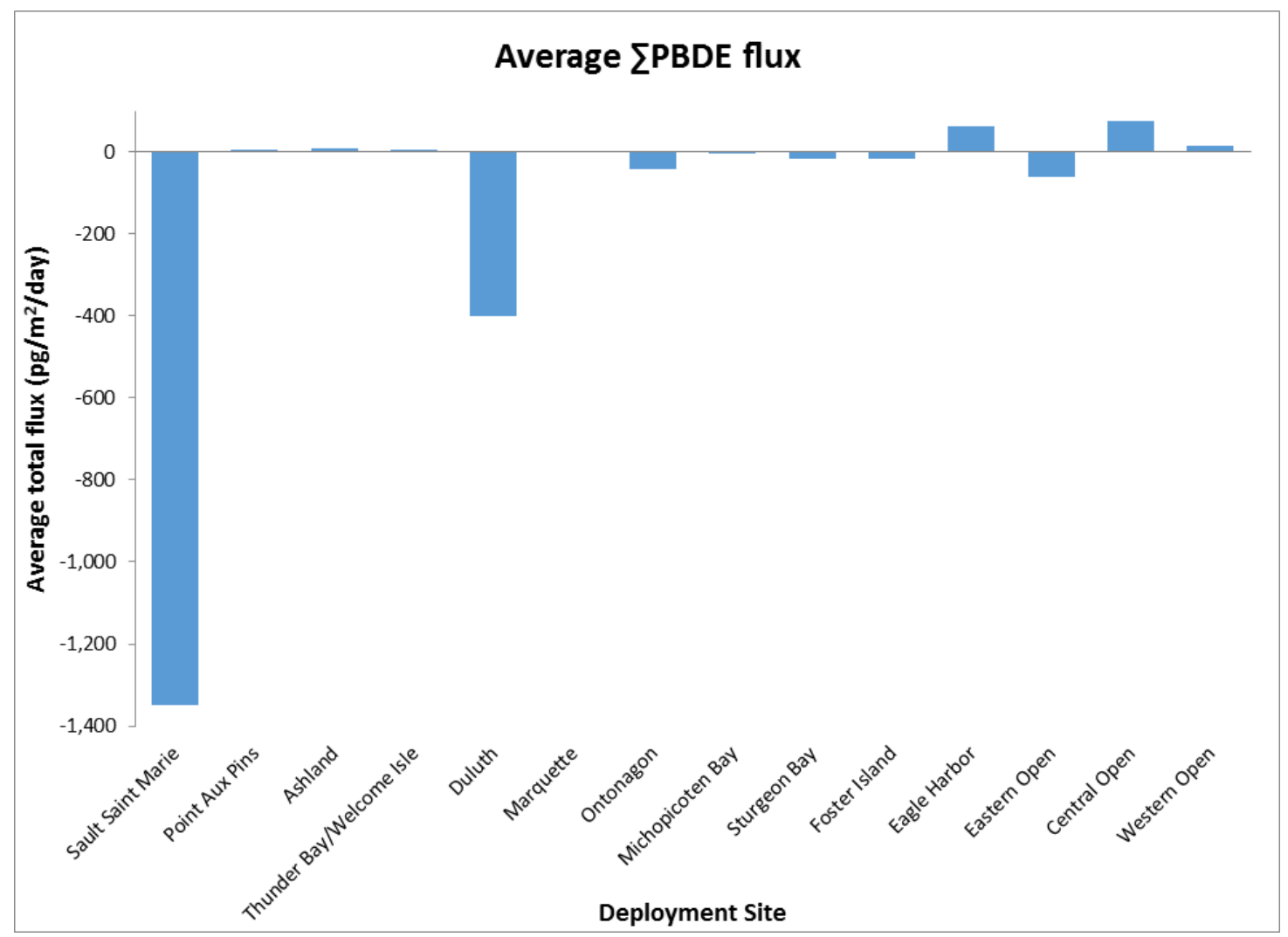

Figure 2.6: $\Sigma_{11}$ PBDE fluxes across the air-water interface of Lake Superior (+ volatilization, - deposition). Averaged from June to October 2011 for all stations except Marquette which was from June-August 2011. 


\section{CHAPTER 3}

\section{ORGANOCHLORINE PESTICIDES}

\section{Introduction}

Organochlorine pesticides (OCPs) were produced and applied extensively in the United States from the 1950s to the 1970s (Shen et al. 2005). Primary application during that time was for agriculture, however pesticide use continued through the 1980s as termite control in residential areas (Shen et al. 2005). Thus, OCPs are found in rural and urban areas alike. Two insecticides which were widely used in North America until recently, endosulfan I and lindane, are now both banned and included in the Stockholm Convention of persistent organic pollutants (POPs). In fact, 14 of the 22 POPs currently identified by UNEP as persistent, bioaccumulative, and harmful are pesticides (Stockholm Convention 2012).

The largest agricultural regions in North America have historically been located to the south/southeast of the Great Lakes. OCPs are transported to Lake Superior by long-range atmospheric transport and deposited from the air into the surface water by wet and dry deposition, as well as by diffusive chemical exchange (Hillery et al. 1998; Swackhamer et al. 1999; Hafner and Hites 2003). Passive transfer of molecules, such as PBTs across the air-water interface is driven by the concentration gradient of an analyte, such that the additions of OCPs to surface water can reverse the gradient and result in volatilization (Hafner and Hites 2003). OCP volatilization is also strongly temperature-dependent, creating seasonal flux cycles 
with greatest release to the atmosphere at the warmest time of year (Cortes et al. 1998; Buehler et al. 2001).

OCP concentrations in atmosphere, water, and biota have been decreasing since regulatory controls were put into effect (Sun et al. 2006; Gouin et al. 2007; Gewurtz et al. 2008). Lake Superior's large surface area, long retention time, and colder water temps have allowed accumulation of these persistent pollutants over the past several decades (Buehler et al. 2004; Gewurtz et al. 2008). Reduced emissions from primary sources to the atmosphere have resulted in steady state and even net volatilization of "legacy" OCPs from the surface water to the overlying air (Hillery et al. 1998). Continued losses from both the air and water may lead to the virtual elimination of most OCPs from the Lake Superior environment by the mid- $21^{\text {st }}$ century (Cortes et al. 1998). Pesticides in current or recent use, such as endosulfan I and its metabolites, may take longer to purge from Lake Superior.

Passive samplers have been effectively used to monitor OCP concentrations in Great Lakes air (Gouin et al. 2007). Polyethylene passive samplers (PEs) rely on diffusion to measure time-integrated truly gas- and dissolved-phase analytes (Morgan and Lohmann 2008), excluding confounding influences from particulates, precipitation, and colloids. This fraction is important to the cycling of persistent pollutants because it is available for bio-uptake and free to passively exchange across the air-water boundary. PEs are an inexpensive alternative to active high-volume air sampling that can expand spatial and temporal monitoring of Lake Superior. Additionally, PEs can be deployed simultaneously in air and water to determine the magnitude of OCP gradients across the air-water interface at each deployment site. 
This study utilized PEs to measure gaseous and dissolved concentrations of 24 OCPs representing both legacy and recent applications. The goals of this monitoring were to (1) determine overall concentrations and distribution patterns across the lake and (2) establish the gradient and magnitude of OCP gas exchange across the air-water interface between mid- and late-summer.

\section{Methods and Materials}

PEs were prepared and deployed as discussed elsewhere (see Chapter 1). Extracts were spiked with 40 ng of ${ }^{13} \mathrm{C}_{6} \mathrm{HCB}$ and ${ }^{13} \mathrm{C}_{12} \mathrm{p}, \mathrm{p}$ '-DDT. Nitrogenevaporated extracts were spiked with $50 \mathrm{ng}$ 2,4,6-tribromobiphenyl to serve as an injection standard.

OCPs were analyzed on a Waters Quattro micro GS Micromass MS-MS and quantified using Waters QuanLynx V4.1 software as detailed elsewhere (Zhang et al. 2012). Samples were held at $100^{\circ} \mathrm{C}$ for 1 minute, ramped up to $220^{\circ} \mathrm{C}$ at $5^{\circ} \mathrm{C} / \mathrm{min}$ and held for 10 minutes, then ramped up to $280{ }^{\circ} \mathrm{C}$ at $4{ }^{\circ} \mathrm{C} / \mathrm{min}$ and held for 5 minutes. Analysis was conducted in splitless injection mode using a $30 \mathrm{~m}$ x $0.250 \mathrm{~mm}$ i.d. (film thickness $0.25 \mu \mathrm{m}) \mathrm{DB}-5 \mathrm{MS}$ column.

Quality assurance and control is discussed elsewhere (see Chapter 1). Average surrogate recoveries for were ca. $50 \%$ for ${ }^{13} \mathrm{C}_{6} \mathrm{HCB}$ and ca. $170 \%$ for ${ }^{13} \mathrm{C}_{12} \mathrm{DDT}$. Spiked matrix recoveries were typically ca. 35-75\% (see Supporting Information).

A total of 24 OCPs were included in quantification (see Supporting Information). Concentrations, flux gradients, and flux rates were determined according to equations presented elsewhere (see Chapter 1). 
Geographic Information System Calculations (GIS)

The proximity of sampling sites to EPA Areas of Concern (AOCs) and National Priorities List Superfund sites (NPLs) was calculated using ArcMap 10.1 (see Supporting Information). Land use data for the United States was obtained from the Multi-Resolution Land Characteristics Consortium National Land Cover Database. The most recent data available from 2006 was used to determine the amount of agricultural land within $10 \mathrm{~km}$ of sampling sites (see Supporting Information).

\section{$\underline{\text { Results and Discussion }}$}

\section{OCP Air Distributions}

\section{Overview}

Nine analytes were consistently found across the lake: hexachlorocyclohexanealpha $(\alpha-\mathrm{HCH})$, hexachlorobenzene (HCB), endosulfan I, heptachlor epoxide, transchlordane, cis-chlordane, trans-nonachlor, $\mathrm{p}, \mathrm{p}$ '-DDE, and combined p,p'-DDD+o,p'DDT (Table 3.1). With the exception of heptachlor epoxide, these compounds have all been listed under the United Nations Environment Programme Stockholm Convention as persistent organic pollutants, toxics to be restricted and eliminated. Concentrations were averaged for each site over the second and third deployments (June-October 2011). Gaseous organochlorine pesticide concentrations in the atmosphere were dominated by HCB at all sites across Lake Superior (Figure 3.1). HCB was present in all samples at a fairly homogenous concentration (range 42-120 $\left.\mathrm{pg} / \mathrm{m}^{3}\right) . \alpha-\mathrm{HCH}$ was also significantly present across the lake at an average of 4.3 $\mathrm{pg} / \mathrm{m}^{3}$. Of the other 24 OCP analytes measured, only endosulfan I was present above 
$1 \mathrm{pg} / \mathrm{m}^{3}$ (average $1.2 \mathrm{pg} / \mathrm{m}^{3}$ ). Generally, the greatest concentrations of individual analytes were measured at Thunder Bay/Welcome Isle. While not significant, lowest concentrations of heptachlor epoxide, endosulfan I, chlordanes, and DDTs were found in the open lake atmosphere. Conversely, open lake sites exhibited slightly elevated $\alpha-\mathrm{HCH}$ and HCB concentrations, similar to Thunder Bay.

\section{Hexachlorocyclohexane $(\mathrm{HCH})$}

Technical $\mathrm{HCH}$ is a mixture of $5 \mathrm{HCH}$ isomers used as broad-spectrum insecticides in the United States and Canada from the 1940s to 1970s (Buehler and Hites 2002). It consisted of $60 \% \alpha-\mathrm{HCH}$, resulting in the release of ca. $6.5 \mathrm{Mt}$ of the isomer between 1948 and 1997 (Shen et al. 2004). $\alpha-\mathrm{HCH}$ was restricted in the United States and Canada in 1978 and has since been banned worldwide, but is still emitted into the environment during the production of lindane and other pesticides (Shen et al. 2005). Extensive use and long atmospheric residence times has led to ubiquitous $\alpha-\mathrm{HCH}$ distributions globally (Hafner and Hites 2003). Relatively uniform distribution across Canada and the United States is expected for a persistent compound with no current use (Shen et al. 2004). Our results are consistent with these patterns, showing fairly uniform distributions of $\alpha-\mathrm{HCH}$ across Lake Superior, where it is present at almost every site (range 1 to $10 \mathrm{pg} / \mathrm{m}^{3}$ ). $\alpha-\mathrm{HCH}$ was not detected during either deployment at Michopicoten Bay. Eagle Harbor exhibited an average of 2.8 $\mathrm{pg} / \mathrm{m}^{3}$, but this is likely an underestimate since $\alpha-\mathrm{HCH}$ was not quantified for the June-August deployment. $\alpha-\mathrm{HCH}$ concentrations at Eagle Harbor from AugustOctober were ca. $5.6 \mathrm{pg} / \mathrm{m}^{3}$. Previous studies of OCPs in the atmosphere over Lake 
Superior reported an $\alpha-\mathrm{HCH}$ range of $6-170 \mathrm{pg} / \mathrm{m}^{3}$ (Perlinger et al. 2005) with decreasing trends over the past 20 years (Cortes et al. 1998; Buehler and Hites 2002; Shen et al. 2004) (Figure 3.2). A half-life estimate of 4 years (Buehler and Hites 2002) predicts 2011 atmospheric concentrations at Eagle Harbor to be ca. $18 \mathrm{pg} / \mathrm{m}^{3}$ and a virtual elimination in the atmosphere by ca. 2040. Since production was discontinued, atmospheric concentrations of $\alpha-\mathrm{HCH}$ are no longer determined by primary sources, but are now mostly a result of evaporation from terrestrial and aquatic surfaces (Shen et al. 2004). Our data suggests that $\alpha-\mathrm{HCH}$ is revolatilizing from Lake Superior, causing atmospheric concentrations over open lake waters to be slightly elevated relative to other lake regions.

The remainder of technical $\mathrm{HCH}$ was composed of $1-13 \% \beta-\mathrm{HCH}$ and $10-15 \%$ $\gamma-\mathrm{HCH}$, or lindane. These two isomers were not detected regularly across Lake Superior in this study. Although once extensively used in Canadian agriculture (Ma et al. 2004), lindane application was abandoned in Canada in 2004 (Sun et al. 2006). Even before the ban, atmospheric $\gamma-\mathrm{HCH}$ had been declining since 1991 (Sun et al. 2006). $\gamma-\mathrm{HCH}$ has a slightly lower air-water partitioning coefficient than $\alpha-\mathrm{HCH}$ and is therefore scavenged more efficiently (Shen et al. 2004) $\gamma$-HCH also reacts more readily in the atmosphere and, thus, is not transported as far as $\alpha-\mathrm{HCH}$ (Shen et al. 2004). Since its disuse in 2004, atmospheric concentrations of $\gamma-\mathrm{HCH}$ may have declined by half according to an estimated half-life of ca. 8 years. Likewise, $\beta-\mathrm{HCH}$ has relatively low volatility and high stability resulting in distributions restricted to areas near point sources (Sun et al. 2006). $\beta-\mathrm{HCH}$ has the greatest physical and metabolic stability among all of the technical $\mathrm{HCH}$ isomers due to its relatively planar 
structure (Sun et al. 2006). These physicochemical properties may explain why $\beta$ $\mathrm{HCH}$ is not commonly detected in the atmosphere over Lake Superior. $\gamma-\mathrm{HCH}$ was detected at Ontonagon from August-October, while both $\gamma-\mathrm{HCH}$ and $\beta-\mathrm{HCH}$ were present at Ashland during the same period. This presence may indicate the historic use of $\mathrm{HCH}$ in those areas. According to 2006 National Land Cover Database maps, the Ontonagon site was within $10 \mathrm{~km}$ of ca. 180,000 acres of agricultural land, the greatest concentration within the same distance from all U.S. sites included in this study. Ashland was within 10km of ca. 73,000 acres of agricultural land (see Supporting Information).

\section{Hexachlorobenzene $(\mathrm{HCB})$}

HCB dominated in Lake Superior air, representing $>80 \%$ of the OCPs measured at every site. HCB is a fungicide used in many applications in the past, but with no current commercial uses as an end product in North America (Buehler et al. 2004; Shen et al. 2005). Production was banned in the United States in 1965, but it is still formed as a byproduct in several manufacturing processes and is a known impurity in many pesticides currently used in the Great Lakes basin (Sun et al. 2006; Buehler et al. 2004). HCB has a very long atmospheric residence time, relatively high vapor pressure, low water solubility, and low sensitivity to hydroxyl radical attack,

resulting in widespread distribution in the global atmosphere and an estimated half-life in the Great Lakes basin of 12-29 years (Shen et al. 2005; Zhang and Lohmann 2010; Buehler et al. 2004; Cortes et al. 1998). Like $\alpha-\mathrm{HCH}$, it is thought that the current source of HCB to the atmosphere is volatilization from contaminated soils and 
possibly from large bodies of water as atmospheric concentrations decrease and permit an equilibrium shift across the air-water interface (Shen et al. 2005; Zhang and Lohmann 2010). HCB was relatively elevated everywhere across Lake Superior, measured at all sites with a range of $42 \mathrm{pg} / \mathrm{m}^{3}$ at Ontonagon to $120 \mathrm{pg} / \mathrm{m}^{3}$ at Foster Island. Average Eagle Harbor gaseous concentration was $64 \mathrm{pg} / \mathrm{m}^{3}$, similar to the value reported from 2000-2001 (Shen et al. 2005). Previous studies indicated concentrations in the Lake Superior atmosphere were ca. $80 \mathrm{pg} / \mathrm{m}^{3}$ (Shen et al. 2005). Though not significantly, concentrations were generally greater at Canadian shore and open-lake sites.

\section{Endosulfan}

Endosulfan I is a broad spectrum insecticide used on fruits, vegetables, cotton, tobacco, and trees, as well in the preservation of wood (Buehler et al. 2004; Shen et al. 2005). Use began in the 1950s and continued until recently (EPA 2010). Although now included in the Stockholm Convention and designated by the EPA for use to be terminated, it is one of the most abundant and ubiquitous OCPs in the continental atmosphere (Shen et al. 2005) and was widely used in the states surrounding Lake Superior (Hafner and Hites 2003). Application in Michigan, Wisconsin, and Minnesota resulted in the short-range atmospheric transport dominating inputs to the Great Lakes (Hafner and Hites 2003). Technical endosulfan is composed of two isomers, alpha and beta (Buehler et al. 2004). Previous studies have found alpha, endosulfan I, to be dominant in North American atmosphere (range 3.1-685 pg/ $/ \mathrm{m}^{3}$ ) (Shen et al. 2005). This pattern was consistent with the Lake Superior atmosphere, 
where concentrations were among the lowest across the continent (Shen et al. 2005). Results from our study indicated similar concentrations, ranging from 0.33 to 2.0 $\mathrm{pg} / \mathrm{m}^{3}$. Atmospheric concentrations at Eagle Harbor averaged $1.5 \mathrm{pg} / \mathrm{m}^{3}$ from our study in 2011 compared to $27 \mathrm{pg} / \mathrm{m}^{3}$ measured in 2000-2001 (Shen et al. 2005). Open lake sites had the lowest concentrations, possibly as a result of their distance from terrestrial sources where this compound is still being emitted. Concentrations may be an order of magnitude lower than 2000-2001 values due to discontinuation of use in North America between sampling periods. The half-life of $9.2+-4$ years reported by Buehler et al. (2004) was estimated when endosulfan was still in use; the decrease may be steeper now that emissions have been reduced, resulting in even faster elimination from the Great Lakes atmosphere. Endosulfan II was not significantly present at any of the Lake Superior sites included in this study. Endosulfan sulfate, an environmental breakdown product of endosulfan, was only detected in the atmosphere at a few sites.

\section{Heptachlor epoxide}

Heptachlor epoxide is the product of heptachlor degradation. Like heptachlor, it is persistent, bioaccumulative, and toxic (Bidleman et al. 1998), however, it is not currently included in the Stockholm Convention of POPs. Heptachlor is a chlorinated cyclodiene that was used for many years as an insecticide for agriculture, lawns, and gardens (Bidleman et al. 1998). Additionally, it was used as a termiticide, but most other applications were canceled in 1988 (Bidleman et al. 1998). Heptachlor is transformed into heptachlor epoxide by three main reactions: photolysis in the atmosphere, hydrolysis in the water, and epoxidation in soils and biota (Bidleman et 
al. 1998). Heptachlor epoxide formed by photolysis is racemic, whereas epoxidation from biological metabolism in agricultural soils produces nonracemic fractions enriched in the (+) enantiomer (Bidleman et al. 1998). Analysis of the enantiomeric ratio indicates that $(+)$ enantiomer-enriched heptachlor epoxide concentrations measured in the Great Lakes region are mainly volatilized from soil rather than the product of photolysis (Shen et al. 2005). Secondary volatilization from soils suggests an aged source and we would expect a fairly uniform distribution.

Heptachlor epoxide was detected in the atmosphere at all sites across Lake Superior at an average of $0.62 \mathrm{pg} / \mathrm{m}^{3}$ (range $\left.0.29-1.1 \mathrm{pg} / \mathrm{m}^{3}\right)$. Concentrations were low and fairly uniform across the lake, in-line with its volatilization from soils. Greatest concentrations were measured at Thunder Bay/Welcome Isle and Sault Saint Marie $\left(1.1 \mathrm{pg} / \mathrm{m}^{3}\right.$ and $0.96 \mathrm{pg} / \mathrm{m}^{3}$, respectively), two populated areas where heptachlor may have been more recently and extensively applied for termite control. Secondary sources are also suggested by inconsistent detection of heptachlor, which is more volatile than heptachlor epoxide and is expected to dissipate more quickly by evaporation (Bidleman et al. 1998). The parent compound was present at fewer than half of the sites, mainly elevated near populated and industrial areas, especially Thunder Bay/Welcome Isle $\left(1.2 \mathrm{pg} / \mathrm{m}^{3}\right)$.

\section{Chlordane}

Technical chlordane (trans-chlordane, cis-chlordane, and trans-nonachlor) was used as an insecticide, herbicide, and termiticide between 1947 and 1988 at which time it was deregistered for all uses in the United States, and 1990 when it was banned 
for all uses in Canada (Hafner and Hites 2003; Shen et al. 2005; IADN 2008). It also has components of heptachlor and has been observed to have similar distribution patterns (Shen et al. 2005). Greatest historical application correlated to urban areas and regions with greatest termite infestations. Source models suggest that volatilization from soil in the southeastern United States is the predominant source of chlordane to the Great Lakes (Hafner and Hites 2003; Sun et al. 2006). Urban sources near the Great Lakes, namely Chicago and Toronto, have continued emissions of racemic chlordane $(\mathrm{TC} / \mathrm{CC}=1.17)($ Gouin et al. 2007). However, rural Great Lakes sites have low TC/CC ratios (annual average 0.72) (Gouin et al. 2007), suggesting atmospheric chlordane concentrations in the region are aged and volatilized from microbially processed soils (Shen et al. 2005). In our study, TC/CC ratios averaged 0.93, but were as low as 0.44 at Eagle Harbor.

Total chlordane averages from June to October ranged from 0.18 to $1.2 \mathrm{pg} / \mathrm{m}^{3}$, generally greater near urban areas and lower at rural sites. Previous measurements at Eagle Harbor from 1996-1998 were 8.6+-1.3 pg/m³ (Buehler et al. 2001). Even accounting for an atmospheric half-life of 8-16 years (IADN 2008; Buehler et al. 2004), current values appear to be an order of magnitude lower than estimated by previous studies.

\section{Dichlorodiphenyltrichloroethane (DDT)}

Technical DDT (65-80\% p,p'-DDT, 15-21\% o,p'-DDT,<4\% p,p'-DDD) was used extensively in the 1940s and 1950s in urban aerial sprays to control mosquitoes (Sun et al. 2006) and widely used on a variety of agricultural crops in the 1960s (Shen 
et al. 2005). It was deregistered in the United States in 1972 and in Canada in 1973 (IADN 2008). DDTs are highly persistent and residues in urban locations may still be sources of these compounds to the local atmosphere (Sun et al. 2006). Because DDTs are less volatile than most OCPs, their atmospheric transport is limited and concentrations tend to be greater near urban sources (Shen et al. 2005; Sun et al. 2006). Thus, unlike other long-banned OCPs, DDTs do not exhibit a uniform distribution. DDT was the first pesticide to be banned and likely has the fewest current sources in the environment (Cortes et al. 1998). Vapor phase concentrations measured over the past few decades have demonstrated a significant decreasing trend at most sites across the Great Lakes (Cortes et al. 1998; IADN 2008). Technical DDT compounds measured in this study were present across Lake Superior at very low concentrations $\left(<0.4 \mathrm{pg} / \mathrm{m}^{3}\right)$. p,p'-DDT was often below detection and p,p'DDD+o,p'-DDT was detected at low concentrations at every site $\left(0.02-0.37 \mathrm{pg} / \mathrm{m}^{3}\right)$. These low concentrations follow a long-term decreasing trends in vapor-phase concentrations, consistent with a reported half-life of 5-17 years (Buehler et al. 2004; IADN 2008). p,p'-DDT had the earliest virtual elimination date of the OCPs measured (ca. 2010) (Cortes et al. 1998). However, p,p'-DDT dechlorinates in the environment to form the metabolites p,p'-DDE and p,p'-DDD (Lohmann et al. 2009; IADN 2008). p,p'-DDD is removed from the atmosphere at the same rate as p,p'DDT (Cortes et al. 1998), but p,p'-DDE has higher vapor pressure and higher Henry's law constant, preferentially partitioning into the gas phase, extending its presence in the atmosphere (Sun et al. 2006). Average p,p'-DDE concentrations ranged from 0.06 
to $1.1 \mathrm{pg} / \mathrm{m}^{3}$ during the sampling period, generally lower over open lake water and greater at locations with greater populations.

\section{Dieldrin}

Dieldrin was not consistently detected in the air. It was used extensively from 1950 to 1974 as an insecticide on cotton, corn, citrus fruits, as well as for termite control (Stockholm Convention 2013; Shen et al. 2005). It was banned for most uses in the United States in 1987 (EPA 2011). In addition to direct emissions, dieldrin is also metabolized from aldrin, another insecticide also listed on the Stockholm Convention of POPs, and both are highly toxic to humans (WHO 2003). Previous atmospheric studies only detected aldrin at 6 of 40 stations across North America, whereas dieldrin was present at 35 sites (Shen et al. 2005). Aldrin quickly breaks down to dieldrin in the environment and biota, leaving dieldrin as the main component to be detected (ATSDR 2011). Additionally, dieldrin binds tightly to soil, is slow to evaporate, and breaks down slowly in water (ATSDR 2011), resulting in low gaseousphase concentrations and greater accumulation of dissolved dieldrin in surface waters. Current atmospheric concentrations measured in this study were lower than what was predicted by previous half-life estimates. Atmospheric concentration at Eagle Harbor was $8.8+-1.4 \mathrm{pg} / \mathrm{m}^{3}$ in 1996-1998 (Buehler et al. 2001) and $7.5 \mathrm{pg} / \mathrm{m}^{3}$ in 2000-2001 (Shen et al. 2005). Cortes et al. (1998) reported a half-life of 52 years at Eagle Harbor, so we would expect dieldrin to continue to be detected in the atmosphere above Lake Superior as well as in the water. Aldrin and its other metabolite, endrin, were not detected in the water during this study. 


\section{Temporal Air Distributions}

It has been well-established that most atmospheric concentrations of semivolatile compounds vary seasonally with temperature, resulting in peak concentrations during summer months (Cortes et al. 1998; Ackerman et al. 2008; Hillery et al. 1998). Previous studies found atmospheric $\alpha-\mathrm{HCH}$ was 4-6 times greater in the summer compared to the late fall and early spring (Perlinger et al. 2005). In this April-October study, atmospheric OCP concentrations were generally consistent, perhaps exhibiting slight increases during August-October when average air and water temperatures were highest.

\section{OCP Water Distributions}

\section{Overview}

Marquette and Sturgeon Bay were not measured from August-October, so are excluded from spatial averages. Only 8 OCPs were measured above the detection limit at all sites from June-October: $\alpha-\mathrm{HCH}, \mathrm{HCB}$, heptachlor epoxide, trans- and cischlordane, trans-nonachlor, p,p'-DDE, and combined p,p'-DDD+o,p'-DDT (Figure 3.3). Endosulfan I was not consistently measured in the water. Dissolved OCP concentrations in Lake Superior surface water were dominated by $\alpha-\mathrm{HCH}$ (average $250 \mathrm{pg} / \mathrm{L}$ ), followed by HCB (average $16 \mathrm{pg} / \mathrm{L}$ ). Heptachlor epoxide was present at fairly uniform concentrations across the lake (average $3.6 \mathrm{pg} / \mathrm{L}$ ). Although not detected at every site, dieldrin was also significantly present at most coastal sites (average $24 \mathrm{pg} / \mathrm{L}$ ). Atmospheric transport has historically been the input of OCPs to Lake Superior (Baker and Eisenreich 1990), rather than from inflow of contaminated 
water. Many of these compounds' dissolved concentrations decreased at most sites from June-August to August-October, with the exceptions of Eagle Harbor, Foster Island, and Thunder Bay/Welcome Isle where most concentrations appeared to increase over the sampling season.

\section{Hexachlorocyclohexane (HCH)}

$\alpha-\mathrm{HCH}$ was present in the water at all sites monitored in this study. It was the dominant OCP (ca. 50-80\% of total OCPs measured), >10 times HCB concentrations, opposite to atmospheric ratios. Excluding Ontonagon, where $\alpha-\mathrm{HCH}$ was only 12 $\mathrm{pg} / \mathrm{L}$, the average concentration in surface lake water was $260 \mathrm{pg} / \mathrm{L}$ (range $110 \mathrm{pg} / \mathrm{L}$ at Eagle Harbor to $440 \mathrm{pg} / \mathrm{L}$ in eastern open lake water). The Duluth water site is several kilometers offshore and exhibited elevated concentrations closer to open lake values than near shore. Many of these values are thought to be underestimated because $\alpha-$ $\mathrm{HCH}$ was not quantified for several sites from June-August. Where present during both the $2^{\text {nd }}$ and $3^{\text {rd }}$ deployments, concentrations decreased up to 3 times between June-August and August-October. Because $\alpha-\mathrm{HCH}$ is no longer directly emitted into the atmosphere, stores of the compound in the surface water of Lake Superior are susceptible to influences from seasonal temperature fluctuations. A strong response to seasonal variation has been well established (Shen et al. 2004; Perlinger et al. 2005). Lake Superior's large surface area $\left(82,100 \mathrm{~km}^{2}\right)$ and long water residence time (191 years), coupled with $\alpha$-HCH's high volatility may result in greater volatilization from the lake surface to the overlying atmosphere with increasing ambient temperatures (Gewurtz et al. 2008). 


\section{Hexachlorobenzene (HCB)}

HCB was also present at all monitored sites, and exhibited similar distribution patterns as $\alpha-\mathrm{HCH}$. Coastal concentrations were fairly uniform, most ranging from 5.4 to $14 \mathrm{pg} / \mathrm{L}$. Again, the Duluth water had a slightly greater average (18 pg/L), approaching the elevated concentrations of the open lake sites (average $23 \mathrm{pg} / \mathrm{L}$ ). Ashland was an outlier where HCB was $37 \mathrm{pg} / \mathrm{L}$. In addition to its application to agricultural seeds as an antifungal agent, HCB was also emitted in the waste streams of wood-preserving plants and the incineration of municipal waste (IADN 2008). Lumber treatment and other heavy industry in Ashland could be the source of this HCB signal in the nearby water. Except at Ashland where concentrations doubled, and at Point Aux Pins where they halved, HCB concentrations in the water remained constant from April-October (average $15 \mathrm{pg} / \mathrm{L}$ ).

\section{Heptachlor Epoxide}

Heptachlor epoxide represented ca. 1-2\% total OCP concentrations at most coastal sites. Heptachlor epoxide concentrations were fairly uniform across the lake, ranging from 1.1 to $5.4 \mathrm{pg} / \mathrm{L}$. Sault Saint Marie had the greatest concentration, however, no consistent trend between urban and rural water concentrations was observed. In fact, open lake sites had concentrations similar to Sault Saint Marie and Station 139 (near Thunder Bay/Welcome Isle). The greatest changes from JuneAugust to August-October generally occurred at sites with the greatest concentrations

during the $2^{\text {nd }}$ deployment. Heptachlor epoxide concentrations decreased at Sault Saint Marie, Ashland, Station 139, eastern open lake, and western open lake. Its 
parent compound, heptachlor, was only measured sporadically, and, thus, is not considered to be significantly present in Lake Superior water.

\section{Chlordane}

Present at lower concentrations than heptachlor epoxide ( $\Sigma$ chlordanes $0.26-1.4$ $\mathrm{pg} / \mathrm{m}^{3}$ ), chlordanes were also uniformly distributed, only slightly elevated at Sault Saint Marie, Point Aux Pins, and Ashland.

\section{Dichlorodiphenyltrichloroethane (DDT)}

p,p'-DDT was not measured above the detection limit at every site. Where detected, it was $<0.5 \mathrm{pg} / \mathrm{L}$. The other two technical DDT compounds, p,p'-DDD and o,p'-DDT, combined were detected at every site, but not consistently during every deployment. Additionally, p,p'-DDD is also a metabolite of p,p'-DDT, and the concentrations detected may be indicative of aged isomers, not from a primary source of technical DDT. Possibly as a result of low volatility, DDT concentrations were slightly greater at southern/United States coastal sites, excluding Eagle Harbor, which is located on Keweenaw Peninsula. Due to its location, Eagle Harbor may be strongly influenced by the surrounding open water. However, concentrations were generally very low and fairly uniform, consistent with its emission history. The exception was at Sault Saint Marie, where p,p'-DDD+o,p'-DDT went from 15 pg/L in April-June to $11 \mathrm{pg} / \mathrm{L}$ in June-August and 6.5 pg/L in August-October. The DDT metabolite o,p'DDD was also present at Sault Saint Marie at high concentrations, ranging from 16 $\mathrm{pg} / \mathrm{L}$ to $12 \mathrm{pg} / \mathrm{L}$ and $13 \mathrm{pg} / \mathrm{L}$ over the same time period. o,p'-DDD was only 
consistently detected at one other site, Station 221 (near Duluth), but at much lower concentrations (average $0.98 \mathrm{pg} / \mathrm{L}$ ). p,p'-DDE was detected at every site at similar concentrations (average $0.98 \mathrm{pg} / \mathrm{L})$ as p,p'-DDD+o,p'-DDT (0.84 pg/L) and o,p'-DDD $(1.0 \mathrm{pg} / \mathrm{L})$. Concentrations for this metabolite were much lower than the other DDTs at Sault Saint Marie, possibly due to its greater vapor pressure and tendency to go into the gas phase. The presence of DDT metabolites and not p,p'-DDT indicates no new inputs of technical DDT in the Lake Superior region. These results agree with previous sediment measurements where surficial sediment concentrations of DDE $(0.43 \mathrm{ng} / \mathrm{g})$ were also greater than those of DDT (0.11 ng/g) (Gewurtz et al. 2008). Although at low concentrations, DDTs are persisting in Lake Superior and, as POPs, are known to have the potential to bioaccumulate and cause toxic effects on non-target organisms (Gouin et al. 2007). In a study of pesticides in Western U.S. National Park fish conducted from 2003-2005, p,p'-DDE was one of the most concentrated semi-volatile contaminants measured in $>75 \%$ of the fish (Ackerman et al. 2008). DDTs as a whole were 2-5 times greater in western U.S. fish than in oceancaught salmon. In Lake Superior DDE reached up to $81+-19 \mathrm{ng} / \mathrm{g}$ in bloater fish (Kucklick and Baker 1998).

\section{Dieldrin}

Dieldrin was regularly detected in the water, in stark contrast to the air, where dieldrin was not consistently detected. Dieldrin represented $10-20 \%$ of total dissolved OCPs measured in Lake Superior water. Excluding Ontonagon, Duluth, and the open lake sites where the analyte was not present above the detection limit, average dieldrin 
concentration was $24 \mathrm{pg} / \mathrm{L}$ (median $30 \mathrm{pg} / \mathrm{L}$ ). Dieldrin was twice as high at Point Aux Pins, the only site that exhibited consistent dieldrin concentrations in the air (average $5.0 \mathrm{pg} / \mathrm{m}^{3}$ ). Concentrations were similar between June-August and August-October at most sites. Studies of western U.S. fish from 2003-2005 found dieldrin at similar concentrations as DDTs, exceeding the calculated subsistence fishing human contaminant health thresholds in half of the fish measured (Ackerman et al. 2008). Concentrations in Lake Superior bloaters were similar to DDE concentrations (Kucklick and Baker 1998).

\section{Endosulfan}

Endosulfan I was not consistently detected in Lake Superior water, only averaging $0.63 \mathrm{pg} / \mathrm{L}$. Endosulfan sulfate, an endosulfan metabolite, was detected at a few sites at high concentrations (44-360 pg/L), possibly indicating a tendency for endosulfan to degrade in Lake Superior water, however measurements were very inconsistent and do not illustrate any definitive trends. Endosulfan sulfate was among the most concentrated and frequently detected contaminants measured in western U.S. National Park fish (Ackerman et al. 2008) and may be a threat to Lake Superior fish as endosulfan I continues to be deposited and degrade into the metabolite.

\section{OCP Air-Water Gradient}

Equilibrium concentration ratios between air and water for $\alpha-\mathrm{HCH}$ were $<1$ at most sites, indicative of net volatilization. However, ratios were only significantly different from equilibrium ( $>3.9$ or $<0.14$ ) at ca. $1 / 3$ of the sites (Figure 3.4A), 
suggesting atmospheric deposition may still play a role in air-water exchange, or that $\alpha-\mathrm{HCH}$ is reaching equilibrium. $\alpha-\mathrm{HCH}$ deposition into Lake Superior has been declining for several years (Cortes et al. 1998; Hillery et al. 1998; Buehler and Hites 2002), allowing for an equilibrium shift across the air-water boundary. Over the past decade, $\alpha-\mathrm{HCH}$ volatilization from Lake Superior surface water has been observed (Shen et al. 2004; Gouin et al. 2007). As $\alpha-\mathrm{HCH}$ concentrations in the air continue to decline, we expect net volatilization to become significant across the entire lake. HCB was also volatilizing from half of the lake sites, but only significantly $<1$ at 2 sites during June-August (Figure 3.3B).

Most other analytes were either significantly volatilizing from the lake, or at ratios indicative of equilibration, as expected for compounds with no current emission sources. The exception was endosulfan I which exhibited ratios well above 1 at all sites from April-October (Figure 3.4C), suggesting overwhelming net deposition consistent with recent widespread use. Only samples from the central and western open lake during August-October deviated from this trend. Technical DDT components (p,p'-DDT and p,p'-DDD+o,p'-DDT) also appeared to be significantly depositing at a few sites, especially from June-August (Figure 3.5), suggesting that these compounds are still being emitted into the atmosphere by secondary sources and continue to be added to Lake Superior. Due to their persistence in the environment, current deposition may be part of a long-term cycling of DDTs across the air-water boundary as indicated by previous studies (Hillery et al. 1998). 


\section{OCP Air-Water Exchange Fluxes}

The OCPs with the greatest concentrations in either air (deposition) or water (volatilization) displayed the greatest flux rates across the air-water boundary in Lake Superior. Average net volatilization of $\alpha-\mathrm{HCH}$ across the entire lake from JuneOctober was $0.70 \mathrm{ng} / \mathrm{m}^{2} /$ day (range below detection to $3.5 \mathrm{ng} / \mathrm{m}^{2} /$ day), with nearly two-thirds of the sites exhibited fluxes not significantly different from equilibrium. Ontonagon was an exception, where $\alpha-\mathrm{HCH}$ appeared to be deposited at a rate of -0.82 ng/m²/day during August-October (Figure 3.4A).

Gaseous HCB fluxes were much greater than those of gaseous $\alpha-\mathrm{HCH}$. Average flux rates across the lake from June-October for HCB were only significantly indicative of volatilization at Ashland (110 ng/m²/day) and Ontonagon ( $\left.25 \mathrm{ng} / \mathrm{m}^{2} / \mathrm{day}\right)$ (Figure 3.4B). Open lake sites and Eagle Harbor were either at, or near, equilibrium. In fact, flux rates from 2002-2003 found HCB to still be depositing at a rate of -14 to $2.2 \mathrm{ng} / \mathrm{m}^{2} /$ day while $\alpha-\mathrm{HCH}$ was ca. equilibrium (Perlinger et al. 2005).

Endosulfan I was significantly deposited at nearly every site included in this study, at an average of $0.013 \mathrm{ng} / \mathrm{m}^{2} /$ day (Figure 3.4C). Deposition appeared to be fairly uniform from June-October. As observed in the flux gradients, most other OCPs measured in this study exhibited a range of deposition, volatilization, and equilibrium across the lake, with average fluxes $<0.1 \mathrm{ng} / \mathrm{m}^{2} /$ day volatilizing out of the lake. The greatest fluxes occurred near populated areas, namely Ontonagon and Ashland. While volatilizing from most sites, technical DDT and its metabolites were depositing into the lake near Thunder Bay/Welcome Isle at an average rate of $0.37 \mathrm{ng} / \mathrm{m}^{2} / \mathrm{day}$, 
possibly indicating more extensive past use or more recent emissions in that region (Figure 3.5).

Where present, dieldrin was volatilizing from the lake at an average rate of $0.46 \mathrm{ng} / \mathrm{m}^{2} /$ day from June-October. Fluxes out of the lake appeared to double between mid to late summer (Figure 3.4D). At these rates, the lake may be serving as an important secondary source of dieldrin to the atmosphere.

\section{Conclusions and Implications}

OCP concentrations were dominated by gaseous HCB in the air and dissolved $\alpha-\mathrm{HCH}$ in the water. Their detection at nearly every site and relatively even distributions are consistent with trends of persistent pesticides with a history of extensive use and well-established regulation. Flux rates for $\mathrm{HCB}$ and $\alpha-\mathrm{HCH}$ tended to be either near equilibrium or volatilizing from the surface of Lake Superior to the atmosphere. Most other legacy compounds were present at very low concentrations and appear to be cycling between the air and water, indicating near-steady state fluxes and overall trends toward virtual elimination from the Lake Superior environment. OCPs with recent emissions, such as endosulfan I, are still undergoing atmospheric transportation to the lake, resulting in strong net deposition across the entire lake surface. Continued monitoring is required to determine the long-term effects of regulation and fate of these compounds in the Lake Superior region.

Polyethylene passive samplers make it possible to easily and affordably monitor continuing OCP trends at a high resolution, distinguishing between background concentrations likely transported over long distances and local influences 
from populated areas. PEs should be deployed year-round for the next several years in order to fully establish seasonal and annual cycles in addition to long-term trends. 


\section{$\underline{\text { Tables and Figures }}$}

Table 3.1: Average OCP concentration in gas- and dissolved-phase by sampling site on Lake Superior June-October 2011

\begin{tabular}{|c|c|c|c|c|c|c|c|c|c|c|c|c|}
\hline & & & Air $(p$ & & & & & & Water & & & \\
\hline Analyte & Mean & Minimum & Maximum & Median & $\begin{array}{l}\text { Number } \\
\text { of Detects } \\
\text { (of 28) }\end{array}$ & $\begin{array}{c}\text { Number } \\
\text { of sites } \\
\text { (of } 14 \text { ) }\end{array}$ & Mean $^{\mathrm{a}}$ & Minimum & Maximum & Median $^{b}$ & $\begin{array}{l}\text { Number } \\
\text { of Detects } \\
\text { (of 26) }\end{array}$ & $\begin{array}{l}\text { Number } \\
\text { of sites } \\
\text { (of } 13 \text { ) }\end{array}$ \\
\hline$\alpha-\mathrm{HCH}$ & 4.2 & $b d$ & 10 & 9.6 & 17 & 13 & 250 & 12 & 440 & 220 & 21 & 13 \\
\hline $\mathrm{HCB}$ & 89 & 41 & 133 & 88 & 27 & 14 & 16 & 5.4 & 37 & 14 & 26 & 13 \\
\hline Heptachlor epoxide & 0.62 & 0.40 & 1.1 & 0.54 & 27 & 14 & 3.8 & 1.1 & 5.4 & 3.4 & 26 & 13 \\
\hline Trans chlordane & 0.27 & 0.095 & 0.63 & 0.24 & 25 & 14 & 0.38 & 0.13 & 0.66 & 0.32 & 26 & 13 \\
\hline Endosulfan 1 & 1.2 & 0.33 & 2.0 & 1.3 & 26 & 14 & 0.63 & $b d$ & 2.0 & 0.32 & 7 & 6 \\
\hline Cis chlordane & 0.31 & 0.083 & 0.59 & 0.30 & 25 & 14 & 0.43 & 0.13 & 0.71 & 0.42 & 26 & 13 \\
\hline Trans nonachlor & 0.47 & 0.20 & 0.83 & 0.46 & 25 & 14 & 0.70 & 0.30 & 1.4 & 0.53 & 26 & 13 \\
\hline$p, p^{\prime}-D D E$ & 0.34 & 0.057 & 1.1 & 0.29 & 26 & 14 & 0.98 & 0.097 & 2.4 & 0.71 & 25 & 13 \\
\hline Dieldrin & 0.68 & $b d$ & 5.0 & $b d$ & 5 & 4 & 24 & bd & 73 & 30 & 12 & 7 \\
\hline$p, p^{\prime}-D D D+o, p^{\prime}-D D T$ & 0.095 & 0.021 & 0.37 & 0.070 & 23 & 14 & 0.84 & 0.093 & 8.6 & 0.17 & 21 & 13 \\
\hline$p, p^{\prime}-D D T$ & 0.032 & $b d$ & 0.24 & 0.0093 & 9 & 8 & 0.12 & $b d$ & 0.35 & 0.088 & 14 & 10 \\
\hline
\end{tabular}

Calculations are based upon site averages from the second (June-August) and third (August-October) deployments

axcludes Marquette and Sturgeon Bay because not present during both June-August and August-October 2011

${ }^{b}$ Analytes with medians below detection were excluded 


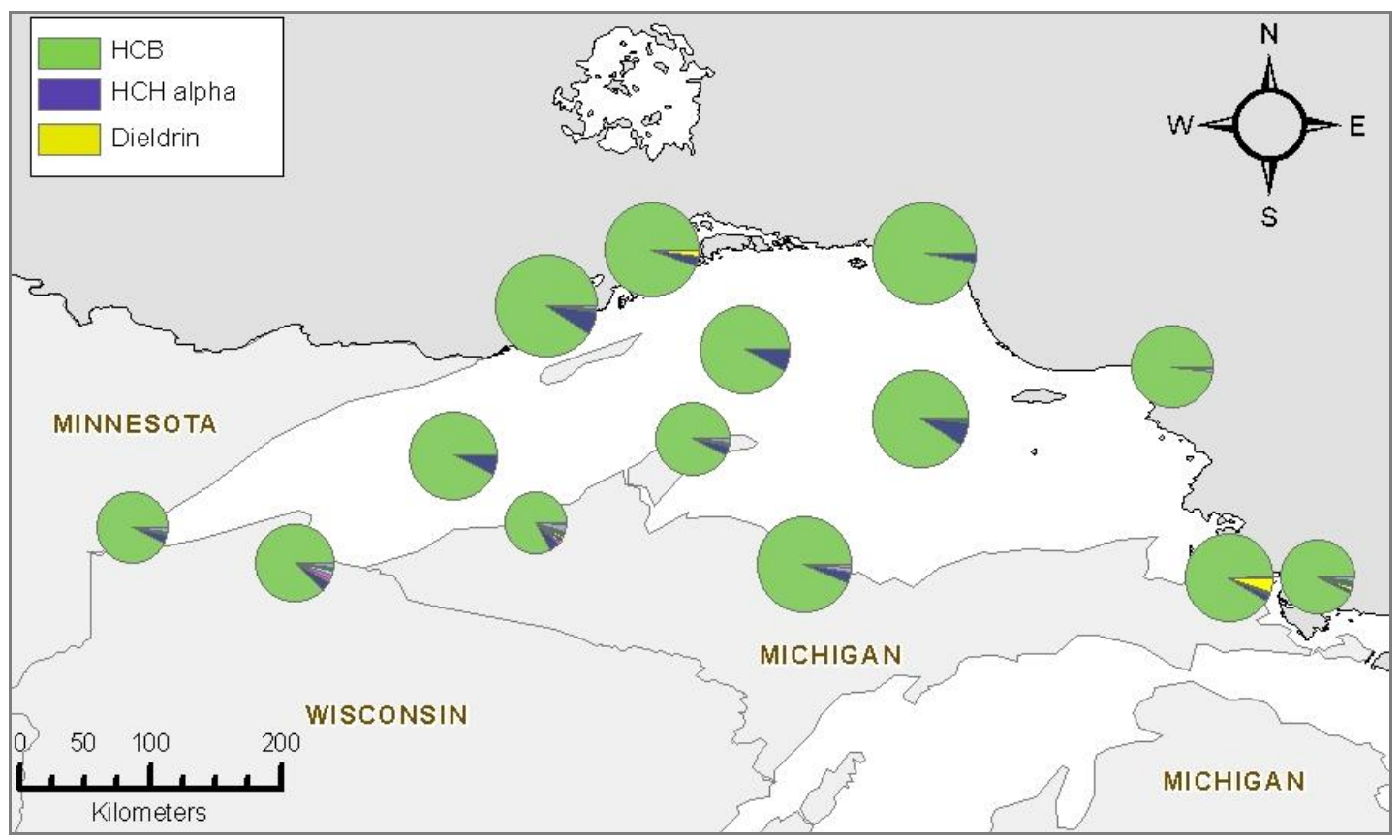

Figure 3.1: Average OCP concentrations in the Lake Superior atmosphere for JuneOctober 2011 showing relative $\Sigma_{24} \mathrm{OCP}$ between sites and relative analyte contribution at each site. Average $\Sigma_{24} \mathrm{OCP}$ ranged from $51\left(\mathrm{pg} / \mathrm{m}^{3}\right)$ at Ontonagon to $140\left(\mathrm{pg} / \mathrm{m}^{3}\right)$ at Thunder Bay/Welcome Isle and Foster Island. 


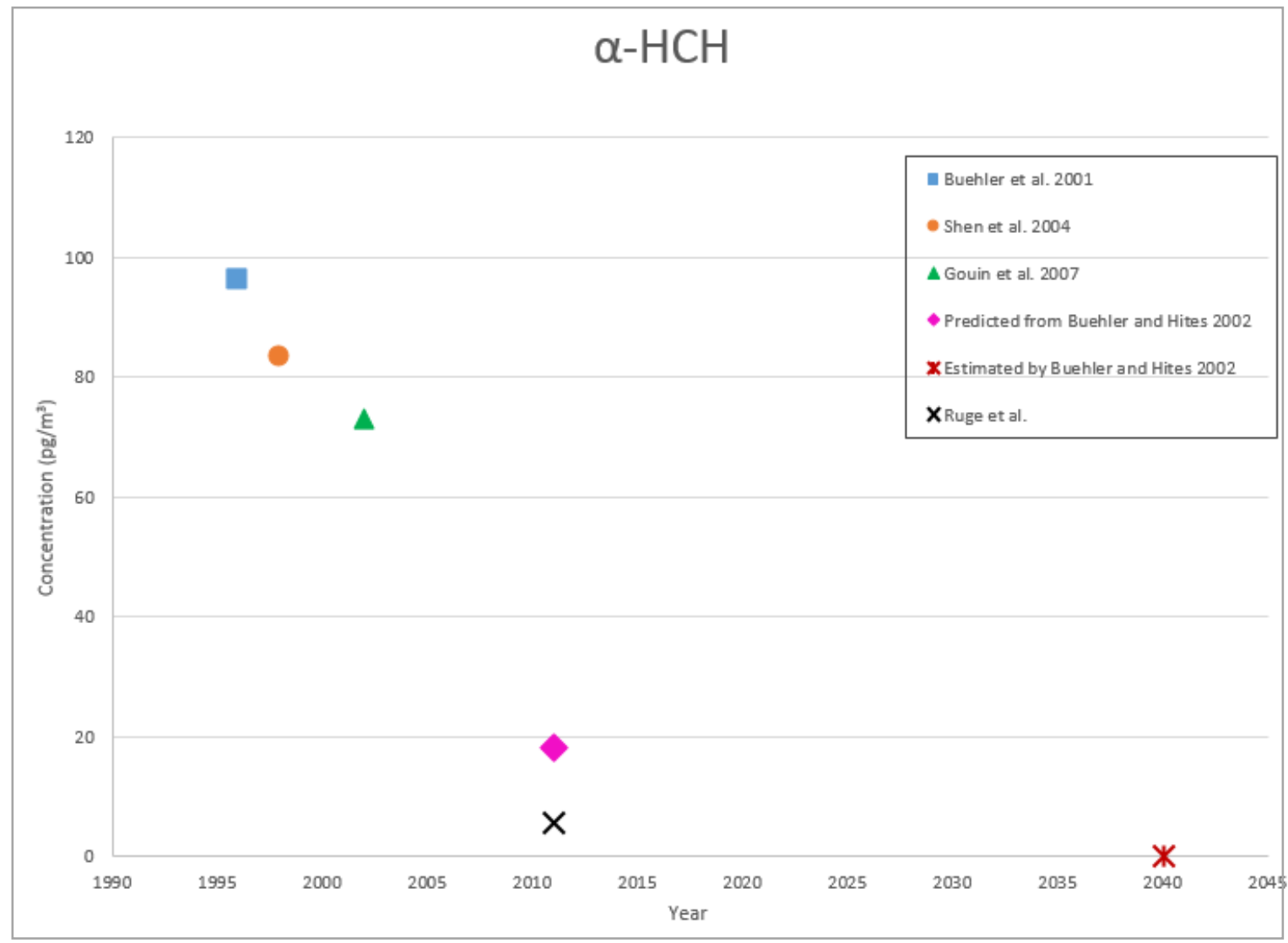

Figure 3.2: $\alpha-\mathrm{HCH}$ trends from 1996 to 2011. Predictions based upon a 4-year halflife determined by Buehler and Hites (2002). 


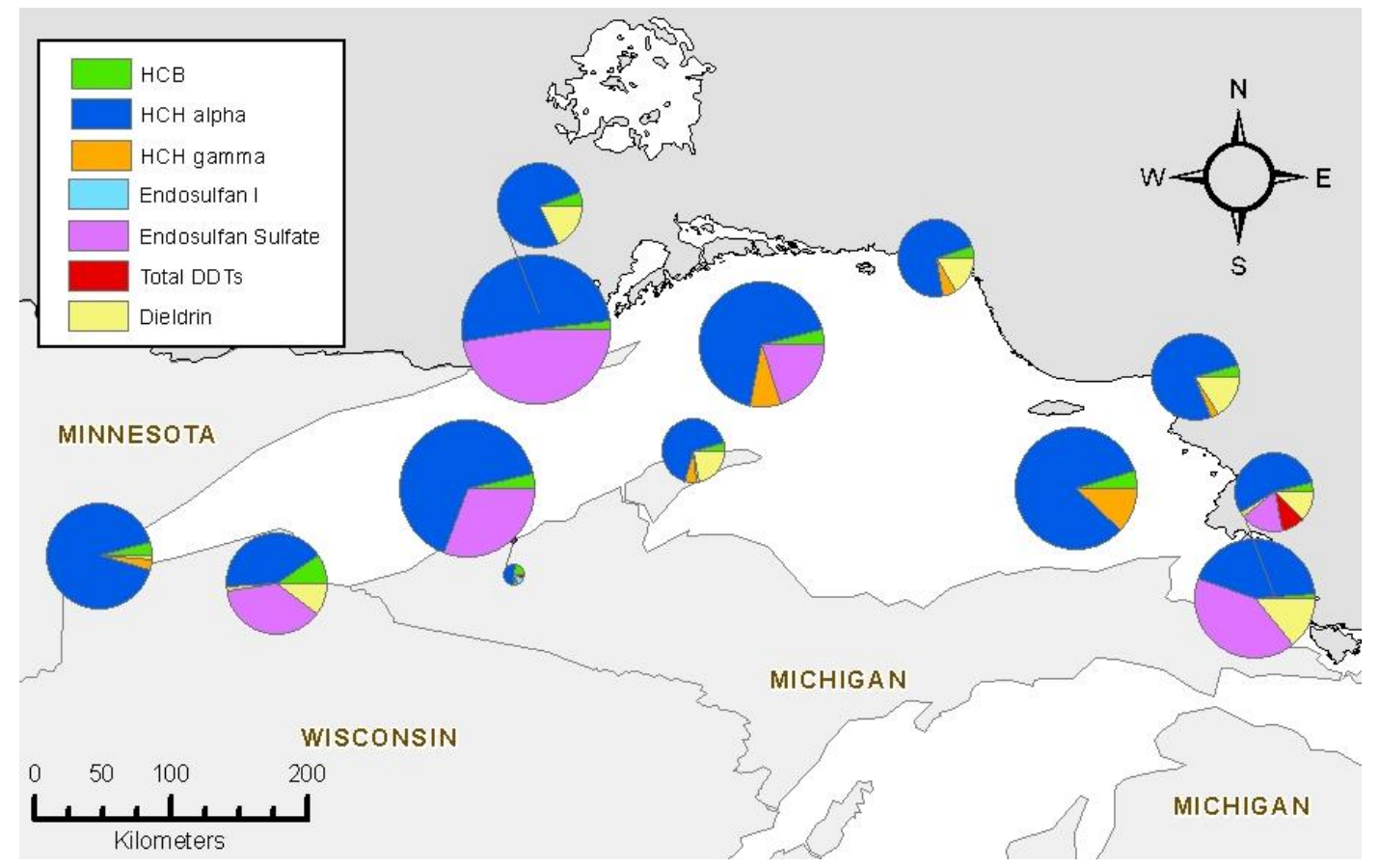

Figure 3.3: Average OCP concentrations in the Lake Superior surface water for JuneOctober 2011 showing relative $\Sigma_{24} \mathrm{OCP}$ between sites and relative analyte contribution at each site. $\Sigma_{24} \mathrm{OCP}$ ranged from $23(\mathrm{pg} / \mathrm{L})$ at Ontonagon to $770(\mathrm{pg} / \mathrm{L})$ at Station 139, offshore from Thunder Bay/Welcome Isle. 


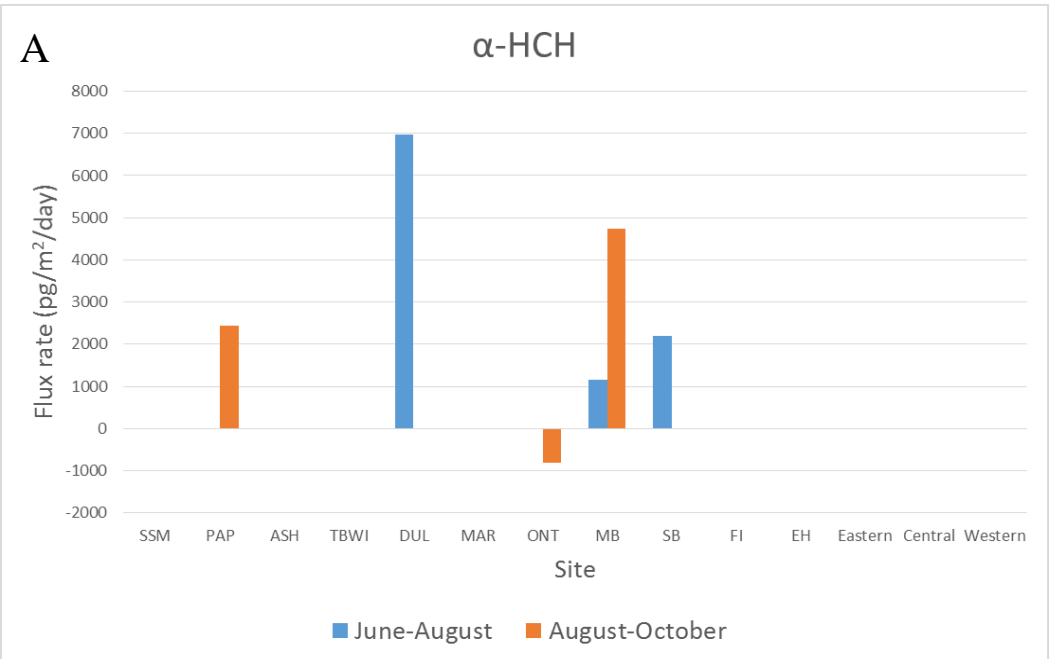

\section{$\mathrm{B}$}

HCB

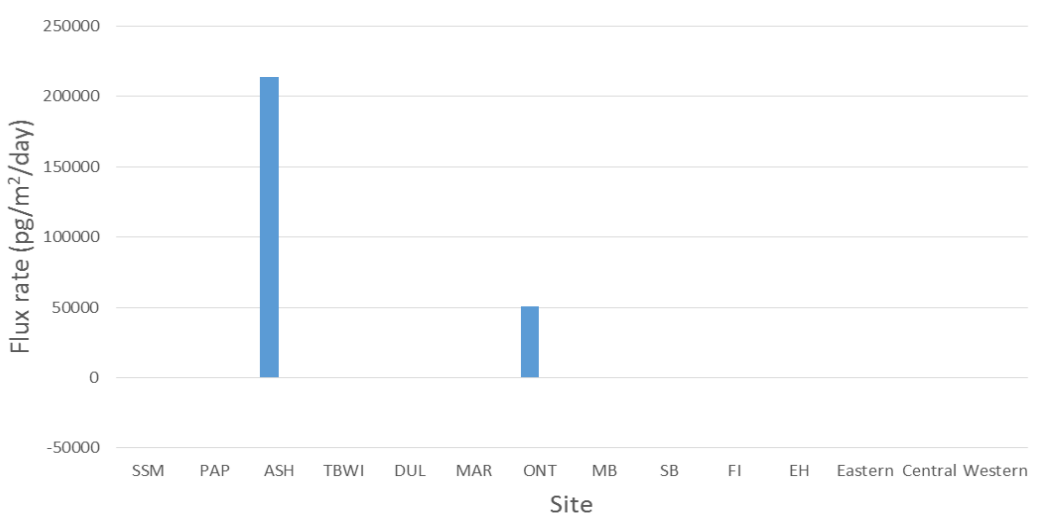

- June-August august-October

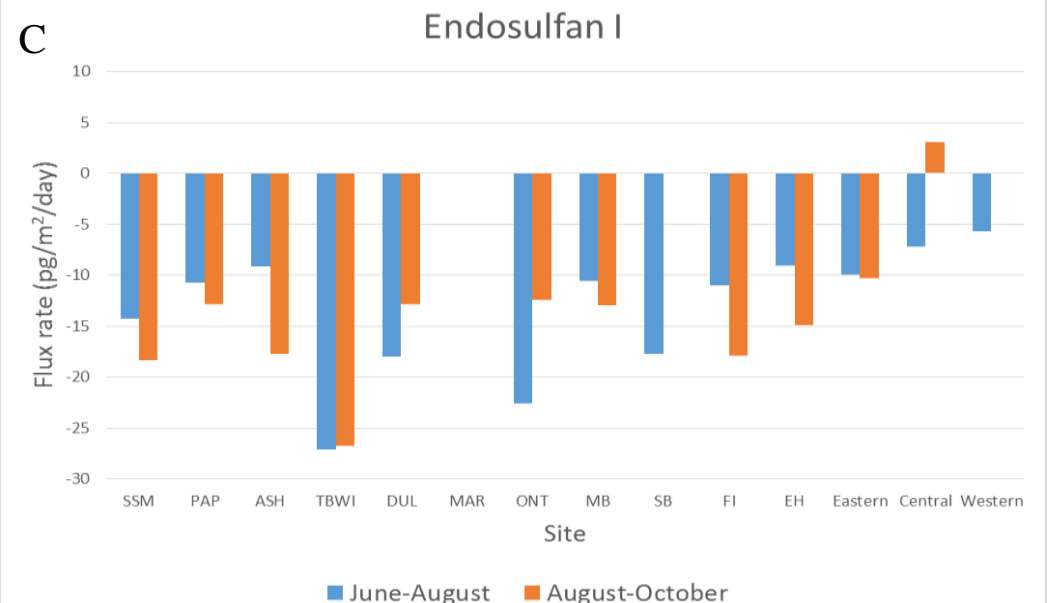

$\mathrm{D}$

Endosulfan I

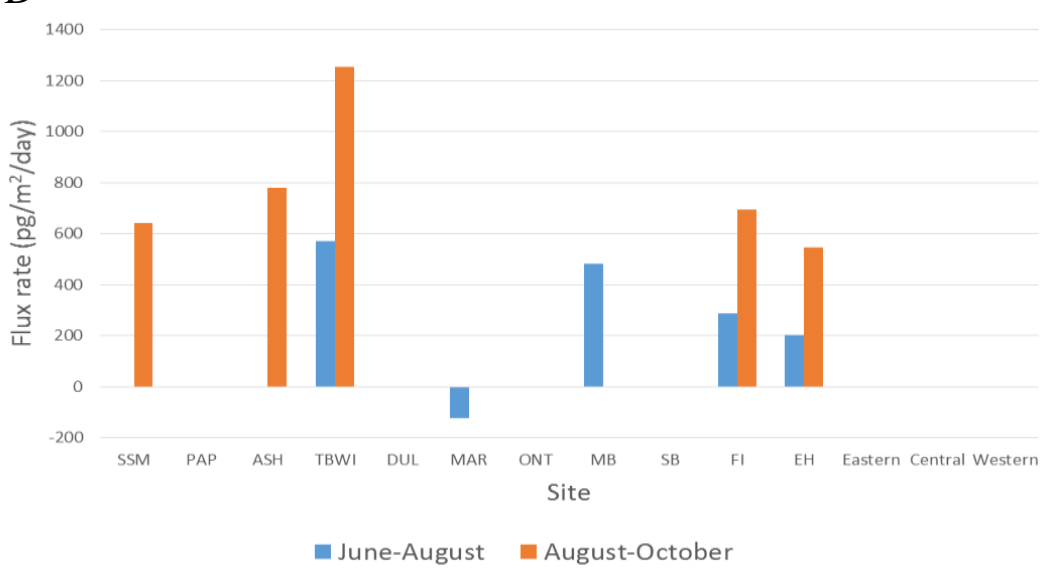

Figure 3.4: OCP flux rates across the air-water interface of Lake Superior. Blue bars represent air-water exchange for June-August 2011; orange bars represent air-water exchange for August-Octobe 2011. Positive values indicate net volatilization; negative values indicate net deposition. Site key: SSM = Sault Saint Marie, PAP = Point Aux Pins, ASH = Ashland, TBWI = Thunder Bay/Welcome Isle, MAR = Marquette, ONT = Ontonagon, DUL = Duluth, MB = Michopicoten Bay, SB = Sturgeon Bay, FI = Foster Island, EH = Eagle Harbor; Eastern, Central, and Western indicate the relative locations of the open lake sites. 


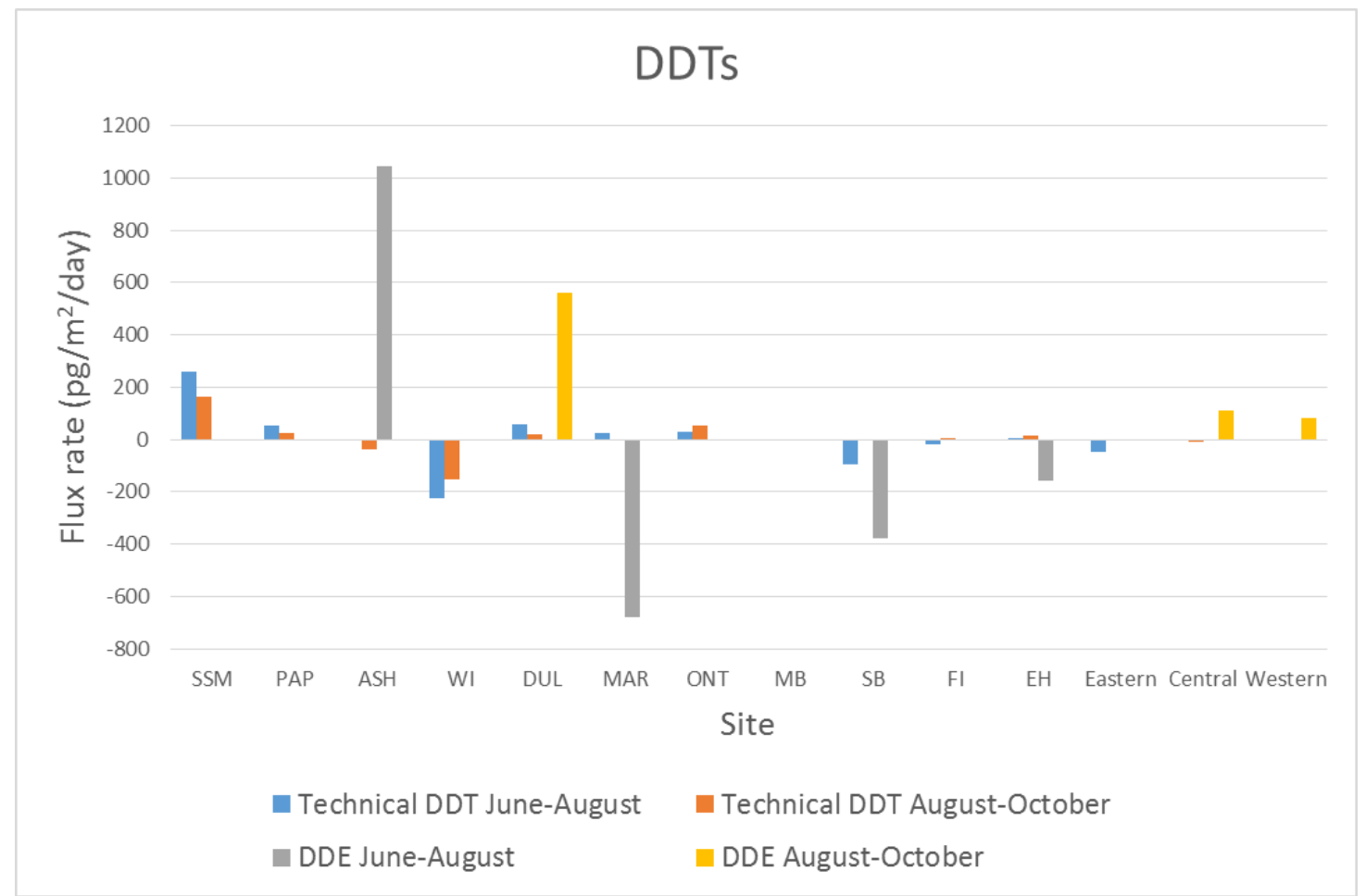

Figure 3.5: DDT fluxes by deployment site and time. Blue and orange are the sum of technical DDT components (p,p'-DDT and p,p'-DDD+o,p'-DDT) and represent primary depositions. Gray and yellow represent the p,p'-DDT metabolite, p,p'-DDE, and represent aged sources. 


\section{CHAPTER 4}

\section{POLYCHLORINATED BIPHENYLS}

\section{Introduction}

Polychlorinated biphenyls (PCBs) were used extensively in United States industry from the 1930s through the 1970s (Buehler and Hites 2002). They were one of the original persistent organic pollutants added to the Stockholm Convention and are known to bioaccumulate and cause adverse, irreversible effects in fish, birds, and mammals in the Great Lakes region (Suchash et al. 1999). Prenatal exposure to PCBs in the Great Lakes region has resulted in lower IQ and provided evidence that PCBs are neurobehavioral toxicants (Stewart et al. 2003; Stewart et al. 2008). Although

production was banned in 1979 (Honrath et al. 1997), significant amounts of PCBs are still present in closed systems as dielectric fluid in electrical transformers and capacitors, in addition to PCB waste in landfills (Suchash et al. 1999). The majority of known PCB releases to the land from 1990-1999 were from transformer or capacitor liquid spills contributing to a total release of 278 pounds to the air and 2,621,169 pounds to the land (U.S. PCB Emissions Inventory 2012).

PCBs are largely urban pollutants (Buehler and Hites 2002), however their resistance to degradation has allowed them to develop a ubiquitous presence in the environment (Suchash et al. 1999). Most sources are located to the south of the Great Lakes, resulting in greater atmospheric concentrations over Lake Superior when winds 
transport PCBs from the south (Suchash et al. 1999). PCBs have been detected in Lake Superior air, water, and sediment for several decades, but concentrations are generally lower than the other Great Lakes, likely due to distance from major urban areas (Gewurtz et al. 2008).

Atmospheric deposition is estimated to provide $90 \%$ of PCBs in Lake Superior (Hornbuckle et al. 1994). Slow degradation and benthic recycling (Hornbuckle et al. 1994; Jeremiason et al. 1998) allows PCBs to remain in the water column after deposition. A reduction in PCB emissions from primary sources to the atmosphere results in a measured revolatilization from the lake and peak concentrations in the air during the warmer months (Buehler et al. 2011). This flux has resulted in a buffered level of PCBs in the atmosphere, whereas surface water and biota concentrations have decreased (Jeremiason et al. 1994; Hillery et al. 1997).

This study aims to increase the sampling area of Lake Superior in order to understand the dynamics of PCB concentrations detected in the lake. Long-range atmospheric transport from industrial areas in the south are expected to result in relatively even distribution of PCBs across Lake Superior. IADN conducts long-term, year-round sampling, generating an invaluable dataset of PBT distributions on the Great Lakes, but sampling sites, such as Eagle Harbor on Lake Superior, were selected to represent remote, background levels. Omission of urban sampling overlooks local sources along the coast of Lake Superior which have already demonstrated elevated PCB concentrations in offshore sediments (Eisenreich and Hollod 1979; Gewurtz et al. 2008). Although limited to one season, this study was conducted to contribute to monitoring of PCBs as they cycle and decline in the environment, as well as increase 
the spatial resolution of PCB measurements in order to more accurately represent the distribution and fluxes of these persistent pollutants across Lake Superior. We also aim to demonstrate the efficacy and efficiency of polyethylene passive sampling as a useful tool for long-term, time-integrated PCB measurements.

\section{Methods and Materials}

PEs were prepared and deployed as discussed elsewhere (see Chapter 1). Extracts were spiked with $50 \mathrm{ng}$ of 7 labeled PCB $\left({ }^{13} \mathrm{C}_{12}-\mathrm{CB} 8,{ }^{13} \mathrm{C}_{12}-\mathrm{CB} 28,{ }^{13} \mathrm{C}_{12-}\right.$ $\left.\mathrm{CB} 52,{ }^{13} \mathrm{C}_{12}-\mathrm{CB} 118,{ }^{13} \mathrm{C}_{12}-\mathrm{CB} 138,{ }^{13} \mathrm{C}_{12}-\mathrm{CB} 180,{ }^{13} \mathrm{C}_{12}-\mathrm{CB} 209\right)$ surrogates. Nitrogenevaporated extracts were spiked with $50 \mathrm{ng}$ 2,4,6-tribromobiphenyl to serve as an injection standard.

OCPs were analyzed on a Waters Quattro micro GS Micromass MS-MS and quantified using Waters QuanLynx V4.1 software as detailed elsewhere (Zhang and Lohmann 2010). Samples were held at $100{ }^{\circ} \mathrm{C}$ for 1 minute, ramped up to $180{ }^{\circ} \mathrm{C}$ at 11 ${ }^{\circ} \mathrm{C} / \mathrm{min}$, ramped up to $260{ }^{\circ} \mathrm{C}$ at $3{ }^{\circ} \mathrm{C} / \mathrm{min}$, then ramped up to $300{ }^{\circ} \mathrm{C}$ at $20^{\circ} \mathrm{C} / \mathrm{min}$ and held for 6 minutes. Analysis was conducted in splitless injection mode using a 30m x $0.250 \mathrm{~mm}$ i.d. (film thickness $0.25 \mu \mathrm{m}$ ) DB-5MS column.

Quality assurance and control is discussed elsewhere (see Chapter 1). Due to problems with the injection standard used, average surrogate recoveries were consistently low, ca. 10-20\% (see Supporting Information). The overall validity of our analytical method was guaranteed through spiked matrix recoveries that were typically ca. $80-120 \%$ for our target analytes. Recoveries confirmed that the overall concentrations reported here are accurate. 
A total of 18 PCBs were included in quantification (see Supporting Information). Concentrations, flux gradients, and flux rates were determined according to equations presented elsewhere (see Chapter 1). Proximity of sampling sites to potential source areas was determined using ArcMap 10.1 (see Supporting Information).

\section{$\underline{\text { Results and Discussion }}$}

\section{PCB Air Distribution}

PCBs were detected in the atmosphere at nearly every site during the sampling season, however distributions were not spatially and temporally uniform. Sault Saint Marie and Marquette had the highest $\Sigma_{18} \mathrm{PCB}$ concentrations from June-August, $>15 \mathrm{x}$ higher than the other sites (Table 4.1). These two sites also had the greatest number of different PCB congeners present (Figure 4.1A), suggesting that Sault Saint Marie and Marquette are current sources of PCBs, probably due to their historical use at both locations. In general, PCB concentrations were higher and more diverse near populated or industrialized areas, as expected for anthropogenic products with no known natural emissions (Hillery et al. 1997; Honrath et al. 1997; Hafner and Hites 2003). Despite associations with larger populations, PCB concentrations were relatively low at the Duluth and Thunder Bay/Welcome Isle stations. As discussed previously, the Duluth site is located northeast of the downtown, and may not receive direct emissions from the city. Likewise, historical consumption of PCBs was lower in Canada than in the United States (3\% of global use versus 46\%), possibly

contributing to lower observed concentrations at Thunder Bay (Hafner and Hites 2003; Sun et al. 2007). Significant quantities of PCBs are still in use as dielectric fluids in 
transformers and capacitors in the industrialized regions to the south of Lake Superior (Suchash et al. 1999), likely contributing to atmospheric PCB levels along the southern shore.

Eagle Harbor exhibited the lowest concentrations from June-August, followed by other rural and open lake sites. Ashland had low concentrations similar to rural sites, distinguishing itself from other industrialized and populated areas. Hexachlorobiphenyls were dominant in the atmosphere across the lake from JuneAugust (Figure 4.2A), representing 40-100\% of most gaseous concentrations. Hexachlorobiphenyls were only ca. $17 \%$ of $\Sigma_{18} \mathrm{PCB}$ at Sault Saint Marie and Marquette due to enhanced contributions from tetra- (41\% and $31 \%$, respectively) and pentachlorobiphenyls (38\% and 52\%, respectively).

Although general distribution patterns of $\Sigma_{18} \mathrm{PCB}$ were similar, atmospheric concentrations decreased at a number of sites from the second deployment (JuneAugust) to the third (August-October) (Figure 4.1B). Concentrations at Eagle Harbor, Foster Island, and two open-lake sites fell below the detection limit. Overall concentrations decreased at Sault Saint Marie and Marquette, but both sites maintained their relative congener contributions. The greatest change occurred at Ashland and Ontonagon where trichlorobiphenyl contributed 31 and $47 \mathrm{pg} / \mathrm{m}^{3}$, respectively. Trichlorobiphenyls were not detected at any other sites and relative congener contributions remained reasonably unchanged from mid to late summer (Figure 4.2B).

Reduced anthropogenic emissions to the environment may explain the current PCB trends in the air above Lake Superior. After production was banned in 1979, 
PCBs over Lake Superior decreased to North American background levels (ca. 1 $\mathrm{ng} / \mathrm{m}^{3}$ ) and remained fairly stable for several years (Baker and Eisenreich 1990; Hillery et al. 1997; Jeremiason et al. 1998). A number of studies from the past 20 years have suggested that gaseous PCB concentrations were maintained in the Great Lakes' atmosphere due to replenishment from the lakes themselves (Baker and Eisenreich 1990; Cortes et al. 1998; Buehler et al. 2004). It was hypothesized that the lakes act as buffers, responding to the reduced atmospheric loadings and releasing PCBs back to the air. This volatilization in turn would lead to lower PCB concentrations in the surface water (Baker and Eisenreich 1990; Jeremiason et al. 1994). Air-water exchange is dominated by the more volatile tri- and tetrachlorobiphenyls. Their vulnerability to $\mathrm{OH}$ radical degradation (Gevao et al. 1998) and subsequent continued volatilization may cause less-chlorinated PCBs to be preferentially removed from the Lake Superior atmosphere over time. Although triand tetrachlorobiphenyls were historically the dominant congeners in the Great Lakes' atmosphere (Baker and Eisenreich 1990; Gevao et al. 1998), in their absence, pentaand hexachlorobiphenyls may appear to dominate. PCB levels in the gas phase have continued to decline significantly (Gewurtz et al. 2008).

Current atmospheric PCB levels indicate a decrease in gaseous PCBs in Lake Superior air over the past decade. Previous IADN studies reported $\mathrm{PCCB}$ at Eagle Harbor ca. 63-95 pg/m³ from 1990-2003 (Hillery et al. 1997; Buehler et al. 2001; Sun et al. 2007). We found concentrations from June-October to be lower by an order of magnitude or below the detection limit, exceeding the 18+-7.1 year estimated half-life for PCBs at Eagle Harbor (Buehler et al. 2004). A number of factors in addition to 
reduced emissions could have contributed to the magnitude of the apparent decrease. Previous studies all reported $\Sigma \mathrm{PCB}$ for more than 18 congeners, possibly adding significant fractions not included in this study. Also, IADN samples were collected using a high-volume active air sampler, which may produce overestimates due to particle desorption on the filter (Perlinger et al. 2005). Additionally, air sampling rates in this study were calculated to be $8-120 \mathrm{~m}^{3} /$ day. Overestimates for the air sampling rate in our study may have resulted in underestimates for PCB concentrations. Conversely, sampling for this study was conducted during the warmest time of year and should have resulted in overestimates compared to the annual average reported by IADN studies. Previous studies indicated enhanced volatilization during the summer resulting in annual maximum vapor-phase concentrations in July/August (Hornbuckle et al. 1994).

\section{PCB Water Distribution}

PCBs were detected at every site from June-August (Figure 4.2C). The highest and most varied concentrations along the coast were at Sault Saint Marie ( $34 \mathrm{pg} / \mathrm{L})$, followed by other urban areas: Duluth (16 pg/L), and Ashland (12 pg/L) (Figure 4.1C). Coastal rural sites exhibited the lowest dissolved concentrations $(<1 \mathrm{pg} / \mathrm{L})$, however open lake sites were similar to developed coastal areas (average $9.4 \mathrm{pg} / \mathrm{L}$ ) (Table 4.1). Hexachlorobiphenyl was dominant in the water at ca. half of the sampling sites while tri- and tetrachlorobiphenyl defined the dissolved concentrations at Duluth, Ashland, and the open lake sites. Lighter PCB congeners may be able to accumulate in the water more than in the air because photochemical degradation occurs much slower in water (Zhang and Lohmann 2010). 
In August-October distributions and relative congener contributions were nearly the same as in June-August, with the exceptions of Duluth and the open lake sites (Figure 4.2D). At these locations, dissolved concentrations decreased dramatically as a result of tri- and tetrachlorobiphenyl losses (Figure 4.1D). Neither PCB concentrations, nor their relative ratios, changed much at Ashland. The history of industry, landfills, and superfund designation in Ashland may indicate a direct and constant input of PCBs to the water near the sampling site. Although not consistent with the low atmospheric concentrations in June-August, enhanced volatilization from the trichlorobiphenyl-rich water at Ashland may have supplied the PCBs observed in the atmosphere in August-October.

Most coastal sites were located ca. 1-20 km from an active or cleaned EPAdesignated Area of Concern or National Priorities List Superfund site. Although designated for a range of pollutants and activities, two sites were specifically marked for PCB releases: (1) Arrowhead Refinery CO., ca. $16 \mathrm{~km}$ from Station 221 (the Duluth water site), and (2) Peninsula Harbor, $~ 11 \mathrm{~km}$ east of Foster Island. Water concentrations at Station 221 were not as great as at sites closer to urban sources, but may be responding to influences from the city of Duluth and its related emissions transported by the St. Louis River. Foster Island is located in a rural area as part of Neys Provincial Park, across open water from the polluted harbor near Marathon, ON. Foster Island does not appear to be significantly impacted by PCBs from the Peninsula Harbor AOC.

PCB concentrations in the Lake Superior water column have been declining for the past few decades (Baker and Eisenreich 1990; Buehler and Hites 2002), removed 
primarily by volatilization (Jeremiason et al. 1998). Sedimentation accounted for $4900 \mathrm{~kg}$ of PCB removal from the surface water between 1980 and 1992, however volatilization to the atmosphere removed $26,500 \mathrm{~kg}$ of PCBs over the same time period (Jeremiason et al. 1994). In 1980 dissolved concentrations in Lake Superior were $2.4 \mathrm{ng} / \mathrm{L}$. This level was reduced to $0.18 \mathrm{ng} / \mathrm{L}$ by 1992 at a first-order decay of 0.2/year (Jeremiason et al. 1994). Dissolved PCB concentrations from this study indicate an elevated rate of removal, perhaps in response to decreased loadings. Overall half-lives for PCBs in both the air and water were estimated to be 5-9 years (Hillery et al. 1998). Applying this rate to 1992 levels yields results similar to urban and industrialized coastal sites measured in this study, but are much higher than rural areas. These results suggest that developed areas continue to have an impact on local PCB concentrations.

Since atmospheric deposition is considered to be the main input mechanism, accounting for $85-90 \%$ of PCB loading into Lake Superior (Eisenreich and Hollod 1979; Honrath et al. 1997), decreased anthropogenic emissions have resulted in reduced levels detected in Lake Superior biota (Hillery et al. 1997; Jeremiason et al. 1998). However, since PCBs bioaccumulate, they may be maintained in higher trophic organisms and remain a potential health hazard (Wong et al. 2004). Lake Superior trout exhibited $\Sigma \mathrm{PCB}$ concentrations ca. $5440 \mathrm{ng} / \mathrm{g}$ lipid (Wong et al. 2004). Penta-, hexa-, and heptachlorobiphenyls tend to be dominant in biota, similar to congener patterns observed in the water column (Kucklick and Baker 1998; Wong et al. 2004). Some PCB removal may occur through biotransformation and sinking of dead organic matter (Kucklick and Baker 1998; Wong et al. 2004), but it has been 
shown that Lake Superior experiences efficient carbon recycling, whereby the pelagic food chain and benthic food web maintain PCBs in the water column (Jeremiason et al. 1998). Despite the hydrophobic nature of PCBs and the sinking of $>50 \%$ of total PCB stores in Lake Superior on settling particles, only 2-5\% of PCBs accumulate in bottom sediments (Jeremiason et al. 1994; Jeremiason et al. 1998). Current surface water concentrations indicate that PCB levels in biota should continue to decrease, but given that the truly dissolved fraction only represents half of the PCBs present in the water column (Baker and Eisenreich 1990), PCBs are expected to continue to be detected in Lake Superior biota, especially in higher trophic level organisms.

\section{PCB Air-Water Gradient}

For the PCB congeners present, concentration ratios between the air and water were predominantly less than one at all sites from June-October. Such low ratios indicate that volatilization was dominating air-water exchange across Lake Superior. Two coastal sites exhibited net deposition for tetra- and pentachlorobiphenyl from June-August: Marquette and Thunder Bay. Marquette is an industrial town with an AOC and remediated NPL, and may be acting as a source of PCBs to the atmosphere, enhancing deposition in the nearby water compared to other Lake Superior sites. Likewise, Thunder Bay is the largest city on Lake Superior and may still be a source of PCBs, even though atmospheric concentrations were much lower than at Marquette. Duluth did not exhibit the same deposition, likely because the air site was located northeast of the city emissions, whereas water samples were collected a few kilometers from the mouth of the St. Louis River. Foster Island was also dominated by PCB deposition. Although overall atmospheric and water concentrations were very 
low at Foster Island, it may be receiving small inputs from the nearby Superfund site at Peninsula Harbor.

Open lake sites had ratios indicating strong volatilization of tri-, tetra-, and pentachlorobiphenyls, and equilibrium for heavier congeners. This pattern is expected for regions with no direct local PCB inputs, where fluxes are controlled by environmental factors, such as ambient temperature and wind speed. Particle scavenging efficiently removed PCBs from the atmosphere, creating an urban to rural gradient in PCB distribution (Buehler et al. 2001; Offenberg and Baker 2002), and possibly limiting the amount and weight of congener transported to the open lake. Additionally, temperature differences between the land and water in the summer cause enhanced offshore air flow, which, in turn, creates a stable atmosphere (Honrath et al. 1997). Reduced atmospheric mixing hinders the interaction of land-based pollutants with the water surface, limiting transportation to within ca. $30 \mathrm{~km}$ from shore. The thinner layer free to exchange PCBs across the air-water boundary quickly equilibrates with the lake surface, supporting the flux gradients observed in the open lake.

Increased temperatures from August-October corresponded with an enhanced volatilization signal for most congeners across the lake. Temperature changes were greatest at the open lake sites (average $6.6^{\circ} \mathrm{C}$ ), likely causing volatilization strong enough to overwhelm deposition of higher molecular weight PCBs. Congeners ranging from penta- to heptachlorobiphenyls had ratios suggesting strong volatilization from open lake surface water. A similar switch from net deposition to net volatilization was observed for Foster Island at a more modest air temperature 
increase $\left(2.8^{\circ} \mathrm{C}\right)$. Changes in gradients may also be caused by reduced atmospheric sources.

The Marquette water sampler from August-October was lost, but Thunder Bay/Welcome Isle exhibited ratios similar to June-August. Ontonagon changed the most, exhibiting strong net deposition of tri- and tetrachlorobiphenyls in response to the elevated atmospheric concentrations of those congeners during the same time period. It is unclear from where the light PCBs originated. Similar to most sites across Lake Superior, heavier congeners present (penta-, hexa-, and heptachlorobiphenyl) were significantly volatilizing from the surface water at this site.

These results follow a trend of reported PCB volatilization from Lake Superior over the past 20 years, the greatest observed fluxes occurring in July-September (Baker and Eisenreich 1990; Hornbuckle et al. 1994). The current study was limited to April-October, restricting its scope to the warmest times of the year. Therefore, it cannot be determined whether these flux gradients are representative of annual airwater exchange, or if net deposition dominates PCB flux during the colder months. We do see a shift in the behavior of PCBs by degree of chlorination compared to previous measurements. Two decades ago, the less-chlorinated congeners $(\leq 5$ chlorines) exhibited volatilization fluxes throughout the year, representing 90\% of PCB volatilization, whereas highly chlorinated congeners had depositional fluxes (Hornbuckle et al. 1994). Our flux gradients suggest that volatilization is dominated by hexachlorobiphenyls in the general absence of tri- and tetrachlorobiphenyls. 


\section{PCB Air-Water Exchange}

Net flux rates for PCBs from June-August were greatest at locations with the highest dissolved-phase concentrations, namely Sault Saint Marie (16 ng/m²/day), Duluth ( $29 \mathrm{ng} / \mathrm{m}^{2} /$ day), Ashland ( $20 \mathrm{ng} / \mathrm{m}^{2} /$ day), and the eastern open lake (18 $\mathrm{ng} / \mathrm{m}^{2} /$ day), all volatilizing out of Lake Superior. Despite similar wind and temperature profiles, fluxes at the other open lake sites were ca. half this value due to lower PCB concentrations in the water. Where present, CB-18 had the greatest flux, volatilizing at an average rate of ca. $6.8 \mathrm{ng} / \mathrm{m}^{2} /$ day. However, CB-18 fluxes were only observed at the open lake sites and 2 coastal locations. In general, volatilization was dominated by $\mathrm{CB}-138$ and -153 , hexachlorobiphenyls that dominated most water and air PCB concentrations across Lake Superior (Figure 4.3), but was only significantly different from net equilibrium at a few populated sites.

Fluxes at Sault Saint Marie (Figure 4.3A), Point Aux Pins, Ashland, and Thunder Bay/Welcome Isle (Figure 4.3B) were relatively stable between June-August and August-October. Fluxes at these sites were generally from the lake to the atmosphere, except at Thunder Bay/Welcome Isle where pentachlorobiphenyls were being deposited at an average of ca. $2.3 \mathrm{ng} / \mathrm{m}^{2} /$ day. Duluth exhibited enhanced volatilization of two hexachlorobiphenyls, CB-138 and -153, but CB-128 appeared to volatilize at a lower rate in the late summer (Figure 4.3C). Tri- and tetrachlorobiphenyls were no longer volatilizing from the Duluth site in AugustOctober because they were not detected in the water. Volatilization may have removed sufficient amounts of the lower molecular weight congeners from the water to the atmosphere to reduce water PCB concentrations below the limit of detection. 
We did not observe a corresponding increase in atmospheric PCB concentrations for Duluth, likely due to the horizontal distance between the air and water sampling sites.

Rural coastal sites exhibited lower PCB flux rates, supporting previously mentioned urban-rural gradients in PCB distributions (Figure 4.3D, 4.3E). An exception was slightly elevated volatilization of CB-153 from Sturgeon Bay from August-October. Eagle Harbor and Michopicoten Bay had the lowest flux rates of the Lake Superior sites sampled.

$\Sigma$ PCB congeners $<5$ chlorines were volatilizing from open lake sites at an average rate of $11 \mathrm{ng} / \mathrm{m}^{2} /$ day from June-August (Figure 4.3F). Fluxes dropped below the detection limit in August-October, possibly as a result of depleted surface stores. Congeners with $\geq 5$ chlorines were generally at equilibrium or not detected in midsummer, but were volatilizing from the open lake from June-October at an average rate of $4.3 \mathrm{ng} / \mathrm{m}^{2} /$ day in the eastern open lake, $1.4 \mathrm{ng} / \mathrm{m}^{2} /$ day in the central open lake, and $0.63 \mathrm{ng} / \mathrm{m}^{2} /$ day in the western open lake.

Net deposition of tetra- and pentachlorobiphenyls dominated flux rates at Marquette from June-August $\left(-12 \mathrm{ng} / \mathrm{m}^{2} /\right.$ day). There is no data for this site from August-October. Ontonagon showed net deposition of tri- and tetrachlorobiphenyls from August-October (-14 ng/m²/day).

Average flux across the lake from June-October was ca. $4.6 \mathrm{ng} / \mathrm{m}^{2} /$ day (range $12 \mathrm{ng} / \mathrm{m}^{2} /$ day to $+24 \mathrm{ng} / \mathrm{m}^{2} /$ day). The range is lower than the annual average reported for 1978 to $1992,63 \mathrm{ng} / \mathrm{m}^{2} /$ day (Hornbuckle et al. 1994). Since sampling for this study was limited to the warm summer months, it was expected that average volatilization rates would be greater than for annual averages where deposition may be 
enhanced in cooler winter months. Overall, water-air exchange appears to be decreasing, consistent with decreasing rates of volatilization observed in the 1990s (Buehler and Hites 2002).

\section{Conclusions and Implications}

PCB concentrations measured in the air and water across Lake Superior exhibited a clear association with urban and industrial areas, consistent with past findings in the Great Lakes region. However, current concentrations appear to be dominated by penta- and hexachlorobiphenyls, whereas past measurements found triand tetrachlorobiphenyls to make the greatest contributions to PCB levels. Eagle Harbor consistently had the lowest PCB concentrations. Atmospheric concentrations at open lake sites were similar to rural coastal areas from June-August, however dropped below the detection limit in August-October. This decrease was likely because net volatilization was stronger in mid-summer, but was not observed in latesummer, curbing the supply to the air. Likewise, PCB concentrations in the open water from June-August were higher than at rural coastal sites, but similar from August-October, perhaps as a result of a greater loss to the atmosphere from the open lake than from coastal waters.

Tandem air-water sampling of 14 sites across the lake demonstrated the efficacy of PEs to enhance the understanding of PCB dynamics in the Lake Superior air and water. They also provided an affordable and easy means of determining simultaneous, time-integrated equilibrium concentrations between the gaseous and dissolved phases and, thus, air-water exchange of PCBs. PEs should be used in 
concert with active high-volume sampling to enhance the spatial resolution of ongoing PCB monitoring in the Great Lakes region. 


\section{$\underline{\text { Tables and Figures }}$}

Table 4.1: $\Sigma_{18} \mathrm{PCB}$ concentrations in air $\left(\mathrm{ng} / \mathrm{m}^{3}\right)$ and water $(\mathrm{ng} / \mathrm{L})$ by deployment period

\begin{tabular}{|c|c|c|c|c|c|c|}
\hline \multirow[b]{2}{*}{ Site } & \multicolumn{3}{|c|}{$\operatorname{Air}\left(\mathrm{pg} / \mathrm{m}^{3}\right)$} & \multicolumn{3}{|c|}{ Water (pg/L) } \\
\hline & April-June & June-August & August-October & April-June & June-August & August-October \\
\hline Sault Saint Marie & 37 & 49 & 37 & 45 & 34 & 31 \\
\hline Point Aux Pins & & 1.2 & 0.74 & & 1.6 & 1.2 \\
\hline Ashland & 1.2 & 0.40 & 31 & 4.0 & 12 & 12 \\
\hline Thunder Bay/Welcome Isle & & 4.7 & 4.1 & & 1.8 & 1.6 \\
\hline Station 139 & & & & & 3.9 & 6.2 \\
\hline Marquette & 13 & 52 & 28 & 29 & 4.6 & N/A \\
\hline Ontonagon & & 1.7 & 57 & & 0.49 & 1.4 \\
\hline Duluth & 5.2 & 3.5 & 1.3 & & 16 & 3.6 \\
\hline Michopicoten Bay & & 0.66 & 0.70 & & 0.53 & 0.18 \\
\hline Sturgeon Bay & & 0.25 & 0.13 & & 0.27 & 0.66 \\
\hline Foster Island & & 0.56 & $b d$ & & 0.17 & 0.41 \\
\hline Eagle Harbor & bd & 0.083 & bd & & 0.035 & 0.13 \\
\hline Eastern Open Lake & & 0.91 & 0.089 & & 13 & 2.7 \\
\hline Central Open Lake & & 0.62 & bd & & 6.2 & 0.88 \\
\hline Western Open Lake & & 0.36 & $\mathrm{bd}$ & & 8.9 & 0.75 \\
\hline
\end{tabular}



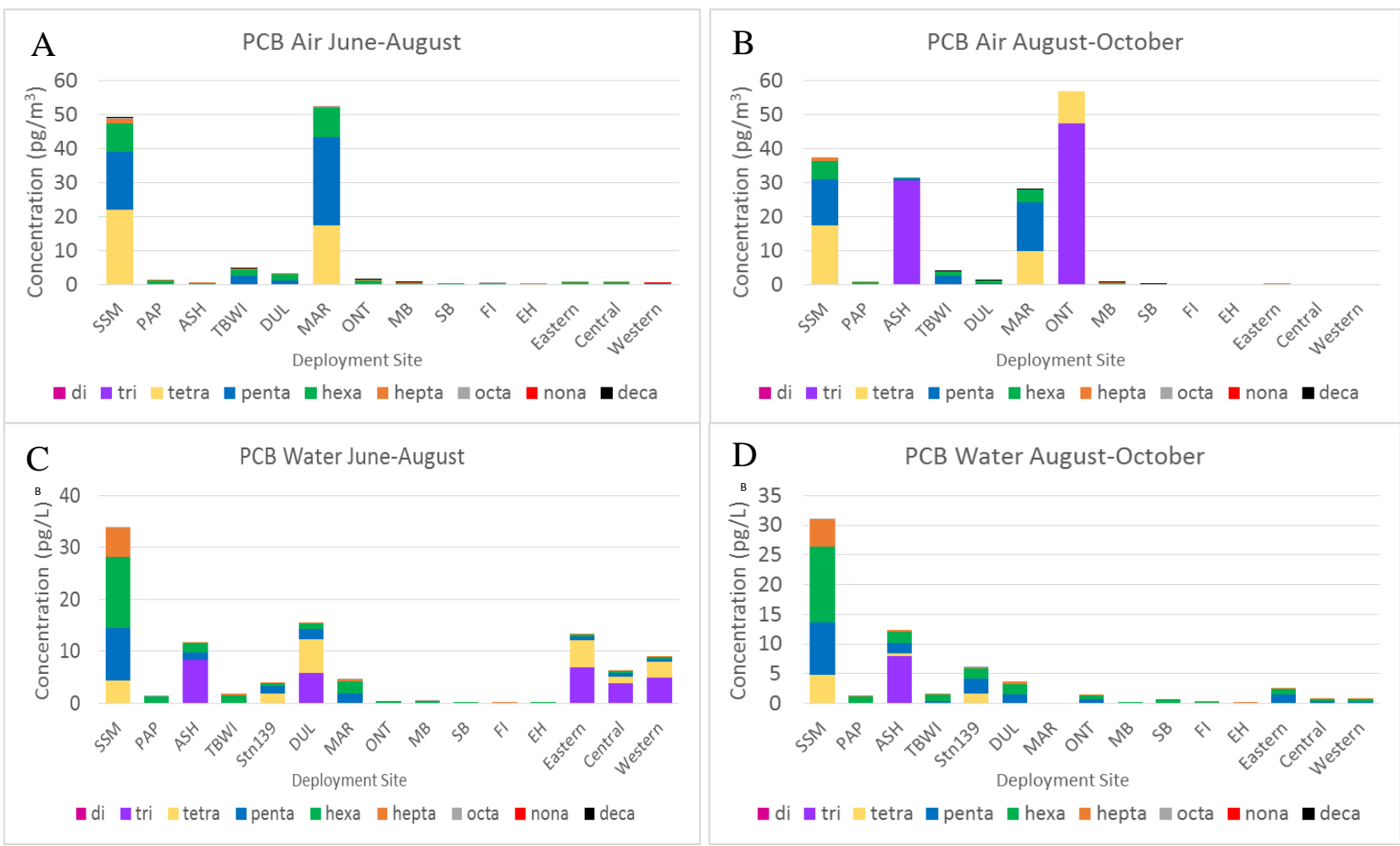

Figure 4.1: Gaseous $\left(\mathrm{pg} / \mathrm{m}^{3}\right)$ and dissolved $(\mathrm{pg} / \mathrm{L}) \mathrm{PCB}$ concentrations at Lake Superior sampling sites grouped by degree of urban development. (A) Atmospheric PCB concentrations averaged for June-August 2011. (B) Atmospheric PCB concentrations averaged for August-October 2011. (C) Dissolved PCB concentrations averaged for June-August 2011. (D) Dissolved PCB concentrations averaged for AugustOctober 2011. Legend: Pink = dichlorobiphenyl (CB8), Purple $=$ trichlorobiphenyls $(\mathrm{CB} 18,28)$, Yellow $=$ tetrachlorobiphenyls $(\mathrm{CB} 44,52,66)$, Blue = pentachlorobiphenyls $(\mathrm{CB} 101,105,118)$; Green $=$ hexachlorobiphenyls (CB128, 138, 153); Orange = heptachlorobiphenyls (CB170, 180, 187); Grey = octachlorobiphenyl (CB195); Red = nonachlorobiphenyl (CB206); and Black = decachlorobiphenyl (CB209). 

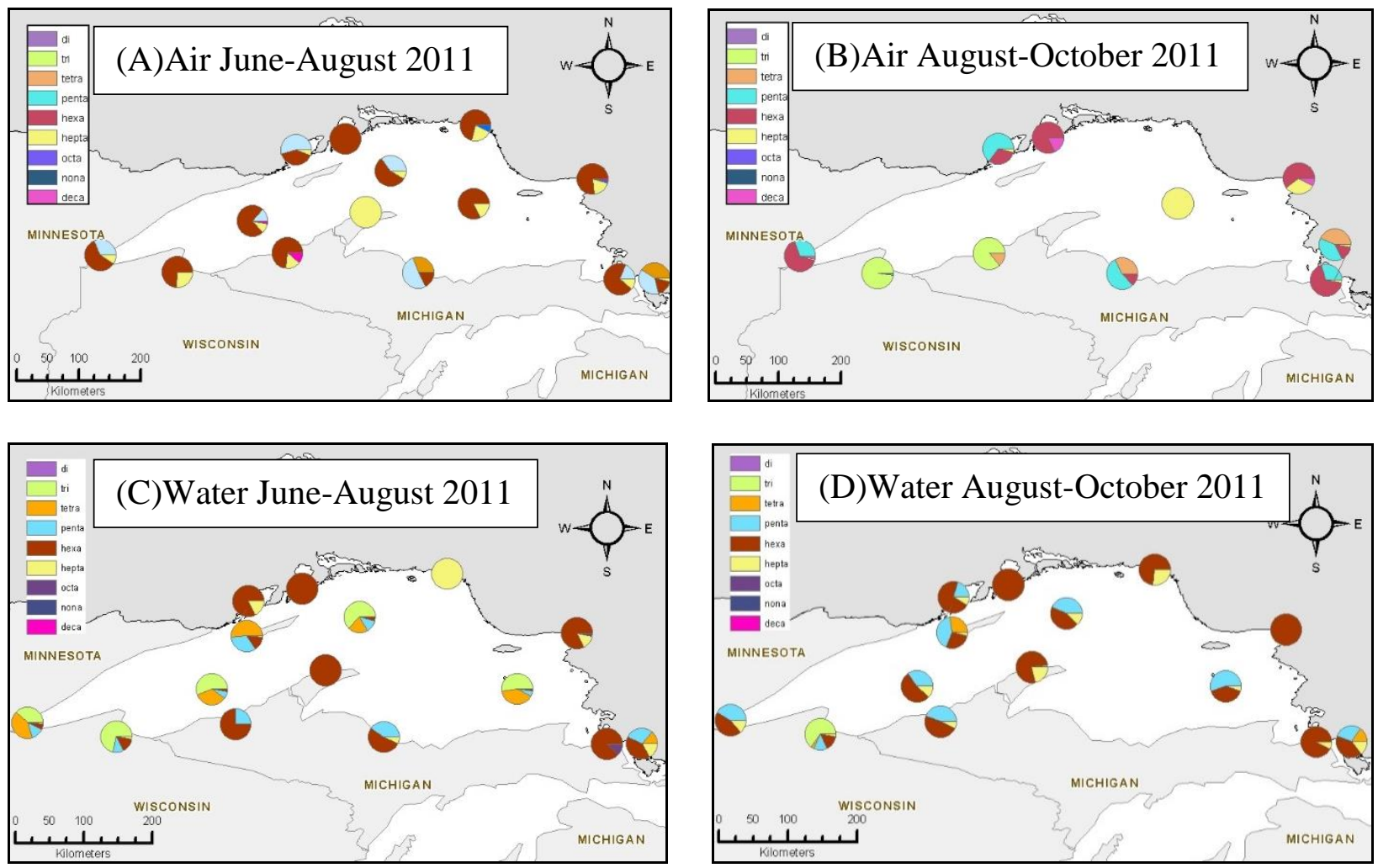

Figure 4.2: Relative PCB contributions from congener groups in atmosphere above Lake Superior averaged for (A) June-August and (B) August-October 2011. Relative PCB contributions from congener groups in Lake Superior water averaged for (C) June-August and (D) August-October 2011. 

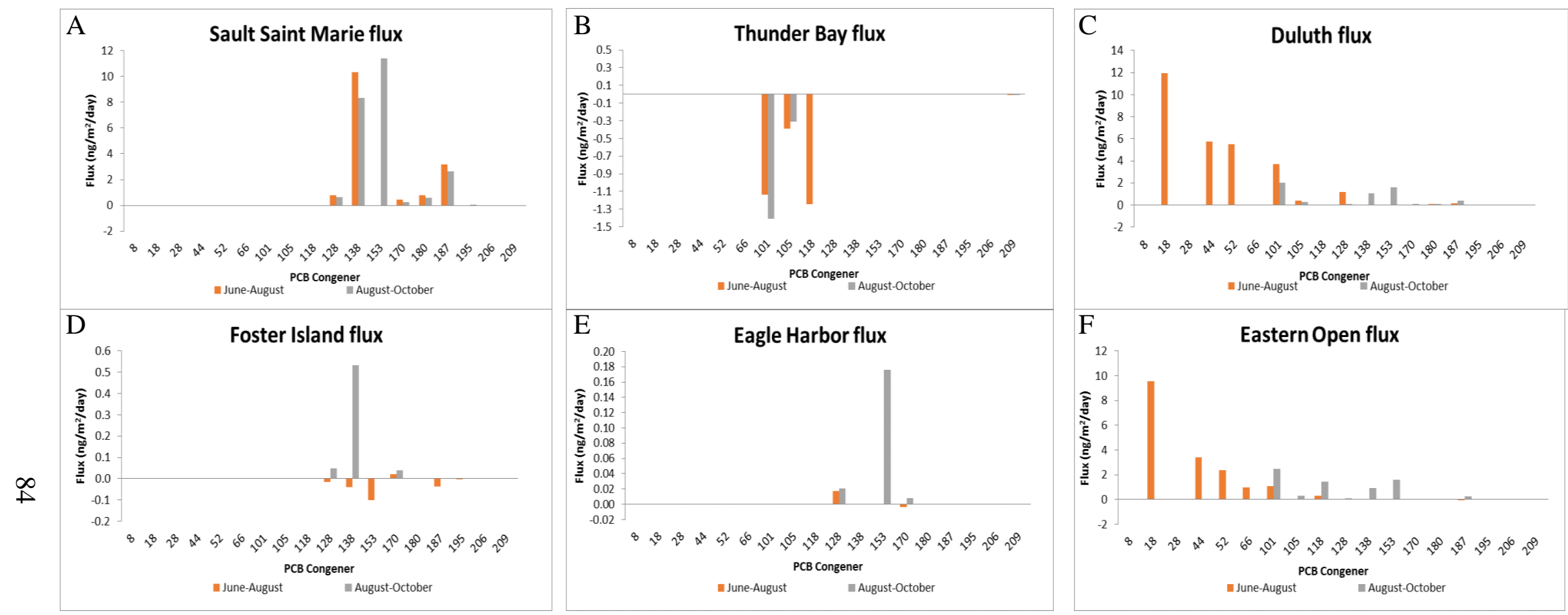

Figure 4.3: PCB flux rates (ng/m²/day) for urban (Sault Saint Marie, Thunder Bay/Welcome Isle, Duluth), rural (Foster Island, Eagle Harbor), and open lake (Eastern) sites. Positive values indicate net volatilization; negative values indicate net deposition. 
SUPPORTING INFORMATION

Total number of tables: $36 \quad$ Figures: $2 \quad$ Pages: 68

\section{CONTENTS}

Sampling proximity to EPA Areas of Concern, National Priority List location,

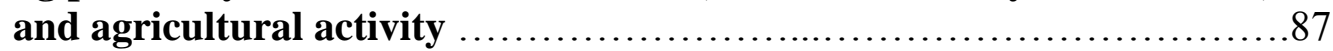

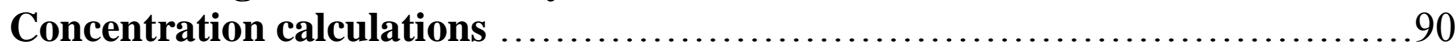

Gas exchange between the atmosphere and water ...........................90

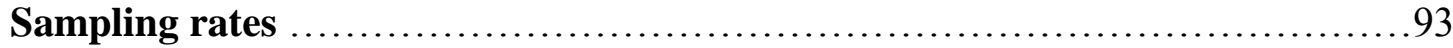

TABLE SI 1: Lake Superior EPA Areas of Concern and National Priority List sites 88

TABLE SI 2: 2006 agricultural land cover within $10 \mathrm{~km}$ of United States sites

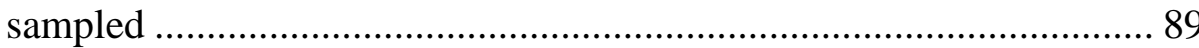

TABLE SI 3: Sampling site information ................................................................. 92

TABLE SI 4: Relevant environmental data: temperature, average wind speed, and pyrene-d10 and brominated biphenyls sampling rates......................... 94

TABLE SI 5: Selected physical constants and equilibrium partitioning constants for all PAH analytes monitored in this study.

TABLE SI 6: Average percent equilibrium achieved during deployment for PAHs derived from calculated sampling rates ............................................. 97

TABLE SI 7: Physicochemical constants for PAHs derived from SPARC ……….... 98

TABLE SI 8: PAH blank corrections ................................................................. 99

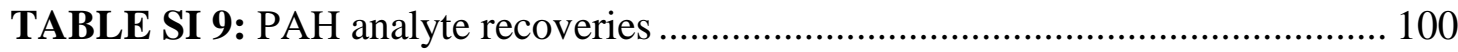

TABLE SI 10: Derived atmospheric concentrations of selected PAHs..................... 101

TABLE SI 11: Derived aqueous concentrations of selected PAHs ............................. 104

TABLE SI 12: Calculated air-water exchange fluxes of selected PAHs ................... 107

TABLE SI 13: Selected physical constants and equilibrium partitioning constants for all PBDE analytes monitored in this study

TABLE SI 14: Average percent equilibrium achieved during deployment for PBDEs derived from calculated sampling rates ............................................ 111

TABLE SI 15: Physicochemical constants for PBDEs derived from SPARC .......... 112

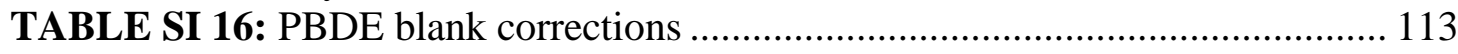

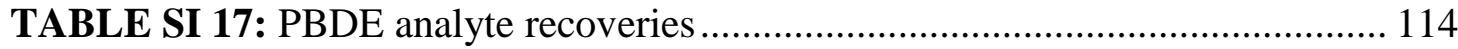

TABLE SI 18: Derived atmospheric concentrations of selected PBDEs ................... 115

TABLE SI 19: Derived aqueous concentrations of selected PBDEs......................... 118

TABLE SI 20: Calculated air-water exchange fluxes of selected PBDEs................. 121

TABLE SI 21: Selected physical constants and equilibrium partitioning constants for all OCP analytes monitored in this study ........................................ 125

TABLE SI 22: Average percent equilibrium achieved during deployment for OCPs derived from calculated sampling rates ............................................ 126

TABLE SI 23: Physicochemical constants for OCPs derived from SPARC ............. 127

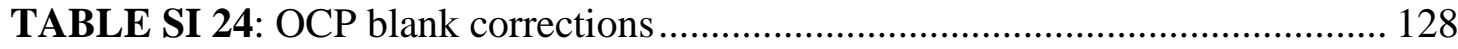


TABLE SI 25: OCP analyte recoveries.......................................................... 129

TABLE SI 26: Derived atmospheric concentrations of selected OCPs ................... 130

TABLE SI 27: Derived aqueous concentrations of selected OCPs ......................... 133

TABLE SI 28: Calculated air-water exchange fluxes of selected OCPs ................. 136

TABLE SI 29: Selected physical constants and equilibrium partitioning constants for all PCB analytes monitored in this study

TABLE SI 30: Average percent equilibrium achieched during deployment for PCBs

derived from calculated sampling rates

TABLE SI 31: Physicochemical constants for PCBs derived from SPARC ............ 141

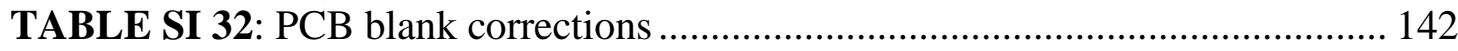

TABLE SI 33: PCB analyte recoveries............................................................ 143

TABLE SI 34: Derived atmospheric concentrations of selected PCBs .................... 144

TABLE SI 35: Derived aqueous concentrations of selected PCBs ........................ 147

TABLE SI 36: Calculated air-water exchange fluxes of selected PCBs ................. 150

FIGURE SI 1: U.S. EPA Areas of Concern and National Priorities List locations ... 87

FIGURE SI 2: Source ratios of PAHs. ........................................................ 124 


\section{Sampling proximity to EPA Areas of Concern, National Priority List locations, and agricultural activity}

The U.S.-Canada Great Lakes Water Quality Agreement (Annex 1 of the 2012 Protocol) defines an AOC as "a geographic area designated by the Parties where significant impairment of beneficial uses has occurred as a result of human activities at the local level" (GLWQA 2012). There are 8 AOCs in the Lake Superior region (FIGURE SI 1). National Priorities List areas are EPA-designated "superfund" sites affected by hazardous substances, pollutants, or contaminants requiring long-term remedial action. There are 6 NPL sites along the U.S. coast of Lake Superior.

Proximity of these impaired locations to PE deployment sites were determined using the ArcGIS (10.1) "Near" tool (TABLE SI 1). U.S. state and Canadian territory data was obtained from the USGS (geonames.usgs.gov/domestic/download_data.htm). All data was converted to the geographic coordinate system GCS_North_American_1983 and projected in the projected coordinate system NAD_1983_UTM_Zone_16N.

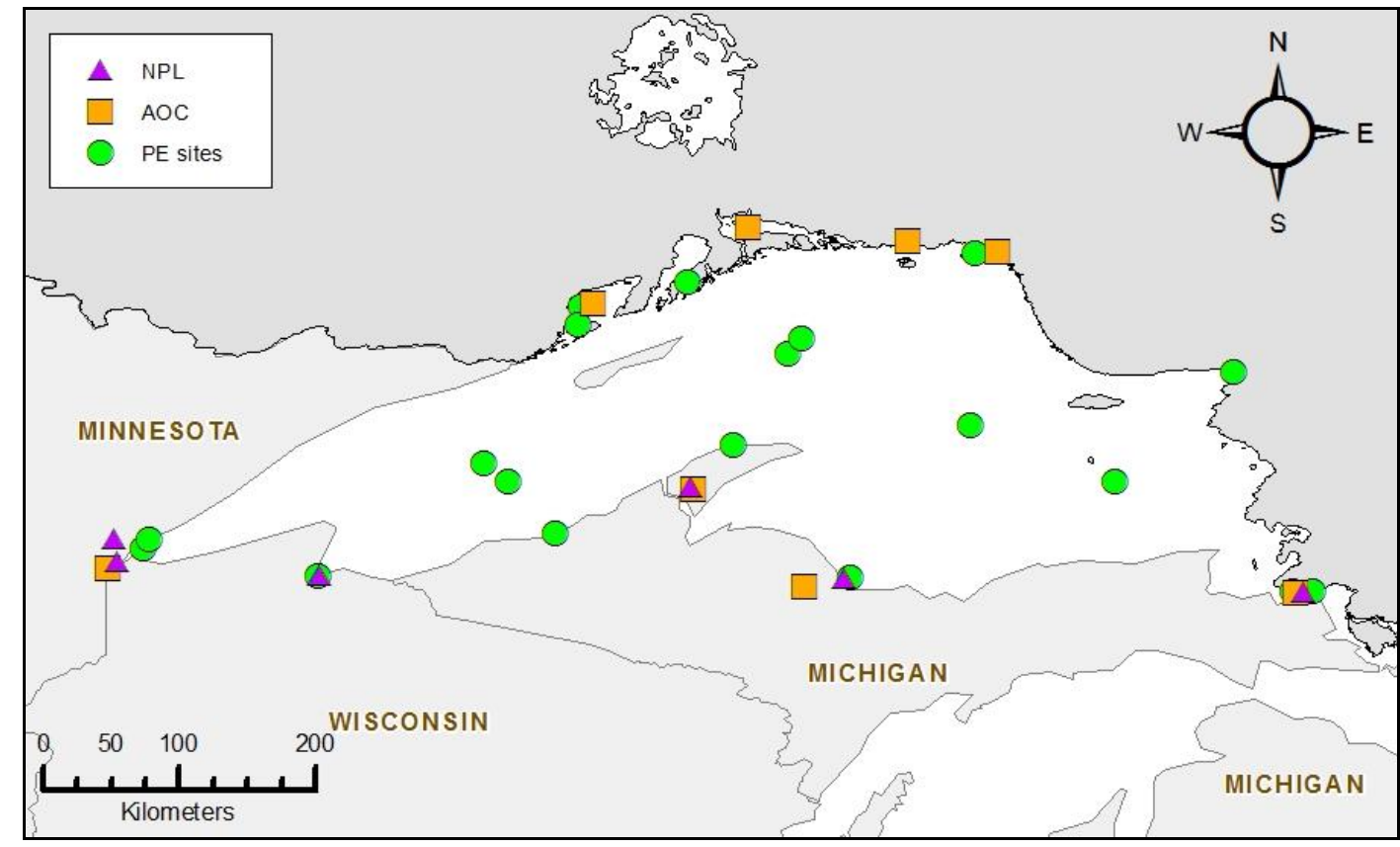

FIGURE SI 1: U.S. EPA Areas of Concern and National Priorities List locations 
TABLE SI 1: Lake Superior EPA Areas of Concern and National Priority List sites

\begin{tabular}{|c|c|c|c|c|}
\hline & \multicolumn{2}{|l|}{ Primary Contaminants } & & $\begin{array}{l}\text { Distance to closest } \\
\text { PF site }(\mathrm{km})\end{array}$ \\
\hline Deer Lake River & \multicolumn{2}{|l|}{ Mercury, historic nutrient loading } & Marquette & 24.0 \\
\hline Jackfish Bay & \multicolumn{2}{|l|}{ Solids (wood fiber), AOX, dioxin } & Foster Island & 34.0 \\
\hline Peninsula Harbour & \multicolumn{2}{|l|}{ Mercury } & Foster Island & 11.0 \\
\hline Nipigon Bay & \multicolumn{2}{|l|}{ Solids, pathogens, biological oxygen demand } & $\begin{array}{l}\text { Sturgeon Bay } \\
\text { Thunder Bay/ }\end{array}$ & 50.0 \\
\hline Thunder Bay & \multicolumn{2}{|l|}{ Pathogens, mercury, PAHs } & Welcome Isle & 6.5 \\
\hline Torch Lake & \multirow{3}{*}{\multicolumn{2}{|c|}{$\begin{array}{l}\text { Copper, mercury, arsenic, lead, chromium, heavy metals } \\
\text { PAHs, mercury, suspended sediment, PCBs, other metals, oil } \\
\text { and Grease, pathogens, nutrients } \\
\text { PAH, arsenic, cyanide, phosphorus, benzene, toluene, oil and } \\
\text { grease, Phenols, ammonia, pathogens/bacteria }\end{array}$}} & $\begin{array}{l}\text { Eagle Harbor } \\
\text { Station 221/ }\end{array}$ & 39.0 \\
\hline St. Louis River & & & Duluth & $22 / 30$ \\
\hline St. Marys River & & & Point Aux Pins & 1.5 \\
\hline \multicolumn{5}{|l|}{ Source: www.epa.gov/glnpo/aoc } \\
\hline National Priorities List Sites & Primary Contaminants & $\begin{array}{l}\text { Cleanup } \\
\text { Status }\end{array}$ & Near PE Site & $\begin{array}{l}\text { Distance to closest } \\
\text { PE site }(\mathrm{km})\end{array}$ \\
\hline Arrowhead Refinery Co. & $\begin{array}{l}\text { PCBs, phenols, cyanide, lead, barium, arsenic, } \\
\text { cadmium, chromium, and selenium } \\
\text { Polynuclear aromatic hydrocarbons and heavy }\end{array}$ & Complete & $\begin{array}{l}\text { Station 221/ } \\
\text { Duluth } \\
\text { Station 221/ }\end{array}$ & $16 / 17$ \\
\hline St. Louis River Site & metals & Underway & Duluth & $16 / 23$ \\
\hline $\begin{array}{l}\text { Ashland/Northern States } \\
\text { Power }\end{array}$ & $\begin{array}{l}\text { Benzo(a)pyrene, benzo(a)anthracene, xylenes, } \\
\text { ethylbenzene, and other VOCs }\end{array}$ & Designed & Ashland & 0.25 \\
\hline Torch Lake & Copper & Complete & Eagle Harbor & 38 \\
\hline Cliff/DOW Dump & $\begin{array}{l}\text { Wood tars, benzene, phenol, xylene, } \\
\text { chloroform, and other toxic constituents }\end{array}$ & Complete & $\begin{array}{l}\text { Marquette } \\
\text { Sault Saint }\end{array}$ & 3.0 \\
\hline Cannelton Industries & Chromium, lead, copper, cyanide, and mercury & Complete & Marie & 4.5 \\
\hline
\end{tabular}


Land use data for the United States was obtained from the National Land Cover Database maintained by the United States Geological Survey

(http://www.mrlc.gov/nlcd06_data.php). The most recent dataset compiled represented land use from 2006. Designation of use had a 30x30-meter resolution. The image map from NLCD was converted to a raster and clipped to a 10-kilometer buffer created around each sampling site. Agricultural use was selected in the attribute table and the number of pixels with that use were calculated using the "Zonal Statistics as Table" tool. Pixel counts were converted to area according to the $30 \times 30$ meter pixel size.

TABLE SI 2: 2006 agricultural land cover within $10 \mathrm{~km}$ of United States sites sampled

\begin{tabular}{lc}
\hline Site & $\begin{array}{c}\text { Agricultural area } \\
\left(\mathrm{km}^{2}\right)\end{array}$ \\
\hline Ontonagon & 715 \\
Point Aux Pins & 700 \\
Duluth & 433 \\
Ashland & 294 \\
Sault Saint Marie & 97 \\
Stn221 & 91 \\
Marquette & 21 \\
Eagle Harbor & 5
\end{tabular}




\section{Concentration calculations}

Analyte responses from GC/MS analysis are converted to concentrations (ng/PE) by:

$$
\mathrm{C}_{\mathrm{PEa}}=\left(\mathrm{R}_{\mathrm{a}} / \mathrm{R}_{\mathrm{s}}\right) *\left(\mathrm{C}_{\mathrm{s}} / \text { slope of standard curve }\right)
$$

where $R_{a}$ is the analyte response, $R_{s}$ is the surrogate response, and $C_{s}$ is the concentration of surrogate added. This calculation corrects for losses in recovery. The percent of recovery is determined by

$$
\text { \%recovery }=\mathrm{C}_{\mathrm{PEs}} / \mathrm{C}_{\mathrm{s}}
$$

where $\mathrm{C}_{\mathrm{PEs}}(\mathrm{pg} / \mathrm{PE})$ is the concentration of surrogate recovered in the $\mathrm{PE}$ after sample processing

$$
\mathrm{C}_{\mathrm{PEs}}=\left(\mathrm{R}_{\mathrm{s}} / \mathrm{R}_{\mathrm{i}}\right) *\left(\mathrm{C}_{\mathrm{i}} / \text { slope of standard curve }\right)
$$

\section{Gas exchange between the atmosphere and water}

Calculations of air-water exchange are based on a modified two-film resistance model. Flux (ng/m²/day) is reported by Schwarzenbach et al. 2003 as

$$
\text { Flux }=\mathrm{k}_{\mathrm{ol}} *\left(\mathrm{C}_{\mathrm{W}}-\mathrm{C}_{\mathrm{A}} / \mathrm{K}_{\mathrm{AW}}\right)
$$

where is $\mathrm{k}_{\mathrm{ol}}$ is mass transfer coefficient (m/day), $\mathrm{C}_{\mathrm{W}}$ is the PBT concentration in water (ng/L), $\mathrm{C}_{\mathrm{A}}$ is the PBT concentration in air (ng/L), and $\mathrm{K}_{\mathrm{AW}}$ is the partitioning coefficient from water to air. We modified this equation to minimize uncertainties associated with the Henry's Law constant, where

$$
\begin{gathered}
\mathrm{C}_{\mathrm{W}}=\mathrm{C}_{\text {eqW }} / \mathrm{K}_{\mathrm{PEW}} \\
\mathrm{C}_{\mathrm{A}}=\mathrm{C}_{\mathrm{eqA}} / \mathrm{K}_{\mathrm{PEA}} \\
\mathrm{K}_{\mathrm{AW}}=\mathrm{C}_{\mathrm{A}} / \mathrm{C}_{\mathrm{W}}
\end{gathered}
$$

Therefore,

$$
\begin{gathered}
\text { Flux }=\mathrm{k}_{\mathrm{ol}} *\left[\left(\mathrm{C}_{\mathrm{eqW}} / \mathrm{K}_{\mathrm{PEW}}\right)-\left(\mathrm{C}_{\mathrm{eqA}} / \mathrm{K}_{\mathrm{PEA}} * \mathrm{~K}_{\mathrm{AW}}\right)\right] \\
\text { Flux }=\mathrm{k}_{\mathrm{ol}} *\left[\left(\mathrm{C}_{\mathrm{eqW}} / \mathrm{K}_{\mathrm{PEW}}\right)-\left(\mathrm{C}_{\mathrm{eqA}} /\left(\mathrm{C}_{\mathrm{eq}} / \mathrm{C}_{\mathrm{w}}\right)\right)\right] \\
\text { Flux } \left.=\mathrm{k}_{\mathrm{ol}} *\left[\left(\mathrm{C}_{\mathrm{eqW}}-\mathrm{C}_{\mathrm{eqA}}\right) / \mathrm{K}_{\mathrm{PEW}}\right)\right]
\end{gathered}
$$

where $\mathrm{C}_{\mathrm{eqW}}$ is the $\mathrm{PBT}$ concentration in the $\mathrm{PE}$ when in equilibrium with the surrounding water and $\mathrm{C}_{\text {eqA }}$ is the $\mathrm{PBT}$ concentration in the $\mathrm{PE}$ when in equilibrium with the surrounding air. The reciprocal of $\mathrm{k}_{\mathrm{ol}}$ is the sum of the resistance to mass transfer in the air and water:

$$
1 / \mathrm{k}_{\mathrm{ol}}=1 / \mathrm{k}_{\mathrm{w}}+1 /\left(\mathrm{k}_{\mathrm{a}} * \mathrm{H}^{\prime}\right)
$$

where $\mathrm{k}_{\mathrm{w}}$ is the air-side mass transfer coefficient, $\mathrm{k}_{\mathrm{a}}$ is the air-side mass transfer coefficient and H' is the $\mathrm{K}_{\mathrm{aw}}$, or, the dimensionless Henry's Law constant. Temperature-corrected $\mathrm{K}_{\mathrm{aw}}$ values for PAHs were calculated following Ma et al. (2010). Temperature-corrected $\mathrm{K}_{\mathrm{aw}}$ values for PBDEs were calculated by

$$
\mathrm{H} /(\mathrm{R} * \mathrm{~T})
$$

Where $\mathrm{H}$ is the temperature-corrected Henry's Law constant from SPARC (https://archemcalc.com/sparc), $\mathrm{R}$ is the gas constant, and $\mathrm{T}$ is the sampling temperature.

The rate of transfer is related to the molecular diffusivity, thus $\mathrm{k}_{\mathrm{w}}$ and $\mathrm{k}_{\mathrm{a}}$ for specific compounds can be predicted by

where

$$
\begin{aligned}
\mathrm{k}_{\mathrm{w}} & =\mathrm{k}_{\mathrm{w}(\mathrm{CO} 2)} *\left[\mathrm{Sc} / \mathrm{Sc}_{(\mathrm{CO} 2)}\right]^{-1 / 2} \\
\mathrm{k}_{\mathrm{a}} & =\mathrm{k}_{\mathrm{a}(\mathrm{H} 2 \mathrm{O})} *\left[\mathrm{D}_{\mathrm{a}} / \mathrm{D}_{\mathrm{a}(\mathrm{H} 2 \mathrm{O})}\right]^{0.67}
\end{aligned}
$$

$$
\begin{gathered}
\mathrm{k}_{\mathrm{w}(\mathrm{CO} 2)}=0.45 * \mathrm{u}_{10}{ }^{1.64} \\
\mathrm{k}_{\mathrm{a}(\mathrm{H} 2 \mathrm{O})} \approx 0.2 * \mathrm{u}_{10}+0.3
\end{gathered}
$$


$\mathrm{u}_{10}$ is the windspeed at ten meters above the water surface obtained from the NOAA National Data Buoy Center (http://www.ndbc.noaa.gov/). Sc is the Schmidt number calculated for each analyte estimated from Schwarzenbach et al. (2 ${ }^{\text {nd }}$ Ed. 2003) by dividing the kinematic viscosity of water by the temperature-dependent molecular diffusivity of the compound in water $\left(\mathrm{D}_{\mathrm{w}}, \mathrm{cm}^{2} / \mathrm{s}\right.$ ) obtained from SPARC (October 2012, https://archemcalc.com/sparc). $D_{a}$ is the temperature-dependent diffusivity of individual compounds in air. Both $\mathrm{D}_{\mathrm{a}}$ and $\mathrm{D}_{\mathrm{a}(\mathrm{H} 2 \mathrm{O})}$ were obtained from SPARC.

Air-water exchange was determined to be significant by the magnitude of the $\mathrm{C}_{\mathrm{eqA}} / \mathrm{C}_{\mathrm{eq}} \mathrm{W}$ ratio, where values $>1$ signify deposition from the air to the water, and values $<1$ demonstrate net volatilization. The range of ratios where air-water exchange does not significantly deviate from equilibrium $(0.137-3.91)$ was determined by error propagation (Glover et al. 2011):

$$
\sigma_{\mathrm{y}}^{2}=\sigma_{\mathrm{a}}^{2}\left(\partial_{\mathrm{y}} / \partial_{\mathrm{a}}\right)^{2}+\sigma_{\mathrm{b}}^{2}\left(\partial_{\mathrm{y}} / \partial_{\mathrm{b}}\right)^{2}
$$

where $\sigma$ is the standard deviation, $\sigma^{2}$ is variance, and a and $b$ represent the components of the equation contributing to the uncertainty. Error was propagated from the uncertainty of the calculated $\mathrm{K}_{\mathrm{PEW}(\mathrm{T})}(\mathrm{SE}=0.27)$ based upon the value reported by Lohmann (2012) and the uncertainty of $\Delta \mathrm{H}_{\mathrm{KPEW}}(50 \%)$ determined by Morgan and Lohmann (2008).

$$
\begin{gathered}
\mathrm{K}_{\mathrm{PEW}(\mathrm{T})}=\mathrm{K}_{\mathrm{PEW}(298 \mathrm{~K})} * \mathrm{e}^{(-(\Delta \mathrm{Hvap} / \mathrm{R}) *[(1 / 298 \mathrm{~K})-(1 / \mathrm{T})])} \\
\operatorname{var}\left[\mathrm{K}_{\mathrm{PEW}(\mathrm{T})}\right]=\operatorname{var}\left[\mathrm{K}_{\mathrm{PEW}(298)]}\right]\left(\partial \mathrm{K}_{\mathrm{PEW}(\mathrm{T})} / \partial \mathrm{K}_{\mathrm{PEW}(298)}\right)^{2}+\operatorname{var}\left[\Delta \mathrm{H}_{\mathrm{KPEW}}\right]\left(\partial \mathrm{K}_{\mathrm{PEW}(\mathrm{T})} /\right. \\
\left.\partial \Delta \mathrm{H}_{\mathrm{KPEW}}\right)^{2}
\end{gathered}
$$

$\operatorname{var}\left[\mathrm{K}_{\mathrm{PEW}(\mathrm{T})}\right]$ was calculated for each $\Delta \mathrm{H}_{\mathrm{KPEW}}$ and then averaged for all temperatures. Next, the variation for the percent equilibrium $(\% \mathrm{Eq})$ was calculated for each site based upon the variation of $\mathrm{K}_{\mathrm{PEW}(\mathrm{T})}$ and the uncertainty of the sampling rate (Rs) model (10\%) (Lohmann et al. 2012), then averaged for every compound:

$$
\begin{gathered}
\% \mathrm{Eq}=1-\mathrm{e}^{[(-\mathrm{Rs} * \mathrm{t}) / \mathrm{V} * \mathrm{KPEW}(\mathrm{T}))]} \\
\operatorname{var}[\% \mathrm{Eq}]=\operatorname{var}[\mathrm{Rs}](\partial \% \mathrm{Eq} / \partial \mathrm{Rs})^{2}+\operatorname{var}[\operatorname{KPEW}(\mathrm{T})]\left(\partial \% \mathrm{Eq} / \partial \mathrm{K}_{\mathrm{PEW}(\mathrm{T})}\right)^{2}
\end{gathered}
$$

Finally, the variance of the air-water flux calculation was determined by the variance of $\% \mathrm{Eq}$ and $\mathrm{K}_{\mathrm{PEW}(\mathrm{T}) \text { : }}$

$$
\begin{gathered}
\text { Flux }=\mathrm{k}_{\mathrm{ol}} *\left[\left(\mathrm{C}_{\text {eqW }}-\mathrm{C}_{\text {eqA }}\right) / \mathrm{K}_{\mathrm{PEW}}\right] \\
\operatorname{var}\left[\mathrm{Flux} / \mathrm{k}_{\mathrm{ol}}\right]=\operatorname{var}[\% \mathrm{Eq}](\partial \mathrm{Flux} / \partial \% \mathrm{Eq})^{2}+\operatorname{var}\left[\mathrm{K}_{\mathrm{PEW}(\mathrm{T})}\right]\left(\partial \% \mathrm{Flux} / \partial \mathrm{K}_{\mathrm{PEW}(\mathrm{T})}\right)^{2}
\end{gathered}
$$


TABLE SI 3: Sampling site information

\begin{tabular}{|c|c|c|c|c|c|c|}
\hline Site & Reservoir & Latitude & Longitude & Deployment 1 & Deployment 2 & Deployment 3 \\
\hline \multirow[t]{2}{*}{ Sault Saint Marie } & Air & $4630^{\prime} 0^{\prime \prime}$ & $8420^{\prime} 0^{\prime \prime}$ & $4 / 25 / 11-6 / 10 / 11$ & $6 / 10 / 11-7 / 29 / 11$ & $7 / 29 / 11-10 / 5 / 11$ \\
\hline & Water & $4630^{\prime} 0^{\prime \prime}$ & $8420^{\prime} 0^{\prime \prime}$ & $4 / 25 / 11-6 / 10 / 11$ & $6 / 10 / 11-7 / 29 / 11$ & $7 / 29 / 11-10 / 5 / 11$ \\
\hline \multirow[t]{2}{*}{ Marquette } & Air & $4632^{\prime} 37^{\prime \prime}$ & $8723^{\prime} 43^{\prime \prime}$ & $4 / 28 / 11-6 / 13 / 11$ & $6 / 13 / 11-7 / 27 / 11$ & $7 / 27 / 11-9 / 30 / 11$ \\
\hline & Water & $4632^{\prime} 37^{\prime \prime}$ & $8723^{\prime} 43^{\prime \prime}$ & $4 / 28 / 11-6 / 13 / 11$ & $6 / 13 / 11-7 / 27 / 11$ & \\
\hline \multirow[t]{2}{*}{ Eagle Harbor } & Air & $47^{\circ} 27^{\prime} 34.4^{\prime \prime}$ & $88^{\circ} 8^{\prime} 56.5^{\prime \prime}$ & 4/26/11-6/1/11 & 6/1/11-8/1/11 & $8 / 1 / 11-10 / 1 / 11$ \\
\hline & Water & $47^{\circ} 27^{\prime} 31.8^{\prime \prime}$ & $88^{\circ} 10^{\prime} 5.0^{\prime \prime}$ & & $7 / 1 / 11-8 / 1 / 11$ & $8 / 1 / 11-10 / 1 / 11$ \\
\hline Ashland & Air & 46 35' 33" & $9053^{\prime} 2^{\prime \prime}$ & $4 / 28 / 11-5 / 31 / 11$ & $5 / 31 / 11-8 / 1 / 11$ & $8 / 1 / 11-10 / 5 / 11$ \\
\hline & Water & $4635^{\prime} 33^{\prime \prime}$ & $9053^{\prime} 2^{\prime \prime}$ & $4 / 28 / 11-5 / 31 / 11$ & $5 / 31 / 11-8 / 1 / 11$ & $8 / 1 / 11-10 / 5 / 11$ \\
\hline \multirow[t]{2}{*}{ Duluth } & Air & $4647^{\prime} 0^{\prime \prime}$ & 92 6' 23" & $4 / 28 / 11-6 / 1 / 11$ & 6/1/11-8/9/11 & $8 / 9 / 11-9 / 29 / 11$ \\
\hline & Water* & & & & & \\
\hline \multirow[t]{2}{*}{ Sturgeon Bay } & Air & $4831^{\prime} 36.4^{\prime \prime}$ & $8826^{\prime} 54.5^{\prime \prime}$ & & $6 / 2 / 11-7 / 26 / 11$ & $7 / 26 / 11-9 / 22 / 11$ \\
\hline & Water & $4831^{\prime} 41.4^{\prime \prime}$ & $8826^{\prime} 56.0^{\prime \prime}$ & & $6 / 2 / 11-7 / 26 / 11$ & $7 / 26 / 11-9 / 22 / 11$ \\
\hline Foster Island & Air & $4843^{\prime} 22.3$ & $8832^{\prime} 53.2^{\prime \prime}$ & & $6 / 3 / 11-7 / 27 / 11$ & $7 / 27 / 11-9 / 23 / 11$ \\
\hline & Water & $4843^{\prime} 25.6$ & 8832 ' 57.1" & & $6 / 3 / 11-7 / 27 / 11$ & $7 / 25 / 11-9 / 23 / 11$ \\
\hline \multirow[t]{2}{*}{ Michopicoten Bay } & Air & $4756^{\prime} 38.3^{\prime \prime}$ & $8451^{\prime} 21.0^{\prime \prime}$ & & $6 / 5 / 11-7 / 28 / 11$ & $7 / 28 / 11-9 / 23 / 11$ \\
\hline & Water & $4756^{\prime} 35.7$ & $8451^{\prime} 20.8^{\prime \prime}$ & & $6 / 5 / 11-7 / 28 / 11$ & $7 / 28 / 11-9 / 23 / 11$ \\
\hline \multirow[t]{2}{*}{ Thunder Bay/Welcome Isle } & Air & $4821^{\prime} 59.4^{\prime \prime}$ & 89 9' 35.0" & & $5 / 31 / 11-7 / 25 / 11$ & $7 / 25 / 11-9 / 21 / 11$ \\
\hline & Water & $4822^{\prime} 2.5^{\prime \prime}$ & 89 9' 31.7 & & $5 / 31 / 11-7 / 25 / 11$ & $7 / 25 / 11-9 / 21 / 11$ \\
\hline \multirow[t]{2}{*}{ Point Aux Pins } & Air & $4629^{\prime} 35.7^{\prime \prime}$ & $8427^{\prime} 50.9^{\prime \prime}$ & & $6 / 6 / 11-7 / 29 / 11$ & $7 / 29 / 11-9 / 24 / 11$ \\
\hline & Water & $4629^{\prime} 34.6 "$ & $8427^{\prime} 54.9 "$ & & $6 / 6 / 11-7 / 29 / 11$ & $7 / 29 / 11-9 / 24 / 11$ \\
\hline \multirow[t]{2}{*}{ Ontonagon } & Air & $46^{\circ} 52^{\prime} 24^{\prime \prime}$ & $89^{\circ} 19^{\prime} 30^{\prime \prime}$ & & $6 / 1 / 11-8 / 1 / 11$ & $8 / 1 / 11-9 / 30 / 11$ \\
\hline & Water & $46^{\circ} 52^{\prime} 24^{\prime \prime}$ & $89^{\circ} 19^{\prime} 30^{\prime \prime}$ & & $6 / 1 / 11-8 / 1 / 11$ & $8 / 1 / 11-9 / 30 / 11$ \\
\hline ODAS45001 & Air & $483^{\prime} 42^{\prime \prime}$ & $8747^{\prime} 27^{\prime \prime}$ & & $5 / 12 / 11-8 / 3 / 11$ & $8 / 3 / 11-10 / 2 / 11$ \\
\hline Stn113 & Water & 48 9' $25^{\prime \prime}$ & $8742^{\prime} 00^{\prime \prime}$ & & $5 / 12 / 11-8 / 3 / 11$ & $8 / 3 / 11-10 / 3 / 11$ \\
\hline ODAS45004 & Air & $4735^{\prime} 7^{\prime \prime}$ & $8635^{\prime} 12^{\prime \prime}$ & & $5 / 19 / 11-7 / 28 / 11$ & $7 / 28 / 11-9 / 28 / 11$ \\
\hline Stn23 & Water & $4712^{\prime} 52^{\prime \prime}$ & $8538^{\prime} 8^{\prime \prime}$ & & $5 / 11 / 11-7 / 27 / 11$ & $7 / 27 / 11-9 / 27 / 11$ \\
\hline ODAS45006 & Air & $4720^{\prime} 2^{\prime \prime}$ & $8947^{\prime} 41^{\prime \prime}$ & & $5 / 16 / 11-7 / 29 / 11$ & $7 / 29 / 11-10 / 2 / 11$ \\
\hline Stn169 & Water & $4712^{\prime} 45^{\prime \prime}$ & $8937^{\prime} 55^{\prime \prime}$ & & $5 / 16 / 11-7 / 29 / 11$ & $7 / 29 / 11-10 / 2 / 11$ \\
\hline Stn221 & Water & $4646^{\prime} 20^{\prime \prime}$ & $922^{\prime} 39^{\prime \prime}$ & & $5 / 17 / 11-7 / 31 / 11$ & $7 / 31 / 11-10 / 1 / 11$ \\
\hline Stn139 & Water & $4815^{\prime} 5^{\prime \prime}$ & $8910^{\prime} 40^{\prime \prime}$ & & $5 / 13 / 11-8 / 1 / 11$ & $8 / 1 / 11-9 / 29 / 11$ \\
\hline
\end{tabular}

Blank deployment dates indicate a PE that was not deployed or not recovered

* Station 221, approximately $3 \mathrm{~km}$ off shore from Duluth was used as a surrogate for Duluth water concentrations 


\section{Sampling rates}

Sampling rates were determined using performance reference compound equilibrium according to Booij and Smedes (2010):

$$
\mathrm{R}_{\mathrm{s}}=-\left(\left[\ln \left(\mathrm{N} / \mathrm{N}_{0}\right)\right] / \mathrm{t}\right) * \mathrm{~K}_{\mathrm{PEW}} * \mathrm{~V}_{\mathrm{PE}}
$$

Equilibrium $(f)$ for analytes was estimated by rearranging the preceding equation to yield

$$
f=\exp \left(-\left(\mathrm{R}_{\mathrm{s}} * \mathrm{t} / \mathrm{K}_{\mathrm{PEW}} * \mathrm{~V}_{\mathrm{PE}}\right)\right.
$$

Derived sampling rates are reported in Table SI 2. Samplers deployed in the water at Canadian coastal sites were housed in steel "spider" carrier cages (Environmental Sampling Technologies, http://www.est-lab.com/spmd.php). Open lake water samplers deployed at Environment Canada buoys were housed in open-ended copper pipes. All other water samplers were attached to moorings using only a single stainless steel wire, possibly explaining the higher sampling rates. 
TABLE SI 4: Relevant environmental data: temperature $\left({ }^{\circ} \mathrm{C}\right)$, average wind speed $(\mathrm{m} / \mathrm{s})$, and pyrene- $\mathrm{d} 10$ and brominated biphenyls sampling rates (air $\mathrm{m}^{3} /$ day; water $\mathrm{L} /$ day)

\begin{tabular}{|c|c|c|c|c|c|c|c|c|c|c|c|c|}
\hline \multirow[b]{3}{*}{ Site } & \multicolumn{12}{|c|}{ Air } \\
\hline & \multicolumn{4}{|c|}{ Deployment 1} & \multicolumn{4}{|c|}{ Deployment 2} & \multicolumn{4}{|c|}{ Deployment 3} \\
\hline & $\begin{array}{l}\text { Average } \\
\text { wind } \\
\text { speed }\end{array}$ & Temperature & $\begin{array}{c}\text { Pyrene-d10 } \\
R_{s}\end{array}$ & $\begin{array}{c}\text { Brominated } \\
\text { Biphenyls } \\
\mathrm{R}_{\mathrm{s}}\end{array}$ & $\begin{array}{l}\text { Average } \\
\text { wind } \\
\text { speed }\end{array}$ & Temperature & $\begin{array}{c}\text { Pyrene-d10 } \\
\mathrm{R}_{\mathrm{s}}\end{array}$ & $\begin{array}{c}\text { Brominated } \\
\text { Biphenyls } \\
R_{s}\end{array}$ & $\begin{array}{l}\text { Average } \\
\text { wind } \\
\text { speed }\end{array}$ & Temperature & $\begin{array}{c}\text { Pyrene-d10 } \\
R_{s}\end{array}$ & $\begin{array}{c}\text { Brominated } \\
\text { Biphenyls } \\
\mathrm{R}_{\mathrm{s}}\end{array}$ \\
\hline Sault Saint Marie & 3.5 & 10.91 & $15.75^{a}$ & $30^{\mathrm{a}}$ & 2.8 & 17.88 & 12 & 50 & 2.8 & 16.79 & $10^{\mathrm{a}}$ & $35^{\mathrm{a}}$ \\
\hline Point Aux Pins & & & & & 3.6 & 17.72 & 30 & 100 & 3.5 & 17.21 & 50 & 120 \\
\hline $\begin{array}{l}\text { Ashland } \\
\text { Thunder Bay }\end{array}$ & 2.7 & 9.03 & 0.6 & 40 & 2.5 & 18.31 & 6.5 & 20 & 2.9 & 16.29 & 9.0 & 35 \\
\hline $\begin{array}{l}\text { Welcome Isle } \\
\text { Station } 139\end{array}$ & & & & & 7.0 & 15.47 & 24 & 50 & 6.4 & 16.32 & $37.5^{\mathrm{a}}$ & $95^{a}$ \\
\hline Marquette & 4.2 & 8.4 & 14 & 40 & 3.6 & 16.44 & $14^{\mathrm{a}}$ & $25^{a}$ & 4.8 & 17.25 & N/A & 30 \\
\hline $\begin{array}{l}\text { Ontonagon } \\
\text { Duluth/Station }\end{array}$ & & & & & 3.0 & 15.03 & 8.5 & 8.0 & $3.5^{d}$ & 17.25 & 9.0 & 20 \\
\hline $\begin{array}{l}221 \\
\text { Michopicoten }\end{array}$ & 4.1 & 7.32 & 3.0 & 30 & 4.0 & 16.75 & 8.5 & 8.0 & 3.6 & 17.45 & 4.3 & 45 \\
\hline Bay* & & & & & $3.9^{b}$ & 15.01 & $55^{\mathrm{a}}$ & $57.5^{\mathrm{a}}$ & $4.6^{\mathrm{e}}$ & 16.67 & 45 & 70 \\
\hline Sturgeon Bay & & & & & 5.4 & 14.16 & 70 & 70 & 6.3 & 16.52 & 50 & 100 \\
\hline Foster Island* & & & & & 3.7 & 13.28 & 37 & 65 & 4.9 & 16.06 & 40 & 85 \\
\hline Eagle Harbor & 3.0 & 7.78 & 18 & 40 & 2.0 & 15.8 & 7.5 & 20 & 2.8 & 17.25 & N/A & 35 \\
\hline ODAS45004 & & & & & $4.0^{c}$ & 9.23 & $4.5^{\mathrm{g}}$ & $20^{\mathrm{g}}$ & 4.2 & 14.27 & 4.5 & 20 \\
\hline $\operatorname{Stn} 23$ & & & & & & & & & & & & \\
\hline $\begin{array}{l}\text { ODAS45001 } \\
\text { Stn113 }\end{array}$ & & & & & 4.4 & 7.33 & $20^{\mathrm{g}}$ & $40^{\mathrm{g}}$ & 5.3 & 14.19 & 20 & 40 \\
\hline $\begin{array}{l}\text { ODAS45006 } \\
\text { Stn169 }\end{array}$ & & & & & 3.9 & 8.11 & $50^{\mathrm{g}}$ & $80^{\mathrm{g}}$ & 4.1 & 15.93 & 50 & 80 \\
\hline
\end{tabular}




\section{TABLE SI 4 (continued)}

\begin{tabular}{|c|c|c|c|c|c|c|c|c|c|}
\hline & \multicolumn{9}{|c|}{ Water } \\
\hline \multirow[b]{2}{*}{ Site } & \multicolumn{3}{|c|}{ Deployment 1} & \multicolumn{3}{|c|}{ Deployment 2} & \multicolumn{3}{|c|}{ Deployment 3} \\
\hline & Temperature & $\begin{array}{c}\text { Pyrene-d10 } \\
\mathrm{R}_{\mathrm{s}} \\
\end{array}$ & $\begin{array}{l}\text { Brominated } \\
\text { Biphenyls } R_{s}\end{array}$ & Temperature & $\begin{array}{c}\text { Pyrene-d10 } \\
\mathrm{R}_{\mathrm{s}}\end{array}$ & $\begin{array}{l}\text { Brominated } \\
\text { Biphenyls } R_{s}\end{array}$ & Temperature & $\begin{array}{c}\text { Pyrene-d10 } \\
\mathrm{R}_{\mathrm{s}}\end{array}$ & $\begin{array}{l}\text { Brominated } \\
\text { Biphenyls Rs }\end{array}$ \\
\hline Sault Saint Marie & 6.08 & $6.5^{\mathrm{a}}$ & $17^{a}$ & 15.16 & 10 & 25 & 20.25 & $10.67^{a}$ & $35^{a}$ \\
\hline Point Aux Pins & & & & 15.19 & N/A & 11 & 19.57 & 2.5 & 13 \\
\hline Ashland & 6.08 & 5.5 & 60 & $11.67^{f}$ & 10 & 40 & $14.21^{f}$ & 12 & 55 \\
\hline Thunder Bay Welcome Isle & & & & 12.23 & 4.0 & 16 & 14.44 & $6.5^{\mathrm{a}}$ & $25^{\mathrm{a}}$ \\
\hline Station 139 & & & & 12.23 & $8.5^{\mathrm{g}}$ & $90^{\mathrm{g}}$ & 14.44 & 8.5 & 90 \\
\hline Marquette & 6.08 & 8.5 & 20 & $11.67^{f}$ & $13.8^{\mathrm{a}}$ & $50^{\mathrm{a}}$ & N/A & N/A & N/A \\
\hline Ontonagon & & & & $11.67^{f}$ & 11 & 50 & $14.21^{f}$ & 15 & 75 \\
\hline Duluth/Station 221 & & & & $11.67^{f}$ & $8.0^{\mathrm{g}}$ & $90^{\mathrm{g}}$ & $14.21^{f}$ & 8.0 & 90 \\
\hline Michopicoten Bay* & & & & $11.67^{f}$ & $5.65^{\mathrm{a}}$ & $27.5^{\mathrm{a}}$ & $14.21^{f}$ & 11 & 40 \\
\hline Sturgeon Bay & & & & 11.35 & 0.45 & 18 & 13.98 & 4.5 & 13 \\
\hline Foster Island* & & & & $11.67^{f}$ & 2.3 & 10 & 16.3 & 6.5 & 25 \\
\hline Eagle Harbor & & & & $11.67^{f}$ & 25 & 60 & $14.21^{f}$ & 15 & 70 \\
\hline ODAS45004 & & & & & & & & & \\
\hline $\operatorname{Stn} 23$ & & & & 6.53 & $7.0^{\mathrm{g}}$ & $110^{\mathrm{g}}$ & 13.46 & 7.0 & 110 \\
\hline ODAS45001 & & & & & & & & & \\
\hline $\operatorname{Stn} 113$ & & & & 5.4 & $8.0^{\mathrm{g}}$ & $150^{\mathrm{g}}$ & 14.38 & 8.0 & 150 \\
\hline ODAS45006 & & & & & & & & & \\
\hline $\operatorname{Stn} 169$ & & & & 5.77 & $14 \mathrm{~g}$ & $150^{\mathrm{g}}$ & 15.62 & 14 & 150 \\
\hline
\end{tabular}

Temperatures averaged over deployment time with data from http://www.glos.us/obs/station, http://www.crh.noaa.gov/greatlakes, http://www.nodc.noaa.gov

Wind speed averaged over deployment time from NOAA National Data Buoy Center (http://www.ndbc.noaa.gov/) data. Sites with (*) did not have available data and denote an average wind speed derived from nearby sites

aReplicate Average

${ }^{\mathrm{b}}$ Average of Foster Island and ODAS45004

'Average of Point Aux Pins and ODAS45001

${ }^{\mathrm{d} A v e r a g e}$ of Ashland and ODA45006

${ }^{\mathrm{e}}$ Average of Foster Island and ODAS45004

${ }^{\mathrm{f}}$ Average of Sturgeon Bay and Thunder Bay

gNo PRCs used in PEs, so sampling rates assumed to be the same as the third deployment 
TABLE SI 5: Selected physical constants and equilibrium partitioning constants for all PAH analytes monitored in this study.

\begin{tabular}{|c|c|c|c|c|c|c|c|}
\hline Compound & Ion & $\begin{array}{c}\mathbf{M W}^{\mathbf{b}} \\
(\mathrm{g} / \mathrm{mol})\end{array}$ & $\log _{\mathrm{PEa}}{ }^{b}$ & $\operatorname{logK}_{P E w}{ }^{c}$ & $\log _{a w}{ }^{d}$ & $\begin{array}{c}\Delta \mathrm{HPEa}^{\mathrm{e}} \\
(\mathrm{kJ} / \mathrm{mol})\end{array}$ & $\begin{array}{c}\Delta \mathrm{H}_{\text {PEw }}{ }^{\mathrm{f}} \\
(\mathrm{kJ} / \mathrm{mol})\end{array}$ \\
\hline Naphthalene & 128 & 128.2 & 4.9 & 3.2 & -1.7 & 55.4 & 25 \\
\hline Biphenyl & 154 & 154.2 & 6.1 & 3.8 & -2.2 & 67.6 & 25 \\
\hline Acenaphthylene & 152 & 152.2 & 5.9 & 3.7 & -2.2 & 66.9 & 25 \\
\hline Acenaphthene & 153 & 154.2 & 6.0 & 3.8 & -2.2 & 66.5 & 25 \\
\hline Fluorene & 166 & 166.2 & 6.5 & 4.0 & -2.5 & 72.1 & 25 \\
\hline Phenanthrene & 178 & 178.2 & 7.0 & 4.3 & -2.7 & 78.3 & 25 \\
\hline Anthracene & 178 & 178.2 & 7.2 & 4.3 & -2.7 & 79.9 & 25 \\
\hline Methyl phenanthrenes ${ }^{a}$ & 192 & 192.3 & 7.8 & 4.6 & -3 & 100.6 & 25 \\
\hline Fluoranthene & 202 & 202.3 & 8.0 & 4.8 & -3.2 & 87.1 & 25 \\
\hline Pyrene & 202 & 202.3 & 8.2 & 4.8 & -3.2 & 89.4 & 25 \\
\hline Retene & 219 & 230.4 & 9.5 & 5.4 & -3.8 & 106.2 & 25 \\
\hline Benz(a)anthracene & 228 & 228.3 & 9.0 & 5.3 & -3.8 & 105.8 & 25 \\
\hline Chrysene & 228 & 228.3 & 9.4 & 5.3 & -3.8 & 106.2 & 25 \\
\hline Benzo(b)fluoranthene & 252 & 252.3 & 10.3 & 5.8 & -4.3 & 116.1 & 25 \\
\hline Benzo(j)fluoranthene & 252 & 252.3 & 10.5 & 5.8 & -4.3 & 117.4 & 25 \\
\hline Benzo(k)fluoranthene & 252 & 252.3 & 10.4 & 5.8 & -4.3 & 117.4 & 25 \\
\hline Benzo(a)pyrene & 252 & 252.3 & 10.4 & 5.8 & -4.3 & 116.7 & 25 \\
\hline Benzo(e)pyrene & 252 & 252.3 & 10.5 & 5.8 & -4.3 & 116.7 & 25 \\
\hline Perylene & 252 & 252.3 & 10.4 & 5.8 & -4.3 & 117.4 & 25 \\
\hline Indeno(1,2,3-,d)pyrene & 276 & 276.3 & 11.3 & 6.3 & -4.8 & 127.4 & 25 \\
\hline Dibenzo(a,h)anthracene & 278 & 278.4 & 11.6 & 6.4 & -4.8 & 130.6 & 25 \\
\hline Benzo(g,h,i)perylene & 276 & 276.3 & 11.4 & 6.3 & -4.8 & 128.9 & 25 \\
\hline $\begin{array}{l}\text { All values at } 25^{\circ} \mathrm{C} \\
\text { a Values from Lohmann (2011) } \\
\text { bValues from Khairy and Lohman } \\
\text { 'Values from Lohmann (2012) } \\
\text { dFinal adjusted values from Ma e } \\
\text { e Values from Khairy and Lohman } \\
{ }^{\mathrm{f}} \text { Recognized average values from }\end{array}$ & $\begin{array}{l}\text { 2014) } \\
\text { l. repor } \\
\text { 2012) } \\
\text { hmann }\end{array}$ & by Lohman & & & & & \\
\hline
\end{tabular}


TABLE SI 6: Average percent equilibrium achieved during deployment for PAHs derived from calculated sampling rates

\begin{tabular}{|c|c|c|c|c|c|c|}
\hline & \multicolumn{3}{|c|}{ Air } & \multicolumn{3}{|c|}{ Water } \\
\hline & Deployment 1 & Deployment 2 & Deployment 3 & Deployment 1 & Deployment 2 & Deployment 3 \\
\hline Naphthalene & $100 \%$ & $100 \%$ & $100 \%$ & $100 \%$ & $100 \%$ & $100 \%$ \\
\hline Biphenyl & $96 \%$ & $100 \%$ & $100 \%$ & $100 \%$ & $98 \%$ & $100 \%$ \\
\hline Acenaphthylene & $98 \%$ & $100 \%$ & $100 \%$ & $100 \%$ & $99 \%$ & $100 \%$ \\
\hline Acenaphthene & $97 \%$ & $100 \%$ & $100 \%$ & $100 \%$ & $98 \%$ & $100 \%$ \\
\hline Fluorene & $89 \%$ & $100 \%$ & $100 \%$ & $100 \%$ & $97 \%$ & $100 \%$ \\
\hline Phenanthrene & $75 \%$ & $100 \%$ & $100 \%$ & $95 \%$ & $94 \%$ & $100 \%$ \\
\hline Anthracene & $68 \%$ & $99 \%$ & $99 \%$ & $95 \%$ & $94 \%$ & $100 \%$ \\
\hline Methyl Phenanthrenes & $30 \%$ & $85 \%$ & $85 \%$ & $79 \%$ & $90 \%$ & $97 \%$ \\
\hline Fluoranthene & $25 \%$ & $76 \%$ & $78 \%$ & $64 \%$ & $84 \%$ & $91 \%$ \\
\hline Pyrene & $17 \%$ & $65 \%$ & $69 \%$ & $64 \%$ & $84 \%$ & $91 \%$ \\
\hline Retene & $0.72 \%$ & $5.6 \%$ & $7.2 \%$ & $23 \%$ & $52 \%$ & $52 \%$ \\
\hline Benz(a)anthracene & $1.90 \%$ & $13.8 \%$ & $17.4 \%$ & $28 \%$ & $59 \%$ & $60 \%$ \\
\hline Chrysene & $0.81 \%$ & $6.2 \%$ & $8.0 \%$ & $28 \%$ & $59 \%$ & $60 \%$ \\
\hline Benzo(b)fluoranthene & $0.085 \%$ & $0.72 \%$ & $0.97 \%$ & $10.0 \%$ & $29 \%$ & $26 \%$ \\
\hline Benzo(j)fluoranthene & $0.052 \%$ & $0.44 \%$ & $0.60 \%$ & $10.0 \%$ & $29 \%$ & $26 \%$ \\
\hline Benzo(k)fluoranthene & $0.065 \%$ & $0.56 \%$ & $0.76 \%$ & $10.0 \%$ & $29 \%$ & $26 \%$ \\
\hline Benzo(a)pyrene & $0.066 \%$ & $0.57 \%$ & $0.77 \%$ & $10.0 \%$ & $29 \%$ & $26 \%$ \\
\hline Benzo(e)pyrene & $0.052 \%$ & $0.45 \%$ & $0.60 \%$ & $10.0 \%$ & $29 \%$ & $26 \%$ \\
\hline Perylene & $0.065 \%$ & $0.56 \%$ & $0.76 \%$ & $10.0 \%$ & $29 \%$ & $26 \%$ \\
\hline Indeno(1,2,3-cd)pyrene & $0.0067 \%$ & $0.061 \%$ & $0.085 \%$ & $3.3 \%$ & $10.8 \%$ & $9.2 \%$ \\
\hline Dibenzo(a,h)anthracene & $0.0031 \%$ & $0.029 \%$ & $0.041 \%$ & $2.63 \%$ & $8.8 \%$ & $7.4 \%$ \\
\hline Benzo(g,h,i)perylene & $0.0051 \%$ & $0.047 \%$ & $0.067 \%$ & $3.3 \%$ & $10.8 \%$ & $9.2 \%$ \\
\hline
\end{tabular}


TABLE SI 7: Physicochemical constants for PAHs derived from SPARC

\begin{tabular}{|c|c|c|c|c|c|c|}
\hline \multirow[t]{2}{*}{ Analyte } & \multicolumn{2}{|c|}{$\mathrm{Da}\left(\mathrm{cm}^{2} / \mathrm{s}\right)$} & \multicolumn{2}{|c|}{$\mathrm{Dw}\left(\mathrm{cm}^{2} / \mathrm{s}\right)$} & \multicolumn{2}{|c|}{$\begin{array}{l}\text { Henry's Law Constant } \\
\left(\mathrm{Pa} /\left(\mathrm{moles} / \mathrm{m}^{3}\right)\right)\end{array}$} \\
\hline & $0^{\circ} \mathrm{C}$ & $25^{\circ} \mathrm{C}$ & $0^{\circ} \mathrm{C}$ & $25^{\circ} \mathrm{C}$ & $0^{\circ} \mathrm{C}$ & $25^{\circ} \mathrm{C}$ \\
\hline Naphthalene & 0.0556 & 0.0655 & 4.69E-06 & $8.03 E-06$ & 68.42 & 54.9 \\
\hline Biphenyl & 0.0481 & 0.0566 & 4.18E-06 & $7.16 \mathrm{E}-06$ & 155.1 & 90.31 \\
\hline Acenaphthylene & 0.0504 & 0.0594 & 4.38E-06 & $7.52 \mathrm{E}-06$ & 7.17 & 9.84 \\
\hline Acenaphthene & 0.0486 & 0.0572 & 4.33E-06 & $7.43 \mathrm{E}-06$ & 3.57 & 6.42 \\
\hline Fluorene & 0.0459 & 0.0541 & 4.11E-06 & 7.05E-06 & 11.55 & 13.52 \\
\hline Phenanthrene & 0.0438 & 0.0517 & 4.02E-06 & $6.90 \mathrm{E}-06$ & 8.75 & 4.21 \\
\hline Anthracene & 0.0441 & 0.052 & 4.04E-06 & $6.94 \mathrm{E}-06$ & 6.74 & 3.31 \\
\hline Methyl Phenanthrenes & 0.0404 & 0.0476 & $3.80 \mathrm{E}-06$ & $6.52 \mathrm{E}-06$ & 6.93 & 3.16 \\
\hline Fluoranthene & 0.0377 & 0.0445 & $3.56 \mathrm{E}-06$ & $6.12 \mathrm{E}-06$ & 18.35 & 1.85 \\
\hline Pyrene & 0.0399 & 0.0471 & $3.72 \mathrm{E}-06$ & $6.40 \mathrm{E}-06$ & 55.35 & 3.86 \\
\hline Retene & 0.034 & 0.0401 & 3.27E-06 & $5.61 E-06$ & 22.21 & 4.27 \\
\hline Benz(a)anthracene & 0.0365 & 0.0431 & $3.57 \mathrm{E}-06$ & $6.14 \mathrm{E}-06$ & 2.38 & 0.18 \\
\hline Chrysene & 0.0363 & 0.0429 & $3.55 \mathrm{E}-06$ & $6.11 \mathrm{E}-06$ & 3.07 & 0.23 \\
\hline Benzo(b)fluoranthene & 0.0326 & 0.0385 & $3.21 \mathrm{E}-06$ & $5.53 \mathrm{E}-06$ & 4.00 & 0.14 \\
\hline Benzo(j)fluoranthene & 0.0327 & 0.0387 & $3.23 \mathrm{E}-06$ & 5.57E-06 & 2.59 & 0.00927 \\
\hline Benzo(k)fluoranthene & 0.0327 & 0.0387 & $3.23 \mathrm{E}-06$ & 5.57E-06 & 2.59 & 0.0927 \\
\hline Benzo(a)pyrene & 0.0343 & 0.0405 & $3.33 \mathrm{E}-06$ & $5.74 \mathrm{E}-06$ & 7.59 & 0.29 \\
\hline Benzo(e)pyrene & 0.0341 & 0.0404 & $3.32 \mathrm{E}-06$ & $5.72 \mathrm{E}-06$ & 9.84 & 0.37 \\
\hline Perylene & 0.0341 & 0.0404 & $3.32 \mathrm{E}-06$ & $5.72 \mathrm{E}-06$ & 9.84 & 0.37 \\
\hline Indeno(1,2,3-cd)pyrene & 0.031 & 0.0367 & 3.04E-06 & $5.27 \mathrm{E}-06$ & 5.37 & 0.13 \\
\hline Dibenzo(a,h)anthracene & 0.0309 & 0.0365 & 3.11E-06 & 5.37E-06 & 2.48 & 0.0759 \\
\hline Benzo(g,h,i)perylene & 0.0342 & 0.0383 & $3.13 E-06$ & $5.40 \mathrm{E}-06$ & 9.97 & 0.25 \\
\hline
\end{tabular}

Obtained June 7, 2013 (https://archemcalc.com/sparc) 
TABLE SI 8: PAH blank corrections

\begin{tabular}{|c|c|c|c|c|c|}
\hline \multirow[b]{2}{*}{ Analyte } & \multirow[b]{2}{*}{$\begin{array}{c}\text { Method Blank Average } \\
\text { (pg/g PE) }\end{array}$} & \multicolumn{2}{|c|}{ Coastal Deployments } & \multicolumn{2}{|c|}{ Cruise Deployments } \\
\hline & & $\begin{array}{c}\text { Field Blank Average } \\
\text { (pg/g PE) }\end{array}$ & $\begin{array}{c}\text { LOD }^{\mathrm{a}} \\
(\mathrm{pg} / \mathrm{g} \mathrm{PE}) \\
\end{array}$ & $\begin{array}{c}\text { Field Blank Average } \\
\text { (pg/g PE) }\end{array}$ & $\begin{array}{c}\mathrm{LOD}^{\mathrm{a}} \\
(\mathrm{pg} / \mathrm{g} \mathrm{PE}) \\
\end{array}$ \\
\hline Naphthalene & $3.0 \mathrm{E}+05$ & $1.9 \mathrm{E}+05$ & $4.4 \mathrm{E}+05$ & $5.3 \mathrm{E}+04$ & $6.4 \mathrm{E}+05$ \\
\hline Biphenyl & $3.2 \mathrm{E}+03$ & $3.5 \mathrm{E}+03$ & $4.0 E+03$ & $1.5 \mathrm{E}+04$ & $1.8 \mathrm{E}+04$ \\
\hline Acenaphthylene & $3.4 \mathrm{E}+03$ & $2.8 \mathrm{E}+03$ & $8.9 \mathrm{E}+03$ & bd & $9.3 \mathrm{E}+03$ \\
\hline Acenaphthene & $7.4 \mathrm{E}+03$ & $4.6 \mathrm{E}+03$ & $2.1 \mathrm{E}+04$ & $2.2 \mathrm{E}+04$ & $3.1 \mathrm{E}+04$ \\
\hline Fluorene & $4.2 \mathrm{E}+03$ & $2.6 \mathrm{E}+03$ & $4.6 \mathrm{E}+03$ & $1.2 \mathrm{E}+04$ & $1.4 \mathrm{E}+04$ \\
\hline Phenanthrene & $2.6 \mathrm{E}+04$ & $1.4 \mathrm{E}+04$ & $4.3 \mathrm{E}+04$ & $2.3 \mathrm{E}+04$ & $5.5 \mathrm{E}+04$ \\
\hline Anthracene & $3.8 \mathrm{E}+02$ & $5.4 \mathrm{E}+02$ & $1.4 \mathrm{E}+03$ & $3.1 \mathrm{E}+03$ & $4.3 \mathrm{E}+03$ \\
\hline Methyl Phenanthrenes & $3.4 \mathrm{E}+04$ & $1.8 \mathrm{E}+04$ & $5.3 E+04$ & $6.0 \mathrm{E}+04$ & $6.9 \mathrm{E}+04$ \\
\hline Fluoranthene & $1.6 \mathrm{E}+04$ & $6.2 \mathrm{E}+03$ & $3.8 \mathrm{E}+04$ & $4.0 \mathrm{E}+04$ & $6.2 \mathrm{E}+04$ \\
\hline Pyrene & $1.2 \mathrm{E}+04$ & $5.8 \mathrm{E}+03$ & $2.6 \mathrm{E}+04$ & $3.0 \mathrm{E}+04$ & $4.2 \mathrm{E}+04$ \\
\hline Retene & $1.1 \mathrm{E}+04$ & $5.7 \mathrm{E}+03$ & $3.8 \mathrm{E}+04$ & $6.6 \mathrm{E}+03$ & $4.6 \mathrm{E}+04$ \\
\hline Benz(a)anthracene & $3.8 \mathrm{E}+02$ & $3.8 \mathrm{E}+02$ & $1.3 \mathrm{E}+03$ & $4.3 \mathrm{E}+02$ & $1.2 \mathrm{E}+03$ \\
\hline Chrysene & $2.1 \mathrm{E}+03$ & $6.9 \mathrm{E}+02$ & $5.5 \mathrm{E}+03$ & $3.9 \mathrm{E}+02$ & $6.3 \mathrm{E}+03$ \\
\hline Benzo(b)fluoranthene & $1.0 \mathrm{E}+03$ & $2.8 \mathrm{E}+02$ & $2.5 \mathrm{E}+03$ & $7.4 \mathrm{E}+02$ & $3.1 \mathrm{E}+03$ \\
\hline Benzo(j)fluoranthene & $2.8 \mathrm{E}+02$ & $4.8 \mathrm{E}+02$ & $1.7 \mathrm{E}+03$ & bd & $1.2 \mathrm{E}+03$ \\
\hline Benzo(k)fluoranthene & $7.1 \mathrm{E}+02$ & $2.1 \mathrm{E}+02$ & $2.5 \mathrm{E}+03$ & $4.6 \mathrm{E}+02$ & $2.9 \mathrm{E}+03$ \\
\hline Benzo(a)pyrene & $5.4 \mathrm{E}+02$ & $7.7 \mathrm{E}+01$ & $1.5 \mathrm{E}+03$ & bd & $1.8 \mathrm{E}+03$ \\
\hline Benzo(e)pyrene & $1.1 \mathrm{E}+03$ & $2.6 \mathrm{E}+02$ & $3.1 E+03$ & $b d$ & $3.9 \mathrm{E}+03$ \\
\hline Perylene & $1.5 \mathrm{E}+04$ & $7.5 \mathrm{E}+01$ & $3.9 \mathrm{E}+04$ & $b d$ & $4.5 \mathrm{E}+04$ \\
\hline Indeno(1,2,3-cd)pyrene & $8.3 \mathrm{E}+02$ & $8.2 E+01$ & $3.1 E+03$ & $b d$ & $3.7 \mathrm{E}+03$ \\
\hline Dibenzo(a,h)anthracene & $6.9 \mathrm{E}+02$ & $6.0 \mathrm{E}+01$ & $2.5 \mathrm{E}+03$ & $b d$ & $3.0 \mathrm{E}+03$ \\
\hline Benzo(g,h,i)perylene & $1.1 \mathrm{E}+03$ & $5.5 \mathrm{E}+01$ & $3.7 \mathrm{E}+03$ & $\mathrm{bd}$ & $4.5 \mathrm{E}+03$ \\
\hline
\end{tabular}

*Excludes Deployment 3 Sault Saint Marie values because values were anomalously high

a3 times the standard deviation used as reporting threshold 
TABLE SI 9: PAH analyte recoveries

\begin{tabular}{|c|c|c|c|}
\hline \multirow[t]{2}{*}{ Analyte } & \multicolumn{2}{|c|}{ Average Surrogate Recovery } & \multirow[t]{2}{*}{ Average Matrix Spike Recovery* } \\
\hline & Air Samples & Water Samples & \\
\hline Acenaphthene-d10 & $61 \%$ & $53 \%$ & $43 \%$ \\
\hline Phenanthrene-d10 & $62 \%$ & $58 \%$ & $48 \%$ \\
\hline Chrysene-d12 & $58 \%$ & $70 \%$ & $51 \%$ \\
\hline Perylene-d12 & $28 \%$ & $62 \%$ & $40 \%$ \\
\hline Naphthalene & & & $2100 \%$ \\
\hline $\begin{array}{l}\text { Biphenyl } \\
\text { Acenaphthylene }\end{array}$ & & & $105 \%$ \\
\hline Acenaphthene & & & $110 \%$ \\
\hline Fluorene & & & $130 \%$ \\
\hline Phenanthrene & & & $210 \%$ \\
\hline Anthracene & & & $86 \%$ \\
\hline \multicolumn{4}{|l|}{ Methyl Phenanthrenes } \\
\hline Fluoranthene & & & $240 \%$ \\
\hline Pyrene & & & $218 \%$ \\
\hline \multicolumn{4}{|l|}{ Retene } \\
\hline Benz(a)anthracene & & & $100 \%$ \\
\hline Chrysene & & & $98 \%$ \\
\hline Benzo(b)fluoranthene & & & $90 \%$ \\
\hline Benzo(j)fluoranthene & & & $44 \%$ \\
\hline Benzo(k)fluoranthene & & & $123 \%$ \\
\hline Benzo(a)pyrene & & & $74 \%$ \\
\hline Benzo(e)pyrene & & & $110 \%$ \\
\hline \multicolumn{4}{|l|}{ Perylene } \\
\hline Indeno(1,2,3-cd)pyrene & & & $100 \%$ \\
\hline Dibenzo(a,h)anthracene & & & $100 \%$ \\
\hline Benzo(g,h,i)perylene & & & $104 \%$ \\
\hline
\end{tabular}

*Average of 4 matrix spikes; excludes 2 
TABLE SI 10: Derived atmospheric concentrations $\left(\mathrm{pg} / \mathrm{m}^{3}\right)$ of selected PAHs $( \pm$ relative standard deviation $)$

\begin{tabular}{|c|c|c|c|c|c|}
\hline \multirow[b]{2}{*}{ Analyte } & \multicolumn{5}{|c|}{ Deployment 1} \\
\hline & Sault Saint Marie & Ashland & Marquette & Duluth & Eagle Harbor \\
\hline Naphthalene & $\mathrm{bd}$ & bd & $b d$ & $b d$ & bd \\
\hline Biphenyl & $1200 \pm 380$ & $b d$ & $b d$ & $b d$ & $b d$ \\
\hline Acenaphthylene & bd & $b d$ & bd & $b d$ & $b d$ \\
\hline Acenaphthene & $13000 \pm 20$ & $b d$ & $b d$ & $b d$ & $b d$ \\
\hline Fluorene & $11000 \pm 470$ & 1000 & bd & bd & $b d$ \\
\hline Methyl Phenanthrenes & $5800 \pm 810$ & 13000 & 630 & 1600 & $b d$ \\
\hline Fluoranthene & $6800 \pm 1100$ & 16000 & 880 & 2100 & $b d$ \\
\hline Pyrene & $3400 \pm 390$ & 7900 & 410 & 970 & $b d$ \\
\hline Retene & bd & 7900 & $\mathrm{bd}$ & $b d$ & bd \\
\hline Benz(a)anthracene & $200 \pm 44$ & 1100 & 22 & 100 & $b d$ \\
\hline Benzo(a)pyrene & $29 \pm 6.9$ & $b d$ & $\mathrm{bd}$ & 34 & $\mathrm{bd}$ \\
\hline Benzo(e)pyrene & $57 \pm 10$ & $b d$ & $\mathrm{bd}$ & 72 & $\mathrm{bd}$ \\
\hline Perylene & bd & $b d$ & bd & $b d$ & $\mathrm{bd}$ \\
\hline Indeno(1,2,3-cd)pyrene & $57 \pm 11$ & $b d$ & $b d$ & $b d$ & $b d$ \\
\hline Dibenzo(a,h)anthracene & $3.5 \pm 4.9$ & $b d$ & $b d$ & $b d$ & $b d$ \\
\hline Benzo(g,h,i)perylene & $53 \pm 8.7$ & $\mathrm{bd}$ & $\mathrm{bd}$ & $\mathrm{bd}$ & $\mathrm{bd}$ \\
\hline
\end{tabular}


TABLE SI 10 (continued)

\begin{tabular}{|c|c|c|c|c|c|c|c|c|c|c|c|c|c|c|}
\hline \multirow[b]{2}{*}{ Analyte } & \multicolumn{14}{|c|}{ Deployment 2} \\
\hline & $\begin{array}{c}\text { Sault } \\
\text { Saint } \\
\text { Marie }\end{array}$ & $\begin{array}{l}\text { Point } \\
\text { Aux } \\
\text { Pins }\end{array}$ & Ashland & $\begin{array}{l}\text { Thunder Bay/ } \\
\text { Welcome Isle }\end{array}$ & Marquette & Ontonagon & Duluth & $\begin{array}{c}\text { Michopicoten } \\
\text { Bay }\end{array}$ & $\begin{array}{c}\text { Sturgeon } \\
\text { Bay }\end{array}$ & $\begin{array}{l}\text { Foster } \\
\text { Island }\end{array}$ & $\begin{array}{l}\text { Eagle } \\
\text { Harbor }\end{array}$ & $\begin{array}{l}\text { ODAS } \\
45004\end{array}$ & $\begin{array}{l}\text { ODAS } \\
45001 \\
\end{array}$ & $\begin{array}{l}\text { ODAS } \\
45006 \\
\end{array}$ \\
\hline Naphthalene & bd & bd & bd & bd & bd & $b d$ & bd & bd & bd & bd & bd & bd & bd & bd \\
\hline Biphenyl & $\mathrm{bd}$ & $\mathrm{bd}$ & $\mathrm{bd}$ & $\mathrm{bd}$ & $\mathrm{bd}$ & $\mathrm{bd}$ & $\mathrm{bd}$ & $\mathrm{bd}$ & $\mathrm{bd}$ & $\mathrm{bd}$ & $\mathrm{bd}$ & $\mathrm{bd}$ & $\mathrm{bd}$ & $\mathrm{bd}$ \\
\hline Acenaphthylene & bd & bd & bd & bd & bd & bd & bd & bd & bd & bd & bd & bd & bd & bd \\
\hline Acenaphthene & 34000 & $\mathrm{bd}$ & bd & bd & $b d$ & bd & $\mathrm{bd}$ & bd & bd & bd & bd & bd & bd & bd \\
\hline Fluorene & 30000 & bd & 1700 & bd & bd & 710 & 1400 & bd & 150 & 580 & bd & bd & bd & bd \\
\hline Phenanthrene & 79000 & 2500 & 4600 & 2800 & $6200 \pm 75$ & $b d$ & 4800 & bd & $b d$ & bd & bd & bd & bd & bd \\
\hline Anthracene & 2900 & bd & 380 & bd & $180 \pm 77$ & bd & 97 & $110 \pm 150$ & bd & 200 & bd & bd & bd & bd \\
\hline Methyl Phenanthrenes & 11000 & 420 & 1100 & 470 & $950 \pm 100$ & bd & 910 & bd & 220 & bd & bd & bd & bd & bd \\
\hline Fluoranthene & 20000 & 2000 & 1900 & 650 & $1900 \pm 560$ & bd & 2300 & bd & bd & 120 & bd & bd & bd & bd \\
\hline Pyrene & 9700 & 740 & 750 & 260 & $880 \pm 300$ & bd & 930 & bd & bd & bd & bd & bd & bd & bd \\
\hline Retene & 780 & 700 & 1400 & 750 & bd & bd & bd & $36 \pm 8.1$ & 260 & 95 & bd & bd & $b d$ & bd \\
\hline Benz(a)anthracene & 610 & 270 & bd & bd & $14 \pm 1.5$ & $b d$ & 23 & bd & bd & bd & 14 & bd & bd & bd \\
\hline Chrysene & 730 & 280 & 80 & bd & $36 \pm 20$ & bd & 59 & bd & bd & bd & bd & bd & bd & 1.4 \\
\hline Benzo(b)fluoranthene & 91 & 25 & 26 & bd & $10 \pm 4.8$ & $b d$ & 15 & bd & bd & bd & bd & bd & bd & bd \\
\hline Benzo(j)fluoranthene & 6.7 & bd & 23 & bd & bd & bd & bd & bd & bd & bd & bd & bd & bd & bd \\
\hline Benzo(k)fluoranthene & 100 & 24 & 40 & bd & $13 \pm 4.4$ & bd & 15 & bd & bd & bd & 15 & bd & $b d$ & bd \\
\hline Benzo(a)pyrene & 37 & 5.2 & 25 & bd & $9.3 \pm 5.4$ & bd & bd & bd & bd & bd & 11 & bd & bd & bd \\
\hline Benzo(e)pyrene & 88 & 11 & 50 & bd & $18 \pm 9.1$ & bd & 17 & bd & bd & bd & 20 & bd & bd & bd \\
\hline Perylene & bd & bd & bd & bd & bd & bd & bd & bd & bd & bd & bd & bd & bd & bd \\
\hline Indeno(1,2,3-cd)pyrene & 44 & 7.7 & 120 & bd & $17 \pm 3.0$ & bd & 17 & bd & bd & bd & bd & bd & bd & bd \\
\hline Dibenzo(a,h)anthracene & bd & bd & 72 & bd & bd & bd & bd & bd & bd & bd & bd & bd & bd & bd \\
\hline Benzo(g,h,i)perylene & 39 & 6.8 & 180 & $\mathrm{bd}$ & $23 \pm 3.4$ & $\mathrm{bd}$ & 20 & bd & $\mathrm{bd}$ & bd & bd & bd & $\mathrm{bd}$ & $\mathrm{bd}$ \\
\hline
\end{tabular}


TABLE SI 10 (continued)

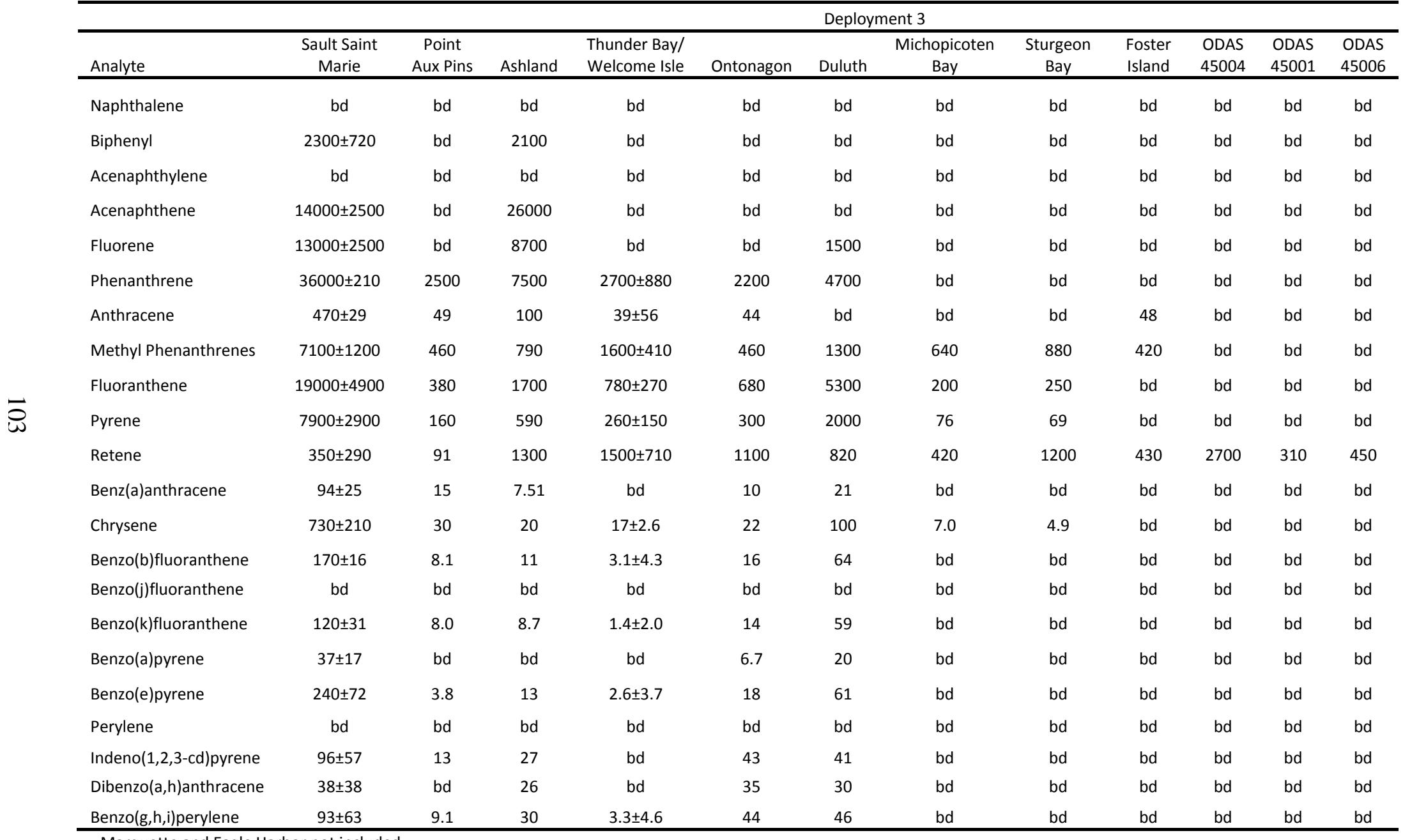

Marquette and Eagle Harbor not included 
TABLE SI 11: Derived aqueous concentrations (pg/L) of selected PAHs ( \pm relative standard deviation)

\begin{tabular}{lccc}
\hline & \multicolumn{3}{c}{ Deployment 1 } \\
\hline Naphthalene & Sault Saint Marie & Ashland & Marquette \\
Biphenyl & $\mathrm{bd}$ & $\mathrm{bd}$ & $\mathrm{bd}$ \\
Acenaphthylene & $\mathrm{bd}$ & $\mathrm{bd}$ & $\mathrm{bd}$ \\
Acenaphthene & $\mathrm{bd}$ & $\mathrm{bd}$ & $\mathrm{bd}$ \\
Fluorene & $6600 \pm 710$ & $\mathrm{bd}$ & $\mathrm{bd}$ \\
Phenanthrene & $4000 \pm 340$ & 340 & 250 \\
Anthracene & $16000 \pm 1900$ & 1300 & $\mathrm{bd}$ \\
Methyl Phenanthrenes & $1400 \pm 410$ & 380 & 79 \\
Fluoranthene & $18000 \pm 1900$ & 7600 & 2200 \\
Pyrene & $42000 \pm 8900$ & 8600 & 3300 \\
Retene & $29000 \pm 5000$ & 12000 & 3000 \\
Benz(a)anthracene & $740 \pm 170$ & 20000 & 650 \\
Chrysene & $2800 \pm 330$ & 1900 & 440 \\
Benzo(b)fluoranthene & $2800 \pm 280$ & 1400 & 680 \\
Benzo(j)fluoranthene & $790 \pm 39$ & 370 & 170 \\
Benzo(k)fluoranthene & $28 \pm 7.4$ & $\mathrm{bd}$ & $\mathrm{bd}$ \\
Benzo(a)pyrene & $570 \pm 65$ & 280 & 130 \\
Benzo(e)pyrene & $240 \pm 49$ & 340 & 55 \\
Perylene & $710 \pm 7.6$ & 480 & 200 \\
Indeno(1,2,3-cd)pyrene & $260 \pm 230$ & 720 & 500 \\
Dibenzo(a,h)anthracene & $160 \pm 82$ & 100 & 32 \\
Benzo(g,h,i)perylene & $130 \pm 210$ & $\mathrm{bd}$ & $\mathrm{bd}$ \\
\hline
\end{tabular}


TABLE SI 11 (continued)

\begin{tabular}{|c|c|c|c|c|c|c|c|c|c|c|c|c|c|c|}
\hline & & & & & & & Deployn & & & & & & & \\
\hline & $\begin{array}{c}\text { Sault } \\
\text { Saint } \\
\text { Marie } \\
\end{array}$ & Ashland & $\begin{array}{c}\text { Thunder } \\
\text { Bay/ } \\
\text { Welcome } \\
\text { Isle }\end{array}$ & $\begin{array}{c}\text { Station } \\
139 \\
\end{array}$ & Marquette & Ontonagon & $\begin{array}{c}\text { Station } \\
221 \\
\end{array}$ & $\begin{array}{c}\text { Michopicoten } \\
\text { Bay } \\
\end{array}$ & $\begin{array}{c}\text { Sturgeon } \\
\text { Bay }\end{array}$ & $\begin{array}{l}\text { Foster } \\
\text { Island } \\
\end{array}$ & $\begin{array}{l}\text { Eagle } \\
\text { Harbor }\end{array}$ & $\begin{array}{c}\text { Station } \\
23 \\
\end{array}$ & $\begin{array}{c}\text { Station } \\
113 \\
\end{array}$ & $\begin{array}{c}\text { Station } \\
169 \\
\end{array}$ \\
\hline Naphthalene & bd & $b d$ & $\mathrm{bd}$ & bd & bd & $b d$ & bd & bd & bd & $b d$ & $b d$ & $b d$ & bd & bd \\
\hline Biphenyl & bd & $\mathrm{bd}$ & $\mathrm{bd}$ & bd & bd & bd & bd & $\mathrm{bd}$ & bd & $\mathrm{bd}$ & bd & bd & bd & bd \\
\hline Acenaphthylene & $b d$ & $b d$ & $b d$ & $b d$ & $b d$ & $b d$ & bd & bd & bd & bd & bd & bd & bd & bd \\
\hline Acenaphthene & 13000 & bd & bd & bd & $b d$ & $b d$ & bd & bd & bd & $b d$ & bd & bd & $\mathrm{bd}$ & bd \\
\hline Fluorene & 6100 & bd & bd & bd & bd & $b d$ & bd & bd & bd & bd & bd & bd & bd & bd \\
\hline Phenanthrene & 16000 & $\mathrm{bd}$ & $\mathrm{bd}$ & bd & $4100 \pm 240$ & bd & bd & $\mathrm{bd}$ & bd & bd & bd & bd & bd & bd \\
\hline Anthracene & 1400 & 170 & 180 & 400 & $230 \pm 27$ & $b d$ & 210 & $b d$ & $b d$ & $b d$ & $b d$ & $b d$ & $b d$ & bd \\
\hline Methyl Phenanthrenes & 7800 & 1100 & 4500 & $b d$ & $2700 \pm 340$ & bd & $b d$ & $2200 \pm 940$ & 7800 & 3400 & $b d$ & $b d$ & bd & bd \\
\hline Fluoranthene & 15000 & 2100 & 930 & 840 & $1600 \pm 340$ & $b d$ & 1700 & $610 \pm 860$ & 4100 & $b d$ & $b d$ & $b d$ & 670 & $b d$ \\
\hline Pyrene & 12000 & 3300 & $b d$ & 1700 & $650 \pm 180$ & 1700 & 4900 & $250 \pm 360$ & $b d$ & $b d$ & $b d$ & 840 & 690 & 460 \\
\hline Retene & 410 & 15000 & 710 & 1000 & $270 \pm 99$ & 1400 & 1600 & $780 \pm 660$ & 5300 & 1200 & $b d$ & $b d$ & 170 & bd \\
\hline Benz(a)anthracene & 1400 & 820 & 14 & 10 & $40 \pm 21$ & 350 & 130 & $85 \pm 120$ & 230 & bd & 6.2 & bd & bd & bd \\
\hline Chrysene & 1300 & 820 & 92 & 52 & $52 \pm 17$ & 210 & 240 & $100 \pm 41$ & $b d$ & $b d$ & $b d$ & 84 & 63 & 45 \\
\hline Benzo(b)fluoranthene & 480 & 290 & 23 & 6.5 & $40 \pm 21$ & 100 & 70 & $19 \pm 27$ & $b d$ & bd & bd & 12 & 7.1 & 8.8 \\
\hline Benzo(j)fluoranthene & bd & $b d$ & 20 & bd & $8.3 \pm 1.2$ & $b d$ & $b d$ & $b d$ & $b d$ & $b d$ & bd & $b d$ & 6.1 & 1.9 \\
\hline Benzo(k)fluoranthene & 360 & 210 & $b d$ & 11 & $43 \pm 8.5$ & 72 & 68 & $14 \pm 20$ & $b d$ & $b d$ & $b d$ & 11 & 19 & 8.0 \\
\hline Benzo(a)pyrene & 120 & 250 & $b d$ & bd & $15 \pm 6.1$ & 34 & 17 & $b d$ & $b d$ & $b d$ & $b d$ & $b d$ & bd & $b d$ \\
\hline Benzo(e)pyrene & 420 & 390 & $b d$ & 8.1 & $22 \pm 9.8$ & 82 & 96 & $16 \pm 23$ & $b d$ & $b d$ & $b d$ & 9.3 & 7.5 & bd \\
\hline Perylene & bd & 370 & $b d$ & bd & bd & 1000 & 130 & $b d$ & $b d$ & $b d$ & bd & bd & $b d$ & bd \\
\hline Indeno(1,2,3-cd)pyrene & 90 & 76 & 820 & bd & $42 \pm 11$ & 9.1 & 12 & $57 \pm 37$ & $b d$ & 100 & $b d$ & 59 & 31 & 4.7 \\
\hline Dibenzo(a,h)anthracene & 13 & 14 & $b d$ & $b d$ & bd & $b d$ & $b d$ & bd & $b d$ & bd & bd & $b d$ & 7.4 & $b d$ \\
\hline Benzo(g,h,i)perylene & 61 & 73 & $\mathrm{bd}$ & bd & $33 \pm 15$ & 14 & 20 & $\mathrm{bd}$ & bd & $\mathrm{bd}$ & $\mathrm{bd}$ & 53 & bd & bd \\
\hline
\end{tabular}

Point Aux Pins not included because sampler not quantified 
TABLE SI 11 (continued)

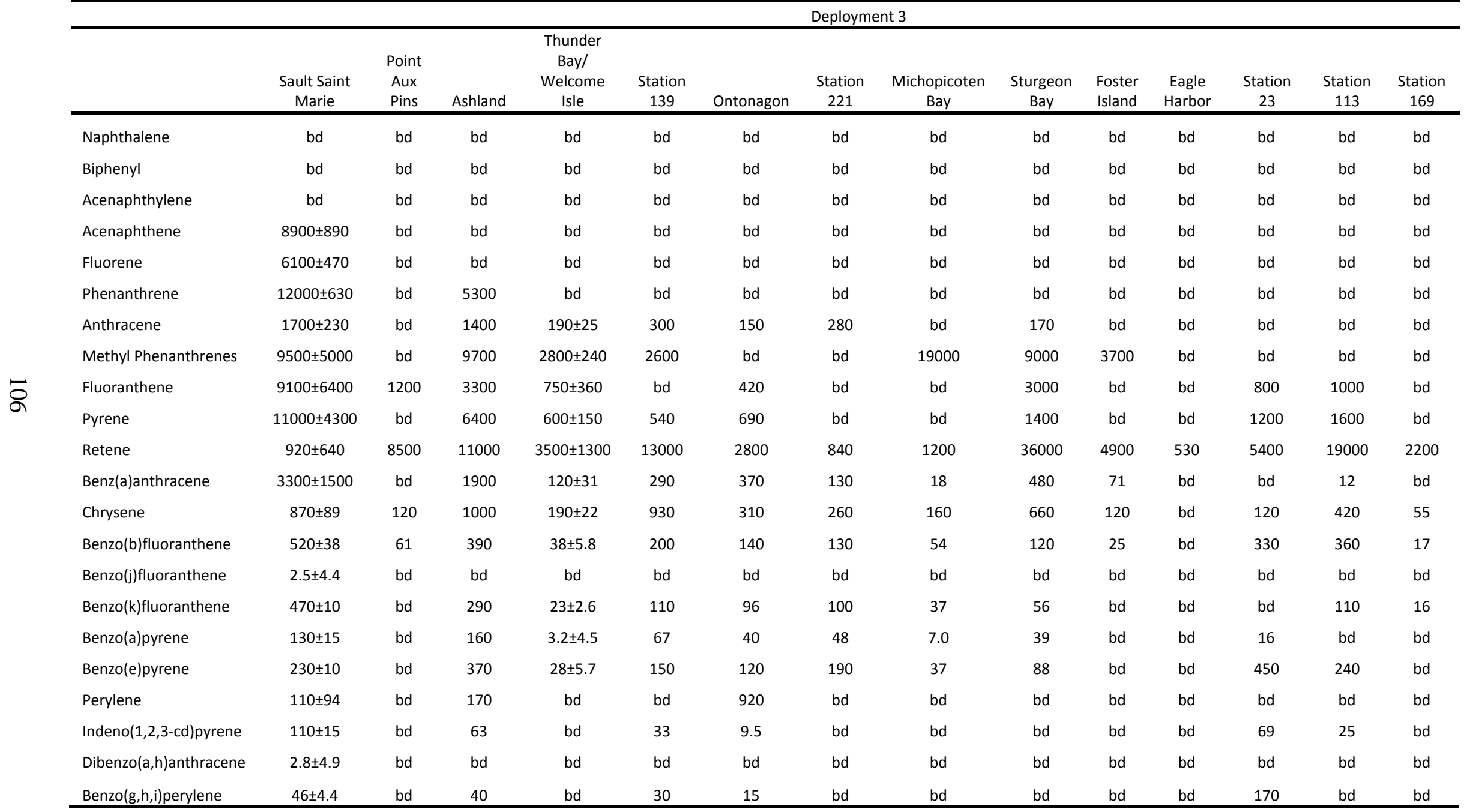

Marquette not included because PE was lost 
TABLE SI 12: Calculated air-water exchange fluxes (ng/ $\mathrm{m}^{2} /$ day) of selected PAHs

\begin{tabular}{lccc}
\hline & \multicolumn{3}{c}{ Deployment 1 } \\
\hline Naphthalene & Sault Saint Marie & Ashland & Marquette \\
Biphenyl & bd & bd & bd \\
Acenaphthylene & -230 & $b d$ & bd \\
Acenaphthene & bd & bd & bd \\
Fluorene & -- & $b d$ & $b d$ \\
Phenanthrene & -- & -- & 77 \\
Anthracene & -- & -5200 & -660 \\
Methyl Phenanthrenes & -- & -410 & -68 \\
Fluoranthene & -- & -18000 & -- \\
Pyrene & -- & -4000 & -- \\
Retene & -- & -2200 & -- \\
Benz(a)anthracene & 5.0 & -2800 & 5.0 \\
Chrysene & -- & -530 & -- \\
Benzo(b)fluoranthene & -33 & -150 & -- \\
Benzo(k)fluoranthene & -18 & -130 & 0.38 \\
Benzo(a)pyrene & -16 & 0.38 & -15 \\
Indeno(1,2,3-cd)pyrene & -11 & 0.56 & 0.12 \\
Benzo(g,h,i)perylene & -56 & 0.13 & 0.056 \\
\hline
\end{tabular}


TABLE SI 12 (continued)

\begin{tabular}{|c|c|c|c|c|c|c|c|c|c|c|c|c|c|}
\hline & & & & & & & & & & & & & \\
\hline & $\begin{array}{c}\text { Sault } \\
\text { Saint } \\
\text { Marie } \\
\end{array}$ & Ashland & $\begin{array}{l}\text { Thunder Bay/ } \\
\text { Welcome Isle }\end{array}$ & Marquette & Ontonagon & $\begin{array}{c}\text { Station } \\
221 \\
\end{array}$ & $\begin{array}{c}\text { Michopicoten } \\
\text { Bay } \\
\end{array}$ & $\begin{array}{c}\text { Sturgeon } \\
\text { Bay }\end{array}$ & $\begin{array}{l}\text { Foster } \\
\text { Island } \\
\end{array}$ & $\begin{array}{l}\text { Eagle } \\
\text { Harbor }\end{array}$ & $\begin{array}{c}\text { Station } \\
23 \\
\end{array}$ & $\begin{array}{c}\text { Station } \\
113 \\
\end{array}$ & $\begin{array}{c}\text { Station } \\
169 \\
\end{array}$ \\
\hline Naphthalene & bd & bd & bd & bd & bd & bd & bd & bd & bd & bd & bd & bd & bd \\
\hline Biphenyl & $\mathrm{bd}$ & $\mathrm{bd}$ & $\mathrm{bd}$ & bd & bd & bd & bd & bd & bd & $\mathrm{bd}$ & bd & bd & bd \\
\hline Acenaphthylene & bd & $b d$ & bd & bd & bd & bd & bd & bd & bd & $\mathrm{bd}$ & bd & bd & $\mathrm{bd}$ \\
\hline Acenaphthene & -- & bd & bd & bd & bd & bd & bd & bd & bd & bd & bd & bd & bd \\
\hline Fluorene & -- & -190 & bd & bd & -130 & -250 & bd & -45 & -150 & bd & bd & bd & bd \\
\hline Phenanthrene & -14000 & -630 & -1200 & -- & bd & -1100 & bd & bd & bd & bd & bd & bd & bd \\
\hline Anthracene & -- & -- & 81 & -- & bd & -- & -50 & 25 & -110 & bd & bd & bd & bd \\
\hline Methyl Phenanthrenes & -- & -- & -- & -- & bd & -1000 & 770 & 3100 & 750 & bd & bd & bd & bd \\
\hline Fluoranthene & -- & -- & -- & -- & bd & -- & 49 & 420 & -38 & bd & bd & 41 & bd \\
\hline Pyrene & -- & -- & -140 & -200 & 93 & -- & 17 & bd & bd & bd & 40 & 32 & 21 \\
\hline Retene & -240 & -- & -450 & 2.6 & 14 & 20 & -- & -- & -- & bd & bd & 1.2 & bd \\
\hline Benz(a)anthracene & -- & 19 & 0.72 & -3.8 & 9.2 & -- & 2.7 & 9.1 & bd & -3.8 & bd & bd & -0.30 \\
\hline Chrysene & -170 & -4.9 & 1.2 & -6.8 & 1.3 & -10 & 0.74 & bd & bd & bd & 0.29 & 0.20 & -- \\
\hline Benzo(b)fluoranthene & -18 & -2.8 & 0.11 & -2.2 & 0.26 & -3.3 & 0.058 & bd & bd & bd & 0.026 & 0.016 & 0.018 \\
\hline Benzo(k)fluoranthene & -23 & -5.2 & bd & -3.1 & 0.15 & -3.5 & 0.037 & bd & bd & -2.8 & 0.021 & 0.035 & 0.014 \\
\hline Benzo(a)pyrene & -8.5 & -3.3 & bd & -2.5 & 0.080 & 0.049 & bd & bd & bd & -2.2 & bd & bd & bd \\
\hline Indeno(1,2,3-cd)pyrene & -21 & -37 & 2.8 & -9.8 & 0.016 & -9.8 & 0.12 & bd & 0.20 & bd & 0.10 & 0.055 & 0.0076 \\
\hline Benzo $(g, h, i)$ perylene & -25 & -76 & $\mathrm{bd}$ & -18 & 0.025 & -15 & bd & bd & bd & $\mathrm{bd}$ & 0.098 & bd & bd \\
\hline
\end{tabular}


TABLE SI 12 (continued)

\begin{tabular}{|c|c|c|c|c|c|c|c|c|c|c|c|c|}
\hline & & & & & & & & & & & & \\
\hline & $\begin{array}{c}\text { Sault } \\
\text { Saint } \\
\text { Marie } \\
\end{array}$ & $\begin{array}{c}\text { Point Aux } \\
\text { Pins } \\
\end{array}$ & Ashland & $\begin{array}{l}\text { Thunder Bay/ } \\
\text { Welcome Isle }\end{array}$ & Ontonagon & $\begin{array}{c}\text { Station } \\
221 \\
\end{array}$ & $\begin{array}{c}\text { Michopicoten } \\
\text { Bay } \\
\end{array}$ & $\begin{array}{c}\text { Sturgeon } \\
\text { Bay }\end{array}$ & $\begin{array}{l}\text { Foster } \\
\text { Island }\end{array}$ & $\begin{array}{c}\text { Station } \\
23 \\
\end{array}$ & $\begin{array}{c}\text { Station } \\
113 \\
\end{array}$ & $\begin{array}{c}\text { Station } \\
169\end{array}$ \\
\hline Naphthalene & bd & bd & bd & bd & bd & bd & bd & bd & bd & bd & $b d$ & $b d$ \\
\hline Biphenyl & -900 & bd & -480 & bd & bd & bd & bd & bd & bd & $b d$ & $b d$ & bd \\
\hline Acenaphthylene & bd & bd & bd & bd & bd & bd & bd & bd & bd & bd & $b d$ & bd \\
\hline Acenaphthene & -- & bd & -5700 & bd & bd & bd & $b d$ & bd & bd & bd & bd & bd \\
\hline Fluorene & -- & bd & -1800 & $b d$ & bd & -320 & bd & bd & bd & bd & $b d$ & bd \\
\hline Phenanthrene & -- & -1000 & -- & -1200 & -550 & -1200 & bd & bd & bd & $b d$ & $b d$ & $b d$ \\
\hline Anthracene & -- & -- & 330 & -- & 28 & 87 & bd & 81 & -38 & bd & $b d$ & bd \\
\hline Methyl Phenanthrenes & -- & -580 & -- & -- & -480 & -1300 & -- & -- & & bd & bd & bd \\
\hline Fluoranthene & -6500 & -- & -- & -- & -130 & -1300 & -64 & -- & bd & 75 & 120 & $b d$ \\
\hline Pyrene & -3200 & -85 & -- & -- & -- & -640 & -31 & -- & bd & 96 & 170 & $b d$ \\
\hline Retene & -230 & -- & -- & -920 & -370 & -280 & -180 & -- & -- & -1500 & -- & -230 \\
\hline Benz(a)anthracene & 85 & -- & 54 & 6.8 & 8.9 & -- & 0.77 & 26 & 3.7 & bd & 0.61 & bd \\
\hline Chrysene & -540 & -19 & -- & -5.9 & -- & -26 & -- & -- & 2.1 & 1.2 & 5.9 & 0.76 \\
\hline Benzo(b)fluoranthene & -68 & -3.2 & -- & -1.3 & -3.6 & -15 & 0.22 & 0.60 & 0.12 & 1.2 & 1.6 & 0.068 \\
\hline Benzo(k)fluoranthene & -54 & -3.8 & -- & -0.64 & -3.7 & -16 & 0.13 & 0.25 & bd & bd & 0.43 & 0.057 \\
\hline Benzo(a)pyrene & -16 & bd & 0.40 & 0.015 & -1.8 & -5.4 & 0.25 & 0.18 & bd & 0.050 & bd & bd \\
\hline Indeno(1,2,3-cd)pyrene & -82 & -11 & -16 & bd & -25 & -24 & bd & bd & bd & 0.15 & 0.075 & bd \\
\hline Benzo(g,h,i)perylene & -100 & -10 & -24 & -4.8 & -34 & -35 & bd & bd & $\mathrm{bd}$ & 0.41 & bd & bd \\
\hline
\end{tabular}


TABLE SI 13: Selected physical constants and equilibrium partitioning constants for all PBDE analytes monitored in this study

\begin{tabular}{|c|c|c|c|c|c|c|}
\hline Compound & Ion & $\begin{array}{c}\mathbf{M W}^{\mathbf{a}} \\
\text { (g/mol) }\end{array}$ & $\log K_{P E a} b$ & $\log K_{\mathrm{PEw}}{ }^{\mathrm{a}}$ & $\begin{array}{c}\Delta \mathrm{H}_{\mathrm{PEa}}{ }^{\mathrm{d}} \\
(\mathrm{kJ} / \mathrm{mol})\end{array}$ & $\begin{array}{c}\Delta H_{\text {PEw }}{ }^{\mathbf{e}} \\
(\mathrm{kJ} / \mathrm{mol})\end{array}$ \\
\hline BDE 2 mono & $248>141$ & 249.1 & 6.60 & 4.5 & 51.975 & 25 \\
\hline BDE 8 di & $327.9>168.1$ & 328 & 7.59 & $5.1^{c}$ & 53.5 & 25 \\
\hline BDE $15 \mathrm{di}$ & $327.9>168.1$ & 328 & 7.53 & 5.1 & 55.934 & 25 \\
\hline BDE 28 tri & $407.8>248$ & 406.9 & 8.49 & 5.7 & 59.332 & 25 \\
\hline BDE 30 tri & $407.8>248$ & 406.9 & 8.64 & $5.7^{c}$ & 57.5 & 25 \\
\hline BDE 47 tetra & $485.7>325.9$ & 485.8 & 9.49 & 6.3 & 62.043 & 25 \\
\hline BDE 49 tetra & $485.7>325.9$ & 485.8 & 9.46 & $6.3^{c}$ & 62.215 & 25 \\
\hline BDE 99 penta & $565.6>405.8$ & 564.7 & 9.87 & 7.0 & 66.359 & 25 \\
\hline BDE 100 penta & $565.6>405.8$ & 564.7 & 9.87 & 7.0 & 64.314 & 25 \\
\hline BDE 153 hexa & $643.5>483.7$ & 643.6 & 10.40 & 7.6 & 70.876 & 25 \\
\hline BDE 154 hexa & $643.5>483.7$ & 643.6 & 10.40 & 7.6 & 68.523 & 25 \\
\hline $\begin{array}{l}\text { All values at } 25^{\circ} \mathrm{C} \\
\text { Li Lohmann (2012) } \\
\text { balues from Khairy and L } \\
\text { CApproximated from Lohr } \\
\text { d Chemspider (2012) } \\
\text { 'Recognized average valu }\end{array}$ & $\begin{array}{l}\text { nann (2014) } \\
\text { (2012) based upon }\end{array}$ & nination & & & & \\
\hline
\end{tabular}


TABLE SI 14: Average percent equilibrium achieved during deployment for PBDEs derived from calculated sampling rates

\begin{tabular}{lccc|ccc}
\hline & \multicolumn{3}{c}{ Air } & \multicolumn{4}{c}{ Water } \\
\hline & Deployment 1 & Deployment 2 & Deployment 3 & Deployment 1 & Deployment 2 & Deployment 3 \\
\hline BDE 2 mono & $100 \%$ & $100 \%$ & $100 \%$ & $99 \%$ & $100 \%$ & $100 \%$ \\
BDE 8 di & $98 \%$ & $99 \%$ & $100 \%$ & $80 \%$ & $95 \%$ & $98 \%$ \\
BDE 15 di & $99 \%$ & $100 \%$ & $100 \%$ & $80 \%$ & $95 \%$ & $98 \%$ \\
BDE 30 tri & $31 \%$ & $67 \%$ & $79 \%$ & $36 \%$ & $70 \%$ & $81 \%$ \\
BDE 28 tri & $40 \%$ & $75 \%$ & $87 \%$ & $36 \%$ & $70 \%$ & $81 \%$ \\
BDE 49 tetra & $5 \%$ & $18 \%$ & $24 \%$ & $11 \%$ & $42 \%$ & $42 \%$ \\
BDE 47 tetra & $5 \%$ & $17 \%$ & $23 \%$ & $11 \%$ & $42 \%$ & $42 \%$ \\
BDE 100 penta & $2 \%$ & $7 \%$ & $10 \%$ & $2 \%$ & $16 \%$ & $11 \%$ \\
BDE 99 penta & $2 \%$ & $7 \%$ & $10 \%$ & $2 \%$ & $16 \%$ & $11 \%$ \\
BDE 154 hexa & $1 \%$ & $2 \%$ & $3 \%$ & $1 \%$ & $5 \%$ & $3 \%$ \\
BDE 153 hexa & $0 \%$ & $2 \%$ & $3 \%$ & $1 \%$ & $5 \%$ & $3 \%$ \\
\hline
\end{tabular}


TABLE SI 15: Physicochemical constants for PBDEs derived from SPARC

\begin{tabular}{|c|c|c|c|c|c|c|}
\hline \multirow[t]{2}{*}{ Analyte } & \multicolumn{2}{|c|}{$\mathrm{Da}\left(\mathrm{cm}^{2} / \mathrm{s}\right)$} & \multicolumn{2}{|c|}{$\mathrm{Dw}\left(\mathrm{cm}^{2} / \mathrm{s}\right)$} & \multicolumn{2}{|c|}{$\begin{array}{l}\text { Henry's Law Constant } \\
\qquad\left(\mathrm{Pa} /\left(\mathrm{moles} / \mathrm{m}^{3}\right)\right)\end{array}$} \\
\hline & $0^{\circ} \mathrm{C}$ & $25^{\circ} \mathrm{C}$ & $0^{\circ} \mathrm{C}$ & $25^{\circ} \mathrm{C}$ & $0^{\circ} \mathrm{C}$ & $25^{\circ} \mathrm{C}$ \\
\hline $\begin{array}{l}\text { BDE } 2 \text { mono } \\
\text { BDE } 8 \text { di }\end{array}$ & 0.0403 & 0.0475 & $3.83 E-06$ & $6.56 \mathrm{E}-06$ & 16.77 & 21.93 \\
\hline $\begin{array}{l}\text { BDE } 15 \mathrm{di} \\
\text { BDE } 30 \text { tri }\end{array}$ & 0.0369 & 0.0436 & $3.63 \mathrm{E}-06$ & $6.24 \mathrm{E}-06$ & 3.57 & 7.3 \\
\hline $\begin{array}{l}\text { BDE } 28 \text { tri } \\
\text { BDE } 49 \text { tetra }\end{array}$ & 0.0347 & 0.041 & $3.48 \mathrm{E}-06$ & $5.98 \mathrm{E}-06$ & 1.23 & 2.98 \\
\hline BDE 47 tetra & 0.0328 & 0.0388 & $3.34 \mathrm{E}-06$ & 5.75E-06 & 0.47 & 1.23 \\
\hline BDE 100 penta & 0.0309 & 0.0365 & $3.22 \mathrm{E}-06$ & $5.53 E-06$ & 0.17 & 0.46 \\
\hline BDE 99 penta & 0.0309 & 0.0365 & $3.22 \mathrm{E}-06$ & $5.53 \mathrm{E}-06$ & 0.12 & 0.36 \\
\hline BDE 154 hexa & 0.0293 & 0.0346 & $3.10 \mathrm{E}-06$ & $5.34 \mathrm{E}-06$ & 0.0442 & 0.13 \\
\hline BDE 153 hexa & 0.0293 & 0.0346 & $3.10 \mathrm{E}-06$ & $5.33 \mathrm{E}-06$ & 0.0306 & 0.11 \\
\hline
\end{tabular}


TABLE SI 16: PBDE blank corrections

\begin{tabular}{lccccc}
\hline & & \multicolumn{2}{c}{ Coastal Deployments } & \multicolumn{2}{c}{ Cruise Deployments } \\
\hline Analyte & $\begin{array}{c}\text { Method Blank Average } \\
(\mathrm{pg} / \mathrm{g} \text { PE })\end{array}$ & $\begin{array}{c}\text { Field Blank Average } \\
(\mathrm{pg} / \mathrm{g} \text { PE) }\end{array}$ & $\begin{array}{c}\mathrm{LOD}^{\mathrm{a}} \\
(\mathrm{pg} / \mathrm{g} \text { PE) }\end{array}$ & $\begin{array}{c}\text { Field Blank Average } \\
(\mathrm{pg} / \mathrm{g} \text { PE) }\end{array}$ & $\begin{array}{c}\text { LOD }^{\mathrm{a}} \\
(\mathrm{pg} / \mathrm{g} \text { PE})\end{array}$ \\
\hline BDE 2 mono & $\mathrm{bd}$ & $\mathrm{bd}$ & $\mathrm{bd}$ & $1.6 \mathrm{E}+02$ & $3.7 \mathrm{E}+02$ \\
BDE 8 di & $\mathrm{bd}$ & $\mathrm{bd}$ & $\mathrm{bd}$ & $\mathrm{bd}$ & $\mathrm{bd}$ \\
BDE 15 di & $\mathrm{bd}$ & $\mathrm{bd}$ & $\mathrm{bd}$ & $\mathrm{bd}$ & $\mathrm{bd}$ \\
BDE 30 tri & $\mathrm{bd}$ & $\mathrm{bd}$ & $\mathrm{bd}$ & $\mathrm{bd}$ & $\mathrm{bd}$ \\
BDE 28 tri & $\mathrm{bd}$ & $8.3 \mathrm{E}-01$ & $5.2 \mathrm{E}+00$ & $1.8 \mathrm{E}+01$ & $2.7 \mathrm{E}+01$ \\
BDE 49 tetra & $9.6 \mathrm{E}+00$ & $3.0 \mathrm{E}+00$ & $2.7 \mathrm{E}+01$ & $\mathrm{bd}$ & $3.1 \mathrm{E}+01$ \\
BDE 47 tetra & $1.0 \mathrm{E}+02$ & $9.4 \mathrm{E}+01$ & $1.1 \mathrm{E}+02$ & $3.5 \mathrm{E}+02$ & $4.0 \mathrm{E}+02$ \\
BDE 100 penta & $2.1 \mathrm{E}+01$ & $2.2 \mathrm{E}+01$ & $6.1 \mathrm{E}+01$ & $5.8 \mathrm{E}+01$ & $8.2 \mathrm{E}+01$ \\
BDE 99 penta & $4.6 \mathrm{E}+01$ & $5.2 \mathrm{E}+01$ & $5.1 \mathrm{E}+01$ & $1.6 \mathrm{E}+02$ & $1.7 \mathrm{E}+02$ \\
BDE 154 hexa & $1.4 \mathrm{E}+02$ & $1.8 \mathrm{E}+02$ & $6.1 \mathrm{E}+02$ & $1.9 \mathrm{E}+01$ & $4.9 \mathrm{E}+02$ \\
BDE 153 hexa & $1.8 \mathrm{E}+00$ & $6.8 \mathrm{E}+00$ & $3.0 \mathrm{E}+01$ & $2.9 \mathrm{E}+01$ & $4.2 \mathrm{E}+01$ \\
BDE 183 hepta & $\mathrm{bd}$ & $4.5 \mathrm{E}+00$ & $2.9 \mathrm{E}+01$ & $4.5 \mathrm{E}+01$ & $1.5 \mathrm{E}+02$ \\
\hline
\end{tabular}

a 3 times the standard deviation used as reporting threshold 
TABLE SI 17: PBDE analyte recoveries

\begin{tabular}{lccc}
\hline Analyte & \multicolumn{2}{c}{ Average Surrogate Recovery } & $\begin{array}{c}\text { Average Matrix Spike } \\
\text { Air Samples }\end{array}$ \\
& $150 \%$ & $150 \%$ & $150 \%$ \\
\hline BDE 28L tri & $120 \%$ & $150 \%$ & $100 \%$ \\
BDE 47L tetra & $140 \%$ & $140 \%$ & $140 \%$ \\
BDE 99L penta & $110 \%$ & $110 \%$ & $120 \%$ \\
BDE 153L hexa & $79 \%$ & $82 \%$ & $90 \%$ \\
BDE 183L hepta & & & $24 \%$ \\
BDE 2 mono & & & $85 \%$ \\
BDE 8 di & & $82 \%$ \\
BDE 15 di & & $81 \%$ \\
BDE 30 tri & & $83 \%$ \\
BDE 28 tri & & $84 \%$ \\
BDE 49 tetra & & $89 \%$ \\
BDE 47 tetra & & $130 \%$ \\
BDE 100 penta & & $84 \%$ \\
BDE 99 penta & & $92 \%$ \\
BDE 154 hexa & & $78 \%$ \\
BDE 153 hexa & & $88 \%$ \\
BDE 183 hepta & & & \\
\hline
\end{tabular}


TABLE SI 18: Derived atmospheric concentrations $\left(\mathrm{fg} / \mathrm{m}^{3}\right)$ of selected PBDEs

\begin{tabular}{|c|c|c|c|c|c|}
\hline \multirow[b]{2}{*}{ Analyte } & \multicolumn{5}{|c|}{ Deployment 1} \\
\hline & Sault Saint Marie & Ashland & Marquette & Duluth & Eagle Harbor \\
\hline BDE 2 mono & bd & bd & $b d$ & $b d$ & $b d$ \\
\hline BDE 8 di & $b d$ & $b d$ & $b d$ & $b d$ & $b d$ \\
\hline BDE $15 \mathrm{di}$ & bd & $b d$ & $b d$ & $b d$ & bd \\
\hline BDE 30 tri & bd & bd & $b d$ & bd & $b d$ \\
\hline BDE 28 tri & $86 \pm 39$ & bd & 50 & 29 & 29 \\
\hline BDE 49 tetra & $64 \pm 32$ & $b d$ & $b d$ & $b d$ & $b d$ \\
\hline BDE 47 tetra & $570 \pm 440$ & 220 & 280 & 590 & bd \\
\hline BDE 100 penta & bd & $\mathrm{bd}$ & $b d$ & $\mathrm{bd}$ & $b d$ \\
\hline BDE 99 penta & $190 \pm 120$ & $b d$ & 120 & 130 & bd \\
\hline BDE 154 hexa & bd & $b d$ & $\mathrm{bd}$ & $\mathrm{bd}$ & $b d$ \\
\hline BDE 153 hexa & $37 \pm 52$ & $b d$ & $b d$ & bd & $b d$ \\
\hline
\end{tabular}


TABLE SI 18 (continued)

\begin{tabular}{|c|c|c|c|c|c|c|c|c|c|c|c|c|c|c|}
\hline & & & & & & & yment 2 & & & & & & & \\
\hline Analyte & $\begin{array}{l}\text { Sault Saint } \\
\text { Marie }\end{array}$ & $\begin{array}{c}\text { Point } \\
\text { Aux Pins }\end{array}$ & Ashland & $\begin{array}{l}\text { Thunder Bay/ } \\
\text { Welcome Isle }\end{array}$ & Marquette & Ontonagon & Duluth & $\begin{array}{c}\text { Michopicoten } \\
\text { Bay } \\
\end{array}$ & $\begin{array}{c}\text { Sturgeon } \\
\text { Bay }\end{array}$ & $\begin{array}{l}\text { Foster } \\
\text { Island }\end{array}$ & $\begin{array}{l}\text { Eagle } \\
\text { Harbor }\end{array}$ & $\begin{array}{l}\text { ODAS } \\
45004 \\
\end{array}$ & $\begin{array}{l}\text { ODAS } \\
45001 \\
\end{array}$ & $\begin{array}{l}\text { ODAS } \\
45006 \\
\end{array}$ \\
\hline BDE 2 mono & 5300 & bd & bd & $b d$ & $\mathrm{bd}$ & bd & bd & $b d$ & $b d$ & bd & bd & $b d$ & bd & bd \\
\hline BDE $8 \mathrm{di}$ & 2500 & $b d$ & $b d$ & bd & $1300 \pm 1900$ & $b d$ & bd & $b d$ & bd & $b d$ & $\mathrm{bd}$ & bd & $b d$ & bd \\
\hline BDE $15 \mathrm{di}$ & 2700 & $b d$ & $b d$ & bd & $9700 \pm 14000$ & $b d$ & $b d$ & $b d$ & $b d$ & $b d$ & bd & $b d$ & $b d$ & bd \\
\hline BDE 30 tri & 240 & $b d$ & $b d$ & bd & $b d$ & $b d$ & bd & bd & bd & $b d$ & bd & bd & $b d$ & bd \\
\hline BDE 28 tri & 75 & 59 & 71 & 73 & $4000 \pm 4500$ & 92 & 81 & $39 \pm 3.0$ & bd & 40 & 43 & 33 & 27 & bd \\
\hline BDE 49 tetra & bd & $b d$ & $b d$ & 29 & $480 \pm 430$ & $b d$ & bd & $b d$ & bd & bd & bd & $b d$ & $b d$ & bd \\
\hline BDE 47 tetra & 340 & 170 & 320 & 350 & $2700 \pm 2300$ & 850 & 3800 & $140 \pm 27$ & 102 & 130 & bd & $b d$ & bd & $b d$ \\
\hline BDE 100 penta & bd & 34 & $b d$ & $b d$ & $140 \pm 23$ & $b d$ & 720 & $22 \pm 31$ & $b d$ & $b d$ & bd & bd & $b d$ & $b d$ \\
\hline BDE 99 penta & 100 & 58 & 170 & 110 & $570 \pm 200$ & 410 & 1600 & $21 \pm 30$ & 49 & $b d$ & bd & 130 & $b d$ & 26 \\
\hline BDE 154 hexa & bd & $b d$ & $b d$ & $\mathrm{bd}$ & bd & $b d$ & bd & bd & $\mathrm{bd}$ & $b d$ & $\mathrm{bd}$ & $b d$ & $b d$ & $b d$ \\
\hline BDE 153 hexa & bd & $\mathrm{bd}$ & 27 & $\mathrm{bd}$ & $140 \pm 72$ & 21 & 150 & bd & bd & $\mathrm{bd}$ & 55 & bd & $\mathrm{bd}$ & $\mathrm{bd}$ \\
\hline
\end{tabular}


TABLE SI 18 (continued)

\begin{tabular}{|c|c|c|c|c|c|c|c|c|c|c|c|c|c|c|}
\hline & & & & & & & ployment & & & & & & & \\
\hline Analyte & $\begin{array}{c}\text { Sault } \\
\text { Saint } \\
\text { Marie }\end{array}$ & $\begin{array}{l}\text { Point } \\
\text { Aux } \\
\text { Pins }\end{array}$ & Ashland & $\begin{array}{l}\text { Thunder Bay/ } \\
\text { Welcome Isle }\end{array}$ & Marquette & Ontonagon & Duluth & $\begin{array}{c}\text { Michopicoten } \\
\text { Bay }\end{array}$ & $\begin{array}{c}\text { Sturgeon } \\
\text { Bay }\end{array}$ & $\begin{array}{l}\text { Foster } \\
\text { Island }\end{array}$ & $\begin{array}{l}\text { Eagle } \\
\text { Harbor }\end{array}$ & $\begin{array}{l}\text { ODAS } \\
45004\end{array}$ & $\begin{array}{l}\text { ODAS } \\
45001\end{array}$ & $\begin{array}{l}\text { ODAS } \\
45006\end{array}$ \\
\hline BDE 2 mono & bd & bd & bd & bd & bd & bd & bd & bd & bd & bd & bd & bd & bd & bd \\
\hline BDE $8 \mathrm{di}$ & $92 \pm 130$ & bd & $b d$ & bd & 300 & bd & bd & bd & bd & bd & bd & 190 & bd & bd \\
\hline BDE $15 \mathrm{di}$ & $174 \pm 250$ & bd & $b d$ & bd & 2400 & bd & $b d$ & $b d$ & $b d$ & bd & $b d$ & 340 & bd & bd \\
\hline BDE 30 tri & bd & bd & $b d$ & bd & bd & bd & $b d$ & bd & bd & bd & $b d$ & 47 & bd & bd \\
\hline BDE 28 tri & bd & 66 & bd & $110 \pm 47$ & 1300 & bd & 29 & 27 & bd & bd & bd & 72 & bd & bd \\
\hline BDE 49 tetra & bd & bd & 25 & $11 \pm 16$ & bd & bd & $b d$ & bd & bd & bd & $b d$ & bd & bd & $b d$ \\
\hline BDE 47 tetra & $530 \pm 72$ & 140 & 140 & $270 \pm 15$ & 1400 & bd & 470 & 110 & 73 & 74 & bd & bd & bd & bd \\
\hline BDE 100 penta & $98 \pm 6.0$ & 110 & 61 & $99 \pm 20$ & 180 & bd & 110 & 180 & 150 & 210 & $b d$ & bd & bd & bd \\
\hline BDE 99 penta & $200 \pm 9.0$ & 50 & 50 & $93 \pm 15$ & 620 & 140 & 190 & 30 & 30 & bd & $\mathrm{bd}$ & bd & $\mathrm{bd}$ & $\mathrm{bd}$ \\
\hline BDE 154 hexa & bd & bd & bd & bd & bd & bd & $\mathrm{bd}$ & bd & $\mathrm{bd}$ & $b d$ & $b d$ & $\mathrm{bd}$ & $\mathrm{bd}$ & $\mathrm{bd}$ \\
\hline BDE 153 hexa & bd & bd & bd & bd & 94 & bd & bd & bd & bd & bd & bd & bd & bd & bd \\
\hline
\end{tabular}


TABLE SI 19: Derived aqueous concentrations (fg/L) of selected PBDEs

\begin{tabular}{lccc}
\hline \multicolumn{4}{c}{ Deployment 1 } \\
\hline & Sault Saint Marie & Ashland & Marquette \\
\hline BDE 2 mono & bd & bd & bd \\
BDE 8 di & bd & bd & bd \\
BDE 15 di & bd & bd & bd \\
BDE 30 tri & bd & bd & bd \\
BDE 28 tri & $120 \pm 37$ & 51 & 98 \\
BDE 49 tetra & $180 \pm 48$ & 54 & 170 \\
BDE 47 tetra & $1100 \pm 390$ & 310 & 1100 \\
BDE 100 penta & $100 \pm 180$ & bd & 220 \\
BDE 99 penta & $650 \pm 260$ & 120 & 538 \\
BDE 154 hexa & bd & bd & bd \\
BDE 153 hexa & bd & bd & bd \\
\hline
\end{tabular}


TABLE SI 19 (continued)

\begin{tabular}{|c|c|c|c|c|c|c|c|c|c|c|c|c|c|c|c|}
\hline & \multicolumn{15}{|c|}{ Deployment 2} \\
\hline & $\begin{array}{c}\text { Sault } \\
\text { Saint } \\
\text { Marie } \\
\end{array}$ & $\begin{array}{l}\text { Point } \\
\text { Aux } \\
\text { Pins } \\
\end{array}$ & Ashland & $\begin{array}{c}\text { Thunder Bay/ } \\
\text { Welcome } \\
\text { Isle }\end{array}$ & $\begin{array}{c}\text { Station } \\
139 \\
\end{array}$ & Marquette & Ontonagon & $\begin{array}{c}\text { Station } \\
221 \\
\end{array}$ & $\begin{array}{c}\text { Michopicoten } \\
\text { Bay } \\
\end{array}$ & $\begin{array}{c}\text { Sturgeon } \\
\text { Bay }\end{array}$ & $\begin{array}{l}\text { Foster } \\
\text { Island }\end{array}$ & $\begin{array}{l}\text { Eagle } \\
\text { Harbor }\end{array}$ & $\begin{array}{c}\text { Station } \\
23 \\
\end{array}$ & $\begin{array}{c}\text { Station } \\
113 \\
\end{array}$ & $\begin{array}{c}\text { Station } \\
169 \\
\end{array}$ \\
\hline BDE 2 mono & bd & bd & bd & $b d$ & $b d$ & bd & $b d$ & $b d$ & bd & bd & bd & $b d$ & bd & $b d$ & $b d$ \\
\hline BDE $8 \mathrm{di}$ & bd & bd & bd & $b d$ & $b d$ & $330 \pm 230$ & $b d$ & $b d$ & bd & $b d$ & $b d$ & $b d$ & bd & $b d$ & bd \\
\hline BDE $15 \mathrm{di}$ & bd & bd & bd & $b d$ & bd & $2000 \pm 1000$ & $b d$ & $b d$ & bd & bd & bd & bd & bd & $b d$ & $b d$ \\
\hline BDE 30 tri & bd & bd & $b d$ & $b d$ & $b d$ & $b d$ & $b d$ & $b d$ & $b d$ & $b d$ & bd & $b d$ & $b d$ & $b d$ & $b d$ \\
\hline BDE 28 tri & 70 & 120 & 63 & 170 & 110 & $2000 \pm 800$ & 34 & 100 & $65 \pm 18$ & 61 & 89 & 53 & 57 & 67 & 49 \\
\hline BDE 49 tetra & 120 & 120 & 60 & 130 & 50 & $430 \pm 160$ & 89 & 57 & bd & $b d$ & bd & $b d$ & 24 & 29 & 27 \\
\hline BDE 47 tetra & 990 & 540 & 550 & 840 & 440 & $2100 \pm 690$ & 210 & 780 & $250 \pm 18$ & $b d$ & bd & 570 & 210 & 330 & 240 \\
\hline BDE 100 penta & 140 & bd & 85 & 140 & 26 & $220 \pm 15$ & $b d$ & 59 & bd & bd & bd & 210 & 13 & 18 & 12 \\
\hline BDE 99 penta & 500 & 250 & 220 & bd & 110 & $490 \pm 97$ & 63 & 210 & $51 \pm 72$ & bd & bd & 380 & 42 & 72 & 72 \\
\hline BDE 154 hexa & $b d$ & $b d$ & bd & bd & $b d$ & bd & $b d$ & $b d$ & bd & $\mathrm{bd}$ & bd & $b d$ & bd & bd & $b d$ \\
\hline BDE 153 hexa & bd & bd & 34 & bd & 17 & $98 \pm 30$ & bd & 15 & bd & $\mathrm{bd}$ & bd & 42 & bd & 5.3 & 8.3 \\
\hline
\end{tabular}


TABLE SI 19 (continued)

\begin{tabular}{|c|c|c|c|c|c|c|c|c|c|c|c|c|c|c|}
\hline & & & & & & & Deployr & & & & & & & \\
\hline & $\begin{array}{c}\text { Sault Saint } \\
\text { Marie }\end{array}$ & $\begin{array}{l}\text { Point } \\
\text { Aux } \\
\text { Pins } \\
\end{array}$ & Ashland & $\begin{array}{l}\text { Thunder Bay/ } \\
\text { Welcome Isle }\end{array}$ & $\begin{array}{c}\text { Station } \\
139 \\
\end{array}$ & Ontonagon & $\begin{array}{c}\text { Station } \\
221 \\
\end{array}$ & $\begin{array}{c}\text { Michopicoten } \\
\text { Bay } \\
\end{array}$ & $\begin{array}{c}\text { Sturgeon } \\
\text { Bay }\end{array}$ & $\begin{array}{l}\text { Foster } \\
\text { Island }\end{array}$ & $\begin{array}{l}\text { Eagle } \\
\text { Harbor }\end{array}$ & $\begin{array}{c}\text { Station } \\
23 \\
\end{array}$ & $\begin{array}{c}\text { Station } \\
113 \\
\end{array}$ & $\begin{array}{c}\text { Station } \\
169 \\
\end{array}$ \\
\hline BDE 2 mono & bd & bd & $b d$ & bd & bd & $b d$ & bd & bd & bd & bd & $b d$ & bd & bd & bd \\
\hline BDE $8 \mathrm{di}$ & bd & bd & $b d$ & $b d$ & bd & $b d$ & $b d$ & bd & bd & $b d$ & bd & $b d$ & bd & bd \\
\hline BDE 15 di & bd & bd & $b d$ & $b d$ & bd & $b d$ & bd & $b d$ & bd & bd & $b d$ & bd & bd & bd \\
\hline BDE 30 tri & bd & bd & $b d$ & $b d$ & bd & 63 & $b d$ & bd & bd & bd & $b d$ & bd & bd & bd \\
\hline BDE 28 tri & $120 \pm 24$ & 62 & 57 & $130 \pm 5.6$ & 63 & 31 & 46 & 35 & 51 & 42 & 44 & 60 & 47 & bd \\
\hline BDE 49 tetra & $80 \pm 18$ & 87 & 63 & $64 \pm 20$ & 34 & 95 & 57 & 30 & bd & bd & 42 & 26 & 70 & bd \\
\hline BDE 47 tetra & $1100 \pm 110$ & 450 & 560 & $680 \pm 40$ & 460 & 330 & 510 & 170 & bd & 180 & 460 & 300 & 620 & bd \\
\hline BDE 100 penta & $270 \pm 30$ & bd & 86 & $97 \pm 14$ & 61 & 40 & 58 & bd & bd & bd & 500 & 39 & 58 & bd \\
\hline BDE 99 penta & $540 \pm 41$ & bd & 200 & $260 \pm 4.9$ & 180 & 150 & 230 & $b d$ & bd & bd & 270 & 136 & 330 & 58 \\
\hline BDE 154 hexa & bd & $b d$ & $b d$ & $b d$ & bd & bd & $b d$ & bd & bd & bd & $b d$ & bd & bd & bd \\
\hline BDE 153 hexa & $\mathrm{bd}$ & bd & $\mathrm{bd}$ & bd & 24 & bd & 22 & bd & bd & bd & 29 & 15 & 17 & bd \\
\hline
\end{tabular}

Marquette not included because PE was lost 
TABLE SI 20: Calculated air-water exchange fluxes ( $\left.\mathrm{pg} / \mathrm{m}^{2} / \mathrm{day}\right)$ of selected PBDEs

\begin{tabular}{lccc}
\hline & \multicolumn{3}{c}{ Deployment 1 } \\
\hline & Sault Saint Marie & Ashland & Marquette \\
\hline BDE 2 mono & bd & bd & bd \\
BDE 8 di & bd & bd & bd \\
BDE 15 di & bd & bd & bd \\
BDE 30 tri & bd & bd & bd \\
BDE 28 tri & -- & 8.3 & -- \\
BDE 49 tetra & -- & 3.4 & 14 \\
BDE 47 tetra & -- & -- & -- \\
BDE 100 penta & 3.0 & bd & 6.5 \\
BDE 99 penta & -- & 1.9 & -- \\
BDE 154 hexa & bd & bd & bd \\
BDE 153 hexa & -0.28 & bd & bd \\
\hline
\end{tabular}


TABLE SI 20 (continued)

\begin{tabular}{|c|c|c|c|c|c|c|c|c|c|c|c|c|c|c|}
\hline & \multicolumn{14}{|c|}{ Deployment 2} \\
\hline & $\begin{array}{c}\text { Sault } \\
\text { Saint } \\
\text { Marie } \\
\end{array}$ & $\begin{array}{c}\text { Point Aux } \\
\text { Pins } \\
\end{array}$ & Ashland & $\begin{array}{l}\text { Thunder Bay/ } \\
\text { Welcome Isle }\end{array}$ & Marquette & Ontonagon & $\begin{array}{c}\text { Station } \\
221 \\
\end{array}$ & $\begin{array}{c}\text { Michopicoten } \\
\text { Bay } \\
\end{array}$ & $\begin{array}{c}\text { Sturgeon } \\
\text { Bay }\end{array}$ & $\begin{array}{l}\text { Foster } \\
\text { Island }\end{array}$ & $\begin{array}{l}\text { Eagle } \\
\text { Harbor }\end{array}$ & $\begin{array}{c}\text { Station } \\
23 \\
\end{array}$ & $\begin{array}{c}\text { Station } \\
113 \\
\end{array}$ & $\begin{array}{c}\text { Station } \\
169 \\
\end{array}$ \\
\hline BDE 2 mono & -1600 & bd & $b d$ & bd & bd & bd & bd & bd & $b d$ & $b d$ & $b d$ & bd & $b d$ & bd \\
\hline BDE $8 \mathrm{di}$ & -530 & bd & bd & bd & -- & bd & bd & $b d$ & $b d$ & $b d$ & $b d$ & $b d$ & $b d$ & bd \\
\hline BDE 15 di & -510 & $b d$ & $b d$ & bd & -- & $b d$ & $b d$ & bd & $b d$ & $b d$ & $b d$ & $b d$ & $b d$ & $b d$ \\
\hline BDE 30 tri & -57 & $b d$ & $b d$ & $b d$ & $b d$ & $b d$ & bd & bd & $b d$ & $b d$ & $b d$ & $b d$ & $b d$ & $b d$ \\
\hline BDE 28 tri & -- & -- & -- & -- & -- & -- & 11 & -- & 20 & -- & -- & 3.6 & -- & 9.8 \\
\hline BDE 49 tetra & 10 & 13 & 5.1 & -- & -- & 7.7 & 6.3 & bd & $b d$ & bd & bd & 2.0 & 2.4 & 2.2 \\
\hline BDE 47 tetra & -- & -- & -- & -- & -- & -150 & -750 & -- & -32 & -32 & 39 & 18 & 27 & 19 \\
\hline BDE 100 penta & 4.6 & -1.3 & 2.6 & 8.2 & -- & $b d$ & -25 & -0.92 & bd & bd & 5.3 & 0.40 & 0.52 & 0.33 \\
\hline BDE 99 penta & -- & -- & -- & -- & -- & -9.6 & -40 & -- & -2.1 & $b d$ & 6.9 & -3.9 & 1.5 & -- \\
\hline BDE 154 hexa & $\mathrm{bd}$ & bd & $\mathrm{bd}$ & bd & $b d$ & $b d$ & $b d$ & bd & $b d$ & $b d$ & $b d$ & $b d$ & bd & bd \\
\hline BDE 153 hexa & $\mathrm{bd}$ & bd & 0.21 & bd & -- & bd & -0.96 & bd & bd & bd & -- & $\mathrm{bd}$ & 0.030 & 0.044 \\
\hline
\end{tabular}


TABLE SI 20 (continued)

\begin{tabular}{|c|c|c|c|c|c|c|c|c|c|c|c|c|c|}
\hline & \multicolumn{13}{|c|}{ Deployment 3} \\
\hline & $\begin{array}{l}\text { Sault Saint } \\
\text { Marie }\end{array}$ & $\begin{array}{c}\text { Point } \\
\text { Aux Pins }\end{array}$ & Ashland & $\begin{array}{l}\text { Thunder Bay/ } \\
\text { Welcome Isle }\end{array}$ & Ontonagon & $\begin{array}{l}\text { Station } \\
221\end{array}$ & $\begin{array}{c}\text { Michopicoten } \\
\text { Bay }\end{array}$ & $\begin{array}{c}\text { Sturgeon } \\
\text { Bay }\end{array}$ & $\begin{array}{l}\text { Foster } \\
\text { Island }\end{array}$ & $\begin{array}{l}\text { Eagle } \\
\text { Harbor }\end{array}$ & $\begin{array}{c}\text { Station } \\
23\end{array}$ & $\begin{array}{c}\text { Station } \\
113\end{array}$ & $\begin{array}{c}\text { Station } \\
169\end{array}$ \\
\hline BDE 2 mono & $b d$ & bd & $b d$ & $b d$ & $b d$ & $b d$ & $b d$ & bd & bd & $b d$ & $b d$ & bd & bd \\
\hline BDE 8 di & -25 & bd & $b d$ & bd & $b d$ & $b d$ & $b d$ & bd & bd & $b d$ & -62 & bd & $b d$ \\
\hline BDE $15 \mathrm{di}$ & -33 & bd & $b d$ & $b d$ & $b d$ & $b d$ & $b d$ & bd & bd & $b d$ & -97 & bd & $b d$ \\
\hline BDE 30 tri & $b d$ & bd & $b d$ & $b d$ & 16 & $b d$ & $b d$ & bd & bd & bd & -17 & bd & $b d$ \\
\hline BDE 28 tri & 21 & -- & 12 & -- & 8.0 & -- & -- & 20 & -- & 9.6 & -- & 15 & $b d$ \\
\hline BDE 49 tetra & 8.9 & 8.9 & -- & -- & 9.8 & 6.0 & 3.7 & bd & bd & 3.8 & 2.7 & 8.9 & $b d$ \\
\hline BDE 47 tetra & -- & -- & -- & -- & 34 & -- & -- & -25 & -- & 41 & 32 & 79 & $b d$ \\
\hline BDE 100 penta & -- & -5.1 & -- & -- & 1.5 & -- & -8.3 & -9.1 & -12 & 16 & 1.5 & 2.6 & bd \\
\hline BDE 99 penta & -- & -1.8 & -- & -- & -- & -- & -1.2 & -1.5 & bd & 6.6 & 3.8 & 11 & 1.7 \\
\hline BDE 154 hexa & $b d$ & bd & $b d$ & bd & bd & $b d$ & $b d$ & bd & bd & $b d$ & bd & $b d$ & $b d$ \\
\hline BDE 153 hexa & bd & bd & bd & bd & bd & bd & bd & bd & bd & 0.20 & 0.12 & 0.16 & bd \\
\hline
\end{tabular}


FIGURE SI 2: Source ratios of PAHs determined according to Yunker et al. (2002). $\mathrm{Ant} / \mathrm{Ant}+\mathrm{Phn}<1$ indicates a petroleum source rather than combustion. The outlying ratio at 0.11 is from Ashland and is indicative of gasoline combustion. Flra/Flra+Pyr $>0.5$ indicates kerosene, grass, coal, and wood combustion, while a ratio $<0.5$

indicates gasoline, diesel, fuel oil, and crude oil combustion. BaA/BaA+Chry $>0.35$ indicates a combustion source, while a ratio of $0.2-0.35$ could indicate either petroleum or combustion. Ratios $<0.2$ indicate a petroleum source. Lake Superior samples yield ratios that suggest a mixture of petroleum and diesel/oil combustion.

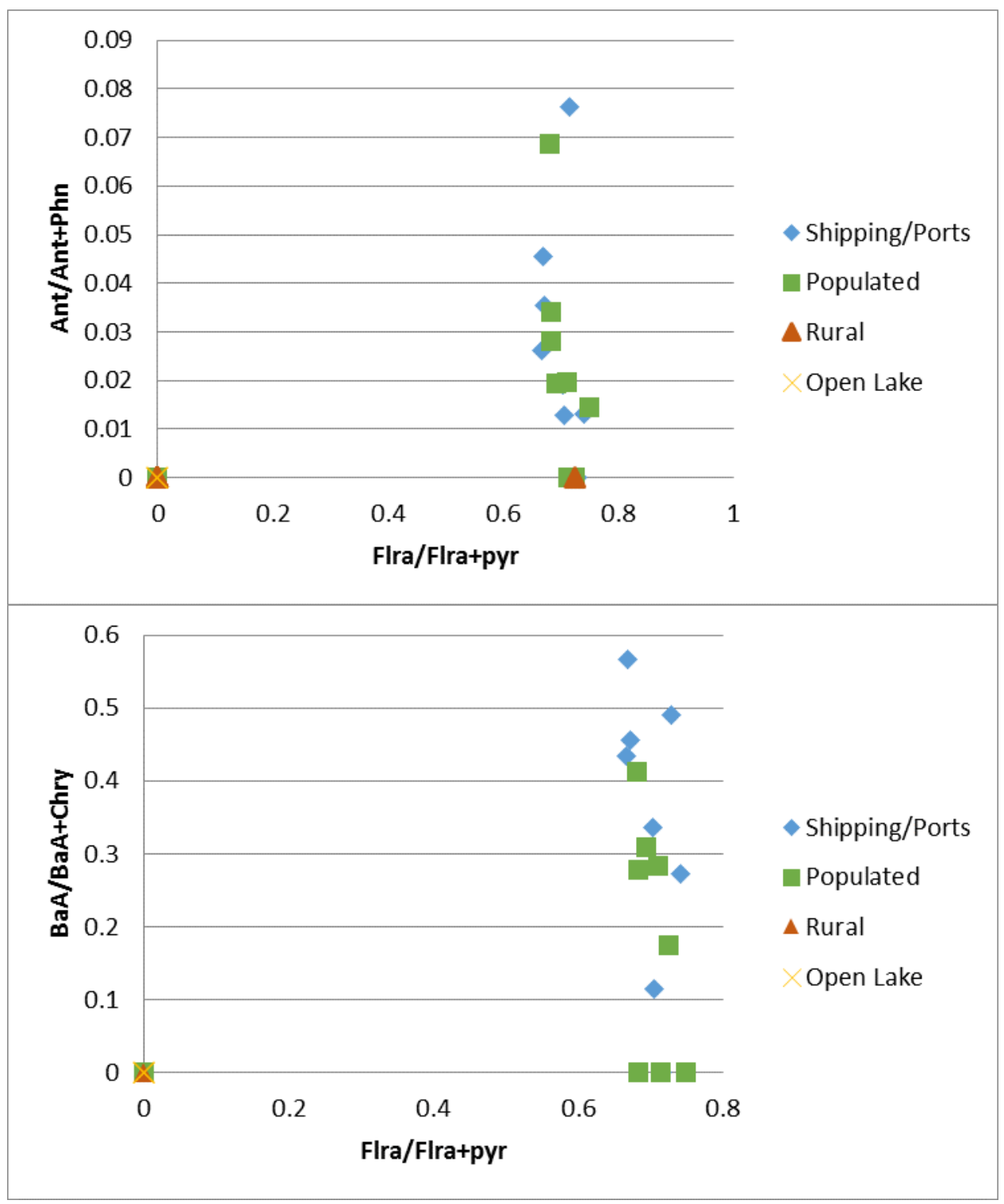


TABLE SI 21: Selected physical constants and equilibrium partitioning constants for all OCP analytes monitored in this study

\begin{tabular}{|c|c|c|c|c|c|c|}
\hline Compound & Ion & $\begin{array}{c}\mathbf{M W}^{\mathbf{a}} \\
(\mathrm{g} / \mathrm{mol})\end{array}$ & $\log K_{P E a}{ }^{b}$ & $\log K_{\mathrm{PEW}}{ }^{c}$ & $\begin{array}{c}\Delta \mathrm{H}_{\mathrm{PEa}}{ }^{\mathrm{e}} \\
(\mathrm{kJ} / \mathrm{mol}) \\
\end{array}$ & $\begin{array}{c}\Delta \mathrm{H}_{\mathrm{PEw}}{ }^{\mathrm{e}} \\
(\mathrm{kJ} / \mathrm{mol})\end{array}$ \\
\hline $\mathrm{HCH}$ alpha & $216.56>180.8$ & 290.8 & 6.87 & 2.8 & $62.1^{f}$ & $-10.51^{\mathrm{h}}$ \\
\hline $\mathrm{HCB}$ & $283.5>248.6$ & 284.8 & 6.87 & 5.2 & $75.9^{f}$ & $-16.57^{h}$ \\
\hline $\mathrm{HCH}$ beta & $216.56>180.8$ & 290.8 & 7.34 & 2.2 & $84.1^{f}$ & $-16.2^{f}$ \\
\hline $\mathrm{HCH}$ gamma & $216.56>180.8$ & 290.8 & 7.16 & 3.0 & $64^{f}$ & $-22.23^{h}$ \\
\hline $\mathrm{HCH}$ delta & $216.56>180.8$ & 290.8 & 7.52 & 2.8 & 80 & -25 \\
\hline Heptachlor & $271.53>236.72$ & 373.3 & 7.12 & 4.8 & 80 & -25 \\
\hline Aldrin & $262.62>192.64$ & 364.9 & 7.26 & 4.9 & 80 & -25 \\
\hline Heptachlor epoxide & $352.05>262.84$ & 389.3 & 7.78 & 4.7 & 80 & -25 \\
\hline Oxychlordane & $185>149$ & 423.8 & 8.21 & $5.6^{d}$ & 80 & -25 \\
\hline Trans chlordane & $371.93>266.1$ & 409.8 & 7.99 & $5.5^{d}$ & $96.414^{\mathrm{g}}$ & -25 \\
\hline Endosulfan 1 & $240.9>205.9$ & 406.9 & 8.33 & 4.5 & 80 & -25 \\
\hline Cis chlordane & $371.93>266.1$ & 409.8 & 8.09 & $5.5^{d}$ & $98.156^{\mathrm{g}}$ & -25 \\
\hline Trans nonachlor & $408.8>299.8$ & 444.2 & 8.35 & $5.8^{d}$ & 80 & -25 \\
\hline$p, p^{\prime}-D D E$ & $246>176$ & 318 & 8.37 & 5.5 & $97.945^{\mathrm{g}}$ & -25 \\
\hline Dieldrin & $262.9>192.9$ & 380.9 & 7.77 & 4.2 & 80 & -25 \\
\hline $0, p^{\prime}-D D D$ & $235.21>164.94$ & 320 & 9.25 & 5.1 & 80 & -25 \\
\hline Endrin & $263>193$ & 380.9 & 8.26 & 4.9 & 80 & -25 \\
\hline Endosulfan II & $195>125$ & 406.9 & 8.35 & $4^{d}$ & 80 & -25 \\
\hline$p, p^{\prime}-D D D+o, p^{\prime}-D D T$ & $235.21>164.94$ & $320.0 / 354.5$ & 8.57 & $5.35^{\ddagger}$ & 80 & -25 \\
\hline Endrin aldehyde & $249.0>214.9$ & 382.9 & 7.85 & 4.2 & 80 & -25 \\
\hline Endosulfan sulphate & $271.9>236.9$ & 422.9 & 8.84 & 2.6 & 80 & -25 \\
\hline$p, p^{\prime}-D D T$ & $235.21>164.94$ & 354.5 & 9.02 & 5.8 & $88.124^{\mathrm{g}}$ & -25 \\
\hline Endrin ketone & $316.9>101$ & 380.9 & 7.67 & $6.2^{d}$ & 80 & -25 \\
\hline Methoxychlor & $226.15>168.93$ & 345.7 & 9.27 & 5.3 & 80 & -25 \\
\hline $\begin{array}{l}\text { All Values at } 25^{\circ} \mathrm{C} \\
\text { a Khairy and Lohmann (2014) } \\
\text { b Khairy and Lohmann (2014) } \\
\text { c Lohmann (2012) } \\
\text { d Calculated from Lohmann ( } \\
\text { e Average values reported by } \\
{ }^{\circ} \text { FAV from Schenker et al. (2C } \\
\text { g Mackay et al. (2006) } \\
\text { h Beyer et al. (2002) } \\
\text { 'Average of individual isomer }\end{array}$ & $\begin{array}{l}\text { 12), reported by Khairy } \\
\text { hmann (2012) } \\
\text { 5) }\end{array}$ & nd Lohmann (2014) & & & & \\
\hline
\end{tabular}


TABLE SI 22: Average percent equilibrium achieved during deployment for OCPs derived from calculated sampling rates

\begin{tabular}{|c|c|c|c|c|c|c|}
\hline & \multicolumn{3}{|c|}{ Air } & \multicolumn{3}{|c|}{ Water } \\
\hline $\mathrm{HCB}$ & $100 \%$ & $100 \%$ & $100 \%$ & $80 \%$ & $94 \%$ & $98 \%$ \\
\hline $\mathrm{HCH}$ gamma & $100 \%$ & $100 \%$ & $100 \%$ & $100 \%$ & $100 \%$ & $100 \%$ \\
\hline $\mathrm{HCH}$ delta & $93 \%$ & $99 \%$ & $100 \%$ & $100 \%$ & $100 \%$ & $100 \%$ \\
\hline Heptachlor & $100 \%$ & $100 \%$ & $100 \%$ & $95 \%$ & $99 \%$ & $100 \%$ \\
\hline Oxychlordane & $45 \%$ & $83 \%$ & $94 \%$ & $43 \%$ & $75 \%$ & $86 \%$ \\
\hline Trans chlordane & $49 \%$ & $88 \%$ & $97 \%$ & $50 \%$ & $81 \%$ & $90 \%$ \\
\hline Endosulfan I & $37 \%$ & $77 \%$ & $89 \%$ & $99 \%$ & $100 \%$ & $100 \%$ \\
\hline Cis chlordane & $41 \%$ & $84 \%$ & $94 \%$ & $50 \%$ & $81 \%$ & $90 \%$ \\
\hline Trans nonachlor & $35 \%$ & $76 \%$ & $88 \%$ & $30 \%$ & $65 \%$ & $75 \%$ \\
\hline Endrin & $41 \%$ & $81 \%$ & $92 \%$ & $91 \%$ & $98 \%$ & $100 \%$ \\
\hline Endosulfan II & $35 \%$ & $76 \%$ & $88 \%$ & $100 \%$ & $100 \%$ & $100 \%$ \\
\hline$p, p^{\prime}-D D D+o, p^{\prime}-D D T$ & $23 \%$ & $62 \%$ & $76 \%$ & $62 \%$ & $87 \%$ & $94 \%$ \\
\hline Endrin aldehyde & $73 \%$ & $95 \%$ & $99 \%$ & $100 \%$ & $100 \%$ & $100 \%$ \\
\hline Endosulfan sulphate & $13 \%$ & $43 \%$ & $57 \%$ & $100 \%$ & $100 \%$ & $100 \%$ \\
\hline$p, p^{\prime}-D D T$ & $8 \%$ & $29 \%$ & $41 \%$ & $30 \%$ & $65 \%$ & $75 \%$ \\
\hline Endrin ketone & $86 \%$ & $98 \%$ & $100 \%$ & $14 \%$ & $46 \%$ & $49 \%$ \\
\hline Methoxychlor & $5 \%$ & $20 \%$ & $29 \%$ & $65 \%$ & $89 \%$ & $95 \%$ \\
\hline
\end{tabular}


TABLE SI 23: Physicochemical constants for OCPs derived from SPARC

\begin{tabular}{|c|c|c|c|c|c|c|}
\hline \multirow[t]{2}{*}{ Analyte } & \multicolumn{2}{|c|}{$\mathrm{Da}\left(\mathrm{cm}^{2} / \mathrm{s}\right)$} & \multicolumn{2}{|c|}{$\operatorname{Dw}\left(\mathrm{cm}^{2} / \mathrm{s}\right)$} & \multicolumn{2}{|c|}{$\begin{array}{l}\text { Henry's Law Constant } \\
\left(\mathrm{Pa} /\left(\mathrm{moles} / \mathrm{m}^{3}\right)\right)\end{array}$} \\
\hline & $0^{\circ} \mathrm{C}$ & $25^{\circ} \mathrm{C}$ & $0^{\circ} \mathrm{C}$ & $25^{\circ} \mathrm{C}$ & $0^{\circ} \mathrm{C}$ & $25^{\circ} \mathrm{C}$ \\
\hline \multicolumn{7}{|l|}{$\mathrm{HCH}$ alpha } \\
\hline \multicolumn{7}{|l|}{$\mathrm{HCB}$} \\
\hline \multicolumn{7}{|l|}{$\mathrm{HCH}$ beta } \\
\hline $\mathrm{HCH}$ gamma & 0.0383 & 0.0452 & $3.79 E-06$ & $6.49 \mathrm{E}-06$ & 0.0189 & 0.19 \\
\hline \multicolumn{7}{|l|}{$\mathrm{HCH}$ delta } \\
\hline Heptachlor & 0.0321 & 0.0379 & $3.24 \mathrm{E}-06$ & $5.55 \mathrm{E}-06$ & 2.59 & 18.08 \\
\hline Aldrin & 0.0317 & 0.0374 & $3.16 \mathrm{E}-06$ & $5.42 \mathrm{E}-06$ & 7.41 & 35.33 \\
\hline Heptachlor epoxide & 0.0328 & 0.0387 & $3.21 \mathrm{E}-06$ & 5.51E-06 & 0.014 & 0.18 \\
\hline Oxychlordane & 0.0315 & 0.0372 & $3.11 \mathrm{E}-06$ & $5.33 \mathrm{E}-06$ & 0.0729 & 0.91 \\
\hline Trans chlordane & 0.0303 & 0.0358 & $3.10 \mathrm{E}-06$ & 5.31E-06 & 0.89 & 7.24 \\
\hline Endosulfan I & 0.0305 & 0.036 & 3.19E-06 & 5.47E-06 & 0.00129 & 0.03 \\
\hline Cis chlordane & 0.0303 & 0.0358 & $3.10 \mathrm{E}-06$ & 5.31E-06 & 0.89 & 7.24 \\
\hline Trans nonachlor & 0.0284 & 0.0336 & $3.00 \mathrm{E}-06$ & $5.15 E-06$ & 0.2 & 2.12 \\
\hline$p, p^{\prime}-D D E$ & 0.0338 & 0.0399 & $3.30 \mathrm{E}-06$ & $5.68 \mathrm{E}-06$ & 1.99 & 4.46 \\
\hline Dieldrin & 0.0316 & 0.0373 & $3.06 \mathrm{E}-06$ & $5.24 \mathrm{E}-06$ & 0.0297 & 0.29 \\
\hline $0, p^{\prime}-D D D$ & 0.0334 & 0.0394 & $3.29 E-06$ & $5.64 \mathrm{E}+06$ & 0.23 & 0.53 \\
\hline Endrin & 0.0316 & 0.0373 & $3.06 \mathrm{E}-06$ & $5.24 \mathrm{E}-06$ & 0.0297 & 0.29 \\
\hline Endosulfan II & 0.0305 & 0.036 & 3.19E-09 & 5.47E-06 & 0.00129 & 0.03 \\
\hline$p, p^{\prime}-D D D+o, p^{\prime}-D D T$ & 0.0331 & 0.039 & $3.27 \mathrm{E}-06$ & 5.61E-06 & 0.0887 & 0.39 \\
\hline Endosulfan sulphate & 0.0291 & 0.0344 & $3.15 E-06$ & $5.40 \mathrm{E}-06$ & 0.00000121 & 0.000285 \\
\hline$p, p^{\prime}-D D T$ & 0.032 & 0.0378 & $3.16 \mathrm{E}-06$ & $5.42 E-06$ & 0.51 & 1.51 \\
\hline Methoxychlor & 0.0303 & 0.0357 & $3.01 \mathrm{E}-06$ & $5.16 \mathrm{E}-06$ & 0.0454 & 0.19 \\
\hline
\end{tabular}

Obtained June 7, 2013 (https://archemcalc.com/sparc) 
TABLE SI 24: OCP blank corrections

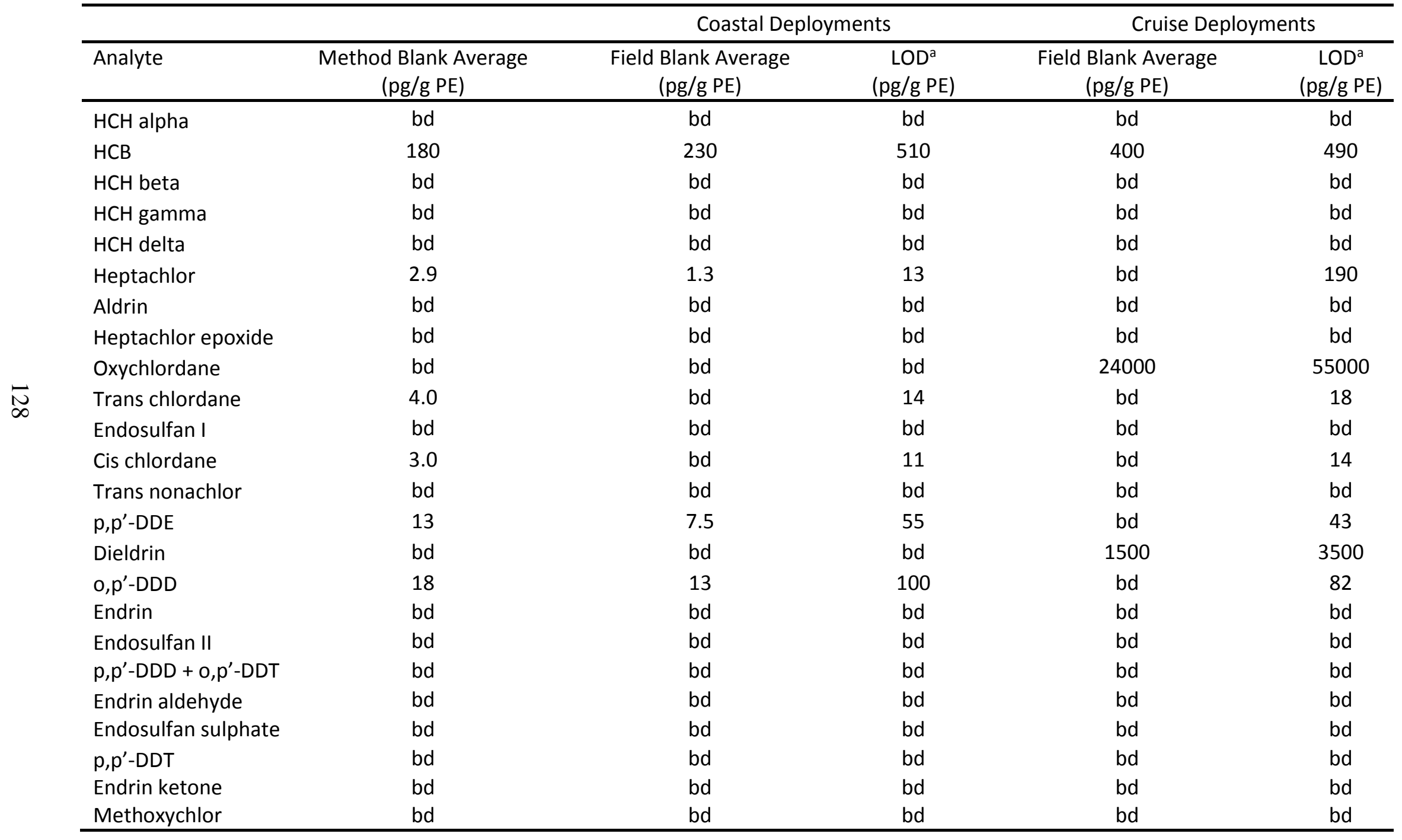


TABLE SI 25: OCP analyte recoveries

\begin{tabular}{|c|c|c|c|}
\hline \multirow[t]{2}{*}{ Analyte } & \multicolumn{2}{|c|}{ Average Surrogate Recovery } & \multirow{2}{*}{$\begin{array}{c}\text { Average Matrix Spike } \\
\text { Recovery }\end{array}$} \\
\hline & Air Samples & Water Samples & \\
\hline L-HCB & $48 \%$ & $52 \%$ & $56 \%$ \\
\hline L-pp-DDT & $176 \%$ & $167 \%$ & $172 \%$ \\
\hline $\mathrm{HCH}$ alpha & & & $51 \%$ \\
\hline $\mathrm{HCB}$ & & & N/A \\
\hline $\mathrm{HCH}$ beta & & & $41 \%$ \\
\hline $\mathrm{HCH}$ gamma & & & $60 \%$ \\
\hline $\mathrm{HCH}$ delta & & & $60 \%$ \\
\hline Heptachlor & & & $66 \%$ \\
\hline Aldrin & & & $73 \%$ \\
\hline Heptachlor epoxide & & & $57 \%$ \\
\hline Oxychlordane & & & $\mathrm{N} / \mathrm{A}$ \\
\hline Trans chlordane & & & $54 \%$ \\
\hline Endosulfan I & & & $51 \%$ \\
\hline Cis chlordane & & & $50 \%$ \\
\hline Trans nonachlor & & & $\mathrm{N} / \mathrm{A}$ \\
\hline$p, p^{\prime}-D D E$ & & & $51 \%$ \\
\hline Dieldrin & & & $56 \%$ \\
\hline $0, p^{\prime}-D D D$ & & & $\mathrm{~N} / \mathrm{A}$ \\
\hline Endrin & & & $100 \%$ \\
\hline Endosulfan II & & & $91 \%$ \\
\hline$p, p^{\prime}-D D D+o, p^{\prime}-D D T$ & & & $36 \%$ \\
\hline Endrin aldehyde & & & N/A \\
\hline Endosulfan sulphate & & & $56 \%$ \\
\hline$p, p^{\prime}-D D T$ & & & $28 \%$ \\
\hline Endrin ketone & & & $27 \%$ \\
\hline Methoxychlor & & & $42 \%$ \\
\hline
\end{tabular}


TABLE SI 26: Derived atmospheric concentrations $\left(\mathrm{fg} / \mathrm{m}^{3}\right)$ of selected OCPs ( \pm relative standard deviation)

Deployment 1

\begin{tabular}{|c|c|c|c|c|c|}
\hline Analyte & Sault Saint Marie & Ashland & Marquette & Duluth & Eagle Harbor \\
\hline $\mathrm{HCH}$ alpha & $b d$ & bd & $b d$ & $b d$ & $b d$ \\
\hline $\mathrm{HCB}$ & $40000 \pm 2800$ & 55000 & 49000 & 52000 & 55000 \\
\hline $\mathrm{HCH}$ beta & $b d$ & bd & bd & bd & 110000 \\
\hline $\mathrm{HCH}$ gamma & bd & bd & $b d$ & bd & $\mathrm{bd}$ \\
\hline $\mathrm{HCH}$ delta & $b d$ & $b d$ & $b d$ & $b d$ & bd \\
\hline Heptachlor & $b d$ & $b d$ & $b d$ & $b d$ & $b d$ \\
\hline Aldrin & bd & $b d$ & bd & $b d$ & bd \\
\hline Heptachlor epoxide & $150 \pm 210$ & 420 & 350 & 260 & 380 \\
\hline Oxychlordane & bd & $b d$ & $b d$ & $\mathrm{bd}$ & $\mathrm{bd}$ \\
\hline Trans chlordane & $280 \pm 90$ & 130 & 210 & 220 & 92 \\
\hline Endosulfan I & $1300 \pm 480$ & 520 & 830 & 330 & 630 \\
\hline Cis chlordane & $280 \pm 96$ & 110 & 240 & 170 & 80 \\
\hline Trans nonachlor & $530 \pm 130$ & 310 & 490 & 480 & 290 \\
\hline$p, p^{\prime}-D D E$ & $420 \pm 97$ & 140 & 530 & 210 & 240 \\
\hline Dieldrin & bd & bd & bd & bd & $b d$ \\
\hline $0, p^{\prime}-D D D$ & $b d$ & $b d$ & bd & $b d$ & $b d$ \\
\hline Endrin & $\mathrm{bd}$ & bd & bd & bd & bd \\
\hline Endosulfan II & bd & $b d$ & bd & bd & bd \\
\hline$p, p^{\prime}-D D D+o, p^{\prime}-D D T$ & $55 \pm 78$ & $b d$ & 74 & $b d$ & 42 \\
\hline Endrin aldehyde & bd & $b d$ & bd & bd & $b d$ \\
\hline Endosulfan sulphate & bd & bd & bd & bd & bd \\
\hline$p, p^{\prime}-D D T$ & $50 \pm 70$ & $b d$ & 210 & $b d$ & $b d$ \\
\hline Endrin ketone & bd & $b d$ & bd & $b d$ & $b d$ \\
\hline Methoxychlor & $b d$ & bd & bd & $b d$ & bd \\
\hline
\end{tabular}


TABLE SI 26 (continued)

\begin{tabular}{|c|c|c|c|c|c|c|c|c|c|c|c|c|c|c|}
\hline & & & & & & & loyment & & & & & & & \\
\hline Analyte & $\begin{array}{c}\text { Sault } \\
\text { Saint } \\
\text { Marie }\end{array}$ & $\begin{array}{l}\text { Point } \\
\text { Aux } \\
\text { Pins }\end{array}$ & Ashland & $\begin{array}{l}\text { Thunder Bay/ } \\
\text { Welcome Isle }\end{array}$ & Marquette & Ontonagon & Duluth & $\begin{array}{c}\text { Michopicoten } \\
\text { Bay }\end{array}$ & $\begin{array}{c}\text { Sturgeon } \\
\text { Bay }\end{array}$ & $\begin{array}{l}\text { Foster } \\
\text { Island }\end{array}$ & $\begin{array}{l}\text { Eagle } \\
\text { Harbor }\end{array}$ & $\begin{array}{l}\text { ODAS } \\
45004\end{array}$ & $\begin{array}{l}\text { ODAS } \\
45001\end{array}$ & $\begin{array}{l}\text { ODAS } \\
45006\end{array}$ \\
\hline $\mathrm{HCH}$ alpha & bd & 4900 & bd & 11000 & bd & bd & bd & bd & bd & bd & bd & 9700 & 8200 & 6800 \\
\hline HCB & 45000 & 57000 & 49000 & 82000 & $56000 \pm 11000$ & bd & 38000 & $83000 \pm 480$ & 80000 & 84000 & 36000 & 94000 & 67000 & 45000 \\
\hline $\mathrm{HCH}$ beta & bd & bd & bd & bd & bd & bd & bd & bd & bd & bd & bd & bd & bd & bd \\
\hline $\mathrm{HCH}$ gamma & bd & bd & bd & bd & bd & bd & bd & bd & bd & bd & bd & 1300 & bd & bd \\
\hline $\mathrm{HCH}$ delta & bd & bd & $b d$ & bd & bd & bd & bd & bd & bd & bd & bd & bd & bd & bd \\
\hline Heptachlor & $b d$ & 1600 & $b d$ & 2400 & bd & bd & bd & bd & bd & bd & bd & bd & bd & bd \\
\hline Aldrin & bd & bd & bd & bd & bd & bd & bd & bd & bd & $\mathrm{bd}$ & $\mathrm{bd}$ & $\mathrm{bd}$ & bd & $\mathrm{bd}$ \\
\hline Heptachlor epoxide & 1200 & 530 & bd & 1400 & $290 \pm 410$ & 580 & 330 & $310 \pm 440$ & 780 & 410 & 440 & 750 & 690 & 490 \\
\hline Oxychlordane & $b d$ & bd & bd & bd & bd & bd & bd & bd & bd & bd & bd & bd & bd & bd \\
\hline Trans chlordane & 630 & 240 & 190 & 620 & $190 \pm 20$ & 190 & 350 & $200 \pm 58$ & 390 & 140 & $b d$ & 300 & 190 & 200 \\
\hline Endosulfan I & 1400 & 900 & 1100 & 1600 & $1900 \pm 250$ & 2500 & 1600 & $1000 \pm 13$ & 1300 & 1100 & 1400 & 1300 & 760 & 650 \\
\hline Cis chlordane & 670 & 250 & bd & 580 & $260 \pm 99$ & 540 & 370 & $180 \pm 51$ & 520 & 190 & 230 & 270 & 170 & 170 \\
\hline Trans nonachlor & 660 & 280 & 430 & 810 & $610 \pm 270$ & 520 & 720 & $320 \pm 78$ & bd & 290 & 410 & 1100 & 550 & 600 \\
\hline$p, p^{\prime}-D D E$ & 600 & 230 & 230 & 580 & $1300 \pm 89$ & 530 & 460 & $140 \pm 28$ & 370 & 140 & 360 & 300 & 110 & 140 \\
\hline Dieldrin & $b d$ & 2800 & $b d$ & bd & $1700 \pm 2400$ & bd & $b d$ & bd & 5600 & bd & bd & bd & bd & $b d$ \\
\hline $0, p^{\prime}-D D D$ & $b d$ & $b d$ & $b d$ & 190 & bd & bd & $b d$ & bd & 190 & $b d$ & $b d$ & $b d$ & bd & $b d$ \\
\hline Endrin & bd & bd & bd & bd & bd & 1700 & $b d$ & bd & bd & bd & bd & bd & bd & $b d$ \\
\hline Endosulfan II & $b d$ & bd & bd & bd & bd & bd & bd & bd & bd & bd & bd & 640 & bd & bd \\
\hline$p, p^{\prime}-D D D+o, p^{\prime}-D D T$ & $b d$ & 140 & $b d$ & 390 & $160 \pm 9.3$ & bd & $b d$ & $59 \pm 83$ & 280 & 92 & 46 & 56 & 34 & 23 \\
\hline Endrin aldehyde & bd & bd & bd & bd & bd & bd & bd & bd & bd & bd & bd & bd & bd & bd \\
\hline Endosulfan sulphate & $b d$ & 140 & bd & $b d$ & bd & bd & bd & bd & 410 & bd & bd & bd & bd & bd \\
\hline$p, p^{\prime}-D D T$ & $b d$ & bd & $b d$ & 290 & bd & bd & bd & $28 \pm 9.8$ & 120 & 29 & bd & 100 & 18 & 19 \\
\hline Endrin ketone & bd & bd & bd & bd & bd & bd & bd & bd & $b d$ & bd & bd & bd & bd & bd \\
\hline Methoxychlor & bd & 36 & bd & bd & bd & bd & $\mathrm{bd}$ & bd & 280 & bd & bd & bd & bd & bd \\
\hline
\end{tabular}


TABLE SI 26 (continued)

\begin{tabular}{|c|c|c|c|c|c|c|c|c|c|c|c|c|c|c|}
\hline \multirow[b]{2}{*}{ Analyte } & \multicolumn{14}{|c|}{ Deployment 3} \\
\hline & $\begin{array}{l}\text { Sault Saint } \\
\text { Marie }\end{array}$ & $\begin{array}{l}\text { Point } \\
\text { Aux } \\
\text { Pins }\end{array}$ & Ashland & $\begin{array}{l}\text { Thunder Bay/ } \\
\text { Welcome Isle }\end{array}$ & Marquette & Ontonagon & Duluth & $\begin{array}{c}\text { Michopicoten } \\
\text { Bay }\end{array}$ & $\begin{array}{c}\text { Sturgeon } \\
\text { Bay }\end{array}$ & $\begin{array}{l}\text { Foster } \\
\text { Island }\end{array}$ & $\begin{array}{l}\text { Eagle } \\
\text { Harbor }\end{array}$ & $\begin{array}{l}\text { ODAS } \\
45004\end{array}$ & $\begin{array}{l}\text { ODAS } \\
45001\end{array}$ & $\begin{array}{l}\text { ODAS } \\
45006\end{array}$ \\
\hline $\mathrm{HCH}$ alpha & $2100 \pm 3000$ & bd & 6500 & $8100 \pm 1200$ & 8500 & 5000 & 4800 & $\mathrm{bd}$ & 6300 & 8400 & 5600 & 8400 & 7400 & 7400 \\
\hline $\mathrm{HCB}$ & $84000 \pm 88$ & 120000 & 88000 & $160000 \pm 13000$ & 160000 & 83000 & 85000 & 87000 & 140000 & 180000 & 93000 & 120000 & 140000 & 120000 \\
\hline $\mathrm{HCH}$ beta & bd & bd & 1900 & bd & bd & bd & bd & bd & bd & bd & bd & bd & bd & bd \\
\hline $\mathrm{HCH}$ gamma & $b d$ & $b d$ & 3400 & $b d$ & bd & 1400 & bd & bd & bd & bd & $b d$ & $b d$ & bd & $b d$ \\
\hline $\mathrm{HCH}$ delta & bd & bd & 2300 & bd & bd & 1100 & bd & bd & bd & bd & bd & bd & bd & $b d$ \\
\hline Heptachlor & $700 \pm 340$ & $b d$ & 1100 & bd & bd & 1200 & bd & bd & bd & bd & 730 & $b d$ & bd & bd \\
\hline Aldrin & bd & $b d$ & bd & $b d$ & bd & 700 & bd & bd & bd & bd & $b d$ & $b d$ & bd & bd \\
\hline Heptachlor epoxide & $780 \pm 190$ & 810 & 850 & $770 \pm 170$ & 560 & 900 & 650 & 740 & 440 & 600 & 650 & 740 & 100 & 520 \\
\hline Oxychlordane & $11000 \pm 1600$ & $b d$ & $\mathrm{bd}$ & bd & bd & $\mathrm{bd}$ & bd & bd & bd & $\mathrm{bd}$ & bd & $b d$ & $\mathrm{bd}$ & $\mathrm{bd}$ \\
\hline Trans chlordane & $630 \pm 38$ & 470 & 580 & $110 \pm 160$ & 230 & 430 & 130 & 240 & 300 & 170 & 290 & 180 & bd & $b d$ \\
\hline Endosulfan I & $1800 \pm 420$ & 980 & 1800 & $1600 \pm 290$ & 1700 & 1500 & 1100 & 880 & 1000 & 1200 & 1600 & 850 & bd & $b d$ \\
\hline Cis chlordane & $520 \pm 160$ & 550 & 410 & $590 \pm 46$ & 300 & 390 & 280 & 240 & 260 & 230 & 420 & 230 & bd & bd \\
\hline Trans nonachlor & $690 \pm 29$ & 770 & 450 & $250 \pm 350$ & 460 & 410 & 320 & 560 & 400 & 360 & 510 & 600 & bd & bd \\
\hline$p, p^{\prime}-D D E$ & $560 \pm 90$ & 220 & 360 & $340 \pm 5.3$ & 850 & 420 & 170 & 290 & 130 & 130 & 300 & 290 & bd & $b d$ \\
\hline Dieldrin & bd & 7200 & bd & bd & bd & bd & bd & 1800 & bd & $b d$ & bd & bd & $b d$ & bd \\
\hline $0, p^{\prime}-D D D$ & bd & $\mathrm{bd}$ & 110 & $11 \pm 27$ & $b d$ & bd & bd & $\mathrm{bd}$ & bd & bd & $b d$ & $b d$ & bd & $b d$ \\
\hline Endrin & bd & $b d$ & 780 & bd & bd & bd & bd & bd & bd & bd & $b d$ & $b d$ & bd & $b d$ \\
\hline Endosulfan II & bd & $b d$ & 1200 & bd & $b d$ & bd & bd & bd & bd & bd & $b d$ & $b d$ & bd & $b d$ \\
\hline$p, p^{\prime}-D D D+o, p^{\prime}-D D T$ & $140 \pm 48$ & 72 & 140 & $350 \pm 85$ & 79 & 67 & 43 & 100 & 110 & bd & 68 & 140 & 10 & 56 \\
\hline Endrin aldehyde & $\mathrm{bd}$ & $\mathrm{bd}$ & $\mathrm{bd}$ & $\mathrm{bd}$ & bd & $\mathrm{bd}$ & $\mathrm{bd}$ & $\mathrm{bd}$ & $\mathrm{bd}$ & bd & $\mathrm{bd}$ & bd & $\mathrm{bd}$ & $b d$ \\
\hline Endosulfan sulphate & bd & bd & bd & $230 \pm 320$ & bd & bd & bd & bd & bd & bd & bd & 130 & $b d$ & $b d$ \\
\hline$p, p^{\prime}-D D T$ & bd & $b d$ & 120 & $190 \pm 12$ & bd & bd & bd & bd & bd & bd & bd & bd & bd & $b d$ \\
\hline Endrin ketone & bd & bd & bd & bd & bd & bd & bd & bd & bd & bd & bd & bd & bd & bd \\
\hline Methoxychlor & $\mathrm{bd}$ & bd & 94 & $220 \pm 150$ & $\mathrm{bd}$ & $\mathrm{bd}$ & $\mathrm{bd}$ & $\mathrm{bd}$ & bd & $\mathrm{bd}$ & $\mathrm{bd}$ & $\mathrm{bd}$ & $\mathrm{bd}$ & $\mathrm{bd}$ \\
\hline
\end{tabular}


TABLE SI 27: Derived aqueous concentrations $(\mathrm{fg} / \mathrm{L})$ of selected OCPs $( \pm$ relative standard deviation)

\begin{tabular}{|c|c|c|c|}
\hline & \multicolumn{3}{|c|}{ Deployment 1} \\
\hline & Sault Saint Marie & Ashland & Marquette \\
\hline $\mathrm{HCH}$ alpha & $\mathrm{bd}$ & bd & bd \\
\hline $\mathrm{HCB}$ & $15000 \pm 2300$ & 8900 & 25000 \\
\hline $\mathrm{HCH}$ beta & bd & bd & $\mathrm{bd}$ \\
\hline $\mathrm{HCH}$ gamma & $\mathrm{bd}$ & 24000 & $b d$ \\
\hline $\mathrm{HCH}$ delta & $\mathrm{bd}$ & 46000 & $\mathrm{bd}$ \\
\hline Heptachlor & $\mathrm{bd}$ & 270 & $b d$ \\
\hline Aldrin & $\mathrm{bd}$ & $b d$ & $b d$ \\
\hline Heptachlor epoxide & $2100 \pm 750$ & 2600 & 3100 \\
\hline Oxychlordane & bd & bd & bd \\
\hline Trans chlordane & $640 \pm 360$ & 350 & 480 \\
\hline Endosulfan I & bd & $b d$ & $b d$ \\
\hline Cis chlordane & $650 \pm 340$ & 310 & 700 \\
\hline Trans nonachlor & $710 \pm 180$ & 340 & 1200 \\
\hline$p, p^{\prime}-D D E$ & $1700 \pm 470$ & 600 & 2100 \\
\hline Dieldrin & bd & 29000 & $\mathrm{bd}$ \\
\hline $0, p^{\prime}-D D D$ & $16000 \pm 1500$ & bd & bd \\
\hline Endrin & bd & bd & bd \\
\hline Endosulfan II & $\mathrm{bd}$ & bd & $b d$ \\
\hline$p, p^{\prime}-D D D+o, p^{\prime}-D D T$ & $15000 \pm 2000$ & 460 & 330 \\
\hline Endrin aldehyde & bd & $\mathrm{bd}$ & $\mathrm{bd}$ \\
\hline Endosulfan sulphate & $\mathrm{bd}$ & bd & $\mathrm{bd}$ \\
\hline$p, p^{\prime}-D D T$ & $b d$ & 57 & bd \\
\hline Endrin ketone & $\mathrm{bd}$ & $b d$ & $b d$ \\
\hline Methoxychlor & $\mathrm{bd}$ & $\mathrm{bd}$ & $\mathrm{bd}$ \\
\hline
\end{tabular}


TABLE SI 27 (continued)

\begin{tabular}{|c|c|c|c|c|c|c|c|c|c|c|c|c|c|c|c|}
\hline & \multicolumn{15}{|c|}{ Deployment 2} \\
\hline & $\begin{array}{l}\text { Sault } \\
\text { Saint } \\
\text { Marie }\end{array}$ & $\begin{array}{c}\text { Point } \\
\text { Aux } \\
\text { Pins }\end{array}$ & Ashland & $\begin{array}{c}\text { Ihunder } \\
\text { Bay/ } \\
\text { Welcome } \\
\text { Isle }\end{array}$ & $\begin{array}{c}\text { Station } \\
139 \\
\end{array}$ & Marquette & Ontonagon & $\begin{array}{c}\text { Station } \\
221 \\
\end{array}$ & $\begin{array}{c}\text { Michopicoten } \\
\text { Bay } \\
\end{array}$ & $\begin{array}{c}\text { Sturgeon } \\
\text { Bay }\end{array}$ & $\begin{array}{l}\text { Foster } \\
\text { Island }\end{array}$ & $\begin{array}{l}\text { Eagle } \\
\text { Harbor }\end{array}$ & $\begin{array}{c}\text { Station } \\
23 \\
\end{array}$ & $\begin{array}{c}\text { Station } \\
113 \\
\end{array}$ & $\begin{array}{c}\text { Station } \\
169 \\
\end{array}$ \\
\hline $\mathrm{HCH}$ alpha & bd & 220000 & bd & 190000 & 620000 & bd & bd & 600000 & $120000 \pm 170000$ & 190000 & $\mathrm{bd}$ & $\mathrm{bd}$ & 640000 & 490000 & 620000 \\
\hline $\mathrm{HCB}$ & 10000 & 10000 & 25000 & 13000 & 18000 & $5900 \pm 360$ & 5100 & 16000 & $15000 \pm 930$ & 8300 & 13000 & 6500 & 32000 & 26000 & 30000 \\
\hline $\mathrm{HCH}$ beta & bd & bd & bd & bd & bd & bd & $\mathrm{bd}$ & bd & bd & $\mathrm{bd}$ & bd & $\mathrm{bd}$ & bd & bd & bd \\
\hline $\mathrm{HCH}$ gamma & $\mathrm{bd}$ & bd & $b d$ & $b d$ & $b d$ & bd & $b d$ & $b d$ & $18000 \pm 26000$ & $b d$ & 27000 & bd & 130000 & 90000 & $b d$ \\
\hline $\mathrm{HCH}$ delta & $\mathrm{bd}$ & $b d$ & $b d$ & $\mathrm{bd}$ & bd & bd & bd & $b d$ & bd & $b d$ & bd & bd & bd & bd & $b d$ \\
\hline Heptachlor & 400 & $b d$ & $b d$ & 200 & $b d$ & bd & $b d$ & $b d$ & $60 \pm 110$ & $b d$ & $b d$ & $b d$ & $b d$ & $b d$ & $b d$ \\
\hline Aldrin & $\mathrm{bd}$ & $\mathrm{bd}$ & bd & $\mathrm{bd}$ & bd & $\mathrm{bd}$ & bd & bd & bd & $\mathrm{bd}$ & $\mathrm{bd}$ & bd & $\mathrm{bd}$ & bd & $\mathrm{bd}$ \\
\hline Heptachlor epoxide & 6100 & 4000 & 8500 & 1900 & 6300 & $430 \pm 380$ & 950 & 5700 & $2800 \pm 1200$ & 1300 & 1800 & 2300 & 7100 & 3000 & 4500 \\
\hline Oxychlordane & $\mathrm{bd}$ & $\mathrm{bd}$ & bd & $\mathrm{bd}$ & $\mathrm{bd}$ & bd & $\mathrm{bd}$ & $\mathrm{bd}$ & bd & $\mathrm{bd}$ & $\mathrm{bd}$ & $\mathrm{bd}$ & bd & $\mathrm{bd}$ & bd \\
\hline Trans chlordane & 820 & 860 & 770 & 200 & 370 & $110 \pm 22$ & $b d$ & 920 & $270 \pm 42$ & 130 & 250 & 120 & 930 & 390 & 580 \\
\hline Endosulfan I & $b d$ & $b d$ & $\mathrm{bd}$ & $b d$ & $b d$ & $11000 \pm 2000$ & $b d$ & $b d$ & $630 \pm 890$ & $b d$ & $b d$ & 1400 & 3400 & $b d$ & $b d$ \\
\hline Cis chlordane & 840 & 500 & 1000 & 340 & 620 & $200 \pm 59$ & bd & 570 & $400 \pm 6.3$ & 150 & 220 & 280 & 930 & 370 & 440 \\
\hline Trans nonachlor & 1300 & 1800 & 1500 & 480 & 1300 & $240 \pm 16$ & 390 & 900 & $580 \pm 120$ & 210 & 540 & 280 & 1100 & 790 & 740 \\
\hline$p, p^{\prime}-D D E$ & 2100 & 970 & 3500 & 330 & 1100 & $210 \pm 36$ & 980 & 1900 & $430 \pm 23$ & 140 & 310 & bd & 1100 & 790 & 1100 \\
\hline Dieldrin & bd & 70000 & $b d$ & 31000 & $b d$ & $b d$ & bd & $b d$ & $41000 \pm 1400$ & 27000 & 30000 & 27000 & $b d$ & $b d$ & $b d$ \\
\hline $0, p^{\prime}-D D D$ & 12000 & bd & $b d$ & bd & $b d$ & bd & $b d$ & 1300 & bd & bd & bd & bd & $b d$ & $b d$ & $b d$ \\
\hline Endrin & $b d$ & bd & $b d$ & $b d$ & $b d$ & bd & $b d$ & $b d$ & $b d$ & $b d$ & $b d$ & $b d$ & $b d$ & $b d$ & $b d$ \\
\hline Endosulfan II & $b d$ & $b d$ & $b d$ & $b d$ & bd & bd & bd & $b d$ & bd & bd & $\mathrm{bd}$ & bd & 96000 & bd & 87000 \\
\hline$p, p^{\prime}-D D D+o, p^{\prime}-D D T$ & 11000 & 490 & $b d$ & 240 & 270 & $250 \pm 18$ & 110 & 540 & $230 \pm 66$ & 92 & 120 & 71 & 260 & 190 & 220 \\
\hline Endrin aldehyde & $\mathrm{bd}$ & bd & $b d$ & $b d$ & bd & bd & bd & bd & $b d$ & $b d$ & bd & bd & $\mathrm{bd}$ & $b d$ & $b d$ \\
\hline Endosulfan sulphate & bd & 420000 & $b d$ & bd & 720000 & bd & bd & $b d$ & $b d$ & $b d$ & $b d$ & bd & $\mathrm{bd}$ & 230000 & 280000 \\
\hline$p, p^{\prime}-D D T$ & $\mathrm{bd}$ & 430 & bd & $b d$ & 180 & $210 \pm 3.9$ & 250 & 320 & $97 \pm 47$ & $b d$ & $\mathrm{bd}$ & 79 & 140 & 84 & 180 \\
\hline Endrin ketone & bd & bd & $b d$ & $b d$ & bd & bd & bd & bd & $b d$ & $b d$ & bd & bd & bd & bd & $b d$ \\
\hline Methoxychlor & $\mathrm{bd}$ & bd & bd & $\mathrm{bd}$ & bd & bd & bd & $b d$ & $\mathrm{bd}$ & $b d$ & bd & $\mathrm{bd}$ & bd & $\mathrm{bd}$ & bd \\
\hline
\end{tabular}


TABLE SI 27 (continued)

\begin{tabular}{|c|c|c|c|c|c|c|c|c|c|c|c|c|c|}
\hline & \multicolumn{13}{|c|}{ Deployment 3} \\
\hline & $\begin{array}{c}\text { Sault Saint } \\
\text { Marie }\end{array}$ & $\begin{array}{c}\text { Point } \\
\text { Aux } \\
\text { Pins }\end{array}$ & Ashland & $\begin{array}{l}\text { Thunder Bay/ } \\
\text { Welcome Isle }\end{array}$ & $\begin{array}{c}\text { Station } \\
139 \\
\end{array}$ & Ontonagon & $\begin{array}{c}\text { Station } \\
221 \\
\end{array}$ & $\begin{array}{c}\text { Michopicoten } \\
\text { Bay } \\
\end{array}$ & $\begin{array}{l}\text { Foster } \\
\text { Island } \\
\end{array}$ & $\begin{array}{l}\text { Eagle } \\
\text { Harbor }\end{array}$ & $\begin{array}{c}\text { Station } \\
23 \\
\end{array}$ & $\begin{array}{c}\text { Station } \\
113 \\
\end{array}$ & $\begin{array}{c}\text { Station } \\
169 \\
\end{array}$ \\
\hline $\mathrm{HCH}$ alpha & $270000 \pm 63000$ & 230000 & 320000 & $250000 \pm 17000$ & 140000 & 23000 & 170000 & 340000 & 340000 & 230000 & 250000 & 280000 & 240000 \\
\hline $\mathrm{HCB}$ & $9700 \pm 3400$ & 4600 & 48000 & $15000 \pm 440$ & 15000 & 5700 & 19000 & 11000 & 13000 & 9300 & 17000 & 17000 & 17000 \\
\hline $\mathrm{HCH}$ beta & bd & bd & bd & bd & bd & bd & $b d$ & bd & bd & bd & bd & bd & bd \\
\hline $\mathrm{HCH}$ gamma & bd & bd & bd & bd & bd & bd & 24000 & bd & bd & 19000 & bd & bd & bd \\
\hline $\mathrm{HCH}$ delta & bd & bd & $b d$ & $b d$ & $b d$ & bd & $b d$ & bd & bd & bd & $b d$ & bd & $b d$ \\
\hline Heptachlor & bd & bd & bd & bd & $b d$ & $b d$ & $b d$ & bd & bd & bd & $b d$ & bd & bd \\
\hline Aldrin & bd & $\mathrm{bd}$ & bd & $b d$ & bd & $\mathrm{bd}$ & bd & $\mathrm{bd}$ & bd & $\mathrm{bd}$ & bd & $\mathrm{bd}$ & $b d$ \\
\hline Heptachlor epoxide & $4800 \pm 1300$ & 4200 & 2400 & $3800 \pm 460$ & 4500 & 1200 & 5100 & 3000 & 3000 & 2800 & 2800 & 3000 & 2400 \\
\hline Oxychlordane & bd & bd & 4900 & bd & $\mathrm{bd}$ & 720 & $b d$ & 9500 & 8100 & bd & bd & bd & bd \\
\hline Trans chlordane & $510 \pm 200$ & 420 & 320 & $330 \pm 48$ & 280 & 260 & 320 & 160 & 170 & 160 & 94 & 120 & 170 \\
\hline Endosulfan I & $2500 \pm 4300$ & bd & bd & $1200 \pm 1800$ & $b d$ & 4100 & bd & bd & bd & bd & $b d$ & 3200 & bd \\
\hline Cis chlordane & $500 \pm 67$ & 930 & 300 & $500 \pm 60$ & 580 & 270 & 420 & 99 & 410 & 240 & 140 & 180 & 140 \\
\hline Trans nonachlor & $960 \pm 250$ & 1000 & 280 & $540 \pm 95$ & 850 & 420 & 570 & 330 & 530 & 310 & 320 & 190 & 180 \\
\hline$p, p^{\prime}-D D E$ & $1600 \pm 490$ & 910 & 1300 & $500 \pm 45$ & 2200 & 1400 & 1600 & 250 & 230 & 190 & 310 & 220 & 190 \\
\hline Dieldrin & $60000 \pm 100000$ & 75000 & 76000 & $68000 \pm 4500$ & bd & $b d$ & $b d$ & 54000 & 46000 & 50000 & $b d$ & bd & bd \\
\hline $0, p^{\prime}-D D D$ & $13000 \pm 6600$ & bd & $b d$ & bd & $b d$ & bd & 690 & $b d$ & bd & bd & $b d$ & bd & bd \\
\hline Endrin & bd & bd & bd & bd & $\mathrm{bd}$ & $b d$ & bd & bd & bd & bd & 7300 & bd & bd \\
\hline Endosulfan II & bd & bd & bd & bd & bd & bd & $b d$ & bd & bd & bd & bd & bd & bd \\
\hline$p, p^{\prime}-D D D+o, p^{\prime}-D D T$ & $6500 \pm 3100$ & 180 & 440 & $b d$ & $\mathrm{bd}$ & 370 & 280 & 100 & 150 & 220 & 140 & bd & bd \\
\hline Endrin aldehyde & bd & bd & bd & bd & bd & bd & $b d$ & $b d$ & bd & bd & $\mathrm{bd}$ & bd & $b d$ \\
\hline Endosulfan sulphate & $88000 \pm 150000$ & bd & 290000 & bd & bd & bd & $b d$ & bd & bd & bd & $b d$ & bd & 120000 \\
\hline$p, p^{\prime}-D D T$ & $330 \pm 290$ & 230 & bd & bd & $b d$ & 440 & 150 & bd & bd & 120 & bd & bd & bd \\
\hline Endrin ketone & bd & bd & bd & bd & bd & bd & $b d$ & bd & bd & bd & bd & bd & bd \\
\hline Methoxychlor & bd & bd & bd & bd & bd & bd & bd & bd & bd & bd & bd & bd & bd \\
\hline
\end{tabular}


TABLE SI 28: Calculated air-water exchange fluxes ( $\mathrm{pg} / \mathrm{m}^{2} /$ day) of selected OCPs

\begin{tabular}{lccc}
\hline & \multicolumn{3}{c}{ Deployment 1 } \\
\hline HCH alpha & Sault Saint Marie & Ashland & Marquette \\
HCB & bd & bd & bd \\
HCH beta & -- & -- & -- \\
HCH gamma & bd & bd & bd \\
HCH delta & bd & 110 & bd \\
Heptachlor & bd & 210 & bd \\
Aldrin & -- & 110 & -- \\
Heptachlor epoxide & bd & bd & bd \\
Oxychlordane & -- & -- & -- \\
Trans chlordane & bd & bd & bd \\
Endosulfan I & -- & -- & -- \\
Cis chlordane & -10 & -3.6 & -7.4 \\
Trans nonachlor & -- & -- & -- \\
p,p'-DDE & -- & -- & -- \\
Dieldrin & -- & -- & -- \\
o,p'-DDD & bd & 160 & bd \\
Endrin & 610 & bd & bd \\
Endosulfan II & bd & bd & bd \\
p,p'-DDD + op-DDT & bd & bd & bd \\
Endosulfan sulphate & 290 & 6.8 & -- \\
p,p'-DDT & bd & bd & bd \\
\hline
\end{tabular}


TABLE SI 28 (continued)

\begin{tabular}{|c|c|c|c|c|c|c|c|c|c|c|c|c|c|c|}
\hline & \multicolumn{14}{|c|}{ Deployment 2} \\
\hline & $\begin{array}{c}\text { Sault } \\
\text { Saint } \\
\text { Marie } \\
\end{array}$ & $\begin{array}{c}\text { Point } \\
\text { Aux } \\
\text { Pins } \\
\end{array}$ & Ashland & $\begin{array}{l}\text { Thunder Bay/ } \\
\text { Welcome Isle }\end{array}$ & Marquette & Ontonagon & $\begin{array}{c}\text { Station } \\
221 \\
\end{array}$ & $\begin{array}{c}\text { Michopicoten } \\
\text { Bay } \\
\end{array}$ & $\begin{array}{c}\text { Sturgeon } \\
\text { Bay }\end{array}$ & $\begin{array}{l}\text { Foster } \\
\text { Island } \\
\end{array}$ & $\begin{array}{l}\text { Eagle } \\
\text { Harbor }\end{array}$ & $\begin{array}{c}\text { Station } \\
23 \\
\end{array}$ & $\begin{array}{c}\text { Station } \\
113 \\
\end{array}$ & $\begin{array}{c}\text { Station } \\
169 \\
\end{array}$ \\
\hline $\mathrm{HCH}$ alpha & bd & -- & bd & -- & bd & bd & 7000 & 1200 & 2200 & bd & bd & -- & -- & -- \\
\hline $\mathrm{HCB}$ & -- & -- & 210000 & -- & -- & 51000 & 170000 & -- & -- & - & -- & -- & -- & -- \\
\hline $\mathrm{HCH}$ beta & bd & bd & bd & bd & bd & bd & bd & bd & bd & bd & bd & bd & bd & bd \\
\hline $\mathrm{HCH}$ gamma & bd & bd & bd & bd & bd & bd & bd & 180 & bd & 220 & $b d$ & -- & 490 & bd \\
\hline $\mathrm{HCH}$ delta & bd & bd & bd & bd & bd & bd & bd & bd & bd & bd & bd & bd & bd & bd \\
\hline Heptachlor & 330 & -510 & bd & -990 & bd & bd & bd & 110 & bd & bd & bd & bd & bd & bd \\
\hline Aldrin & bd & bd & bd & bd & bd & bd & bd & bd & bd & bd & bd & bd & bd & bd \\
\hline Heptachlor epoxide & -- & -- & 56 & -- & -- & -- & 40 & -- & -- & -- & -- & -- & -- & -- \\
\hline Oxychlordane & bd & bd & bd & bd & bd & bd & bd & bd & bd & bd & bd & bd & bd & bd \\
\hline Trans chlordane & -- & -- & 260 & -- & -- & -46 & -- & -- & -- & -- & 34 & -- & -- & -- \\
\hline Endosulfan I & -14 & -11 & -9.1 & -27 & -- & -23 & -18 & -11 & -18 & -11 & -9.1 & -10 & -7.2 & -5.7 \\
\hline Cis chlordane & -- & -- & 300 & -- & -- & -130 & -- & -- & -- & -- & -- & -- & -- & -- \\
\hline Trans nonachlor & -- & 150 & 97 & -- & -- & -- & -- & -- & 18 & -- & -- & -- & -- & -- \\
\hline$p, p^{\prime}-D D E$ & -- & -- & 1100 & -- & -680 & -- & -- & -- & -380 & -- & -160 & -- & -- & -- \\
\hline Dieldrin & bd & -- & bd & 570 & -120 & bd & -- & 480 & -- & 290 & 200 & bd & bd & bd \\
\hline $0, p^{\prime}-D D D$ & 470 & bd & bd & -370 & bd & bd & 63 & bd & -320 & bd & bd & bd & bd & bd \\
\hline Endrin & bd & bd & bd & bd & bd & -72 & bd & bd & bd & bd & bd & bd & bd & bd \\
\hline Endosulfan II & bd & bd & bd & bd & bd & bd & bd & bd & bd & bd & bd & -- & bd & 32 \\
\hline$p, p^{\prime}-D D D+o, p^{\prime}-D D T$ & 260 & -- & bd & -40 & -- & 2.5 & 16 & -- & -29 & -6.2 & -- & -- & -- & -- \\
\hline Endosulfan sulphate & bd & -- & bd & bd & bd & bd & bd & bd & -5.6 & bd & bd & bd & 0.17 & 0.22 \\
\hline$p, p^{\prime}-D D T$ & $\mathrm{bd}$ & 52 & $\mathrm{bd}$ & -180 & 24 & 24 & 40 & -- & -65 & -13 & 6.1 & -46 & -- & -- \\
\hline
\end{tabular}


TABLE SI 28 (continued)

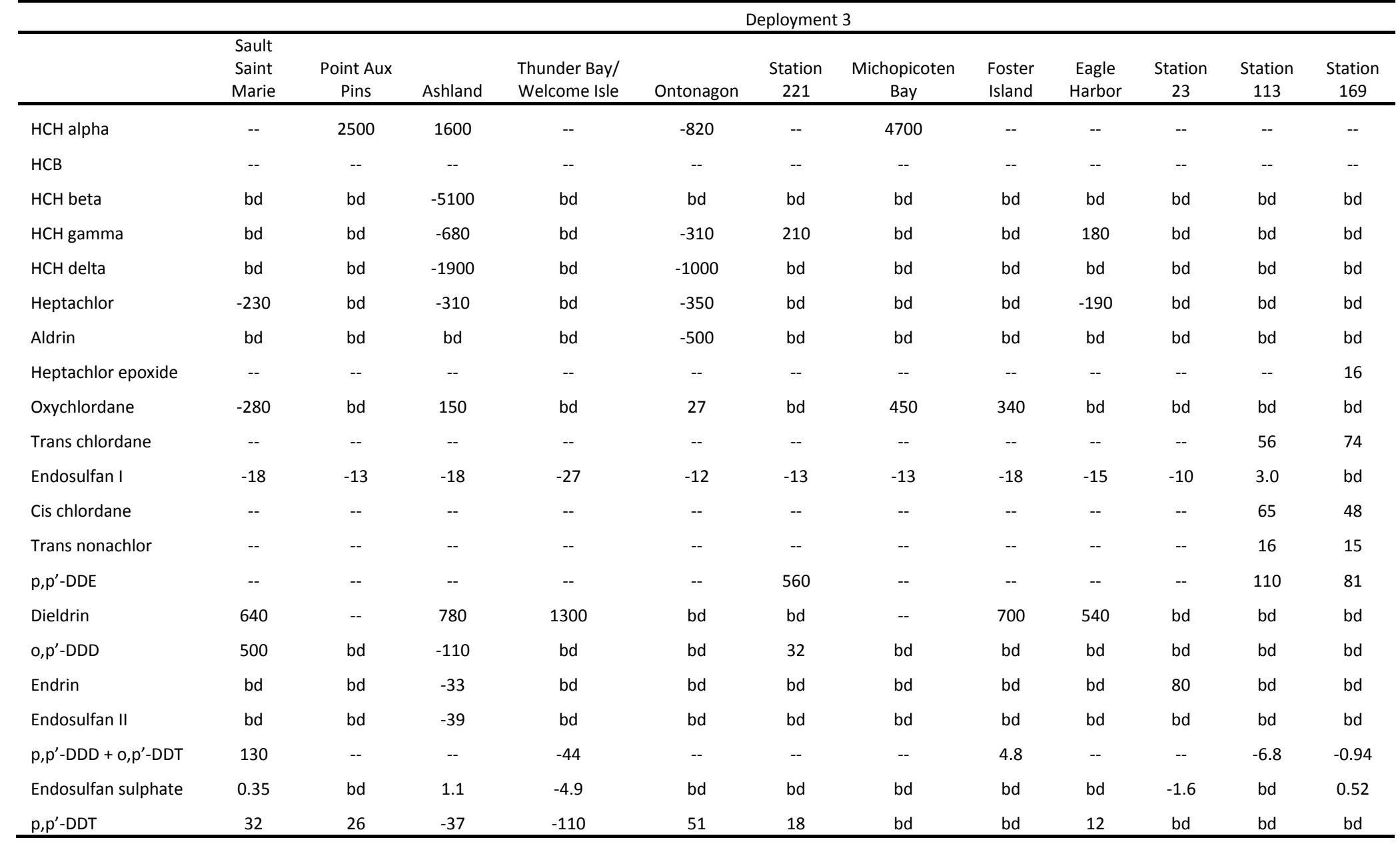


TABLE SI 29: Selected physical constants and equilibrium partitioning constants for all PCB analytes monitored in this study

\begin{tabular}{|c|c|c|c|c|c|c|}
\hline Compound & Ion & $\begin{array}{c}\mathbf{M W}^{\mathbf{a}} \\
\text { (g/mol) }\end{array}$ & $\log K_{\mathrm{PEa}}{ }^{b}$ & $\log K_{P E W}{ }^{c}$ & $\begin{array}{c}\Delta \mathrm{H}_{\mathrm{PEa}}{ }^{\mathrm{e}} \\
(\mathrm{kJ} / \mathrm{mol})\end{array}$ & $\begin{array}{c}\Delta \mathbf{H}_{\text {PEw }}{ }^{f} \\
(\mathrm{~kJ} / \mathrm{mol})\end{array}$ \\
\hline CB8 & $222>152$ & 223.098 & 6.66 & 4.50 & 72.00 & $25^{g}$ \\
\hline CB18 & $256>185.9$ & 257.543 & 6.91 & 4.90 & 75.00 & 21.10 \\
\hline CB28 & $256>185.9$ & 257.543 & 7.26 & 5.40 & 78.00 & 21.20 \\
\hline CB44 & $290>219.9$ & 291.988 & 7.62 & 5.50 & 81.00 & 21.90 \\
\hline CB52 & $290>219.9$ & 291.988 & 7.55 & 5.70 & 81.00 & 21.00 \\
\hline CB66 & $290>219.9$ & 291.988 & 8.26 & 6.00 & 85.27 & 23.60 \\
\hline CB101 & $326>255.9$ & 326.433 & 8.24 & 6.30 & 85.00 & 22.60 \\
\hline CB105 & $326>255.9$ & 326.433 & 8.75 & 6.40 & 89.37 & $25^{\mathrm{g}}$ \\
\hline CB118 & $326>255.9$ & 326.433 & 8.72 & 6.40 & 89.40 & 24.60 \\
\hline CB128 & $360>289.8$ & 360.878 & 8.86 & 6.60 & 93.04 & $25^{\mathrm{g}}$ \\
\hline CB138 & $360>289.8$ & 360.878 & 8.91 & 7.00 & 92.00 & 26.30 \\
\hline CB153 & $360>289.8$ & 360.878 & 8.85 & 6.80 & 91.00 & 26.20 \\
\hline CB170 & $396>323.7$ & 395.323 & 9.36 & 7.30 & 98.48 & $25^{g}$ \\
\hline CB180 & $396>323.7$ & 395.323 & 9.44 & 7.10 & 97.00 & 26.50 \\
\hline CB187 & $396>323.7$ & 395.323 & 9.25 & 7.10 & 94.00 & 27.40 \\
\hline CB195 & $430>357.7$ & 429.768 & 10.10 & $7.51^{d}$ & 99.88 & $25^{\mathrm{g}}$ \\
\hline CB206 & $464>393.6$ & 464.213 & 10.30 & $7.45^{d}$ & 103.41 & $25^{g}$ \\
\hline CB209 & $498>427.6$ & 498.658 & 10.20 & $9.67^{d}$ & 107.05 & $25^{\mathrm{g}}$ \\
\hline $\begin{array}{l}\text { All values at } 25^{\circ} \mathrm{C} \\
\text { a Mackay et al. }(2 \mathrm{C} \\
{ }^{\mathrm{b}} \text { Khairy and Lohm } \\
{ }^{\mathrm{C}} \text { Lohmann (2012) } \\
{ }^{\mathrm{d} C a l c u l a t e d ~ f r o m ~} \\
{ }^{\mathrm{e}} \text { Komp and McLac } \\
{ }^{\mathrm{f}} \text { Morgan and Lohr } \\
{ }^{\mathrm{g}} \text { Recognized aver }\end{array}$ & $\begin{array}{l}\text { 5) } \\
\text { in (2014) } \\
\text { relation between Kp } \\
\text { an (1997) } \\
\text { ann (2008) } \\
\text { e value (Lohmann } 20\end{array}$ & nd solubility fo & wing Lohmann & 012) & & \\
\hline
\end{tabular}


TABLE SI 30: Average percent equilibrium achieved during deployment for PCBs derived from calculated sampling rates

\begin{tabular}{lcccccc}
\hline & \multicolumn{3}{c}{ Air } & \multicolumn{3}{c}{ Water } \\
\hline & Deployment 1 & Deployment 2 & Deployment 3 & Deployment 1 & Deployment 2 & Deployment 3 \\
\hline CB8 & $100 \%$ & $100 \%$ & $100 \%$ & $99 \%$ & $100 \%$ & $100 \%$ \\
CB18 & $100 \%$ & $100 \%$ & $100 \%$ & $93 \%$ & $98 \%$ & $100 \%$ \\
CB28 & $99 \%$ & $100 \%$ & $100 \%$ & $61 \%$ & $86 \%$ & $94 \%$ \\
CB44 & $88 \%$ & $98 \%$ & $100 \%$ & $53 \%$ & $82 \%$ & $90 \%$ \\
CB52 & $91 \%$ & $99 \%$ & $100 \%$ & $39 \%$ & $72 \%$ & $82 \%$ \\
CB66 & $38 \%$ & $79 \%$ & $91 \%$ & $21 \%$ & $55 \%$ & $63 \%$ \\
CB101 & $39 \%$ & $80 \%$ & $92 \%$ & $12 \%$ & $43 \%$ & $43 \%$ \\
CB105 & $13 \%$ & $45 \%$ & $60 \%$ & $9 \%$ & $38 \%$ & $36 \%$ \\
CB118 & $14 \%$ & $47 \%$ & $62 \%$ & $9 \%$ & $38 \%$ & $36 \%$ \\
CB128 & $10 \%$ & $37 \%$ & $51 \%$ & $6 \%$ & $30 \%$ & $25 \%$ \\
CB138 & $9 \%$ & $34 \%$ & $48 \%$ & $2 \%$ & $16 \%$ & $11 \%$ \\
CB153 & $10 \%$ & $38 \%$ & $52 \%$ & $4 \%$ & $22 \%$ & $17 \%$ \\
CB170 & $3 \%$ & $13 \%$ & $20 \%$ & $1 \%$ & $9 \%$ & $6 \%$ \\
CB180 & $2 \%$ & $11 \%$ & $18 \%$ & $2 \%$ & $13 \%$ & $9 \%$ \\
CB187 & $4 \%$ & $18 \%$ & $26 \%$ & $2 \%$ & $13 \%$ & $9 \%$ \\
CB195 & $1 \%$ & $3 \%$ & $4 \%$ & $1 \%$ & $6 \%$ & $4 \%$ \\
CB206 & $0 \%$ & $2 \%$ & $3 \%$ & $1 \%$ & $7 \%$ & $4 \%$ \\
CB209 & $0 \%$ & $2 \%$ & $3 \%$ & $0 \%$ & $0 \%$ & $0 \%$ \\
\hline
\end{tabular}


TABLE SI 31: Physicochemical constants for PCBs derived from SPARC

\begin{tabular}{|c|c|c|c|c|c|c|}
\hline \multirow[t]{2}{*}{ Analyte } & \multicolumn{2}{|c|}{$\mathrm{Da}\left(\mathrm{cm}^{2} / \mathrm{s}\right)$} & \multicolumn{2}{|c|}{$\mathrm{Dw}\left(\mathrm{cm}^{2} / \mathrm{s}\right)$} & \multicolumn{2}{|c|}{$\begin{array}{l}\text { Henry's Law Constant } \\
\left(\mathrm{Pa} /\left(\mathrm{moles} / \mathrm{m}^{3}\right)\right)\end{array}$} \\
\hline & $0^{\circ} \mathrm{C}$ & $25^{\circ} \mathrm{C}$ & $0^{\circ} \mathrm{C}$ & $25^{\circ} \mathrm{C}$ & $0^{\circ} \mathrm{C}$ & $25^{\circ} \mathrm{C}$ \\
\hline CB8 & 0.041 & 0.0484 & $3.81 \mathrm{E}-06$ & $6.54 \mathrm{E}-06$ & 10.78 & 17.73 \\
\hline CB18 & 0.0388 & 0.0458 & $3.65 \mathrm{E}-06$ & $6.27 \mathrm{E}-06$ & 13.34 & 22.06 \\
\hline CB28 & 0.0386 & 0.0456 & $3.65 \mathrm{E}-06$ & $6.28 \mathrm{E}-06$ & 5.58 & 10.47 \\
\hline CB44 & 0.0366 & 0.0432 & $3.52 \mathrm{E}-06$ & $6.05 \mathrm{E}-06$ & 4.21 & 9.21 \\
\hline CB52 & 0.0367 & 0.0433 & $3.51 \mathrm{E}-06$ & $6.03 \mathrm{E}-06$ & 7.37 & 13.1 \\
\hline CB66 & 0.0365 & 0.0431 & $3.52 \mathrm{E}-06$ & $6.06 \mathrm{E}-06$ & 2.39 & 4.88 \\
\hline CB101 & 0.0348 & 0.041 & 3.39E-06 & $5.83 \mathrm{E}-06$ & 4.02 & 7.75 \\
\hline CB105 & 0.0347 & 0.0409 & $3.41 \mathrm{E}-06$ & 5.87E-06 & 0.55 & 1.96 \\
\hline CB118 & 0.0346 & 0.0409 & $3.41 \mathrm{E}-06$ & $5.86 \mathrm{E}-06$ & 0.86 & 2.21 \\
\hline CB128 & 0.0331 & 0.039 & $3.29 \mathrm{E}-06$ & 5.67E-06 & 0.92 & 3.73 \\
\hline CB138 & 0.0331 & 0.0391 & $3.29 \mathrm{E}-06$ & $5.66 \mathrm{E}-06$ & 1.42 & 4.2 \\
\hline CB153 & 0.033 & 0.039 & $3.29 \mathrm{E}-06$ & $5.65 \mathrm{E}-06$ & 1.97 & 4.43 \\
\hline CB170 & 0.0315 & 0.0372 & $3.19 \mathrm{E}-06$ & $5.49 \mathrm{E}-06$ & 0.58 & 2.92 \\
\hline CB180 & 0.0316 & 0.0373 & 3.19E-06 & $5.49 \mathrm{E}-06$ & 0.69 & 3.09 \\
\hline CB187 & 0.0316 & 0.0374 & 3.19E-06 & $5.49 \mathrm{E}-06$ & 0.82 & 3.07 \\
\hline CB195 & 0.0298 & 0.0352 & $3.11 \mathrm{E}-06$ & $3.34 \mathrm{E}-06$ & 0.45 & 2.59 \\
\hline CB206 & 0.0284 & 0.0336 & $3.02 \mathrm{E}-06$ & $5.19 \mathrm{E}-06$ & 0.32 & 2.1 \\
\hline CB209 & 0.0265 & 0.0313 & $2.94 \mathrm{E}-06$ & $5.06 \mathrm{E}-06$ & 0.26 & 1.65 \\
\hline
\end{tabular}

Obtained June 7, 2013 (https://archemcalc.com/sparc) 
TABLE SI 32: PCB blank corrections

\begin{tabular}{lccccc}
\hline & \multicolumn{2}{c}{ Coastal Deployments } & \multicolumn{2}{c}{ Cruise Deployments } \\
\hline Analyte & $\begin{array}{c}\text { Method Blank } \\
\text { Average } \\
(\mathrm{pg} / \mathrm{g} \text { PE) }\end{array}$ & $\begin{array}{c}\text { Field Blank } \\
\text { Average } \\
(\mathrm{pg} / \mathrm{g} \text { PE) }\end{array}$ & $\begin{array}{c}\text { LOD }^{\mathrm{a}} \\
(\mathrm{pg} / \mathrm{g} \text { PE) }\end{array}$ & $\begin{array}{c}\text { Field Blank } \\
\text { Average } \\
(\mathrm{pg} / \mathrm{g} \text { PE) }\end{array}$ & $\begin{array}{c}\text { LOD }^{\mathrm{a}} \\
(\mathrm{pg} / \mathrm{g} \mathrm{PE})\end{array}$ \\
\hline CB8 & 150 & 180 & 190 & 830 & 1200 \\
CB18 & 210 & 220 & 210 & 280 & 540 \\
CB28 & 360 & 350 & 640 & 760 & 1600 \\
CB44 & 230 & 200 & 320 & 320 & 680 \\
CB52 & 330 & 360 & 460 & 520 & 1100 \\
CB66 & 170 & 150 & 310 & 410 & 840 \\
CB101 & 240 & 210 & 410 & 730 & 960 \\
CB105 & 79 & 43 & 140 & 78 & 170 \\
CB118 & 120 & 110 & 180 & 400 & 510 \\
CB128 & bd & 5.7 & 25 & bd & bd \\
CB138 & 56 & 65 & 120 & 210 & 250 \\
CB153 & 110 & 97 & 130 & 350 & 400 \\
CB170 & bd & 2.7 & 17 & bd & bd \\
CB180 & 94 & 74 & 300 & 110 & 350 \\
CB187 & 3.1 & 34 & 89 & 65 & 150 \\
CB195 & bd & bd & bd & bd & bd \\
CB206 & 260 & 150 & 680 & 56 & 700 \\
CB209 & 24 & 26 & 37 & 53 & 72 \\
\hline
\end{tabular}


TABLE SI 33: PCB analyte recoveries

\begin{tabular}{lccc}
\hline Analyte & \multicolumn{2}{c}{ Average Surrogate Recovery } & Average Matrix Spike \\
& Air Samples & Water Samples & Recovery \\
\hline 13 CB 8 & $10 \%$ & $9 \%$ & $10 \%$ \\
13 CB28 & $11 \%$ & $12 \%$ & $12 \%$ \\
13 CB52 & $11 \%$ & $12 \%$ & $12 \%$ \\
13 CB118 & $11 \%$ & $13 \%$ & $12 \%$ \\
13 CB138 & $12 \%$ & $14 \%$ & $13 \%$ \\
13 CB180 & $16 \%$ & $18 \%$ & $18 \%$ \\
13 CB209 & $15 \%$ & $17 \%$ & $17 \%$ \\
12 CB8 & & & $98 \%$ \\
12 CB18 & & & $90 \%$ \\
12 CB28 & & & $102 \%$ \\
12 CB44 & & $109 \%$ \\
12 CB52 & & $97 \%$ \\
12 CB66 & & $11 \%$ \\
12 CB101 & & $110 \%$ \\
12 CB105 & & $124 \%$ \\
12 CB118 & & $123 \%$ \\
12 CB128 & & $34 \%$ \\
12 CB138 & & $103 \%$ \\
12 CB153 & & $101 \%$ \\
12 CB170 & & $82 \%$ \\
12 CB180 & & $94 \%$ \\
12 CB187 & & $89 \%$ \\
12 CB195 & & \\
12 CB206 & & \\
12 CB209 & & \\
\hline
\end{tabular}


TABLE SI 34: Derived atmospheric concentrations $\left(\mathrm{fg} / \mathrm{m}^{3}\right)$ of selected PCBs

\begin{tabular}{lccccc}
\hline \multicolumn{5}{c}{ Deployment 1 } \\
\hline Analyte & Sault Saint Marie & Ashland & Marquette & Duluth & Eagle Harbor \\
\hline CB8 & bd & bd & bd & bd & bd \\
CB18 & bd & bd & bd & 4800 & bd \\
CB28 & bd & bd & bd & bd & bd \\
CB44 & $2900 \pm 370$ & bd & bd & bd & bd \\
CB52 & $6200 \pm 660$ & bd & 2600 & bd & bd \\
CB66 & $1600 \pm 560$ & bd & bd & bd & bd \\
CB101 & $9800 \pm 3200$ & bd & 4100 & bd & bd \\
CB105 & $1600 \pm 590$ & bd & 910 & bd & bd \\
CB118 & $4300 \pm 1700$ & bd & 2400 & bd & bd \\
CB128 & $480 \pm 290$ & bd & 240 & bd & bd \\
CB138 & $4000 \pm 1700$ & bd & 1300 & bd & bd \\
CB153 & $4600 \pm 2100$ & $b d$ & 1200 & 380 & bd \\
CB170 & $210 \pm 93$ & 95 & bd & 84 & bd \\
CB180 & $260 \pm 360$ & 930 & bd & bd & bd \\
CB187 & $720 \pm 330$ & bd & 130 & bd & bd \\
CB195 & bd & 50 & 24 & bd & bd \\
CB206 & bd & bd & bd & bd & bd \\
CB209 & $48 \pm 68$ & 110 & bd & bd & bd \\
\hline
\end{tabular}


TABLE SI 34 (continued)

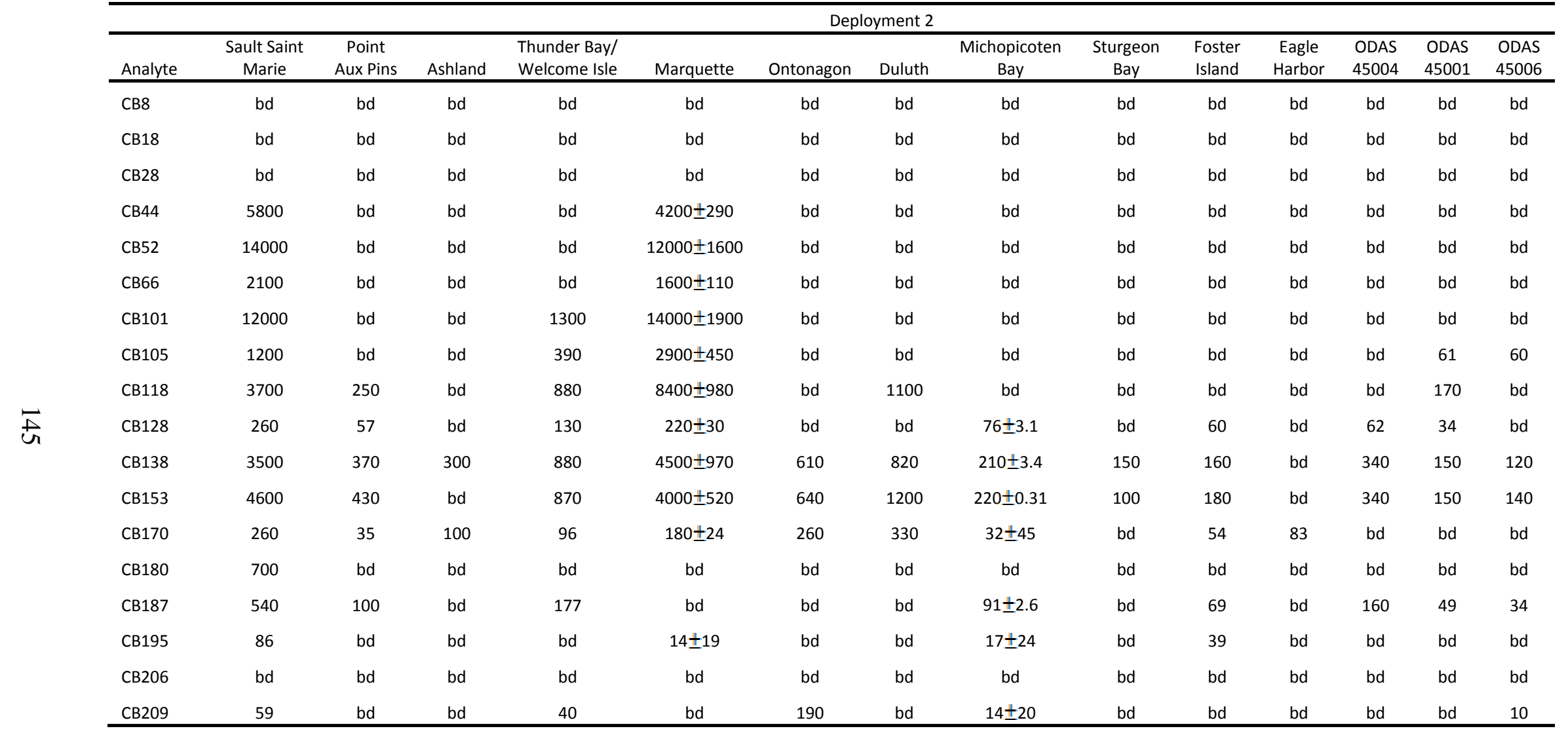


TABLE SI 34 (continued)

\begin{tabular}{|c|c|c|c|c|c|c|c|c|c|c|c|c|c|c|}
\hline & & & & & & Depl & /ment 3 & & & & & & & \\
\hline Analyte & $\begin{array}{l}\text { Sault Saint } \\
\text { Marie }\end{array}$ & $\begin{array}{c}\text { Point } \\
\text { Aux } \\
\text { Pins } \\
\end{array}$ & Ashland & $\begin{array}{l}\text { Thunder Bay/ } \\
\text { Welcome Isle }\end{array}$ & Marquette & Ontonagon & Duluth & $\begin{array}{c}\text { Michopicoten } \\
\text { Bay } \\
\end{array}$ & $\begin{array}{c}\text { Sturgeon } \\
\text { Bay }\end{array}$ & $\begin{array}{l}\text { Foster } \\
\text { Island }\end{array}$ & $\begin{array}{l}\text { Eagle } \\
\text { Harbor }\end{array}$ & $\begin{array}{l}\text { ODAS } \\
45004 \\
\end{array}$ & $\begin{array}{l}\text { ODAS } \\
45001 \\
\end{array}$ & $\begin{array}{l}\text { ODAS } \\
45006 \\
\end{array}$ \\
\hline CB8 & bd & bd & $b d$ & bd & bd & $b d$ & $b d$ & bd & bd & bd & bd & bd & bd & bd \\
\hline CB18 & bd & bd & 17000 & bd & bd & 20000 & $b d$ & $b d$ & bd & $b d$ & bd & bd & bd & bd \\
\hline CB28 & bd & $b d$ & 14000 & bd & bd & 27000 & $b d$ & bd & bd & $b d$ & bd & $b d$ & bd & bd \\
\hline CB44 & $5000 \pm 130$ & $b d$ & bd & bd & $b d$ & 4200 & $b d$ & bd & $b d$ & bd & $b d$ & $b d$ & bd & bd \\
\hline CB52 & $11000 \pm 650$ & $b d$ & bd & bd & 8600 & 5400 & bd & bd & $b d$ & $b d$ & $b d$ & bd & $b d$ & bd \\
\hline CB66 & $1300 \pm 24$ & $b d$ & $b d$ & $b d$ & 960 & bd & $b d$ & $b d$ & $b d$ & bd & $b d$ & $b d$ & $b d$ & bd \\
\hline CB101 & $9700 \pm 670$ & bd & bd & $1600 \pm 520$ & 8300 & bd & $b d$ & bd & bd & $b d$ & bd & bd & bd & bd \\
\hline CB105 & $730 \pm 120$ & $b d$ & 170 & $280 \pm 63$ & 1300 & bd & bd & $b d$ & bd & $b d$ & $b d$ & bd & $b d$ & bd \\
\hline CB118 & $2900 \pm 390$ & 240 & 270 & $680 \pm 51$ & 4800 & bd & 410 & bd & bd & $b d$ & bd & $b d$ & bd & bd \\
\hline CB128 & $b d$ & $b d$ & $b d$ & $110 \pm 150$ & bd & bd & bd & bd & bd & $b d$ & $b d$ & bd & bd & bd \\
\hline CB138 & $2500 \pm 990$ & 260 & 140 & $530 \pm 6.1$ & 1700 & $b d$ & 390 & 260 & 110 & $b d$ & $b d$ & $b d$ & $b d$ & bd \\
\hline CB153 & $3200 \pm 510$ & 230 & 160 & $670 \pm 27$ & 1900 & bd & 440 & 170 & bd & bd & bd & $b d$ & $b d$ & bd \\
\hline CB170 & $200 \pm 3.5$ & 17 & bd & bd & bd & bd & 27 & 95 & bd & $b d$ & $b d$ & 89 & bd & bd \\
\hline CB180 & $500 \pm 23$ & $b d$ & bd & bd & bd & bd & bd & bd & bd & $b d$ & $b d$ & bd & $b d$ & bd \\
\hline CB187 & $160 \pm 28$ & bd & $b d$ & $140 \pm 100$ & bd & bd & bd & 120 & bd & $b d$ & $b d$ & $b d$ & bd & bd \\
\hline CB195 & bd & $b d$ & $b d$ & bd & bd & bd & bd & bd & bd & bd & $b d$ & $b d$ & bd & bd \\
\hline CB206 & $b d$ & $b d$ & $b d$ & bd & $b d$ & bd & $b d$ & bd & $b d$ & $b d$ & $b d$ & $b d$ & $b d$ & bd \\
\hline CB209 & $\mathrm{bd}$ & $\mathrm{bd}$ & $b d$ & $15 \pm 22$ & 54 & $\mathrm{bd}$ & 38 & 54 & 20 & $\mathrm{bd}$ & $\mathrm{bd}$ & $\mathrm{bd}$ & bd & bd \\
\hline
\end{tabular}


TABLE SI 35: Derived aqueous concentrations (fg/L) of selected PCBs

\begin{tabular}{lccc}
\hline \multicolumn{4}{c}{ Deployment 1 } \\
\hline & Sault Saint Marie & Ashland & Marquette \\
\hline CB8 & bd & bd & bd \\
CB18 & bd & 1600 & 2600 \\
CB28 & bd & bd & 2300 \\
CB44 & $1600 \pm 260$ & bd & 2100 \\
CB52 & $3800 \pm 830$ & bd & 3700 \\
CB66 & bd & bd & 1200 \\
CB101 & $6700 \pm 1500$ & 610 & 5500 \\
CB105 & $1900 \pm 400$ & bd & 1300 \\
CB118 & $5400 \pm 1100$ & 410 & 3400 \\
CB128 & $1200 \pm 280$ & 110 & 450 \\
CB138 & $8600 \pm 1900$ & 530 & 2900 \\
CB153 & $8200 \pm 2000$ & 450 & 2500 \\
CB170 & $1800 \pm 510$ & 61 & 240 \\
CB180 & $2300 \pm 650$ & bd & bd \\
CB187 & $2300 \pm 570$ & 190 & 340 \\
CB195 & $160 \pm 150$ & 26 & bd \\
CB206 & bd & bd & bd \\
CB209 & $150 \pm 55$ & bd & bd \\
\hline
\end{tabular}


TABLE SI 35 (continued)

\begin{tabular}{|c|c|c|c|c|c|c|c|c|c|c|c|c|c|c|c|}
\hline & & & & & & & & & & & & & & & \\
\hline & $\begin{array}{c}\text { Sault } \\
\text { Saint } \\
\text { Marie }\end{array}$ & $\begin{array}{c}\text { Point } \\
\text { Aux } \\
\text { Pins }\end{array}$ & Ashland & $\begin{array}{l}\text { Thunder Bay/ } \\
\text { Welcome Isle }\end{array}$ & $\begin{array}{c}\text { Station } \\
139\end{array}$ & Marquette & Ontonagon & $\begin{array}{l}\text { Station } \\
221\end{array}$ & $\begin{array}{c}\text { Michopicoten } \\
\text { Bay }\end{array}$ & $\begin{array}{c}\text { Sturgeon } \\
\text { Bay }\end{array}$ & $\begin{array}{l}\text { Foster } \\
\text { Island }\end{array}$ & $\begin{array}{l}\text { Eagle } \\
\text { Harbor }\end{array}$ & $\begin{array}{c}\text { Station } \\
23\end{array}$ & $\begin{array}{c}\text { Station } \\
113\end{array}$ & $\begin{array}{c}\text { Station } \\
169\end{array}$ \\
\hline CB8 & bd & bd & bd & bd & bd & bd & bd & bd & bd & bd & $\mathrm{bd}$ & bd & bd & bd & $\mathrm{bd}$ \\
\hline CB18 & $b d$ & bd & 6000 & bd & bd & bd & bd & 5900 & bd & $\mathrm{bd}$ & bd & bd & 6900 & 3900 & 5000 \\
\hline CB28 & bd & bd & 2500 & bd & bd & bd & bd & bd & bd & bd & bd & bd & bd & bd & $\mathrm{bd}$ \\
\hline CB44 & 1100 & bd & bd & bd & bd & bd & bd & 2500 & bd & bd & bd & bd & 2000 & 1300 & 1200 \\
\hline CB52 & 2400 & bd & bd & bd & 2000 & bd & bd & 3900 & bd & bd & bd & bd & 2800 & bd & 1800 \\
\hline CB66 & 960 & bd & bd & bd & bd & bd & bd & bd & bd & bd & bd & bd & 460 & bd & bd \\
\hline CB101 & 4800 & bd & 640 & bd & 630 & $1100 \pm 55$ & bd & 1100 & bd & bd & bd & bd & 440 & 390 & 330 \\
\hline CB105 & 1400 & bd & bd & bd & 170 & $220 \pm 34$ & bd & 250 & bd & bd & bd & bd & 86 & 110 & 94 \\
\hline CB118 & 4000 & bd & 680 & bd & 470 & $530 \pm 91$ & 130 & 640 & bd & bd & bd & bd & 240 & 240 & 240 \\
\hline CB128 & 1000 & 170 & 170 & 160 & 77 & $210 \pm 20$ & bd & 79 & $59 \pm 8.3$ & bd & bd & 35 & 34 & 46 & 35 \\
\hline CB138 & 6800 & 610 & 910 & 830 & 260 & $1200 \pm 140$ & 220 & 440 & $240 \pm 95$ & 270 & bd & bd & 140 & 110 & 110 \\
\hline CB153 & 5800 & 620 & 680 & 530 & 220 & $1100 \pm 77$ & 140 & 490 & $140 \pm 200$ & bd & bd & $\mathrm{bd}$ & 130 & 130 & 120 \\
\hline CB170 & 1500 & bd & 110 & 130 & 20 & $160 \pm 28$ & bd & 38 & bd & bd & 170 & bd & bd & bd & 9.0 \\
\hline CB180 & 2600 & bd & bd & $\mathrm{bd}$ & bd & bd & bd & 59 & $\mathrm{bd}$ & bd & bd & bd & bd & bd & $\mathrm{bd}$ \\
\hline CB187 & 1600 & bd & 170 & 200 & 43 & $150 \pm 25$ & bd & 72 & $78 \pm 110$ & bd & bd & bd & 21 & 25 & 26 \\
\hline CB195 & 61 & 190 & bd & bd & bd & $6.5 \pm 11$ & bd & bd & $17 \pm 24$ & bd & bd & bd & bd & bd & bd \\
\hline CB206 & $b d$ & bd & bd & bd & bd & bd & bd & $b d$ & bd & bd & $b d$ & bd & bd & bd & bd \\
\hline CB209 & $\mathrm{bd}$ & $\mathrm{bd}$ & $\mathrm{bd}$ & $\mathrm{bd}$ & bd & bd & bd & bd & bd & bd & $\mathrm{bd}$ & $\mathrm{bd}$ & $\mathrm{bd}$ & bd & bd \\
\hline
\end{tabular}


TABLE SI 35 (continued)

\begin{tabular}{|c|c|c|c|c|c|c|c|c|c|c|c|c|c|c|}
\hline & \multicolumn{14}{|c|}{ Deployment 3} \\
\hline & $\begin{array}{l}\text { Sault Saint } \\
\text { Marie }\end{array}$ & $\begin{array}{c}\text { Point } \\
\text { Aux Pins }\end{array}$ & Ashland & $\begin{array}{l}\text { Thunder Bay/ } \\
\text { Welcome Isle }\end{array}$ & $\begin{array}{c}\text { Station } \\
139 \\
\end{array}$ & Ontonagon & $\begin{array}{c}\text { Station } \\
221 \\
\end{array}$ & $\begin{array}{c}\text { Michopicoten } \\
\text { Bay }\end{array}$ & $\begin{array}{c}\text { Sturgeo } \\
\text { n Bay }\end{array}$ & $\begin{array}{l}\text { Foster } \\
\text { Island }\end{array}$ & $\begin{array}{l}\text { Eagle } \\
\text { Harbor }\end{array}$ & $\begin{array}{c}\text { Station } \\
23\end{array}$ & $\begin{array}{c}\text { Station } \\
113 \\
\end{array}$ & $\begin{array}{c}\text { Station } \\
169 \\
\end{array}$ \\
\hline CB8 & bd & bd & bd & $b d$ & $b d$ & bd & bd & bd & $b d$ & bd & $b d$ & $b d$ & $b d$ & bd \\
\hline CB18 & bd & $b d$ & 5200 & $b d$ & bd & $b d$ & $b d$ & $b d$ & $b d$ & $b d$ & $\mathrm{bd}$ & bd & $b d$ & $\mathrm{bd}$ \\
\hline CB28 & $b d$ & bd & 2800 & $b d$ & $b d$ & bd & $b d$ & $b d$ & $b d$ & $b d$ & $b d$ & $b d$ & $b d$ & $b d$ \\
\hline CB44 & $1500 \pm 200$ & bd & $b d$ & $b d$ & bd & $b d$ & $b d$ & $b d$ & $b d$ & $b d$ & $\mathrm{bd}$ & $b d$ & $b d$ & $b d$ \\
\hline CB52 & $2300 \pm 130$ & $b d$ & bd & $b d$ & 1700 & $b d$ & $b d$ & $b d$ & $b d$ & bd & $b d$ & $b d$ & $b d$ & $b d$ \\
\hline CB66 & $1000 \pm 130$ & bd & 410 & $b d$ & bd & bd & bd & bd & $b d$ & bd & bd & bd & $b d$ & bd \\
\hline CB101 & $4500 \pm 96$ & bd & 850 & $b d$ & 1300 & bd & 660 & $b d$ & $b d$ & $b d$ & $b d$ & 690 & $b d$ & $b d$ \\
\hline CB105 & $1300 \pm 140$ & bd & 300 & bd & 320 & 250 & 210 & bd & $b d$ & bd & $b d$ & 180 & 98 & $\mathrm{bd}$ \\
\hline CB118 & $3100 \pm 91$ & $b d$ & 600 & $320 \pm 13$ & 930 & 390 & 640 & $b d$ & $b d$ & bd & $b d$ & 590 & 290 & 270 \\
\hline CB128 & $820 \pm 100$ & bd & 170 & $110 \pm 27$ & 130 & 72 & 120 & 55 & $b d$ & 45 & 27 & 68 & $b d$ & 36 \\
\hline CB138 & $6000 \pm 280$ & 540 & 890 & $520 \pm 21$ & 800 & 350 & 740 & 120 & 330 & 260 & bd & 460 & 200 & 170 \\
\hline CB153 & $5900 \pm 340$ & 570 & 780 & $460 \pm 22$ & 780 & 260 & 780 & $b d$ & 330 & bd & 79 & 520 & 190 & 190 \\
\hline CB170 & $1000 \pm 120$ & 93 & 130 & $b d$ & 88 & 39 & 100 & bd & $b d$ & 110 & 29 & 43 & 44 & 26 \\
\hline CB180 & $2100 \pm 55$ & bd & bd & $\mathrm{bd}$ & $b d$ & $b d$ & 180 & $b d$ & $b d$ & bd & $b d$ & bd & $b d$ & $b d$ \\
\hline CB187 & $1400 \pm 64$ & $b d$ & 210 & $130 \pm 14$ & 150 & 70 & 200 & bd & $b d$ & bd & $b d$ & 100 & 66 & 63 \\
\hline CB195 & $170 \pm 37$ & $b d$ & bd & $b d$ & 11 & $b d$ & bd & $b d$ & bd & bd & $b d$ & bd & $b d$ & $b d$ \\
\hline CB206 & $b d$ & bd & bd & $b d$ & $b d$ & $\mathrm{bd}$ & bd & bd & $b d$ & bd & $b d$ & $b d$ & $b d$ & bd \\
\hline CB209 & bd & bd & $\mathrm{bd}$ & bd & bd & bd & bd & bd & bd & bd & bd & bd & bd & $\mathrm{bd}$ \\
\hline
\end{tabular}


TABLE SI 36: Calculated air-water exchange fluxes ( $\mathrm{pg} / \mathrm{m}^{2} /$ day) of selected PCBs

\begin{tabular}{lccc}
\hline \multicolumn{4}{c}{ Deployment 1 } \\
\hline CB8 & Sault Saint Marie & Ashland & Marquette \\
CB18 & bd & bd & bd \\
CB28 & bd & 1700 & 3600 \\
CB44 & bd & bd & 2500 \\
CB52 & -- & bd & 3600 \\
CB66 & -- & bd & -- \\
CB101 & -1700 & bd & 2600 \\
CB105 & -- & 1300 & -- \\
CB118 & -- & $b d$ & -- \\
CB128 & -- & 410 & -- \\
CB138 & -- & 20 & -- \\
CB153 & 5900 & 270 & -- \\
CB170 & -- & 450 & -- \\
CB180 & 120 & -- & 11 \\
CB187 & 580 & -140 & bd \\
CB195 & 1800 & 110 & -- \\
CB206 & 7.9 & -- & -1.6 \\
CB209 & bd & bd & bd \\
\hline
\end{tabular}


TABLE SI 36 (continued)

\begin{tabular}{|c|c|c|c|c|c|c|c|c|c|c|c|c|c|c|}
\hline & & & & & & $\mathrm{De}$ & loyment 2 & & & & & & & \\
\hline & $\begin{array}{c}\text { Sault Saint } \\
\text { Marie }\end{array}$ & $\begin{array}{c}\text { Point } \\
\text { Aux Pins }\end{array}$ & Ashland & $\begin{array}{l}\text { Thunder Bay/ } \\
\text { Welcome Isle }\end{array}$ & Marquette & Ontonagon & $\begin{array}{c}\text { Station } \\
221 \\
\end{array}$ & $\begin{array}{c}\text { Michopicoten } \\
\text { Bay } \\
\end{array}$ & $\begin{array}{c}\text { Sturgeon } \\
\text { Bay }\end{array}$ & $\begin{array}{l}\text { Foster } \\
\text { Island }\end{array}$ & $\begin{array}{l}\text { Eagle } \\
\text { Harbor }\end{array}$ & $\begin{array}{c}\text { Station } \\
23 \\
\end{array}$ & $\begin{array}{c}\text { Station } \\
113 \\
\end{array}$ & $\begin{array}{c}\text { Station } \\
169 \\
\end{array}$ \\
\hline CB8 & bd & bd & bd & bd & bd & bd & bd & bd & $\mathrm{bd}$ & bd & bd & bd & $b d$ & bd \\
\hline CB18 & bd & $b d$ & 9500 & bd & bd & bd & 12000 & bd & bd & bd & bd & 9500 & 5200 & 6300 \\
\hline CB28 & bd & bd & 3800 & $\mathrm{bd}$ & bd & bd & bd & bd & $\mathrm{bd}$ & bd & $b d$ & bd & $b d$ & bd \\
\hline CB44 & -- & bd & bd & $b d$ & -2100 & bd & 5800 & bd & bd & bd & $\mathrm{bd}$ & 3400 & 2200 & 2000 \\
\hline CB52 & -- & $b d$ & bd & bd & -1900 & bd & 5500 & bd & bd & bd & bd & 2400 & bd & 1300 \\
\hline CB66 & -- & bd & bd & bd & -1400 & bd & bd & bd & bd & bd & bd & 970 & bd & bd \\
\hline CB101 & -- & $\mathrm{bd}$ & 1700 & -1100 & -- & bd & 3700 & bd & bd & bd & bd & 1100 & 940 & 750 \\
\hline CB105 & -- & $b d$ & $b d$ & -390 & -1400 & bd & 390 & bd & bd & bd & bd & 60 & -- & -- \\
\hline CB118 & -- & -210 & 1300 & -1300 & -5600 & 210 & -- & bd & bd & bd & bd & 310 & -- & 280 \\
\hline CB128 & 810 & 150 & 150 & -- & -- & bd & 1200 & -- & bd & -15 & 17 & -- & -- & 7.0 \\
\hline CB138 & 10000 & 1100 & 1400 & -- & -- & -- & -- & -- & 380 & -41 & bd & -- & -- & -- \\
\hline CB153 & -- & 1500 & 1600 & -- & -- & -- & -- & -- & -74 & -100 & bd & -- & -- & -- \\
\hline CB170 & 460 & -2.8 & -- & -- & -- & -12 & -11 & -1.9 & $\mathrm{bd}$ & 20 & -3.4 & $\mathrm{bd}$ & bd & 0.34 \\
\hline CB180 & 800 & bd & $b d$ & $b d$ & bd & $b d$ & 24 & bd & bd & $b d$ & $b d$ & $b d$ & $b d$ & bd \\
\hline CB187 & 3200 & -62 & 360 & -- & 300 & bd & 170 & -- & $b d$ & -37 & bd & -55 & -- & -- \\
\hline CB195 & -- & 50 & bd & $b d$ & -- & bd & $b d$ & -- & bd & -4.7 & bd & $b d$ & $b d$ & bd \\
\hline CB206 & bd & $b d$ & $b d$ & $b d$ & bd & $b d$ & $b d$ & $b d$ & $b d$ & $b d$ & bd & $b d$ & $b d$ & bd \\
\hline CB209 & -0.7 & bd & bd & -0.8 & bd & -1.8 & bd & -0.17 & bd & bd & bd & bd & $\mathrm{bd}$ & -0.064 \\
\hline
\end{tabular}


TABLE SI 36 (continued)

\begin{tabular}{|c|c|c|c|c|c|c|c|c|c|c|c|c|c|}
\hline & \multicolumn{13}{|c|}{ Deployment 3} \\
\hline & $\begin{array}{l}\text { Sault Saint } \\
\text { Marie }\end{array}$ & $\begin{array}{c}\text { Point } \\
\text { Aux Pins }\end{array}$ & Ashland & $\begin{array}{l}\text { Thunder Bay/ } \\
\text { Welcome Isle }\end{array}$ & Ontonagon & $\begin{array}{c}\text { Station } \\
221 \\
\end{array}$ & $\begin{array}{c}\text { Michopicoten } \\
\text { Bay }\end{array}$ & $\begin{array}{c}\text { Sturgeon } \\
\text { Bay }\end{array}$ & $\begin{array}{l}\text { Foster } \\
\text { Island } \\
\end{array}$ & $\begin{array}{l}\text { Eagle } \\
\text { Harbor }\end{array}$ & $\begin{array}{c}\text { Station } \\
23 \\
\end{array}$ & $\begin{array}{c}\text { Station } \\
113 \\
\end{array}$ & $\begin{array}{c}\text { Station } \\
169 \\
\end{array}$ \\
\hline CB8 & bd & $\mathrm{bd}$ & $\mathrm{bd}$ & bd & bd & bd & bd & bd & bd & $b d$ & bd & bd & bd \\
\hline CB18 & bd & $b d$ & -- & bd & -6100 & bd & bd & bd & bd & bd & bd & bd & bd \\
\hline CB28 & bd & bd & -- & bd & -5500 & bd & bd & bd & $b d$ & bd & bd & bd & bd \\
\hline CB44 & -- & bd & bd & bd & -2000 & bd & bd & bd & bd & bd & bd & bd & $b d$ \\
\hline CB52 & -- & bd & bd & bd & -830 & bd & bd & bd & bd & bd & bd & bd & $b d$ \\
\hline CB66 & -- & bd & 910 & bd & bd & $b d$ & bd & bd & bd & bd & bd & bd & bd \\
\hline CB101 & -- & bd & 2300 & -1400 & bd & 2000 & bd & bd & bd & $\mathrm{bd}$ & 2500 & bd & bd \\
\hline CB105 & -- & bd & -- & -310 & 340 & 280 & bd & bd & bd & bd & 310 & 150 & bd \\
\hline CB118 & -- & -220 & -- & -- & 780 & -- & bd & bd & bd & bd & 1500 & 680 & 50 \\
\hline CB128 & 650 & bd & 120 & -- & 56 & 92 & 50 & bd & 47 & 21 & 72 & bd & 9.4 \\
\hline CB138 & 8200 & 810 & 1200 & -- & 550 & 1000 & -- & 580 & 530 & bd & 920 & 330 & 57 \\
\hline CB153 & 12000 & 1300 & 1600 & -- & 620 & 1600 & -100 & 1000 & bd & 180 & 1600 & 500 & 80 \\
\hline CB170 & 270 & 25 & 30 & bd & 10 & 23 & -6.9 & bd & 38 & 8.1 & -- & 9.5 & 5.4 \\
\hline CB180 & 600 & bd & $\mathrm{bd}$ & $\mathrm{bd}$ & bd & 63 & $\mathrm{bd}$ & $b d$ & bd & $\mathrm{bd}$ & bd & bd & bd \\
\hline CB187 & 2600 & bd & 360 & -- & 140 & 390 & -78 & bd & bd & bd & 270 & 140 & 17 \\
\hline CB195 & 34 & bd & bd & $b d$ & bd & bd & bd & bd & bd & bd & bd & bd & bd \\
\hline CB206 & bd & $\mathrm{bd}$ & bd & bd & bd & bd & bd & bd & bd & bd & bd & bd & bd \\
\hline CB209 & bd & $\mathrm{bd}$ & $\mathrm{bd}$ & -0.37 & $\mathrm{bd}$ & -0.38 & -0.7 & -0.25 & bd & bd & bd & bd & bd \\
\hline
\end{tabular}




\section{BIBLIOGRAPHY}

Ackerman, L.K..; Schwindt, A.R.; Massey Simonich, S.L.; Koch, D.C.; Blett, T.F.; Schreck, C.B.; Kent, M.L.; Landers, D.H. Atmospherically deposited PBDEs, pesticides, PCBs, and PCHs n Western U.S. National Park fish: concentrations and consumption guidelines. Environmental Science and Technology, 2008, 42, 2334-2341.

Adams, R.G; Lohmann, R.; Fernandez, L.A.; Macfarlane, J.K.; Gschwend, P.M. Polyethylene devices: Passive samplers for measuring dissolved hydrophobic organic compounds in aquatic environments. Environmental Science and Technology, 2007, 41, 1317-1323.

Agency for Toxic Substances and Disease Registry, ATSDR, 2001. Accessed July 26, 2013. http://www.atsdr.cdc.gov/toxfaqs/tf.asp?id=316\&tid=56.

Austin, J.A.; Colman, S.M. Lake Superior summer water temperatures are increasing more rapidly than regular air temperatures: a positive ice-albedo feedback. Geophysical Research Letters, 2007, 34, L06604.

Baker, J.E. and Eisenreich S.J. Concentrations and fluxes of polycyclic aromatic hydrocarbons and polychlorinated biphenyls across the air-water interface of Lake Superior. Environmental Science and Technology, 1990, 24, 342-352.

Bidleman, T.F.; Jantunen, L.M.M.; Wiberg, K.; Harner, T.; Brice, K.A.; Su, K.; Falconer, R.L.; Leone, A.D.; Aigner, E.J.; Parkhurst, W.J.; Soil as a source of atmospheric heptachlor epoxide. Environmental Science and Technology, 1998, 32, 1546-1548. 
Booij, K.; Smedes, F.; van Weerlee, E.M. Spiking of performance reference compounds in low density polyethylene and silicone passive water samplers. Chemosphere, 2002, 46, 1157-1161.

Booij, K. and Smedes, F. An Improved method for estimating in situ sampling rates of nonpolar passive samplers. Environmental Science and Technology, 2010, 44, 6789-6794.

Buehler, S.S.; Basu, I.; Hites, R.A. A comparison of PAH, PC, and pesticide concentrations in air at two rural sites on Lake Superior. Environmental Science and Technology, 2001, 35, 2417-2422.

Buehler, A.A. and Hites R.A. The Great Lakes' Integrated Atmospheric Deposition Network. Environmental Science and Technology, 2002, 36, 354A-359A.

Buehler, S.S.; Basu, I.; Hites, R.A. Causes of variability in pesticide and PCB concentrations in air near the Great Lakes. Environmental Science and Technology, 2004, 38, 414-422.

Crimmins, B.S.; Pagano, J.J.; Xia, X.; Hopke, P.K.; Milligan, M.S.; Holsen, T.M. Polybrominated biphenyl ethers (PBDEs): Turning the corner in Great Lakes trout 1980-2009. Environmental Science and Technology, 2012, 46, 98909897.

Beyer, A.; Wania, F.; Gouin, T.; Mackay, D.; Matthies, M. Selecting internally consistent physicochemical properties of organic compounds. Environmental Science and Technology, 2002, 21(5), 941-953. 
Buckley, D.R.; Rockne, K.J.; Li, A.; Mills, W.J. Soot deposition in the Great Lakes: implications for semi-volatile hydrophobic organic pollutant deposition. Environmental Science and Technology, 2004, 38, 1732-1739.

Cortes, D.R.; Basu, I.; Sweet, C.W.; Brice, K.A.; Hoff, R.M.; Hites, R.A. Temporal trends in gas-phase concentrations of chlorinated pesticides measured at the shores of the Great Lakes. Environmental Science and Technology, 1998, 32, 1920-1927.

Cortes, D.R.; Basu, I.; Sweet, C.W.; Hites, R.A. Temporal trends in and influence of wind on PAH concentrations measured near the Great Lakes. Environmental Science and Technology, 2000, 34, 356-360.

Eisenreich, S.J. and Hollod G.J. Accumulation of polychlorinated biphenyls (PCBs) in surficial Lake Superior sediments. Atmospheric Deposition. Environmental Science and Technology, 1979, 13, 569-573.

Gevao, B.; Hamilton-Taylor, J.; Jones, K.C. Polychlorinated biphenyl and polycyclic aromatic hydrocarbon deposition to and exchange at the air-water interface of Esthwaite Water, a small lake in Cumbria, UK. Environmental Pollution, 1998, $102,63-75$.

Gewurtz, S.B.; Shen, L.; Helm, P.A.; Waltho, J.; Reiner, E.J.; Painter, S.; Brindle, I.D.; Marvin, C.H. Spatial distribution of legacy contaminants in sediments of Lakes Huron and Superior. Journal of Great Lakes Research, 2008, 34, 153168. 
Glover, D.M.; Jenkins, W.J.; Doney, S.C. Chapter 2: Measurement theory, probability distributions, error propagation and analysis. In Modeling Methods for Marine Science; Cambridge University Press: New York, 2011.

Gouin, T.; Jantunen, L.; Harner, T.; Blanchard, P.; Bidleman, T. Spatial and temporal trends of chiral organochlorine signatures in Great Lakes air suing passive air samplers. Environmental Science and Technology, 2007, 41, 3877-3883.

Great Lakes Commission, GLC, Great Lakes Air Deposition Program. Updated 2011, Accessed June 17, 2013. http://www.glc.org/glad/about.

Great Lakes Commission, GLC, About the Great Lakes Commission. Great Lakes Commission. Updated 2012, Accessed June 17, 2013. http://www.glc.org/about/.

Great Lakes Water Quality Agreement, GLWQA, Protocol amending the agreement between The United States of America and Canada on Great Lakes water quality, 1978, as amended on October 16, 1983 and on November 18, 1987. United States Environmental Protection Agency and Environment Canada, 2012.

Gustafson, K.E. and Dickhut, R.M. Gaseous exchange of polycyclic aromatic hydrocarbons across the air-water interface of Southern Chesapeake Bay. Environmental Science and Technology, 1997, 31, 1623-1629.

Hafner, W.D. and Hites, R.A. Potential sources of pesticides, PCBs, and PAHs to the atmosphere of the Great Lakes. Environmental Science and Technology, 2003, 37, 3764-3773. 
Hillery, B.R.; Basu, I.; Sweet, C.W.; Hites, R.A. Temporal and spatial trends in a long-term study of gas-phase PCB concentrations neat the Great Lakes. Environmental Science and Technology, 1997, 31, 1811-1816.

Hillery, B.R.; Simcik, M.F.; Basu, I.; Hoff, R.M.; Strachan, W.M.J.; Burniston, D.; Chan, C.H.; Brice, K.A.; Sweet, C.W.; Hites, R.A. Atmospheric deposition of toxic pollutants to the Great Lakes as measured by the Integrated Atmospheric Deposition Network. Environmental Science and Technology, 1998, 32, 22162221.

Honrath, R.E.; Sweet, C.I.; Plouff, C.J. Surface exchange and transport processes governing atmospheric PCB levels over Lake Superior. Environmental Science and Technology, 1997, 31, 842-852.

Hornbuckle, K.C.; Jeremiason, J.D.; Sweet, C.W.; Eisenreich, S.J. Seasonal variations in air-water exchange of polychlorinated biphenyls in Lake Superior. Environmental Science and Technology, 1994, 28, 1491-1501.

Integrated Atmospheric Deposition Network, IADN, Atmospheric deposition of toxic substances to the Great Lakes: IADN results through 2005.

Integrated Atmospheric Deposition Network, IADN, Cooperating to implement the Great Lakes Water Quality Agreement: Technical Summary and Progress of the Integrated Atmospheric Deposition Network (IADN) 2002-2008. United States-Canada IADN Scientific Steering Committee, October 2008.

Jeremiason, J.D.; Hornbuckle, K.C.; Eisenreich, S.J. PCBs in Lake Superior, 19781992: decreases in water concentrations reflect loss by volatilization. Environmental Science and Technology, 1994, 28, 903-914. 
Jeremiason, J.D.; Eisenreich, S.J.; Baker, J.E.; Eadie, B.J. PCB decline in settling particles and benthic recycling of PCBs and PAHs in Lake Superior. Environmental Science and Technology, 1998, 32, 3249-3256.

Khairy, M.A. and Lohmann, R. Field validation of polyethylene passive air samplers for parent and alkylated PAHs in Alexandria, Egypt. Environmental Science and Technology, 2012, 46, 3990-3998.

Khairy, M.A. and Lohmann, R. Feasibility of using low density polyethylene sheets to detect atmospheric organochlorine pesticides in Alexandria, Egypt. Environmental Pollution, 2013, 48, 151-158.

Khairy, M.A. and Lohmann, R. Field calibration of low density polyethylene passive samplers for gaseous POPs. Environmental Science: Processes and Impacts, 2014, Advance Article, DOI: 10.1039/C3EM00493G.

Komp, P. and McLachlan, S. Octanol/air partitioning of polychlorinated biphenyls. Environmental Toxicology and Chemistry, 1997, 16, 2433-2437.

Kucklick, J.R. and Baker, J.E. Organochlorines in Lake Superior's food web. Environmental Science and Technology, 1998, 32, 1192-1198.

Li, A.; Rockne, K.J.; Sturchio, N.; Song, W.; Ford, J.C.; Buckley, D.R.; Mills, W.J. Polybrominated diphenyl ethers in the sediments of the Great Lakes. 4. Influencing factors, trends, and implications. Environmental Science and Technology, 2006, 40, 7528-7534.

Lohmann, R.; Goia, R.; Jones, K.C.; Nizzetto, L.; Temme, C.; Xie, Z.; Schulz-Bull, D.; Morgan, E.; Jantunen, L. Organochlorine pesticides and PAHs in the 
surface water and atmosphere of the North Atlantic and Arctic Ocean.

Environmental Science and Technology, 2009, 43, 5633-5639.

Lohmann, R. Critical review of low-density polyethylene's partitioning and diffusion coefficients for trace organic contaminants and implications for its use as a passive sampler. Environmental Science and Technology, 2012, 46, 606-618.

Lohmann, R.; Booij, K.; Smedes, F. Use of passive sampling devices for monitoring and compliance checking concentrations in water. Environmental Science and Technology, 2012, 19, 1885-1895.

Lake Superior Binational Forum, LSBF, Lake Superior and climate change impacts. Updated February 2013, Accessed April 29, 2013. http://www.superiorforum.org/outreach-2/climate-change-awareness.

Ma, J.; Daggupaty, S.; Harner, T.; Blanchard, P.; Waite, D. Impacts of Lindane Usage in the Canadian prairies on the Great Lakes ecosystem. 2. Modeled fluxes and loadings to the Great Lakes. Environmental Science and Technology, 2004, 38, 984-990.

Ma, Y-G.; Lei, T.D.; Xiao, H.; Wania, F.; Wang, W-H. Critical review and recommended values for the physical-chemical property data of 15 polycyclic aromatic hydrocarbons at $25^{\circ} \mathrm{C}$. Journal of Chemical \& Engineering Data, 2010, 55, 819-825.

Mackay, D.; Shiu, W.Y.; Ma, K.C. Physical-Chemical Properties and Environmental Fate Handbook (2 ${ }^{\text {nd }}$ Edition); Taylor \& Francis Group: Boca Raton, FL, 2006. Minnesota Sea Grant, Superior facts: 3-quadrillion gallons, one Great Lake. Accessed December 5, 2012. http://www.seagrant.umn.edu/superior/facts. 
Moen, S. Lake Superior feels the heat: climate change discussed at conference. UMN Sea Grant. Published May 2008.

Morgan EJ, Lohmann R. Detecting air-water and surface-deep water gradients of PCBs using polyethylene passive samplers. Environmental Science and Technology, 2008, 42, 7248-7253.

National Oceanic and Atmospheric Administration, NOAA, National Data Buoy Center. 2011. http://www.ndbc.noaa.gov/.

New York Times, NYT, "Water levels fall in Great Lakes, taking a toll on shipping." By John Schwartz. Published June 10, 2013.

Offenberg, J.H. and Baker, J.E. Precipitation scavenging of polychlorinated biphenyls and polycyclic aromatic hydrocarbons along an urban to over-water transect. Environmental Science and Technology, 2002, 36, 3763-3771.

Ontario Ministry of Natural Resources. 2012. http://www.mnr.gov.on.ca.

Perlinger, J.A.; Tobias, D.E.; Morrow, P.S.; Doskey, P.V. Evaluation of novel techniques for measurement of air-water exchange of persistent bioaccumulative toxicants in Lake Superior. Environmental Science and Technology, 2005, 39, 8411-8419.

Raff, J.D. and Hites, R.A. Deposition versus photochemical removal of PBDEs from Lake Superior air. Environmental Science and Technology, 2007, 41, 67256731.

Sabin, L.D.; Maruya, K.A.; Lao, W.; Diehl, D.; Tsukada, D.; Stolzenbach, K.D.; Schiff, K.C. Exchange of polycyclic aromatic hydrocarbons among the atmosphere, water, and sediment in coastal embayments of southern 
California, USA. Environmental Toxicology and Chemistry. 2010, 29, 265275.

Schenker, U.; Macleod, M.; Scheringer, M.; Hungerbuhler, K. Improving data quality for environmental fate models: a least squares adjustment procedure for harmonizing physicochemical properties of organic compounds. Environmental Science and Technology, 2005, 39, 8434-8441.

Schwarzenbach, R.P.; Gschwend, P.M.; Imboden, D.M. Chapter 20: Air-water exchange. In Environmental Organic Chemistry ( $2^{\text {nd }}$ Ed.); John Wiley \& Sons, Inc.:Hoboken, NJ, 2003.

Norwegian Pollution Control Authority, SFT, Guidance on alternative flame retardants to the use of commercial Pentabromodiphenylether (c-PentaBDE). SFT, Oslo, February 2009.

Shen, L.; Wania, F.; Lei, Y.D.; Teixeira, C.; Muir, D.C.G.; Bidleman, T.F. Hexachlorocyclohexanes in the North American Atmosphere. Environmental Science and Technology, 2004, 38, 965-975.

Shen, L.; Wania, F.; Lei, Y.D.; Teixeira, C.; Muir, D.C.G.; Bidleman, T.F. Atmospheric distribution and long-range transport behavior of organochlorine pesticides in North America. Environmental Science and Technology, 2005, $36,409-420$.

Slater, G.F.; Benson, A.A.; Marvin, C.; Muir, D. PAH fluxes to Siskiwit revisited: trends in fluxes and sources of pyrogenic PAH and perylene constrained via radiocarbon analysis. Environmental Science and Technology, In Press. 
Simcik, M.F.; Jeremiason, J.D.; Lipiatou, E.; Eisenreich, S.J. Enhanced removal of hydrophobic organic contaminants by settling sediments in western Lake Superior. Journal of Great Lakes Research. 2003, 29, 41-53.

Stewart, P.W.; Reihman, J.; Lonky E.I.; Darvill, T.J.; Pagano, J. Cognitive development in preschool children prenatally exposed to PCBs and MeHg. Neurotoxicology and Teratology, 2003, 25, 11-22.

Stewart, P.W.; Lonky, E.; Reihman, J.; Pagano, J.; Gump, B.B.; Darvill, T. The relationship between prenatal PCB exposure and intelligence (IQ) in 9-year-old children. Environmental Health Perspectives, 2008, 116, 1416-1422.

Stockholm Convention, Listing of POPs. Accessed July 24, 2013. chm.pops.int.

Suchash, S.; Honrath, R.E. Kahl, J.D.W. Back-trajectory analysis of atmospheric polychlorinated biphenyl concentrations over Lake Superior. Environmental Science and Technology, 1999, 33, 1509-1515.

Sun, P.; Backus, S. Blanchard, P. Hites, R.A. Annual variation of polycyclic aromatic hydrocarbon concentrations in precipitation collected near the Great Lakes. Environmental Science and Technology, 2008, 40, 696-701.

Sun, P.; Backus, S.; Blanchard, P.; Hites, R.A. Temporal and spatial trends of organochlorine pesticides in Great Lakes precipitation. Environmental Science and Technology, 2006, 40, 2135-2141.

Sun, P.; Basu, I.; Blanchard, P.; Brice, K.A.; Hites, R.A. Temporal and spatial trends of atmospheric polychlorinated biphenyl concentrations near the Great Lakes. Environmental Science and Technology, 2007, 41, 1131-1136. 
Swackhamer, D.L.; Schottler, S.; Pearson, R.F. Air-water exchange and mass balance of toxaphene in the Great Lakes. Organohalogen Compounds. 1999, 33, 38643872.

United States Army Corps of Engineers, USACE, St. Marys Falls Canal, Michigan: Statistical report of lake commerce passing through St. Marys Falls Canal Sault Ste Marie during 2010 navigation season. United States Army Engineer District, Detroit, Sault Ste. Marie Area Office, 2011.

United States Environmental Protection Agency, U.S. EPA, Emerging contaminant polybrominated biphenyl ethers (PBDE) and polybrominated biphenyls (PBB). Solid Waste and Emergency Response (5106P). EPA 505-F-007. April 2008.

United States Environmental Protection Agency, U.S. EPA, EPA action to terminate endosulfan, June 2010. Accessed July 24, 2013. http://www.epa.gov/oppsrrd1/reregistration/endosulfan/endosulfan-canclfs.html.

United States Environmental Protection Agency, U.S. EPA, Aldrin/Dieldrin, 2011. Accessed July 24, 2013. http://www.epa.gov/pbt/pubs/aldrin.htm.

United States Environmental Protection Agency, U.S. EPA, Great Lakes Water Quality Agreement of 2012. September 7, 2012. http://www.epa.gov/glnpo/glwqa/.

United States Environmental Protection Agency, U.S. EPA, EnviroMapper. Accessed July 24, 2013. http://www.epa.gov/emefdata/em4ef.home. 
Venier, M. and Hites, R.A. Atmospheric deposition of PBDEs to the Great Lakes featuring a Monte Carlo analysis of errors. Environmental Science and Technology, 2008, 42, 9058-9064.

Wisconsin Department of Natural Resources. Accessed 2012. http://dnr.wi.gov/topic/Brownfields/Ashland.html.

Wong, C.S.; Mabury, S.A.; Whittle, D.M.; Backus, S.M.; Teixeira, C.; Devault, D.S.; Bronte, C.R.; Nuir, S.C.G. Organochlorine compounds in Lake Superior: chiral polychlorinated biphenyls and biotransformation in the aquatic food web. Environmental Science and Technology, 2004, 38, 84-92.

World Health Organization, WHO, Aldrin and Dieldrin in drinking-water: Background document for development of WHO Guidelines for Drinkingwater Quality. WHO/SDE/WSH/03.03/73, 2003.

Yunker, M.B.; Macdonald, R.W.; Vingarzan, R.; Mitchell, R.H.; Goyette, D.; Sylvestre, S. PAHs in the Fraser River basin: a critical appraisal of PAH ratios as indicators of PAH source and composition. Organic Geochemistry. 2002, 33, 489-515.

Zhang, L. and Lohmann, R. Cycling of PCBs and HCB in the surface ocean-lower atmosphere of the open Pacific. Environ. Sci. Technol. 2010, 44, 38323838.

Zhang, L.; Bidleman, T.; Perry, M.J; Lohmann, R. Fate of chiral and achiral organochlorine pesticides in the North Atlantic Bloom Experiment. Environmental Science and Technology, 2012, 46, 8106-8114. 